University of Rhode Island

DigitalCommons@URI

Open Access Master's Theses

1982

\title{
AN INVESTIGATION OF THE POTENTIAL OF SOY CELLULOSE AS A TABLET DISINTEGRANT
}

Divyakant S. Desai

University of Rhode Island

Follow this and additional works at: https://digitalcommons.uri.edu/theses

\section{Recommended Citation}

Desai, Divyakant S., "AN INVESTIGATION OF THE POTENTIAL OF SOY CELLULOSE AS A TABLET

DISINTEGRANT" (1982). Open Access Master's Theses. Paper 190.

https://digitalcommons.uri.edu/theses/190

This Thesis is brought to you for free and open access by DigitalCommons@URI. It has been accepted for inclusion in Open Access Master's Theses by an authorized administrator of DigitalCommons@URI. For more information, please contact digitalcommons-group@uri.edu. 
AN INVESTIGATION OF THE

POTENTIAL OF SOY CELLULOSE

AS A TABLET DISINTEGRANT

BY

DIVYAKANT S. DESAI

\begin{abstract}
A THESIS SUBMITTED IN PARTIAL
FULFILLMENT OF THE REQUIREMENTS

FOR THE DEGREE OF

MASTER OF SCIENCE

IN

PHARMACY
\end{abstract}

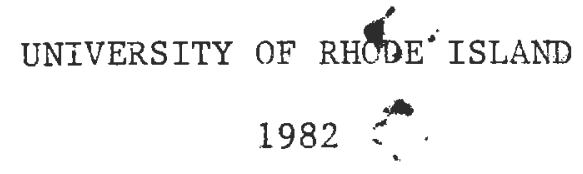


SOY CELLULOSE AS A TABLET DISINTEGRANT 


\section{MASTER OF SCIENCE THESIS}

OF

DIVYAKANT S. DESAI

\section{Approved:}

Thesis Committee

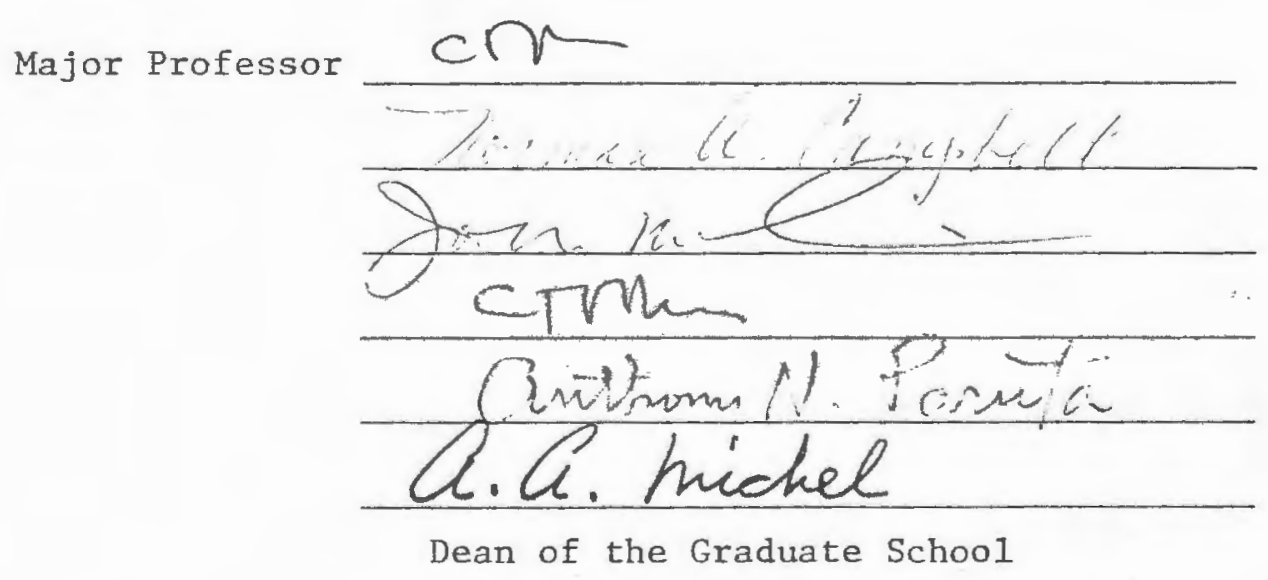

UNIVERSITY OF RHODE ISLAND

1982 
$\underline{\text { ABSTRACT }}$

Scanning Electron Micrographs of soy cellulose (Emcosoy) particles were studied to further the understanding of the morphology of the substance and thereby to increase the comprehension of how the excipient functions in tablet systems.

Bulk swelling and water uptake were studied for Emcosoy, CLD II, corn Starch, and Ac-Di-Sol. Emcosoy had maximum swelling about 56\%; followed by CLD II 49\% and Ac-Di-So1 9\%. No swelling was observed in Corn Starch. An ideal disintegrant should perform uniformly in $\mathrm{pH}$ range of gastrointestinal tract in order to disintegrate the tablet. When Emcosoy and Ac-Di-Sol were tested against various $\mathrm{pH}$ values, there was no significant difference in swelling of these disintegrants. Since alcohol and sodium lauryl sulfate are often used as dissolution media, the effect of different concentrations were also observed on Emcosoy and Ac-Di-So1. There was no significant effect.

Another important preformulation test reported in this thesis is a comparative study of the viscosity of different concentrations of various disintegrants. When a tablet disintegrant reacts with water a gel may be formed. If the gel is too viscous, it impedes the water penetration in the tablet. Generally it can be said that the cellulose group of disintegrants (AC-Di-Sol, CLD II and Emcosoy) had a viscous gel compared to starch group of disintegrants (Corn Starch, Explotab and Sta-Rx 1500). If the viscosity of the gel of starch group of disintegrants has to be arranged indescending order then Explotab is followed by Sta-Rx 1500 which is followed by corn starch. If the viscosity of the gel of 
cellulose group of disintegrants had to be arranged in descending order then CLD II is followed by Emcosoy which is followed by AcDi-Sol.

Plastic deformation and elasticity of various disintegrants were studied using a Universal Instron Testing Machine. High plastic deformation of the disintegrant particles, may be advantageous since the deformed particles are "energy-rich" and that energy is released when the particles are exposed to water. The energy-rich particles probably swell more rapidly in water, unlike undeformed grains, which require more energy of swelling in order to well. Ac-Di-Sol particles have good plastic deformation compared to Emcosoy and Explotab particles. The three major mechanisms of disintegrant action are : (i) swelling (ii) capillary action (wicking) and (iii) deformation. Emcosoy particles swell considerably and they have good wicking effect, but they have poor plastic deformation.

Following the performulation study, Emcosoy (soy cellulose) was compared with other disintegrants in about 45 formulations. About 100 dissolution profiles were obtained on various vitamin formulations using either Emcompress or Endex as the tablet matrix. Emcosoy is as effective a disintegrant as Ac-Di-Sol and very much more effective than Corn Starch. The results of preformulation study and formulation study strongly indicate that Emcosoy is a powerful tablet disintegrant which deserves careful consideration by all formulators. 


\section{ACKNOWLEDGMENTS}

I want to express my deep gratitude to Dr. Christopher T. Rhodes who is also guardian of my shortcomings, for his unceasing encouragement and guidance during this study and preparation of thesis.

I also want to thank my graduate committee members, Dr. Anthony

17. Paruta and Dr. Norman A. Campbell, for their advice and encouragement.

Grateful acknowledgment is made of the invaluable cooperation and support of Edward Mendell Company, and special thanks to Dr. Joseph L. Kanig for his advice during the study.

Appreciation is also acknowledged of the invaluable cooperation of Dr. Joan M. Lausier in solving many problems with the tablet press. Grateful acknowledgment is also made of the invaluable cooperation of Dr. Chong $M$. Lee and Dr. Martin A. Saad in conducting elasticity study on Instron Testing Machine.

Thanks are also due to Donald Scales for Scanning Electron Microscopy work, to Jack Hoblitzell for developing the negative of Scanning Electron Micrographs, to Edward M. Rudnic and Rao N. Chilamkurti for their invaluable help at all stages of the study.

I also wish to acknowledge the help of $\mathrm{Dr}$. George E. Osborne for kindly reading the manuscripts. Appreciation is also acknowledged of the formidable task of Mrs. Susan Killian and Miss Robin Dexter who typed the manuscript. 
ABSTRACT . . . . . . . . . . . . . . . . . . . . $i$

ACKNOWLEDGEMENTS . . . . . . . . . . . . . . . . .

TABLE OF CONTENTS . . . . . . . . . . . . . . . . . . . iv iv

LIST OF TABLES

LIST OF FIGURES • • • . . . . . . . . . . . . . . . . . . ix

I. INTRODUCTION • • . . . . . . . . . . . . . . . . . I

A. 1. Bioavailability Considerations . . . . . . . . . . 2

2. Disintegration of a Tablet and Disintegrants . . . . 7

13. Mechanism of Disintegrant Action . . . . . . . . 13

B. 1. Objective and Justification for the Present Study . . 17

II. EXPERIMENTAL . . . . . . . . . . . . . . . . . . 19

A. Equipment . . . . . . . . . . . . . . 19

B. Materials . . . . . . . . . . . . . 21

C. Methods . . . . . . . . . . . . . . . 23

1. Scanning Electron Micrographs . . . . . . 23

2. Bulk Swelling and Water Uptake . . . . . . . 25

3. Water Penetration of Disintegrants . . . . . 28

4. Energy of Wetting . . . . . . . . . . . . 29

5. Wetting and Drying of Disintegrants . . . . . 31

6. Aqueous Dispersion . . . . . . . . . . . 31

7. Comparative Study of the Viscosity of Different
Strength Solutions on Various Disintegrants . .

8. Maximum Hydration Capacity of Various Disintegrants 34

9. Emcosoy - Sieve Analysis ........... . 35

10. Plastic Deformation and Elasticity of Various Disintegrants . . . . . . . . . . . . 35 
12. Tablet Productions:. . . . . . . . . . . . 43

a. Weight . . . . . . . . . . . . . 44

b. Thickness . . . . . . . . . . . . 45

c. Hardness . . . . . . . . . . . . . 45

d. Friability .............. . 46

e. Disintegration . . . . . . . . . . . 46

f. Dissolution ............. . . 46

III. RESULTS AND DISCUSSIONS . . . . . . . . . . . 50

1. Scanning Electron Mircographs . . . . . . . . 50

2. Bulk Swelling and Water Uptake . . . . . . . . 50

3. Water Penetration of Disintegrants . . . . . 667

4. Energy of Wetting . . . . . . . . . . 72

5. Wetting and Drying of Disintegrants . . . . . . 72

6. Aqueous Dispersion . . . . . . . . . . . . 79

7. Comparative Study of the Viscosity of Different Strength Solutions of Various Disintegrants . . . . .79

8. Maximum Hydration Capacity of Various Disintegrants. .89

9. Emcosoy: Sieve Analysis . . . . . . . . . 89

10. Plastic Deformation and Elasticity of Various Disintegrants . . . . . . . . . . . . . . . . . . .91

11. Tablet Production . . . . . . . . . . . . . 99

IV. CONCLUSION 176

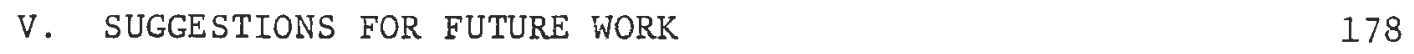

VI. REFERENCES 179

VII. BIBLIOGRAPHY 183

$\begin{array}{lll}\text { VIII. APPENDIX } & 187\end{array}$ 


\section{LIST OF TABLES}

TABLE

PAGE

I. Swelling of Different Disintegrants in Water. . . . . 60

II. Swelling of Emcosoy in Citrate-Phosphate-Borate/Hcl

Buffer. . . . . . . . . . . . . 60

III. $t$-Test for Buffer Reading . . . . . . . . . 60

IV. Swelling of Ac-Di-Sol in Distilled Water. . . . . . 61

V. Swelling of Emcosoy in Alcohol. . . . . . . . . . 62

VI. t-Test for Alcohol Reading with Emcosoy as Disintegrant 63

VII. Swelling of Encosoy in Sodium Lauryl Sulfate. . . . . 63

VIII. t-Test for Sodium Lauryl Sulfate Reading with Emcosoy as a Disintegrant . . . . . . . . . . . . 64

IX. Swelling of Ac-Di-Sol in Citrate-Phosphate-Burase/Hc1 Buffer. . . . . . . . . . . . . . 64

X. t-Test for Citrate-Phosphate-Borak/Hcl Buffer Reading with Ac-Di-Sol as Disintegrant. . . . . . . . 65

XI. Swelling of Ac-Di-Sol in Sodium Lauryl Sulfate. . . . 65

XII. t-Test for Sodium Lauryl Sulfate Reading. . . . . . 65-a

XIII. Swelling of Ac-Di-Sol in Alcohol. . . . . . . . . 66

XIV. t-Test for Ac-Di-Sol Swelling in Alcohol. . . . . . . 66

$X V$. Water Penetration in $(\mathrm{cm})^{2}$ in Emcosoy Powder Bed at $22 \pm 1^{\mathrm{c}}$.................. 68

XVI. Water Penetration in $(\mathrm{cm})^{2}$ in Ac-Di-Sol Powder Bed at $22 \pm 1^{c}$................. 68

RVII. Water Penetration in $(\mathrm{cm})^{2}$ in CLD II Powder Bed at $22 \pm 1^{c}$.................. . . 68 
XVIII. Water Penetration in $(\mathrm{cm})^{2}$ in Explotab Powder Bed at $22 \pm 1^{\mathrm{c}}$................. . . 60

XIX. Energy of Wetting of Emcosoy Particles........ . 74

xx. Comparison of Swelling of Original Emcosoy and Modified Emcosoy. . . . . . . . . . . . . . . . . 77

XXI. Comparison of the Physical Properties of the Tablets Made by Using Original Emcosoy and Modified Emcosoy. . 78

XXII. Viscosity Study of Gel Formed by Various Disintegrants . 80

XXIII. Viscosity Study of Gel Formed by Various Disintegrants . 81

XXIV. Emcosoy (2\%) Dispersion in Water and Dilute Acid (Hicl 1 in 100). . . . . . . . . . . . . . . 90

XXV. Emcosoy -- Sieve Analysis. . . . . . . . . . . 90

XXVI. Modulus of Elasticity of Various Disintegrants . . . 92

XXVII. Percentage Plastic Deformation of Various Disintegrants . . . . . . . . . . . . . . 93

XXVIII. Multivitamin Formulations with Emcompress as a Matrix. .102

XXIX. Multivitamin Formulations with Emdex as a Matrix . . . .103

XXX. Pyridoxine Hydrochloride Formulations with Emcompress as a Matrix. . . . . . . . . . . . . . . 104

XXXI. Pyridoxine Hydrochloride Formulations with Emdex as a Matrix. . . . . . . . . . . . . . 105

XXXII. Ascorbic Acid Formulation with Emcompress as a Matrix. . . . . . . . . . . . . 106

XXXIII. Dissolution Data of Ilultivitamin Formulations with Emcompress as a Matrix. . . . . . . . . . 107

XXXIV. Dissolution Data of Multivitamin Formulations with Emdex as a Matrix . . . . . . . . . . . . . 119 
XXXV. Dissolution Data of Pyridoxine Hydrochloride Formulation with Emcompress as a Matrix. . . . . . . . . . . 131

XXXVI. Dissolution Data of Pyridoxine Hydrochloride Formulation with Emdex as a Matrix . . . . . . . . . . . . 144

XXXVII. Dissolution Data of Ascorbic Acid Formulation with Emcompress as a Matrix. . . . . . . . . . . . . 156 
LIST OF FIGURES

FIGURE

PAGE

1. Working Principle of Scanning Electron Microscope. . 24

2. U-tube Apparatus . . . . . . . . . . . . 26

3. The U.S.P. Disintegration Apparatus In Use . . . . 47

4. Scanning Electron Micrographs of Emcosoy Particles . 51

5. Scanning Electron Micrographs of Emcosoy Particles . 52

6. Percentage Swelling of Ac-Di-Sol as Function of Different Weights of Disintegrants . . . . . . 54

7. Log of Percentage Strelling of Ac-Di-Sol as Function of Different Weights of Disintegrants . . . . . . 55

8. Milliliter of Water Travelled in Ac-Di-Sol as Function of Different Weights . . . . . . . . . 56

9. Water Absorption Test in Ac-Di-Sol . . . . . . . . 57

10. Percentage Swelling of Ac-Di-Sol as a Function Different Concentration Sodium Lauryl Sulfate Solution. . 58

11. Percentage Swelling of Ac-Di-So1 as a Function of Different Concentrations of Alcohol. . . . . . . 59

12. The Penetration of Water Into Various Disintegrants. . 70

13. Energy of Wetting of Emcosoy Particles . . . . . 73

14. Dilatant, Newtonian, and Pseudo Plastic Profiles . . 84

15. Rheological Profiles of Explotab, Emcosoy, and Ac-DiSol -- All at 10\% Concentration. . . . . . . . . 85

16. Rheological Profile of Corn Starch and Sta-Rx 1500 at $14 \%$ Concentration . . . . . . . . . . 86

17. Rheological Profile of Poliplasdone XI at $14 \%$ Concentration of the Disintegrant . . . . . . . . 87

18. Rheological Profile of CLD II Gel at $4 \%$ Concentration of the Disintegrant............ . 88 
19. Dissolution Profiles of Multivitamin Formulation, Emcompress as a Matrix, Emcosoy, Ac-Di-Sol and Explotab at $0.5 \%$ Concentration. . . . . . . . . . . . . 108

20. Three Dissolution Profiles of Multivitamin Formulations, Emcompress as a Matrix, and Emcosoy as a Disintegrant at $0.5 \%$ Concentration. . . . . . . . . . . . . 109

21. Three Dissolution Profiles of Multivitamin Formulations Containing 0.5\% Ac-Di-So1, Emcompress as a liatrix. . . . 110

22. Three Dissolution Profiles of Multivitamin Formulations Containing 0.5\% Explotab, Emcompress as a Matrix . . . .

23. Dissolution Profiles of Multivitamin Formulations, Emcompress as a Matrix, Ac-Di-Sol and Explotab at $1.0 \%$ Concentration. . . . . . . . . . . . . . . .

24. Three Dissolution Profiles of Multivitamin Formulations Containing 1\% of Emcosoy, Emcompress as a Matrix . . . . 113

25. Three Dissolution Profiles of Multivitamin Formulations Containing 1\% of Ac-Di-Sol, Emcompress as a Matrix . . . . 114

26. Three Dissolution Profiles of Multivitamin Formulations Containing 1\% of Explotab, Emcompress as a Matrix. . . . 115

27. Dissolution Profiles of Multivitamin Formulations, Encompress as a Matrix, Emcosoy and Corn Starch at 3.0\% Concentration. . . . . . . . . . . . . . . 116

28. Two Dissolution Profiles of Multivitamin Formulations Containing 3\% of Emcosoy, Emcompress as a Matrix . . . . 117

29. Two Dissolution Profiles of Multivitamin Formulations Containing 3\% of Corn Starch, Emcompress as a Matrix . . 118

30. Dissolution Profiles of Multivitamin Formulations Containing $0.5 \%$ of Emcosoy, Ac-Di-So1, and Explotab, Emdex as a Matrix. . . . . . . . . . . . . 120

31. Three Dissolution Profiles of Multivitamin Formulations Containing $0.5 \%$ of Emcosoy, Emdex as a Natrix. . . . . . 121

32. Three Dissolution Profiles of Multivitamin Formulations Containing $0.5 \%$ of Ac-Di-Sol, Emdex as a Matrix. . . . . . 122 
33. Three Dissolution Profiles of Multivitamin Formulations Containing $0.5 \%$ of Explotab, Emdex as a Matrix. . . . . . 123

34. Dissolution Profiles of Multivitamin Formulations Containing 1.0\% of Emcosoy, Ac-Di-Sol, and Explotab, Emdex as a Matrix . . . . . . . . . . . . . . . 124

35. Three Dissolution Profiles of Multivitamin Formulations Containing 1.0\% of Emcosoy, Emdex as a Matrix . . . . . . 125

36. Three Dissolution Profiles of Multivitamin Formulations Containing 1.0\% of Ac-Di-Sol, Endex as a Natrix . . . . . . 126

37. Three Dissolution Profiles of Kultivitamin Formulations Containing $1.0 \%$ of Explotab, Emdex as a Natrix. . . . . .

38. Dissolution Profiles of Multivitamin Formulations Containing 3.0\% of Encosoy and Corn Starch, Emdex as a Matrix. . . . . 128

39. Two Dissolution Profiles of Multivitamin Formulations Containing 3\% of Emcosoy, Emdex as a Matrix. . . . . . . . . . 129

40. Two Dissolution Profiles of Multivitamin Formulations Containing 3\% of Corn Starch, Emdex as a Matrix. . . . . . . 130

41. Dissolution Profiles of Pyridoxine Hydrochloride Formulations Containing 0.5\% of Enicosoy, Explotab, and Ac-Di-So1. Emcompress as a Matrix. . . . . . . . . . . . . 132

42. Two Dissolution Profiles of Pyridoxine Hydrochloride Formulations Containing 0.5\% Emcosoy, Emcompress as a Matrix • . 133

43. Two Dissolution Profiles of Pyridoxine Hydrochloride Formulations Containing 0.5\% Ac-Di-Sol, Emcompress as a Matrix . 134

44. Two Dissolution Profiles of Pyridoxine Hydrochloride Formulations Containing 0.5\% Explotab, Emcompress as a Matrix. • 135

45. Dissolution Profiles of Hyridoxine Hydrochloride Formulations Containing 1.0\% of Emcosoy, Ac-Di-So1 and Explotab, Emcompress as a Matrix. . . . . . . . . . . . 136

46. Two Dissolution Profiles of Pyridoxine Hydrochloride Formulations Containg 1.0\% of Emcosoy, Emcompress as a Matrix. . 137 
47. Two Dissolution Profiles of Pyridoxine Hydrochloride Formulations Containing $1.0 \%$ of Ac-Di-So1, Emcompress as a

Matrix. . . . . . . . . . . . . . . 138

48. Two Dissolution Profiles of Pyridoxine Hydrochloride Containing 1\% of Explotab, Emcompress as a Natrix. . . . . . 139

49. Dissolution Profiles of Pyridoxine Hydrochloride Formulations Containing 2.0\% of Emcosoy, Ac-Di-Sol, Explotab, and Corn Starch; Emcompress as a Matrix . . . . . . . . . . 140

50. Two Dissolution Profiles of Pyridoxine Hydrochloride Formulations Containing 2.0\% Emcosoy, Emcompress as a Matrix . . 141

51. Two Dissolution Profiles of Pyridoxine Hydrochloride Formulations Containing 2\% of Ac-Di-Sol, Encompress as a Matrix. 142

52. Two Dissolution Profiles of Pyridoxine Hydrochloride Formulations Containing 2\% of Explotab, Emcompress as a Matrix . 143

53. Dissolution Profiles of Pyridoxine Hydrochloride Formulations Containing $0.5 \%$ of Emcosoy, Ac-Di-Sol and Explotab; Emdex as a Matrix. . . . . . . . . . . . . . . . 145

54. Two Dissolution Profiles of Pyridoxine Hydrochloride Formulations Containing 0.5\% of Emcosoy, Emdex as a Matrix . . 146

55. Two Dissolution Profiles of Pyridoxine Hydrochloride Formulations Containing $0.5 \%$ of Ac-Di-Sol, Emdex as a Matrix . 147

56. Two Dissolution Profiles of Pyridoxine Hydrochloride Formulations Containing 0.5\% of Explotab, Emdex as a Matrix. . . 148

57. Dissolution Profiles of Pyridoxine Hydrochloride Formulations Containing 1\% of Emcosoy, Ac-Di-Sol and Explotab; Emdex as a Matrix . . . . . . . . . . . . . . 149

58. Two Dissolution Profiles of Pyridoxine Hydrochloride Formulations Containing 1\% of Emcosoy, Emdex as a Matrix . . . 150

59. Two Dissolution Profiles of Pyridoxine Hydrochloride Formulations Containing 1\% of Ac-Di-Sol, Emdex as a Matrix . . . 151 
60. Two Dissolution Profiles of Pyridoxine Hydrochloride Formulations Containing 1\% of Explotab, Emdex as a Matrix. . . . 152

61. Dissolution Profiles of Pyridoxine Hydrochloride Formulations Containing $0.5 \%$ of Emcosoy and Corn Starch, Emdex as a Matrix. . . . . . . . . . . . . . . . . 153

62. Dissolution Profiles of Pyridoxine Hydrochloride Formulations Containing 3\% of Emcosoy, Emdex as a Matrix . . . . . 154

63. Dissolution Profiles of Pyridoxine Hydrochloride Formulations Containing 3\% of Corn Starch, Emdex as a Matrix . . . . 155

64. Dissolution Profiles of Ascorbic Acid Formulations Containing $0.5 \%$ of Ac-Di-So1 and Emcosoy, Emcompress as a Matrix . . 157

65. Two Dissolution Profiles of Ascorbic Acid Formulations Containing $0.5 \%$ of Emcosoy, Emcompress as a Matrix . . . . . 158

66. Two Dissolution Profiles of Ascorbic Acid Formulations Containing $0.5 \%$ of Ac-Di-Sol, Encompress as a Hatrix . . . . 159

67. Dissolution Profiles of Ascorbic Acid Formulations Containing 1.0\% of Emcosoy, Ac-Di-Sol and Explotab, Emcompress as a Matrix. . . . . . . . . . . . . . . . 160

68. Two Dissolution Profiles of Ascorbic Acia Formulations Containing 1.0\% of Emcosoy, Emcompress as a Matrix. . . . . . 161

69. Two Dissolution Profiles of Ascorbic Acid Formulations Containing $1 \%$ of Ac-Di-Sol, Emcompress as a Matrix . . . . . 162

70. Two Dissolution Profiles of Ascorbic Acid Formulations Containing 1.0\% of Explotab, Emcompress as a Matrix. . . . . 163

71. Dissolution profiles of Ascorbic Acid Formulations Containing 2.0\% of Emcosoy, Ac-Di-Sol, Explotab and Corn Starch, Encompress as a Matrix. . . . . . . . . . . . . 164

72. Dissolution Profiles of Ascorbic Acid Formulations Containing 2.0\% of Emcosoy, Replicate 1, Emcompress as a Matrix. . . 165

73. Dissolution Profiles of Ascorbic Acid Formulations Containing 2.0\% of Emcosoy, Replicate 2, Emcompress as a Matrix. . . . 166 
74. Dissolution Profiles of Ascorvic Acid Formulations Containing 2.0\% of Ac-Di-Sol, Replicate 1, Emcompress as a Matrix. . . 167

75. Dissolution Profiles of Ascorbic Acid Formulations Containing 2.0\% of Ac-Di-Sol, Replicate 2, Emcompress as a Matrix. . . 168

76. Dissolution Profiles of Ascorbic Acid Formulations Containing 2.0\% of Explotab, Replicate 1, Emcompress as a Matrix . . 169

77. Dissolution Profiles of Ascorbic Acid Formulations Containing $2.0 \%$ of Explotab, Replicate 2, Emcompress as a Matrix . . . 170

78. Dissolution Profiles of Ascorbic Acid Formulations Containing $2.0 \%$ of Corn Starch, Replicate 1, Emcompress as a Matrix. . 171

79. Dissolution Profiles of Ascorbic Acid Formulations Containing $2.0 \%$ of Corn Starch, Replicate 2, Emcompress as a Matrix. - 172

80. Dissolution Profiles of Ascorbic Acid Formulations Containing 3.0\% of Corn Starch and Emcosoy, Emcompress as a Matrix . . 173

81. Two Dissolution Profiles of Ascorbic Acid Formulations Containing 3\% of Emcosoy, Emcompress as a Matrix . . . . . . . 174

82. Two Dissolution Profiles of Ascorbic Acid Formulations Containing 3\% of Corn Starch, Emcompress as a Matrix . . . . . 175 


\section{INTRODUCIION}

There are two classes of drugs administered orally in tablet dosage form. These are: (1) insoluble drugs intended to exert a local effect in the gastrointestinal tract (such as many antacids and absorbents), and (2) soluble drugs intended to exert a systemic drug effect following their dissolution in the gut and subsequent absorption.

In the case of drug products intended to exert a systemic effect, the design of a dosage form which rapidly disintegrates and dissolves may or may not be critical, depending on whether the drug is absorbed in the upper gastrointestinal tract or more generally throughout the intestinal tract. Because dosage forms must be designed to disintegrate or dissolve to release the drug in an available form at or above the region of absorption in the gut, the design must also be based on the solubility properties of the drug at or above its absorption site.

The present study covers the bioavailability consideration of the tablet as a dosage form, the disintegration process in general, and the information about a few widely accepted new disintegrants. The mechanism of disintegrant action will be discussed with the help of numerous references on the subject. 


\section{Bioavailability Considerations:}

Bioavailability has been defined as the measurement of both the relative amount of an administered dose that reaches the general circulation (i.e., the extent of absorption of a given dose) and the rate at which this occurs ( 1 ).

Some of the most impressive biopharmaceutical research with practical implications, published during the middle nineteen sixties, was that which demonstrated that different products of the same drug, although chemically identical in terms of drug content, could produce significantly different blood levels. For example, a study of the blood levels produced by different brands of tetracycline, all containing the same amount of drug, showed that the best brand gave blood levels ten times as high as the worst (2).

Glazko, et al, showed that four different brands of $250 \mathrm{mg}$ chloramphenicol capsules had different in vitro and in vivo bioavailability (3). Levy, et al, studied absorption and dissolution of two brands of phenytoin capsules and found that there was a significant difference in the bioavailability of the drug because each product differed from the other in disintegration and deaggregation (4). Bioavailability has been a major problem for pharmaceutical dosage formulators. The subject has drawn considerable attention since the nineteen fifties. Proctor, in 1862 , stated: "The reason why 
pills occasionally pass through the stomach undissolved must be sought for in the state of the patient or in the composition of the pill, rather than in the nature of the coating." (5). Proctor was not discussing enteric-coated pills, since the first enteric coating (Keratin) was described by Unna in $1884--22$ years later. Today, we realize Proctor's statement is only partially true, and that all three factors he discussed, the state of the patient, the composition and the nature of the coating, may determine in vivo disintegration time and rate of dissolution and absorption of the drug.

Unfortunately, Proctor's concern was not shared by other scientists. The need to quantify tablet disintegration by official standards was not recognized until just prior to World War II, and specifications for tablet disintegration did not appear in the USP until the fourteenth revision which was published in 1950 . During the course of subsequent disintegration testing experiments, it was theorized and eventually proven that drug dissolution must follow tablet disintegration if bioavailability is to occur (6).

The topic of bioavailability has now become of interest to government; the FDA (Food and Drug Administration) has already issued specific regulations on bioavailability.

When a drug in a dosage form is administered to a patient, the first steps in the sequence whereby the drug reaches the site of action are cormonly disintegration and dissolution. The importance of these processes is 
understood when one realizes that solid oral dosage forms (mainly compressed tablets or hard gelatin capsules) are by far the most important dosage form class in terms of either doses administered per year or dollar value of drug dispensed (7). The process of disintegration, dissolution, and absorption can be outlined as follows (8):
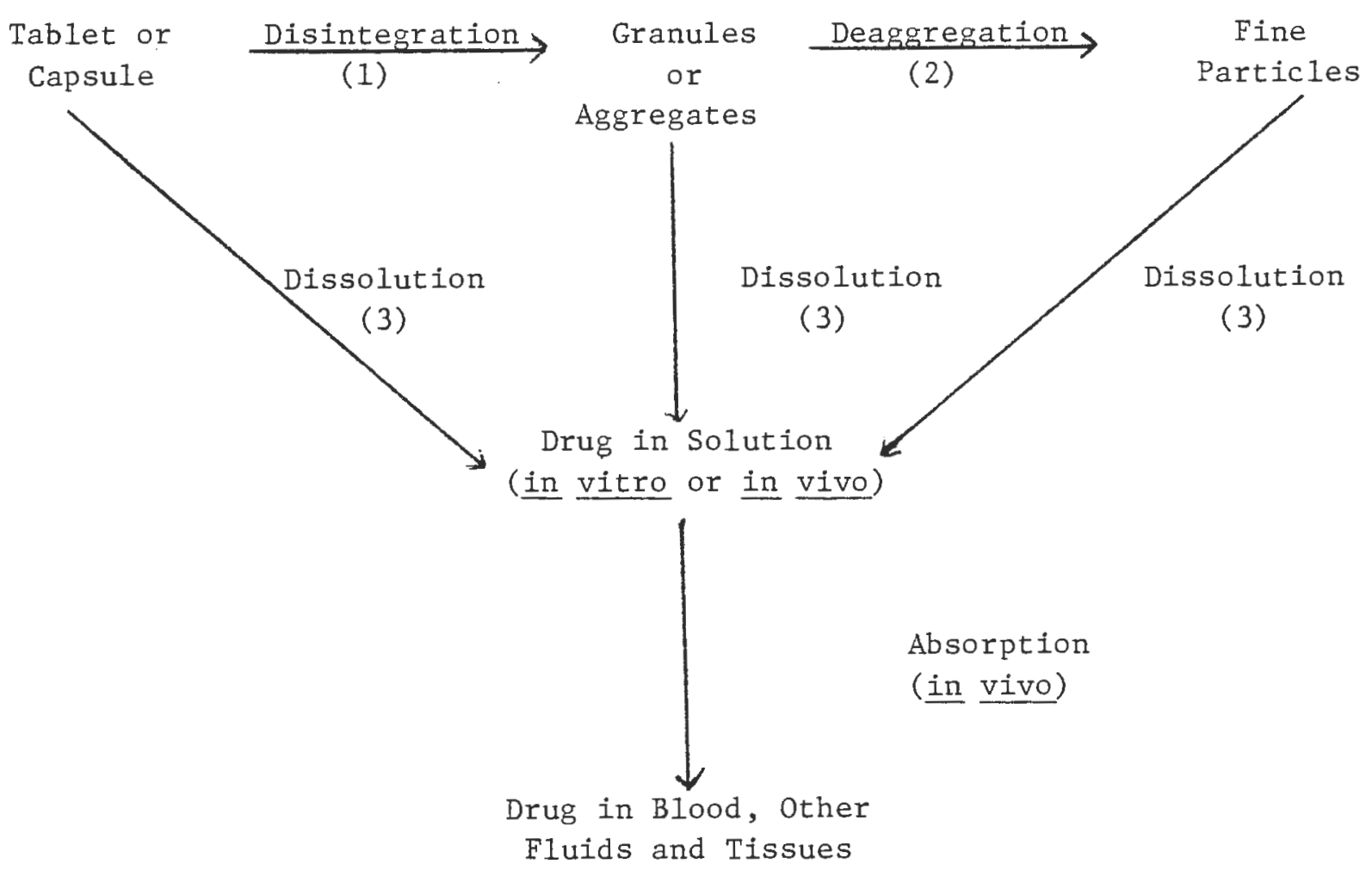

Before drugs can effectively pass through the gastrointestinal wall, they must be in solution. Drugs which are only sparingly soluble in the gastrointestinal content at or above their absorption site can have, as the controlling process affecting their absorption, the rate of drug solution in these fluids. In this type of system, the drug goes into solution at a slow rate, absorption occurs almost immediately and is 
not, therefore, the rate-limiting step. In one study, Nelson (9) correlated the blood level concentration of various theophylline salts with their dissolution rates.

Drugs which exert a systemic effect must dissolve as a prerequisite to effective drug absorption. The various processes of tablet making, including the aggregation of drug into granular particles, the use of binders, and the compaction of the system into a dense tablet, are all factors which militate against a rapid drug dissolution and absorption in the gastrointestinal tract. In considering, in a general manner, the availability of drugs from various classes of dosage forms, drugs administered in solution will usually produce the most available arug product, provided that the drug does not precipitate in the stomach or is not deactivated there. The second most available form of a therapeutic agent would be drug dispersed in a fine suspension, followed by micronized drug in capsule form, followed by uncoated tablets, with coated tablets being the least bioavailable drug product in general. In formulating and designing drug products, as well as in considering methods of manufacture, the fact that the tablet dosage form is one of the least bioavailable forms (all other factors being equal) should be kept in mind (10) .

Many factors can affect drug dissolution rates from tablets; hence, possibly drug bioavailability, including the crystal size of the drug, tablet disintegration mechanisms and rates, the method of granulation, 
type and amount of granulating agent employed, type, amount and method of incorporation of disintegrants and lubricants, and other formulations and processing factors.

Levy, et al (11), showed the effect of granule size upon the dissolution rate of salicylic acid. Salicylic acid of two mesh ranges containing $300 \mathrm{mg}$ of aspirin and $60 \mathrm{mg}$ of starch, were compressed at $715 \mathrm{~kg} \mathrm{~cm}^{-2}$. The 60 to 80 mesh granules had better vitro bioavailability than 40 to 60 mesh granules.

Lachman, et al (12), studied the effect of crystal size and granule size on a delayed-action matrix using tripelennamine hydrochloride. He notes that while granule and crystal size both affected release rate, in this instance the crystal size played a greater role than granule size in dissolution rate.

Paul, et al (13) showed that with nitrofurantoin there was an optimal average crystal size of about 150 mesh, which resulted in adequate drug excretion (hence, absorption and efficacy), but minimized emesis. This exemplifies a situation in which too rapid drug dissolution in the stomach may produce nausea and emesis; an intermediate release rate reduced this effect while achieving adequate bioavailability.

Numerous accounts of the effect of particle size on dissolution rate of steroids have been reported. In one study, Campagna, et al (14), showed that, in spite of good disintegration, therapeutic inefficacy of prednisone tablets could occur. 
As discussed above, bioavailability of the drug depends on many factors. The ensuing discussion will focus on the disintegration process, disintegrants available, and the mechanism action of disintegrants.

2. Disintegration of a Tablet and Disintegrants

Complete tablet disintegration is defined by NF XIII (15) as: ". . . that state in which any residue of the tablet, except fragments of insoluble coating, remaining on the screen is a soft mass having no palpably firm core." This often makes tablet disintegration a necessary first step to achieve rapid availability of the active ingredient(s). The importance of tablet disintegration was recognized as early as 1879 , when a patent recommended that pills be perforated to admit gastric juice for better disintegration (16).

Reasons for Measuring Disintegration Times and Rates of Dissolution

(i) For research purposes to elucidate the mechanism involved in the processes and to determine the relative importance of the various variables involved in the process of disintegration, deaggregation, and dissolution.

(ii) For developmental purposes to guide the pharmaceutical formulator in the preparation of optimum dosage forms of drugs for clinical trial. 
(iii) For control purposes to ensure that a given pharmaceutical product is essentially uniform from lot to lot.

(iv) For predictive purposes so that one may estimate rate(s) of absorption in man from measurement of disintegration time and/or rates of dissolution in vitro. Such predicting requires careful correlation of in vitro and in vivo results.

Our discussion of disintegration will be confined to uncoated tablets designed to release all the active ingredient(s) rapidly.

The disintegration of a tablet depends on compression force, tablet hardness, properties of fillers and active ingredients, properties of binders,properties and concentration of disintegrant and the properties of lubricants. All these factors play an important role in tablet disintegration. If we keep other factors identical (compressive force, fillers, active ingredient binders, and 1ubricant) in two formulations but select two different disintegrants at the same concentration for these two formulations, the in vitro bioavailability will entirely depend on the quality of the disintegrants. The drug will be released quickly from a tablet which disintegrates faster because it has better disintegrants. Thus, the disintegrants play a role in the disintegration process. The ensuing discussion will focus on different disintegrants. 
Disintegrant is a term applied to substance added to a tablet granulation for the purpose of causing the compressed tablet to break apart when placed into an aqueous environment. The disintegrant in a tablet formula may be considered as a dispersing agent for the dry compacted tablet mass in the gastric milieu. Ideally, it should cause the tablet to disrupt not only into the granulated form which it was compressed, but also into the powder particles from which the granulation was prepared.

The function of the disintegrant is, in effect, to counteract the action of the tablet binders and the physical forces of compression necessary to form the tablet. The stronger the effect of the binder, the more efficient must be the disrupting effect of the disintegrant in order to release the active ingredient in the gastrointestinal tract (17). - There are two methods used for incorporating disintegrating agents into tablets. These methods are called external addition and internal addition. The most common method is the external addition method in which the disintegrant is added to the sized granulation with mixing just prior to compression. In the internal addition method, the disintegrant is mixed with other powders before wetting the powder mixture with the granulating solution. Thus, the disintegrant is incorporated within the granule. When this method is used, part of the disintegrant is added internally and part by external addition. Many experts believe that use of the two-step method usually produces better and more complete disintegration than the usual method of adding the dis- 
integrant to the granulation surface only.

Six basic categories of disintegrants have been described: starches, clays, celluloses, algins, gums, and miscellaneous. Many disintegrants have also been shown to possess binder or adhesive properties. Since disintegration is the opposite operation to granulation (agglomeration) and the subsequent formation of strong compacts, one must carefully weigh these two phenomena when designing a tablet (18).

Formulators have tried a number of materials as tablet disintegrants with varying degrees of success. Lowenthal tabulated all the disintegrants with their pertinent references in a review article of "Disintegration of Tablet," in Journal of Pharmaceutical Sciences (19).

In the past six to seven years, exciting developments have occurred in the area of tablet disintegrants. A number of new disintegrants have been marketed in this period. Attention will be focused on these "super disintegrants", as they are called, because of their remarkable quality as disintegrants.

(i) Direct-Compression Starch:

One of the most significant modifications of starch for direct-compression tableting came with the advent of starch 1500 (Colorion, Inc., West Point, Pennsylvania, originally marketed by A.E. Staley Co. as Sta-Rx 1500). The material is prepared by subjecting ordinary corn starch to physical compression or shear in high moisture conditions; that preparation causes both an increase in temperature and a partial 
gelatinization of some of the starch. Direct compression starch retains its disintegrating characteristics despite its partial pregelatinization. While plain starch acts as a disintegrant primarily through wicking action and the elastic recovery of compression-deformed grains when they are wetted, Starch 1500 also acts by truly swelling in the presence of moisture.

\section{(ii) Sodium Carboxymethyl Starch:}

Another of the modifications of starch aimed at improving its disintegration properties involves chemical changes that form a low-substituted sodium carboxymethyl starch. The addition of the carboxymethyl groups makes the starch grains more hydrophilic -- but not completely water soluble. The process also causes a two- to three-fold increase in the size of the starch grains. A minimum of $3 \%$ to $4 \%$ sodium carboxymethyl starch is required for most formulations. The sodium carboxymethyl starch is marketed as Primojel HV (Generichem Corp., Little Falls, New Jersey, and Explotab, Edward Mendell Co., Carme1, New York).

(iii) Cross-Linked Sodium Carboxymethy I Cellulose:

Internally cross-linked carboxymethyl cellulose fibers have been introduced commercially -- as AC-Di-Sol (FMC Corp., Philadelphia, Pennsylvania), and as CLD Cellulose (Buckeye 
Cellulose Corp., Memphis, Tennessee), for use as tablet disintegrants. The cross-linking greatly reduces water solubility while still permitting the material to swell and absorb many times its weight in water without losing individual fiber integrity. Cross-linked sodium carboxymethyl cellulose may be used as a tablet disintegrant in concentrations as low as $1 \%$, although $2 \%$ is recommended for tablets made by direct compression, and a $3 \%$ level for those made by wet granulation. (iv) Cross-Linked Polyvinylpyrolidone:

Cross-linked polyvinylpyrolidone (PVP) is a homopolymer of $\mathrm{k}$-vinyl-d-pyrolidene and has been marketed as PolyplasdoneXI (GAF Corp., New York, New York). Because of its high molecular weight and cross-linked structure, it is insoluble in water but is still very hydrophilic. The particles of PVP are porous in nature. As water is absorbed into the porous structure of the agglomerates, the lattice structure of polymer expands, causing high stress on surrounding tablet components. The porous nature of the particles provides intraparticulate wicking of water. Like cross-linked carboxymethyl cellulose, cross-linked PVP has the ability to shrink to its original particle size when dried and then expand again when rewetted. Both cross-1inked carboxymethyl cellulose and cross-linked PVP would thus appear to be effective disintegrants in tablets made by wet granulation, as well as in those produced by direct 
compression.

Shangraw, et al, discussed the properties of these disintegrants in detail with their scanning electron micrographs in the Pharmaceutical Technology article (20).

3. Mechanism of Disintegrant Action:

For various disintegrants, various theories relating to their disintegration actions have been proposed; but none has truly explained the disintegrant properties of all the agents. The three major mechanisms of action are (i) swelling, (ii) porósity and capillary action (wicking), and (iii) deformation.

\section{(i) Swelling:}

Rank orders of decrease in swelling of various starches under different conditions were described as: wheat, corn, potato, arrowroot, and rice (21); potato, corn and wheat (22); and potato, wheat, and rice (23).

Tablets made with low pressure have high porosity, and hence, too much space. When starch swells, no pressure is exerted; therefore, disintegration is slow. Medium pressure allows just enough space so that when the starch swells, it exerts pressure on the granules to cause disintegration. High pressure, producing low porosity, decreases the ability of fluid to enter; so, disintegration is again slow $(24,25)$. Starch swelling was claimed to be dependent upon amylose and 
amylopectin content; the amylopectin expands, and the amylose gives osmotic pressure (26).

Borzenou and Nesmiyan (27) reported that the degree of swelling of acid carboxymethyl cellulose was $220 \%$; of sodium carboxymethyl cellulose, $400 \%$; of sodium alginate, $450 \%$ : and of ultraamylopectin, $1100 \%$. A mixture of starch with $0.1 \%$ ultra-anylopectin gave maximum swelling, while acid carboxymethyl cellulose starch mixture (3:97) gave the second largest swelling. A mixture of ultraamylopectin-starch $(2: 97)$ as $10 \%$ of a formulation gave the best disintegration times, while acid carboxymethyl cellulose starch (3:97) gave the second best disintegrant times. It was suggested that starch forms the capillaries, and the ultraamylopectin acts as a swelling agent (28).

Many substances swell to a greater degree than the starches, but are poorer disintegrants. Anylose does not swell but has been stated to cause good disintegration (29). Although starch grains swell in water according to some views which I do not share, the rate and extent of swelling is still debated $(30-32)$

Whenever swelling of disintegrant particles take place with great force, it overcomes the adhesiveness of other ingredients in a tablet and causes the tablet to fall to powder.

(ii) Porosity and Capillary Action (Wicking):

Porosity of tablets has been studied with increasing fre- 
quency in recent years, using a variety of materials and numerous experimental methods. Porosity, void space, and pore size decrease as pressure increases $(33-46)$. Potato and corn starches increase mean pore diameters and porosity (47-50). Pore size and volume decrease as the moisture content of starch increases. The rate of penetration of fluids into a tablet is proportional to mean pore diameter or porosity (51-52); corn and starches increase penetration of fluids into tablets. Permeability of tablet decreases as pressure increases. The effect of starch on porosity may be due to its poor ability to bond and compress (52). In 1955, Curlin reported that although aspirin tablets containing starch disintegrated in 15 seconds, starch grains were not swollen; nevertheless, a drop of dye solution placed on the tablet penetrated rapidly. He suggested that the disintegrating action of starch was due to capillary action, rather than to swelling (53).

Wicking is due to capillarity of fibers. Stiff fibers of uniform structure and resistance to collapse are required for good wicking. The fibers should have zero contact angle and should not swell (54). This would appear to rule out any wicking effect due to starch or cellulose fibers. 
The existence of pores or capillaries is not the complete answer to the mechanism of action of disintegrants, because semipolar and nonpolar fluids penetrate into tablets (55), yet do not cause the tablets to break. Also, tablets do disintegrate with minimum porosity (56).

(iii) Deformation:

Plastic deformation of starch grains under high pressure has been reported by a number of investigators (57). Starch grains are generally thought to be elastic; therefore, any grains that are deformed under pressure tend to return to their original shape and size when the pressure is removed. However, it has been suggested that compression may cause more permanent deformation -- that the deformed starch grains are energy rich and that this energy is released when the grains are exposed to water (58). The energy-rich starch grains swell rapidly in water, unlike undeformed grains, which require more heat in order to swell.

The various mechanism of disintegration action discussed under a separate heading, Interrelationships, probably occur in almost all tablet formulations. 
B. 1. Objective and Justification for the Present Study:

As discussed earlier, tablet disintegration has been increasingly

viewed as an important factor in formulating pharmaceutical systems. Mechanisms by which tablet disintegrants function have been investigated.

The current concern about bioavailability of drug products has made formulators very selective in the use of disintegrants. The United States Pharmacopoeia is presently considering a radical extension of dissolution test requirements to most conventional tablets and capsules, and thus a number of formulators are now re-evaluating their formulations to see whether it is now appropriate to alter the identity or quantity of disintegrant (59).

The pharmaceutical industry has been using corn starch and guar gum extensively as tablet disintegrants for many years. Both disintegrants are natural source materials, but their function as a tablet disintegrant are not satisfactory. There is, however, a demand from certain segments of the pharmaceutical industry, particularly those concerned with vitamin formulations, which require a powerful disintegrant of natural origin.

Soy cellulose (Emcosoy), is an all-natural source material, derived from defatted soy beans by a special process. It contains no sugar or starch, and it has been given GRAS status (Generally Regarded 
As Safe) by the United States Food and Drug Administration (60). Many formulators are not aware of the potential of this material because of the lack of authentic and extensive study. It is hoped that the present study will provide a reliable evaluation of soy cellulose (Emcosoy) as an effective substitute for corn starch and guar gum. 
II. EXPERINENTAL

\section{A. Equipment:}

The following items were used:

Mettler K5 Balance, Mettler Instrument Corp., Hightstown, NJ.

Mettler 13 Balance, Mettler Instrument Corp., Hightstown, NJ.

Sieve Shaker, Fisher Wheeler, New Britian, CT.

Brookfield Synchro Lectic Viscometer, Model RVT, Stoughton, MA. (Food Science and Nutrition Department, URI).

Instron Universal Testing Instrument, Instron Corporation, Canton, MA. (Department of Mechanical Engineering, Wales, URI).

Scanning Electron Microscope, Cambridge Instruments, Cambridge, England (Graduate School of Oceanography, URI).

Twin Shel1 Dry Blender, Patterson Kelly, East Strousburg, PA.

U-tube type water uptake apparatus (Two water reservoirs are joined by rubber tube; one is to measure the swelling of disintegrant, and the other to measure the water uptake. (Fig. ).

Stokes Rotary B2 Tablet Press, Pennwault Corporation, Warminster, PA.

Erweka Hardness Tester, Erweka G. m. b. H. Frankfurt, West Germany .

Roche Friabilator, Erweka G. m. b. H. Frankfurt, West Germany.

U.S.P. Disintegration Apparatus, Scientific Glass Apparatus Co., Bloomfield, NJ.

U.S.P. Basket Dissolution Apparatus, Precision Scientific Co., Chicago, IL.

Dissograph (programmable automated dissolution test analyzer), Hanson Research Corp., Northridge, CA. 
Perkin Elmer Hitachi 200 Spectrophotometer with recorder, Perkin Elmer Corporation, Norwalk, CT.

Hewlett Packard Calculator with plotter, Hewlett Packard Calculator Products Division, Loveland, Co.

Computer, Itel As/5, running IBM OS/MVT with HASP II, Version 3. (URI Academic Computer Center, Tyler Hial1, URI, Kingston, RI 02881). 


\section{B. Materials:}

The following chemicals were obtained from Amend Drug and Chemical Company, Irvington, NJ:

Riboflavin USP, Lot D 14687 M 23;

Niacin USP Lot D 15492 R 19;

Ascorbic Acid USP Lot D 15128023;

Pyridoxine Hydrochloride USP Lot F 15949B24;

Corn Starch USP Lot C 712551;

Sodium Lauryl Sulfate USP Lot D 14148 I 01.

The following materials were obtained from Edward Mendell

Company, Carmel, NJ:

Calcium Phosphate Dihydrate (Emcompress) Lot No. 9229;

Soy Cellulose (Emcosoy) Lot No. SY $131 \mathrm{X}$;

Emdex (90 to $92 \%$ Dextrose + 3 to $5 \%$ Maltose + Higher Glucose) $\vee 15$

Sodium Starch Glycolate (Emplotab) Lot No. C 192 X;

Other materials used in this study included:

Carmellose (Type A) (Ac-Di-Sol) - Lot No. 6379. FMC Corp., Philadelphia, PA.

Carmellose (Type B) (CLD II) - Lot No. 1026 BP. Buckeye Cellulose Corp., Memphis, TN.

Granulated Ascorbic Acid - Lot No. 230020; Roche Laboratories, Nutley, NJ.

Magnesium Stearate - Lot No. N 49483; Ruger Chemical Company, Inc., Irvington, $\mathrm{NJ}$. 
Stearic Acid, Ruger Chemical Company, Inc., Irvington, NJ. Sta-Rx 1500 (modified starch) - Colordon, Inc., West Point, PA.

Polyplascione XL (Cross-linked polyvinylpyrrolidone), GAF Corporation, NY.

NOTE: Emcompress, Endex, Encosoy, Ac-Di-Sol, CLD II, Explotab, Polyplasdone XI, and Sta-Rx 1500 are trade names. Trade names are used throughout the thesis due to their familiarity and convenience. 


\section{Methods:}

There are several tests which can be used to evaluate disintegrants before using them in actual formulations. No one test is perfect; each has its advantages and disadvantages. The behavior of disintegrants alone could be vastly different compared to their behavior in compressed tablets. Some of these tests may, however, be useful as the basis of a raw material specification designed to control lot-to-lot variation. ( 59) .

\section{Scanning Electron Micrographs:}

The role of particle morphology(size, shape and composition) in the production of tablets has long been discussed. This theoretical effort has found an ally in scanning electron microscopy (SEM), which has made it possible to obtain direct photographs of tableting excipients and finished compacts. This instrument provides scanning electron micrographs of a range of disintegrating agents, lubricants, and glidants in an attempt to further the understanding of the morpholosy of those substances and thereby to increase the comprehension of how the excipients function in tablet systems. ( 6 ).

Fig. ( 1 ) depicts the principle of the scanning electron microscope. The entire procedure was carried out as follows:

a. An adhesive was placed on a metal stub, which was coated with gold or cadmium.

b. A few disintegrant particles were sprinkled on the stub. 
Working Principle of Scanning Electron Microscope :

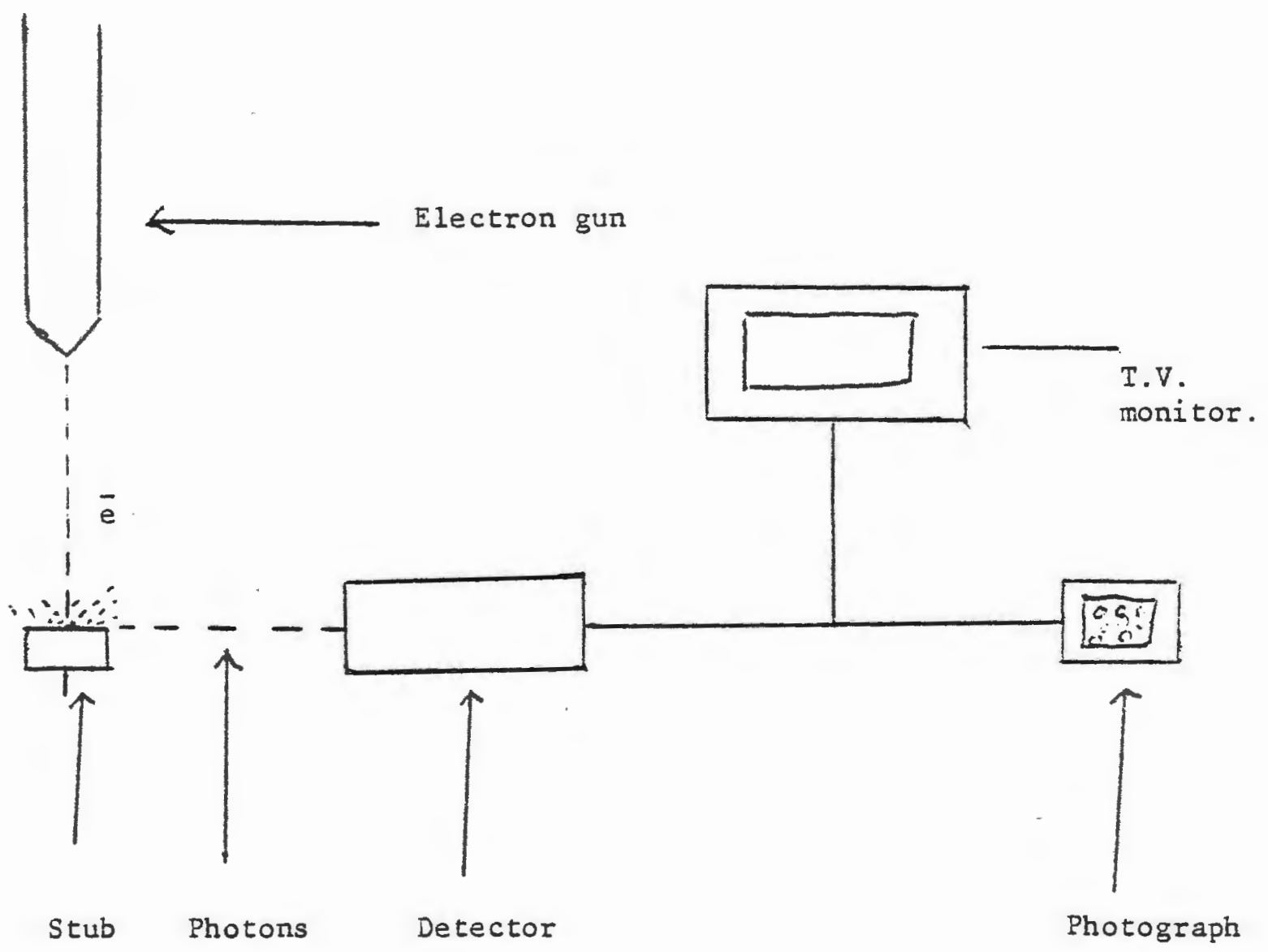

Fig. 1 
c. The stub was placed in electron microscope and photographs were taken. The Emcosoy particles were magnified 200, 1070,1100 , and 2200 times to its original size.

The scanning electron microscope helps in elucidating the structure of individual disintegrant particles by magnifying them to thousands of times their original size (Fig. 4,5). (Note: The scanning electron microscopy work was performed by Mr. Donald Scales of the URI Graduate School of Oceanography).

\section{Bulk Swelling and Water Uptake:}

One relatively simple test used by many groups involved in the evaluation of tablet disintegrants is the quantification of the interaction of a bulk powder bed, composed of pure disintegrant, with water. There are several types of apparatus which can be used for this purpose. The one used in this study consisted of a calibrated glass reservoir (containing water or other appropriate fluid), connected at its base by a U-tube to a second glass reservoir which contained the disintegrant powder (Fig. 2). Values sought were the decrease in volume of water in the reservoir and the increase in size of the powder bed (the two values are not necessarily identical) as a function of time. The percentage of swelling and the percentage of water uptake 


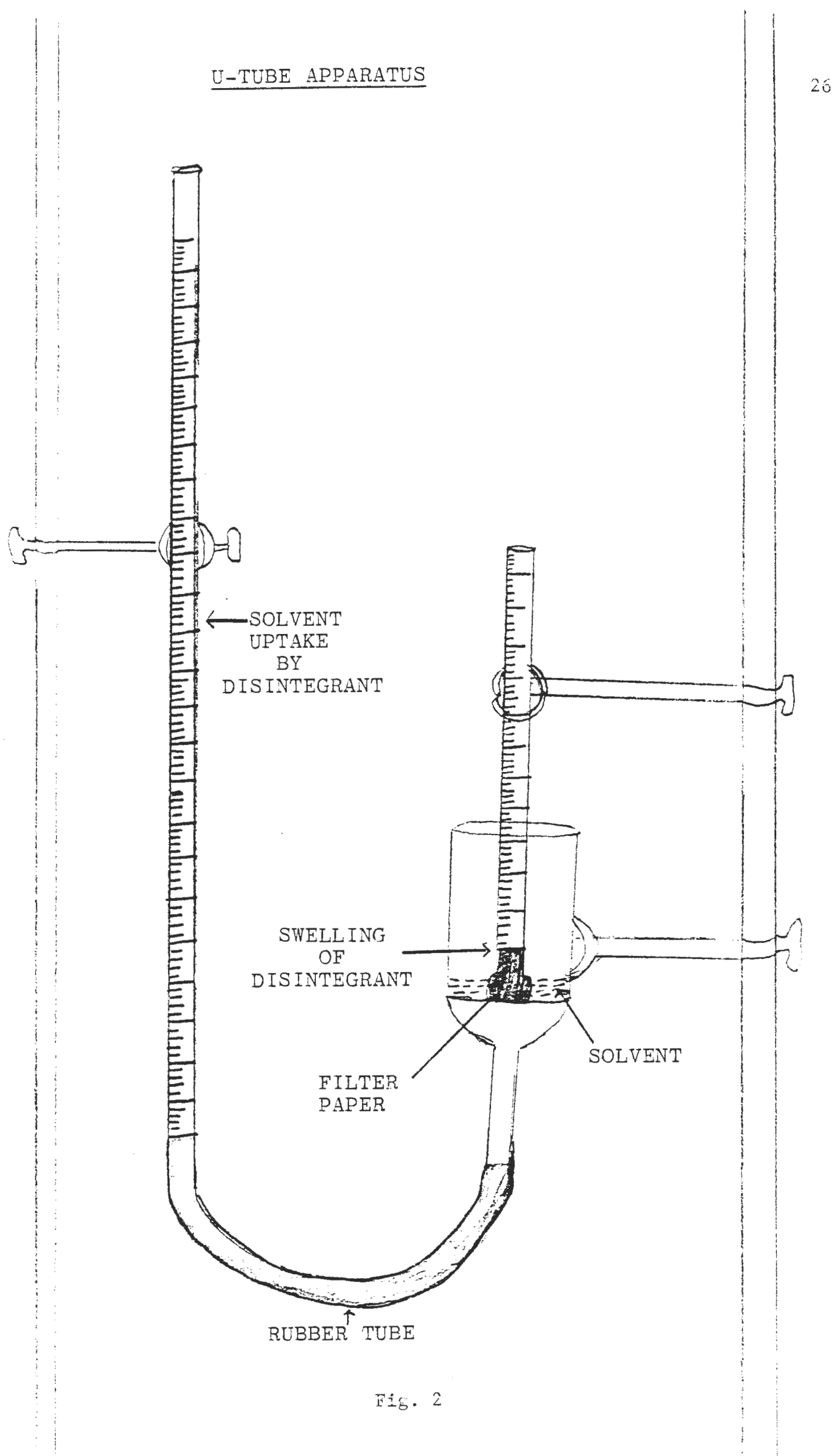




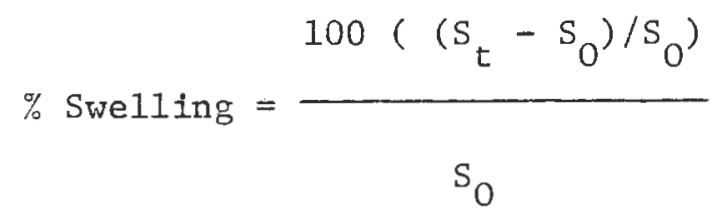

where $\mathrm{S}_{0}$ is the disintegrant level in the tube at time zero, and $S_{t}$ is the disintegrant level in the tube at any time $t$.

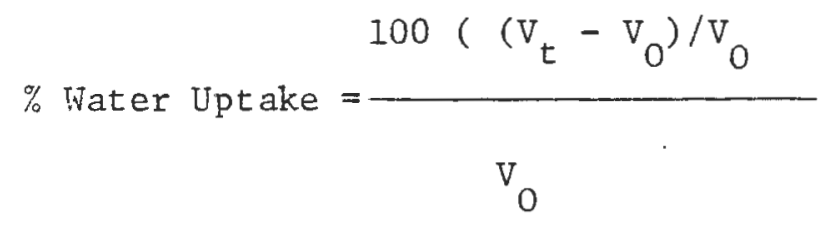

where $V_{0}$ is the water level in the calibrated reservoir at time zero, and $V_{t}$ is the water level in the calibrated reservoir at time $t$.

Percentage of swelling and water uptake were plotted versus time. This test is helpful in determining the ease and extent of bulk powder interaction with water ( 61 ).

The disintegrants used for this test were Emcosoy, Ac-Di-Sol, corn starch, and CLD II. The solvents were distilled water, ethanol/water mixtures, and sodium lauryl sulfate solutions.

Air pressure was used to remove air bubbles from the lower funnel shape portion of the reservoir. The apparatus was left undisturbed for half an hour, so the water levels in both reservoirs remained constant. The readings were taken initially at short intervals, but later at an interval of twenty minutes. 
3. Water Penetration of Disintegrants:

Although tine mechanism of disintegration is very complicated and has not been completely determined (40), the penetration of liquid into a tablet is the first step in the process of tablet disintegration.

In this test the water penetration in various disintegrants was compared. The penetration of a liquid into a capillary is expressed by the following equation:

$$
L^{2}=\frac{R_{\gamma} \cos \theta t}{2 n}
$$

Where: L is the penetrated length of capillary

$R$ is the radius of capillary

$\gamma$ is the surface tension of liquid

$\eta$ is the viscosity of solution

$\theta$ is the angle or contact

$t$ is the time in seconds

The penetrated length of powder bed can be seen visually in a calibrated tube. Then the reading, which is in milliliters, can be converted into centimeters by multiplying it by 2.1 , since $1 \mathrm{mI}=$ $2.1 \mathrm{~cm}$. 


$$
\begin{gathered}
L^{2}=\frac{R_{\gamma} \operatorname{Cos} \theta}{2 \pi} \\
L^{2}=k t
\end{gathered}
$$

Where: $k=R \gamma \cos \theta$ which is called penetrating rate constant. $\mathrm{k}$ varies with materials used; i.e., it depends on the average radius of void space $R$, and contact angle $\theta$.

The water temperature was about $22 \pm 1^{\circ} \mathrm{C}$. The tube containing disintegrants was tapped ten times in all the cases. The water penetration was measured at intervals of twenty minutes. $L^{2}$ vs. t was plotted.

\section{Energy of Wetting:}

Penetration rate of water into disintegrant bed also depends on temperature of water ( 55 ). An attempt was nade to find out approximate energy of wetting of Emcosoy. The water temperatures were 22, 29.2 , and $37^{\circ} \mathrm{C}$ respectively. The temperature range was kept as wide as possible; temperatures included storage condition (room temperature), as well as temperatures of the mediums (for disintegration and dissolution tests).

The entire experiment was carried out the same way as discussed under water penetration of disintegrants. Nogami, et al, derived an equation from Andrade's equation:

$$
\eta=A e^{E / R T}
$$


Where $E$ is the activation energy of viscosity, A the constant, and $\mathrm{R}$ the gas constant. On the other hand, the adhesion tension, $r \operatorname{Cos} \theta$, depends on temperature at a constant pressure $P$, as:

$$
\Delta \mathrm{H}=\gamma \operatorname{Cos} \theta-\mathrm{T} \quad \frac{(\delta r \operatorname{Cos} \theta)}{(\partial \mathrm{T})} \mathrm{P}
$$

Where $\Delta \mathrm{H}$ is the heat wetting. If systems are not disturbed during the wetting process, $\Delta \mathrm{H}$ is independent of temperature. In this experiment, pressure $\mathrm{p}$ is considered constant; solving above equation.

$$
\gamma \cos \theta=\Delta \mathrm{H}-\mathrm{CT}
$$

is obtained, where $\mathrm{C}$ is the positive constant; combining all abovementioned equations :

$$
k=\frac{\gamma}{2 A}(\Delta \mathrm{H}-\mathrm{CT}) \quad \mathrm{e}-{ }^{\mathrm{E}} / \mathrm{RT}
$$

Since generally $\Delta \mathrm{H} / \mathrm{CT}$ is coming between one and two, taking logarithm of equation, approximating $\log (\Delta \mathrm{H} / \mathrm{CT}-1)$ to $\Delta \mathrm{H} / \mathrm{CT}+\mathrm{C}^{\prime \prime}$

$$
\log \frac{k}{T}=a-\frac{\beta}{R T}
$$

Where $\alpha=\log \quad \mathrm{C}+\mathrm{C}^{\mathrm{n}}, \mathrm{B}=\mathrm{E}-\frac{\mathrm{R}}{\mathrm{C}} \Delta \mathrm{H}$

$\mathrm{L}^{2}=\mathrm{kt}$ we discussed under water penetration of disintegrants.

We can obtain value of $k$ from slope of each straight line and then plotting $\log \mathrm{k} / \mathrm{T}$ vs. $1-$. Slope $=B / \mathrm{R}$ we can calculate the value of $\beta$-energy of wetting by multiplying slope by $R\left(1.987 \mathrm{cal} . \mathrm{deg} \cdot{ }^{-1} \mathrm{~mole}^{-1}\right)$. 


\section{Wetting and Drying of Disintegrants:}

The effect of wetting and drying was observed on Emcosoy. Emcosoy was wetted with excess of water in a petri dish (diameter $22 \mathrm{~cm})$. Then the first batch was dried at room temperature $\left(21^{C}\right)$; second and third batches were dried inside the oven at $40^{C}$ and and $60^{\mathrm{C}}$ respectively. The cake-iike mass that formed on drying was reduced to fine particles by using a Fitzpatrick Corminuting Machine. The sieve, 非00, was placed at collecting end of machine. The particles received through the "00" sieve passed through the 100 mesh (U.S. Standard) screen.

The bulk swelling was determined by using the U-tube-type apparatus for all the batches. The batch which was deemed most promising in all respects was compressed as formulation IV. Tablets from both batches were made at identical press settings, using original Emcosoy for comparison purposes. Tablets from both batches were compared for weight, thickness, hardness, and disintegration time.

\section{Aqueous Dispersion:}

Emcosoy (2g) was dispersed in $100 \mathrm{ml}$ of dilute hydrochloric acid solution ( 1 in $100, \mathrm{pH} .70$ ), and in $100 \mathrm{ml}$ water in two measuring cylinders. It was left overnight with periodic stirring initially. The disintegrant settled at the bottom, the volume of disintegrant was measured in the beginning and at the end to find out the percentage of swelling. 
The measuring cylinder provides larger room for the swelling of disintegrant particles, compared to calibrated tube used in bulk swelling study. The medium was kept acidic to simulate effect of gastric $\mathrm{pH}$ on the swelling of the disintegrant. In another cylinder, the effect of water on swelling of disintegrant was observed. The percentage of swelling of disintegrant in neutral and acidic medium was compared.

7. Comparative Study of the Viscosity of Different Strength Solutions on Various Disintegrants:

Determination of the viscosity of solution or gel (disintegrant and solvent interaction) is important because:

a. a viscous gel that sometimes forms on the surface of a disintegrating tablet due to solvent disintegrant interaction, impedes the further penetration of water into the tablet and thus prolongs the process of disintegration.

b. The contribution of disintegrant in increasing the viscosity of dissolution medium is important. Increase in viscosity increases the diffusion layer thickness value (Diffusion Layer Mode1) and thus slows down the dissolution rate. According to Noyes-Whitney Law:

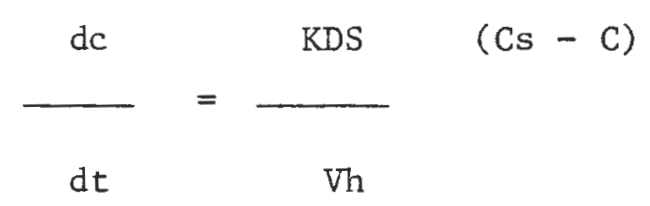


Where: $d c / d t$ is the rate at which drug is dissolving

$\mathrm{K}$ is the Constant

$D$ is the Diffusion Coefficient

$S$ is the Surface Area of Particle

$V$ is the Volume of Solution

$h$ is the Thickness of Diffusion Layer

$(\mathrm{Cs}-\mathrm{C})$ is the Conc. Gradient

The equation can be further simplified:

$$
\begin{array}{lll}
\frac{d c}{d t} & =K^{\prime} s(C s-C) & K D \\
& K^{\prime} s C s & \text { Where } K=\frac{}{V h}
\end{array}
$$

Where $C$ is very small

Particle Cs $\underset{\longrightarrow}{\mathrm{h}} \mathrm{C}$

Stirring reduces the value of $h$. If we have two solutions, A and $B$, $A$ has a higher viscosity than $B$; then stirring will reduce the value of $h$ in $B$ easily and dissolution process will be enhanced. Thus, viscosity plays an important role in dissolution and ultimately in the bioavailability of the product. Although the overall impact may be small, it still may be an important factor.

Solutions of different disintegrants were prepared from $2 \%$ to $16 \%$ by dispersing the disintegrant in water at $37^{\circ} \mathrm{C}$. The resulting solutions were stirred with glass rod to mix the disintegrant and water thoroughly. The viscosity of the solution was determined by using a Brookfield yiscometer. 
Shear rate $(\gamma): \frac{2 \pi R \cdot r p s}{\delta}$

$$
\mathrm{rps}=\mathrm{rpm} / 60
$$

Shear Stress $(\tau): \quad F \%$

$$
R^{2} \cdot 2 \pi \cdot L
$$

Viscosity $=\tau / \gamma$ (Poise)

$R$ is the radius in the spindle.

$\delta$ is the portion of the solution which is subjected to stress.

$F$ is 7,187 dyne-cm

L is the height of spindle in a solution.

$\%$ is the torque reading.

Spindle: Big to small ( 1 to 7 )

Twenty, fifty, and a hundred rpm were used. The dial reading

was taken when the pointer had completed one full return.

The easiest method of calculating viscosity is to use the Brook-

field Viscometer Scale, which is applicable if the

experimental conditions comply with those mentioned by the manu-

facturer. In this study, the scale was used because the experimental conditions were well within the realm of those mentioned by the manufacturer.

The rheological pattern of the different disintegrant solution was studied. Their viscosities were compared.

8. Maximum Hydration Capacity of Various Disintegrants:

The concentration of disintegrant in a hundred milliliter was increased to a point where there was not enough water to wet all 
the disintegrant particles. The solution was stirred with a glass rod to disperse the disintegrant. Maximum hydration capacity of Ac-Di-So1, Emcosoy and CLD II was compared.

\section{Emcosoy-Sieve Analysis:}

Sieving is a commonly used method for measuring particle size distribution because it is inexpensive, simple, and rapid with little variation between operators, provided that similar procedure are followed. The procedure involves the mechanical shaking of a sample through a series of successive smaller sieves, and the weighing of the portion of the sample retained on each sieve. The type of motion influences sieving vibratory motion is most efficient, followed successively by side-top motion, bottom-top motion, rotary motion with top, and rotary motion.

One hundred gram poizder was placed on the top sieve, and the mechanical shaking was continued for 30 minutes. The portion of the sample retained on each sieve was weighed. The results obtained were tabulated (Table XXV), and the average diameter of Emcosoy particle was calculated as shown in the table.

10. Plastic Deformation and Elasticity of Various Disintegrants:

Plastic deformation of starch grains under high pressure has been reported by a number of investigators $(62,63)$. Starch grains are generally thought to be elastic; in fact, most materials are elastic up to a certain extent. Elastic grains deformed under 
pressure tend to return to their original shape and size when the deforming pressure is removed. However, it has been suggested that compression may cause more permanent deformation, which is termed, "plastic deformation." These deformed starch grains are energy rich and this energy is released when the grains are exposed to water ( 64 ). The energy-rich starch grains swell rapidly in water, unlike undeformed grains, which require more heat in order to swell. Recently published electron photomicrographs of potassium chloride and aspirin tablets clearly show deformed starch grains both on the external surfaces and in crosssections of tablets ( 63 ). These grains returned to their original shape when the tablets were exposed to moisture. We can classify various disintegrant particles into two categories: those permanently deformed by the compression (in other words, these particles are nonelastic particles); and those much less permanently deformed by the compression (elastic particles).

In the past, the scanning electron microscope was used for gaining insight into the behavior of solids under compression. It is a powerful tool; however, it does not express elasticity in any arithmetic numbers, so it is almost impossible to compare plastic deformation elasticities of various disintegrants. 
The Instron Universal Testing Instrument, which is widely used in food science to study textural properties of cooked comminuted fish muscle ( 65 ), was used. This equipment is also used in textile industries, packaging industries, and rubber industries. It evaluates properties in terms of shear strength, compressive strength, modules of elasticity, resilience, and puncture strength of the material.

This machine was used in the present study for determining deformation of the disintegrants, as well as compressive force needed to achieve those deformations. Modules of elasticity, percentage of plastic deformations and percentage of recovery were also calculated. A fewaccessories were designed to use the machine for handing powder-like materials.

The disintegrant was placed in a cylinder which had one end left open; the other end was closed by a removable bottoi. These removable bottoms were designed to facilitate the removal of compressed powder. The piston, which was attached to a load cell, could move upward or downward freely, into the cylinder through the open end. The load cell has a capacity to apply compressive force up to 20,000 Ibs. The load cell was connected to controlling panels which had a digital dial that showed the distance traveled by the load cell. It also had switches which regulated upward or downward movement of a loading cell, as well as the distance that would be traveled by the loading cell. There 
was a dial which could be rotated to regulate the compressive force of the loading cell. The movement of the loading cell with the piston could be synchronized with the movement of the chart paper.

The chart paper had ten big divisions, and each big division was divided into ten small divisions; so the total number of small divisions was one hundred. A mobile recorder pen moved along the base line of the paper, with the movement of piston. When the piston applied pressure on the disintegrant particles, the pen moved on the calibrated chart paper; so by counting the small divisions, one can determine the pressure applied by the piston.

The piston can move down and up once or more times; that makes it possible to apply single compression or cyclic compression.

The data was interpreted as follows:

$$
\begin{aligned}
\text { Deformation distance } & =\text { Load Cel1 } \div \text { Chart } \\
& =5 \mathrm{in} / \mathrm{min} . \times 1 / 2 \mathrm{~min} / \mathrm{in} . \\
& =.251 \text { oad cell/chart } \\
\text { Modulus of Elasticity } & =\frac{\text { Compressive Stress }}{\text { Corresponding Strain }} \\
& =\frac{\mathrm{F} / \mathrm{A}}{\Delta \mathrm{L} / \mathrm{L}}
\end{aligned}
$$


Where $\mathrm{F}$ is Compressive Force

$A$ is the area of the piston which comes in contact with powder.

$\Delta \mathrm{L}$ is the reduction in the height of disintegrant.

I is the original height of disintegrant in a cylinder.

Now, for example, if pen travelled 9.2 divisions on chart paper:

$$
\begin{aligned}
& 25 \times \frac{9.8}{10}=0.23 \text { inch }(\Delta \mathrm{L}) \\
& \frac{\Delta \mathrm{L}}{\mathrm{L}}=\frac{.23}{2.25}=.102 \\
& \frac{F}{A}=\frac{\text { Compressive Force }}{\text { Area of Piston }\left(E^{2}\right)} \\
& =\frac{2.85 \times 10^{3} \text { (From Chart) }}{3.14 \times(0.55)^{2}} \\
& =2850=956.38 \mathrm{lb} / \mathrm{in}^{2} \\
& \text { Elasticity }=\frac{F / A}{\Delta^{L / L}} \\
& =956.381 \mathrm{~b} / \mathrm{in}^{2} \\
& .1022 \\
& =9357.931 \mathrm{~b} / \mathrm{in}^{2}
\end{aligned}
$$

How to achieve desired deformation (if you want to attempt $10 \%$ deformation).

The height of disintegrant in a cylinder is 2.25 inches. $10 \%$ of this height $=0.23$ inch.

When the piston touched the porder in a cylinder, the reading was adjusted to zero. Then the distance 0.23 inch (as calculated above) would be set on the scale and the "down" switch would be pressed. The pis- 
ton would travel 0.25 inch in a powder bed, and the compressive force needed to travel that distance would be recorded on a chart paper. 10\%, 20\%, and sometimes $40 \%$ deformations were attempted.

$$
\begin{aligned}
& \text { Plastic Deformation: } \quad=\frac{D_{3}-D_{1}}{\text { Sample Height }} \\
& D_{1} \text { is the distance travelled by piston during cycle one. } \\
& D_{3} \text { is the distance travelled by piston during third cycle. }
\end{aligned}
$$$$
\text { If } \mathrm{D}_{1}=0
$$$$
\text { and } \mathrm{D}_{3}=11 \mathrm{div} \text {. on chart, }
$$$$
\mathrm{D}_{3}=11 \times \frac{.25^{\prime \prime}}{10 \mathrm{div}}=.275
$$$$
\begin{aligned}
\% \text { Plastic deformation } & =\frac{\mathrm{D}_{3}-\mathrm{D}_{1}}{\text { Sample Height }} \\
& =\frac{.275-0}{2.25} \times 100 \\
& =12.22 \%
\end{aligned}
$$

$\%$ Recovery $=20-12.22$

$=7.78 \%$

The height of the disintegrants were adjusted to 2.25 inch after tapping. Modulus of elasticity values at various attempted deformations and the compressive force needed to achieve that deformation were compared for various disintegrants. Percentages of plastic deformation and percentages of recovery were also compared for various disintegrants. 
11. Formulations:

\begin{tabular}{|c|c|c|c|c|}
\hline \multirow{9}{*}{\multicolumn{2}{|c|}{ Formula I: }} & \multicolumn{2}{|l|}{ Riboflavin } & $0.57 \%$ \\
\hline & & \multicolumn{2}{|l|}{ Pyridoxine hydrochloride } & $0.86 \%$ \\
\hline & & \multicolumn{2}{|l|}{ Niacin } & $5.70 \%$ \\
\hline & & \multicolumn{2}{|l|}{ Ascorbic acid } & $17.10 \%$ \\
\hline & & \multicolumn{2}{|l|}{ Disintegrant* } & $0.5 \%$ or $1.0 \%$ \\
\hline & & & or & $3.0 \%$ \\
\hline & & \multicolumn{2}{|l|}{ Stearic acid } & $2.5 \%$ \\
\hline & & \multicolumn{2}{|l|}{ Emcompress or Emdex ad } & $100 \%$ \\
\hline & & \multicolumn{3}{|l|}{ Tablet weight $350 \mathrm{mg}$. } \\
\hline \multirow[t]{6}{*}{ Formula } & II: & \multicolumn{2}{|l|}{ Pyridoxine hydrochloride } & $5.0 \%$ \\
\hline & & \multicolumn{2}{|l|}{ Disintegrant* } & $0.5 \%$ or $1.0 \%$ \\
\hline & & & or & $2.0 \%$ or $3.0 \%$ \\
\hline & & \multicolumn{2}{|l|}{ Magnesium stearate } & $0.5 \%$ \\
\hline & & \multicolumn{2}{|l|}{ Emcompress or Emdex ad } & $100 \%$ \\
\hline & & \multicolumn{3}{|l|}{ Tablet weight $200 \mathrm{mg}$} \\
\hline \multirow[t]{5}{*}{ Formula } & III: & Ascorbic acid & & $25.0 \%$ \\
\hline & & \multirow[t]{2}{*}{ Disintegrant* } & & $0.5 \%$ or $1.0 \%$ \\
\hline & & & or & $=2.0 \%$ or $3.0 \%$ \\
\hline & & Stearic acid & & $2.5 \%$ \\
\hline & & Emcompress ad & & $100 \%$ \\
\hline
\end{tabular}

*Emcosoy, Explotab, Ac-Di-Sol and Corn Starch were used as disintegrants. 


$\begin{array}{lll}\text { Formula IV: } & \text { Hydrochlorothiazide } & 20.0 \% \\ & \text { Disintegrant } * * \text { A or B } & 1.0 \% \\ & \text { Magnesium stearate } & 0.5 \% \\ & \text { Emcompress ad } & 78.5 \%\end{array}$

Tablet weight $200 \mathrm{mg}$

**Disintegrant A is original Emcosoy

Disintegrant $B$ is modified Emcosoy 


\section{Tablet Production}

The active ingredient (or ingredients) was mixed with matrix in a twin shell dry blender for five minutes. The disintegrant was then added and mixing was continued for five minutes. After completion of this blending, stearic acid in Formulas I and II and magnesium stearate in Formula II was added, and the eixing process was continued for an additional five minutes. The formulations were compressed on a Stokes Rotary tablet press. A punch size of $3 / 8^{\prime \prime}$ for multivitamin and ascorbic acid formulations and punch size of $1 / 4^{\prime \prime}$ for pyridoxine formulations were used.

Disintegrants were studied in the presence of single active ingredient Formula II (pyridoxine hyärochloride) and Formula III (ascorbic acid), and more than one active ingredient (multi-vitamin formulation) Formula I, using water insoluble (Emcompress) and water soluble (Emdex) matrices. Tablets were made using various disintegrants with identical press settings Formula I contained riboflavin, pyridoxine hydrochloride, niacin, and ascorbic acid as active ingredients. Emcosoy, Ac-Di-So1, and Explotab were used as disintegrants at $0.5 \%$ and $1 \%$ level, and Emcosoy and corn starch at 3\% leve1. Emcompress and Emdex were used as matrices. Stearic acid was used as lubricant at $2.5 \%$ level.

Formula II contained pyridoxine hydrochloride as active ingredient. Emcosoy, Ac-Di-Sol, and Explotab were used as disintegrant at $0.5 \%, 1 \%$, and $2 \%$ level. Corn starch and Emcosoy were used 
as disintegrant at $2 \%$ and $3 \%$ leve1. Magnesium stearate was used as 1ubricant at $0.5 \%$ level. Emcompress and Emdex were used as matrices.

Formula III contained ascorbic acid as active ingredient and stearic acid as lubricant at 2.5\% 1eve1. Emcosoy, Ac-Di-So1, and Explotab were used as disintegrant at $0.5 \%, 1 \%$, and $2 \% 1$ level. Corn starch and Emcosoy were used at $3 \%$ level. At $2 \%$ disintegration level, granulated ascorbic acid was used, while the rest of the formulation contained ascorbic acid USP.

Formulas I and III contained ascorbic acid as active ingredient; stearic acid (2.5\%) was used as a lubricant, since alkaline lubricant, such as magnesium and calcium stearate and minerals; e.g., talc and hydrated silico aluminate, were shown to decrease the stability of ascorbic acid tablets $(66,67)$.

\section{Physical Tests:}

Various physical tests were performed on the tablets:

a. Weight: The weight of each individual tablet was determined by dusting each tablet off with a camel-hair brush, and placing it on an electric balance. This procedure was repeated for twenty tablets. The data from the tablets was analyzed for sample mean and Relative Standard Deviation (R.S.D.), using a computer program. This procedure is explained below. The R.S.D. value was used as 
a measure of weight variation within a sample of tablets. The physical tests were run for twenty trials on each sample set. The data from the sample set was analyzed for mean value and Relative Standard Deviation (R.S.D.). A digital computer program written in Fortran was used to calculate these values, using the equation:

Relative Standard Deviation $=\operatorname{RSD}=100(\mathrm{~S} / \overline{\mathrm{x}})$

Where: $S$ is the Standard Deviation of Sample, and $\bar{x}$ is the Sample Mean

The computer program used appears in Appendix

b. Thickness: The thickness of twenty tablets was determined by first dusting off the surface of the tablet with a brush, and then placing it in the jaws of a micrometer. The measurements were recorded and analyzed for mean value and R.S.D. as a measure of variation.

c. Hardness: The hardness of twenty tablets was determined by placing each tablet in an electronic hardness tester (Erweka) which recorded the breaking strength of the tablet in kilograms. This procedure was repeated twenty times, and the data were analyzed for sample mean and R.S.D. as a measure of variation. 
d. Friability: This test is a measure of abrasion resistance and was determined by first weighing twenty tablets after dusting, placing them in a Roche friabilator which rotated at a fixed rate for twenty minutes. The total weight of the twenty tablets (or what was left) was recorded, and the percent friability was determined as follows:

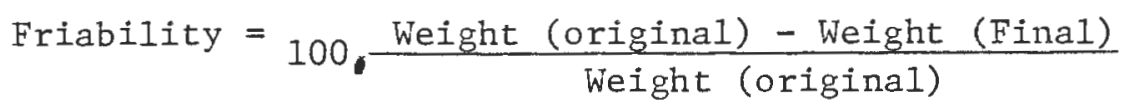

e. Disintegration: Tablet disintegration was tested by using the U.S.P. apparatus with discs as described in the National Formulary rIV (68). Fig.3 schematically illustrates how this apparatus is set up. The time needed for all the fragments to pass through the mesh at the bottom of the test cage was noted visually, and was recorded. A mean value for six tablets was calculated, and the range of values was also recorded.

f. Dissolution: Drug dissolution was measured using a U.S.P. apparatus, and according to monographs in U.S.P. XX. The exact equipment used was the U.S.P. "basket" assembly, and $5 \mathrm{~m} 1$ samples were removed at times of $1,2,4,7,10$, $20,40,60$, minutes, etc. until $100 \%$ dissolution was observed. Plots of these readings were made to depict the dissolution process. 


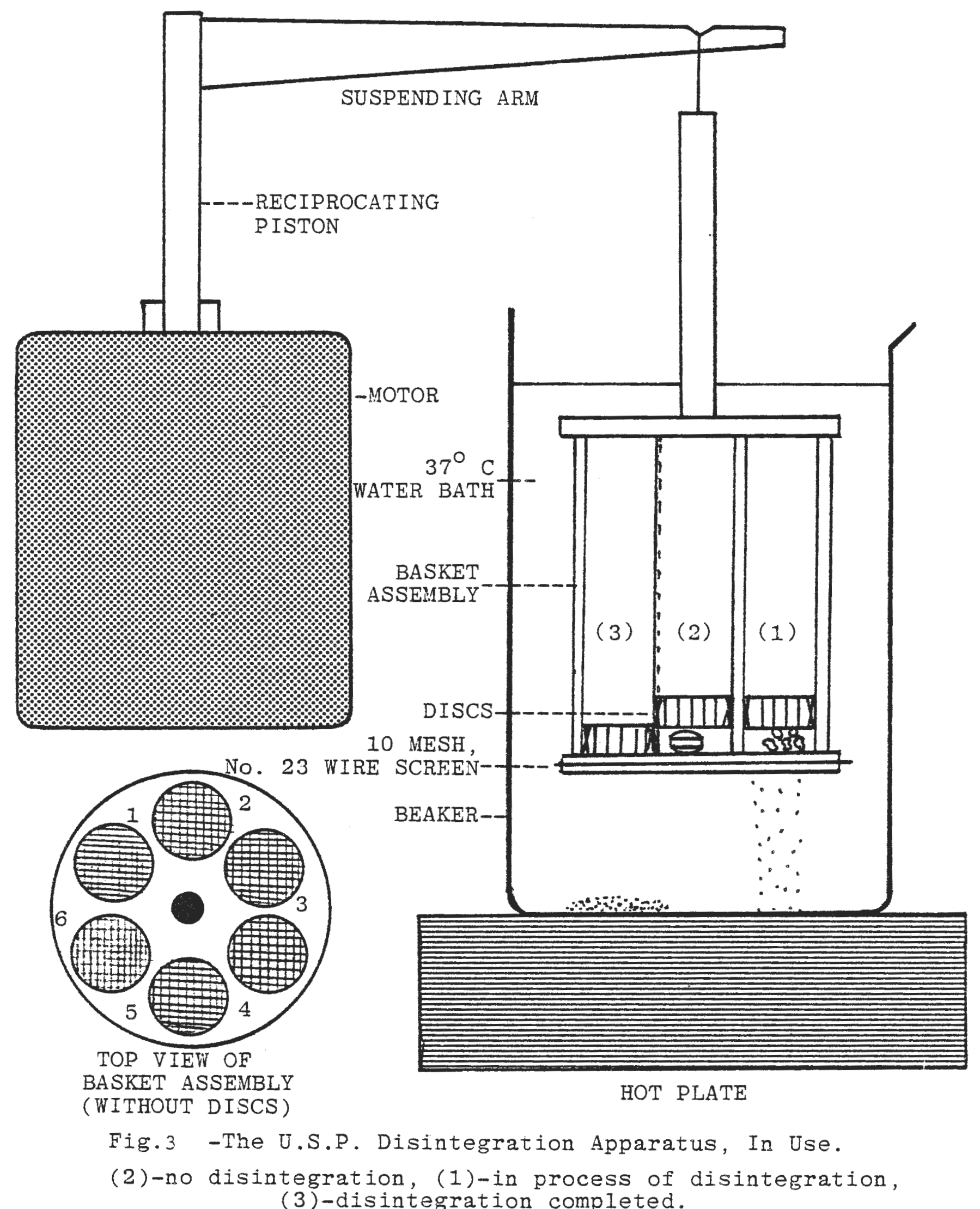


i. Dissograph: This is a programmable dissolution test apparatus. It has the capacity to monitor the dissolution of six tablets simultaneously. Sample solution was pumped from dissolution flask to a cuvette cell. Dilution was carried out if reeded. Then samples were analyzed in a spectrophotometer. Readings were recorded on the Dissograph scale. The sampling time can be programmed according to convenience. The significance of this apparatus is that all the functions are controlled automatically. The Dissograph was used to analyze the dissolution profiles of multivitamin formulations.

ii. Analytical Procedures: The dissolution medium was selected as appropriate for any given drug, on the basis of stability and solubility of drug. The drug or vitamin solution was scanned using an ultra-violet spectrophotometer to find $\lambda \max --$ the wavelength at which the solution gives maximum absorbance. Once this value was determined, the spectrophotometer was set at this wavelength, and each sample was analyzed for absorbance at this wavelength at various concentrations; the results were recorded in a Beer's plot. The drug monograph, as it appeared in the U.S.P. XX, was used as a reference for 
determining the dissolution medium for the test. The dissolution samples (five milliliters) were not returned to the dissolution bath so that there was a certain amount of drug being lost in each sample. This drug loss was reflected in subsequent samples. This loss which must be accounted for was corrected by using a digital computer program utilizing the following equations to determine the amount of drug in the five milliliter sample:

$$
\text { Conc. }=(\mathrm{A}-\mathrm{b}) / \mathrm{m}
$$

Where: A is the absorbance

$$
\begin{aligned}
& \mathrm{m} \text { is the slope of Beer's plot } \\
& \mathrm{b} \text { is the intercept of Beer's plot }
\end{aligned}
$$

The computer program appears in Appendix 
III. RESULTS AND DISCUSSIONS

\section{Scanning Electron Micrographs:}

The scanning electron micrographs of Emcosoy are shown on pages 51 and 52. As can be seen in figures 4. 5 the flake-like material appears to consist of the ground cell walls of soy beans and probably contains some proteinaceous material. It swells in the presence of water, and the cellular nature of the soy polysaccharides appears to exert a. wickingeffect (20). This mechanisn of tablet disintegration is so effective that Emcosoy can be used as a tablet disintegrant in concentrations as low as . $5 \%$.

\section{Bulk Swelling and Water Uptake:}

Although investigators have proposed and evaluated numerous compounds as tablet disintegrants, relatively few are in common use today; only modified starches, cellulose derivatives, and some ion-exchange resins are widely used. Depending on the type of disintegrant used, many theories relating to mechanism of action of tablet disintegration have been proposed, but none has fully explained the disintegrant properties of all the agents. Lowenthal, in two review articles, had discussed in detail the different mechanisms and factors affecting tablet disintegration $(19,70)$. The three major mechanisms of action are: (1) swelling, (2) porvisity and capillary action (wicking), and (3) deformation. Even though these concepts are listed separately, interrelationships probably occur in almost all tablet disintegration. 

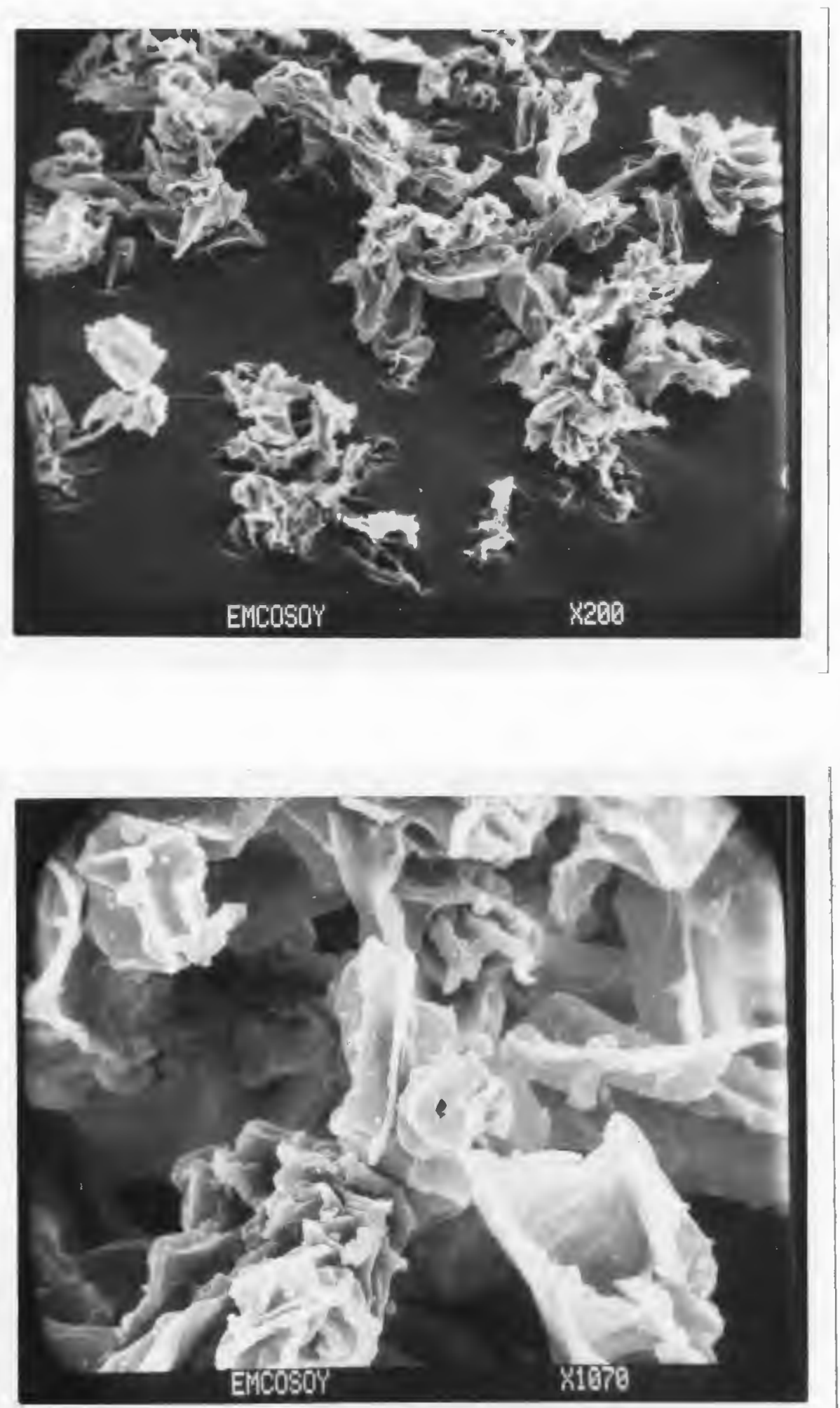
SCANNING ELECTRON MICROGRAPHS OF EMCOSOY PARTICLES
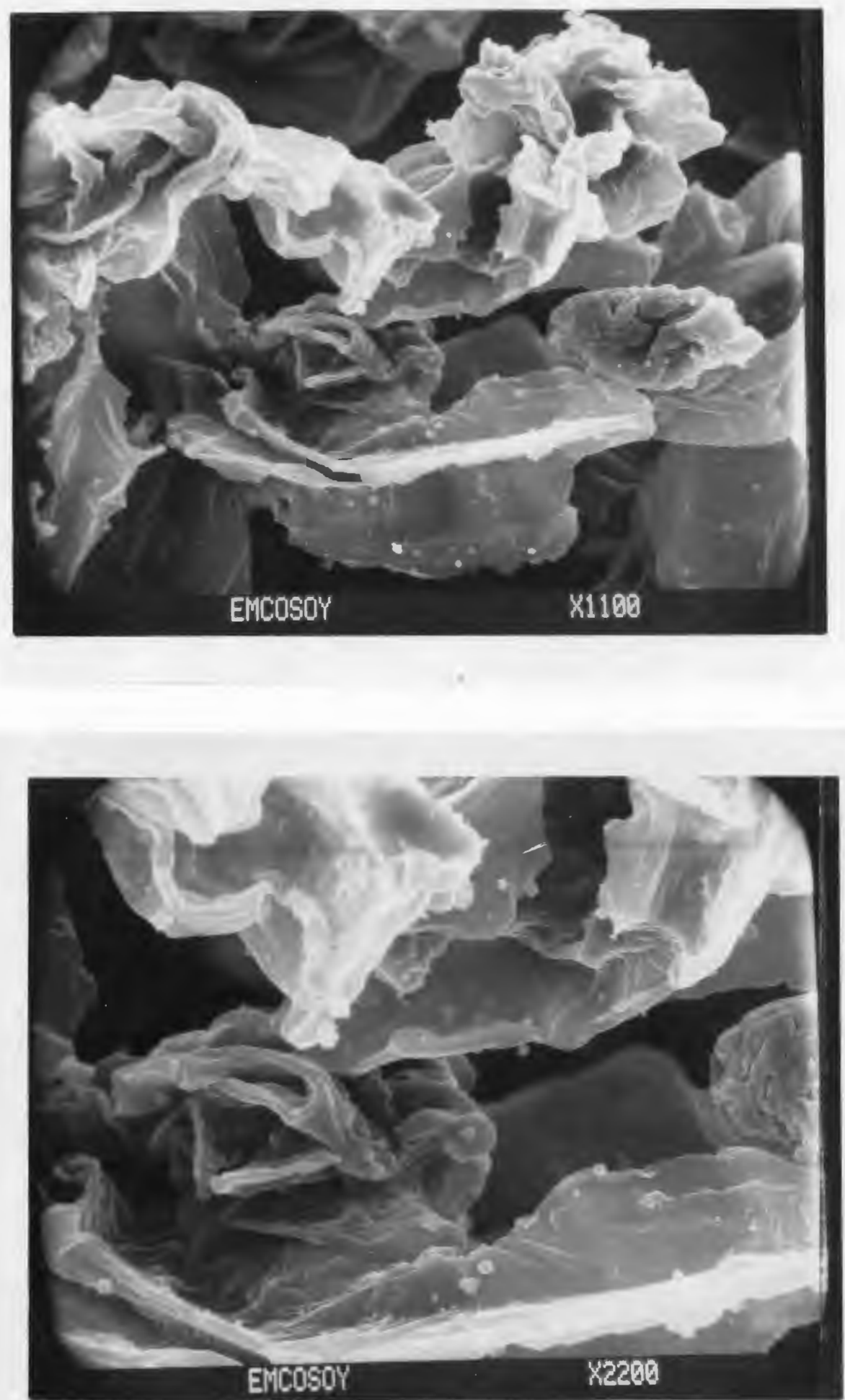

Fig. 5 
As explained in the experiment section, U-tube type apparatus was used for determining the bulk swelling of various disintegrants. Bulk swelling of Emcosoy, Ac-Di-Sol, CLD and corn starch were determined. All the disintegrants had equal initial volume in the calibrated tube, since the volume difference was used in calculating percentage swelling. For one disintegrant, different initial weight would give different percentages of swelling as found out in Ac-Di-Sol, Table IV, and graph on page 54. Logarithm of percentage swelling vs. time would give almost a straight line (Fig. 7 ). For different initial weight, the amount of water that would travel in a powder bed would vary (Fig. 8 ). The amount of water travel would reduce as the weight of the disintegrant increased.

The percentage of swelling decreased with increased initial weight of the disintegrant because the particles in the bottom portion of the tube came in contact with water of the reservoir first; they tried to swell, but their swelling was reduced by the weight of particles on the top. As the weight of the disintegrant was increasing, the bulk of particles on top was increasing; at the same time the amount of particles which were in contact with water remained the same. So, the swelling was reduced with increases in weight of the disintegrant.

Average bulk swelling of Emcosoy, Ac-Di-Sol, CLD, and corn starch were compared. Time required to reach the swelling and amount of water travelled in various disintegrantswere compared (Table I ). As it can be seen from the table, Emcosoy had maximum swelling, while corn starh had no swelling. Time required to achieve that swelling 


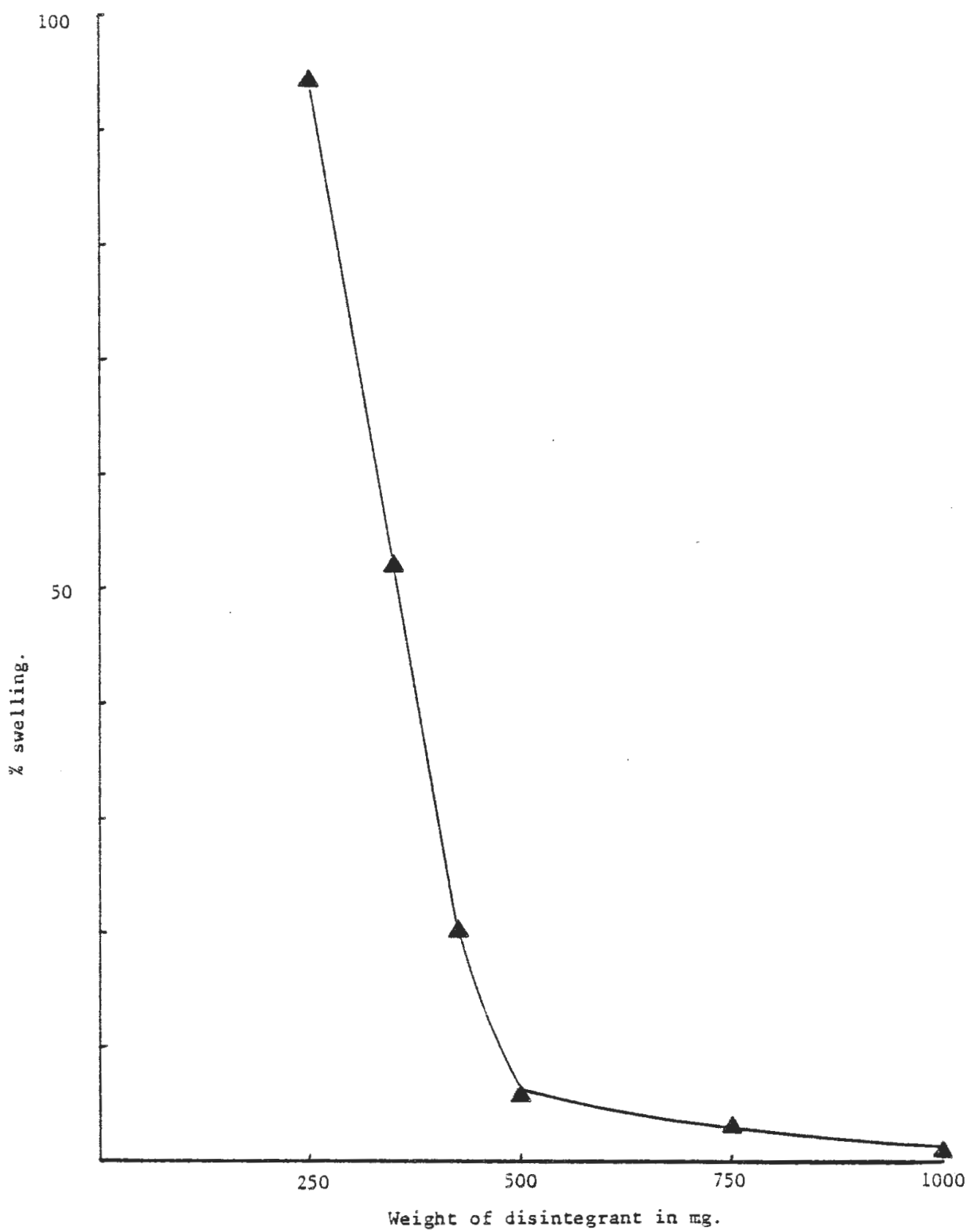

Fig. 6 


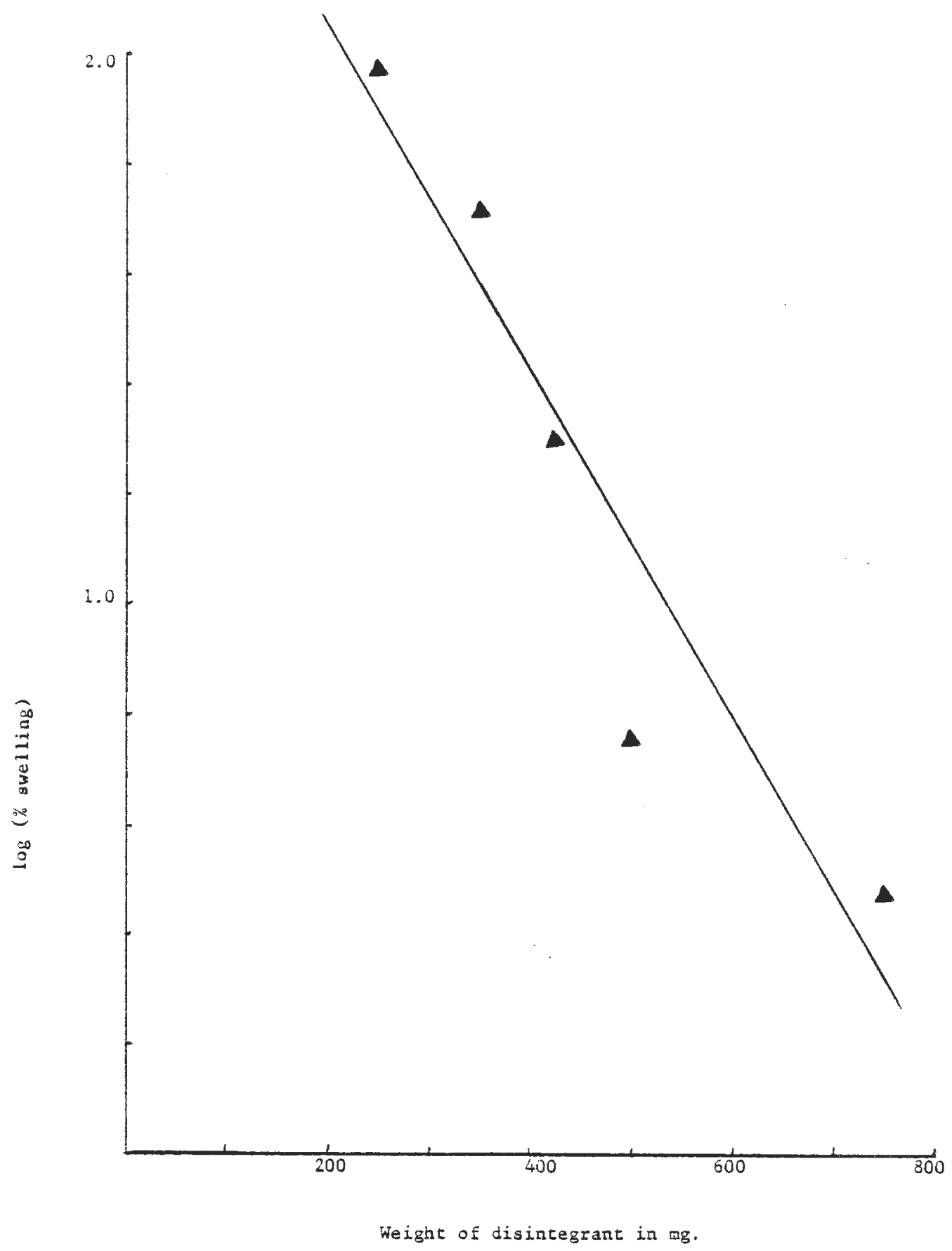

Fig. 7 


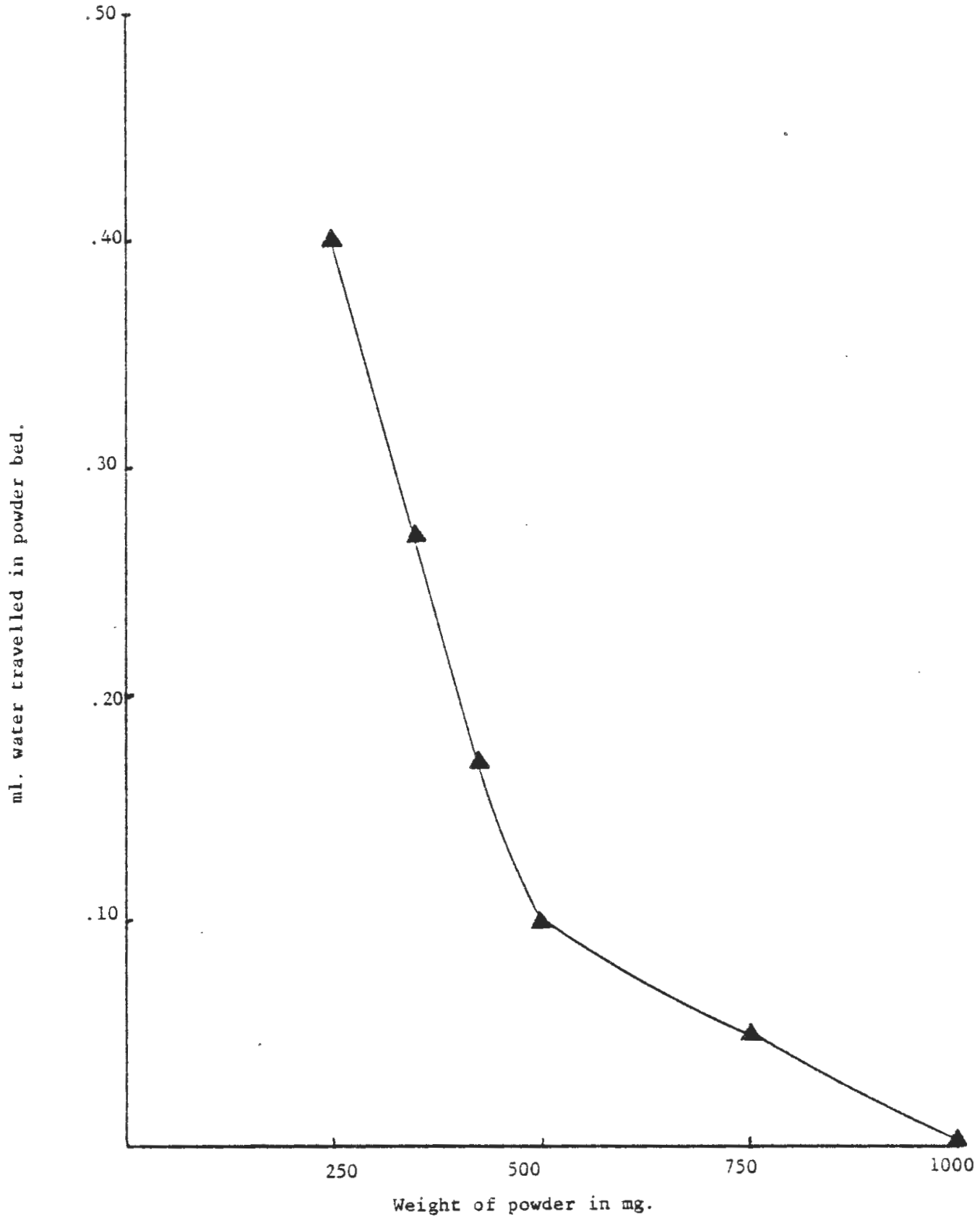

Fig. 8 


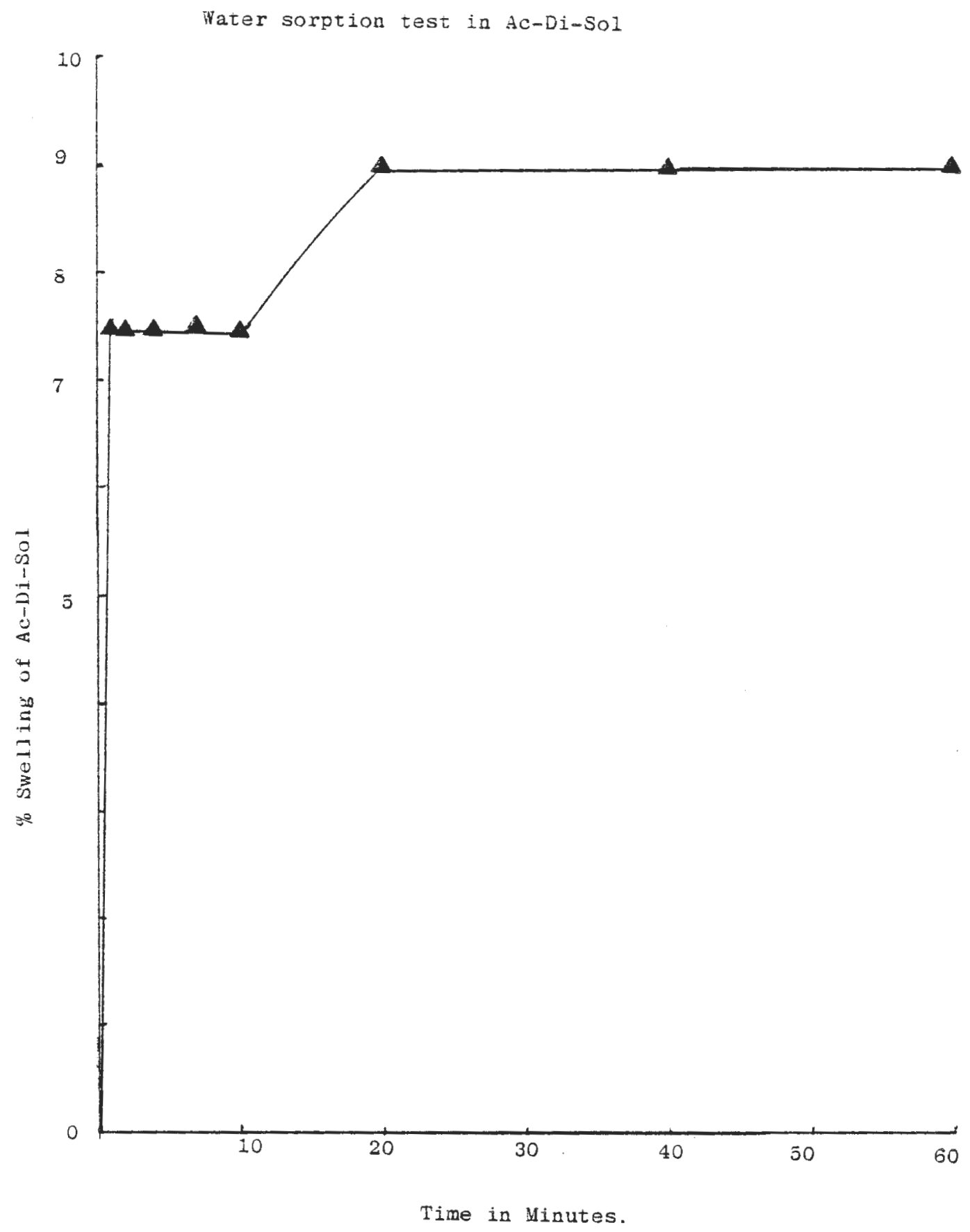

Fig. 9 


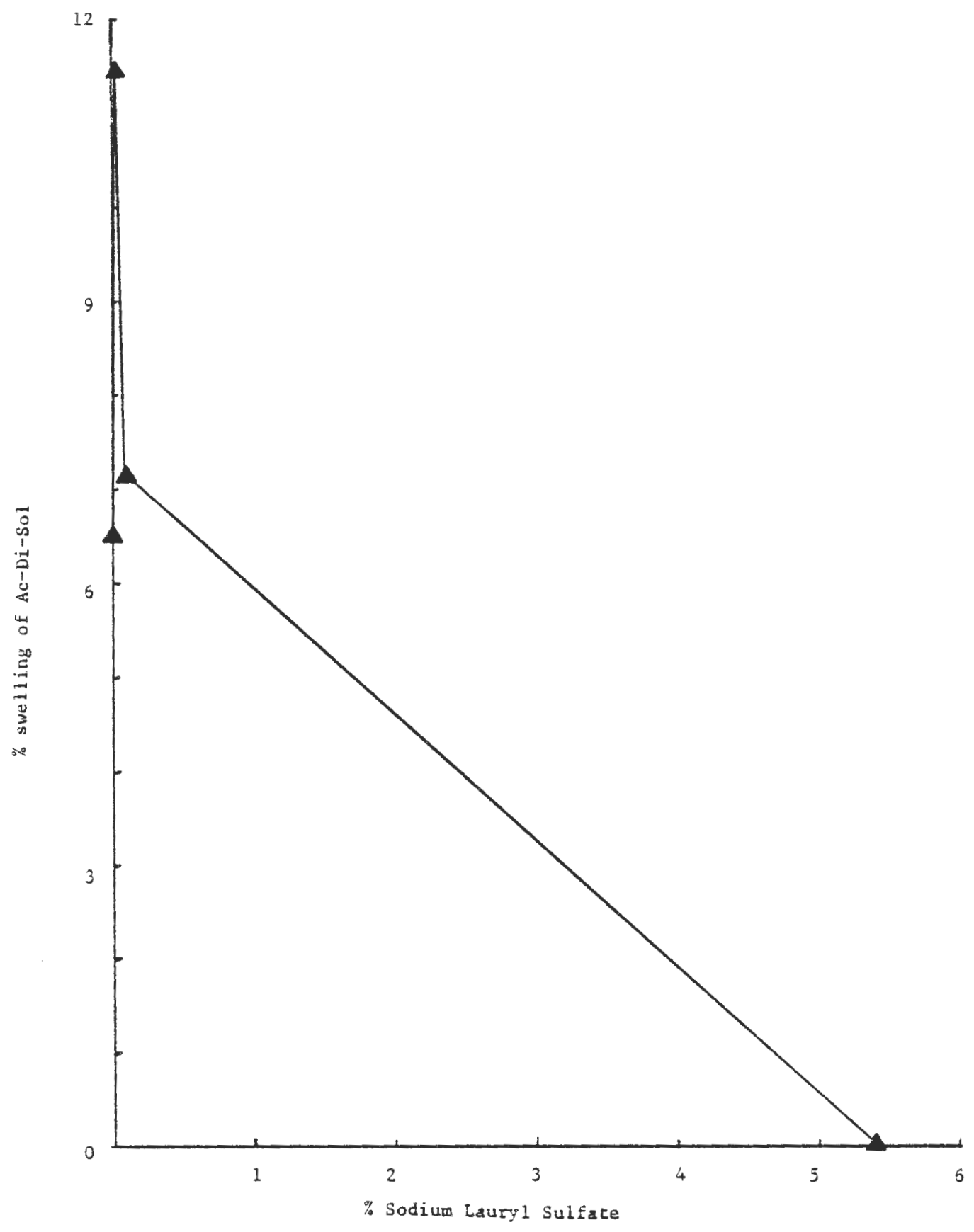

Fig. 10 


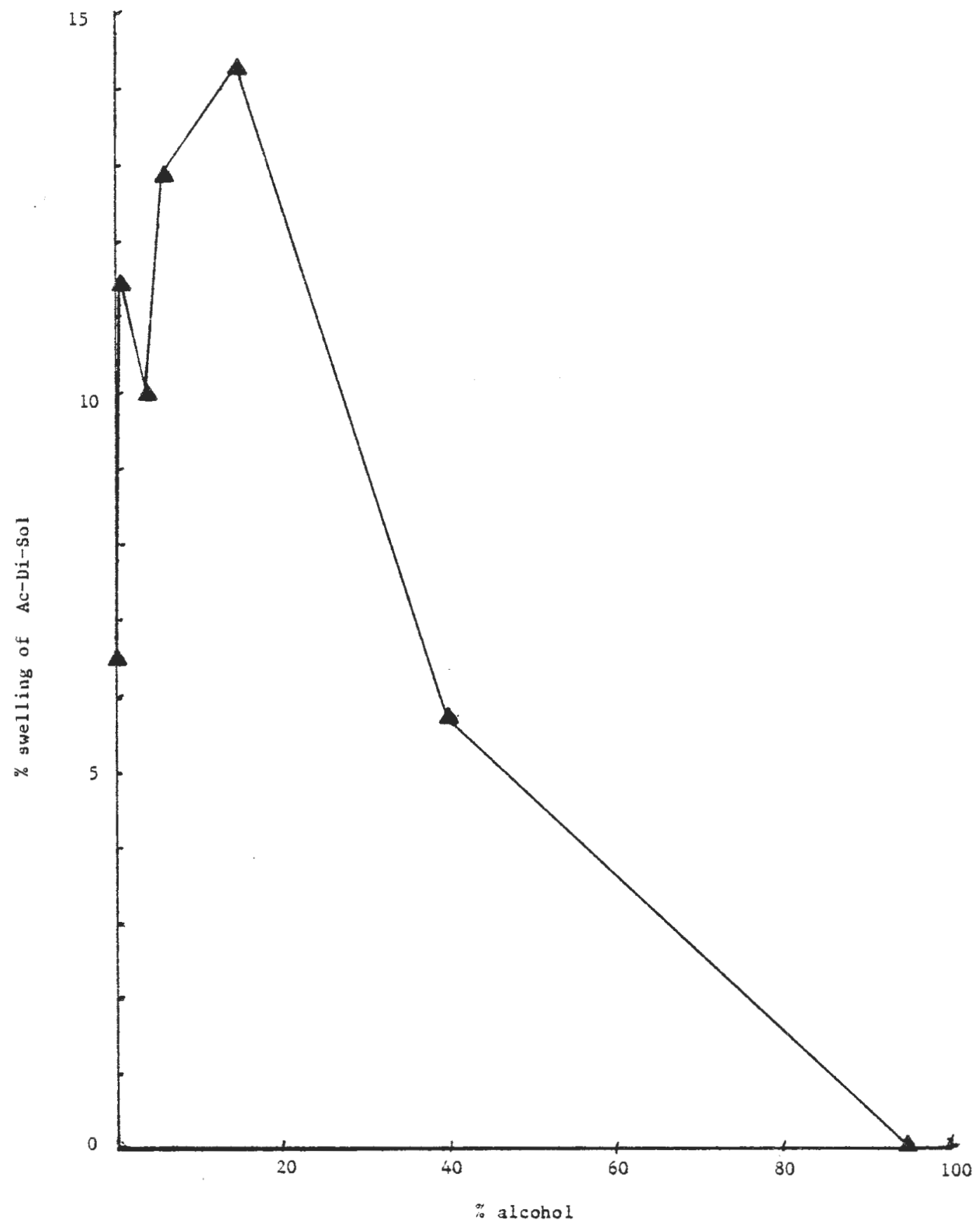

Fig. 11 
TABLE I

\begin{tabular}{lccc} 
Disintegrant & $\begin{array}{c}\text { Time Required to } \\
\text { Reach Plateau }\end{array}$ & $\begin{array}{c}\text { Water Travelled } \\
\text { in Powder Bed }\end{array}$ & \% Swelling \\
\hline CLD & $10 \mathrm{~min}$. & $.3 \mathrm{ml}$. & 48.57 \\
Emcosoy & $90 \mathrm{~min}$. & $1.04 \mathrm{ml}$. & 55.71 \\
Ac-Di-Sol & $20 \mathrm{~min}$. & $.10 \mathrm{ml}$. & 8.96 \\
Corn Starch & $6 \mathrm{~min}$. & $.70 \mathrm{ml}$. & $\mathrm{nil}$.
\end{tabular}

TABLE II

Disintegrant: Emcosoy

Solvent: $\quad$ Citrate-Phosphate-Borate/Hcl buffer

$\mathrm{PH}$ \% Swelling of Disintegrant Average Swelling

2

00.00

10.00

5.00

4

14.29

14.29

14.29

6

28.57

15.71

22.14

8

22.86

22.86

22.86

TABLE III

$t$ Test for Buffer Reading

Buffer $\mathrm{PH} \quad 5$ Computer $t$ Table Value Comment

2

$4 \cdot 3$

Not Significant

2

2.10

4.3

Not Significant 


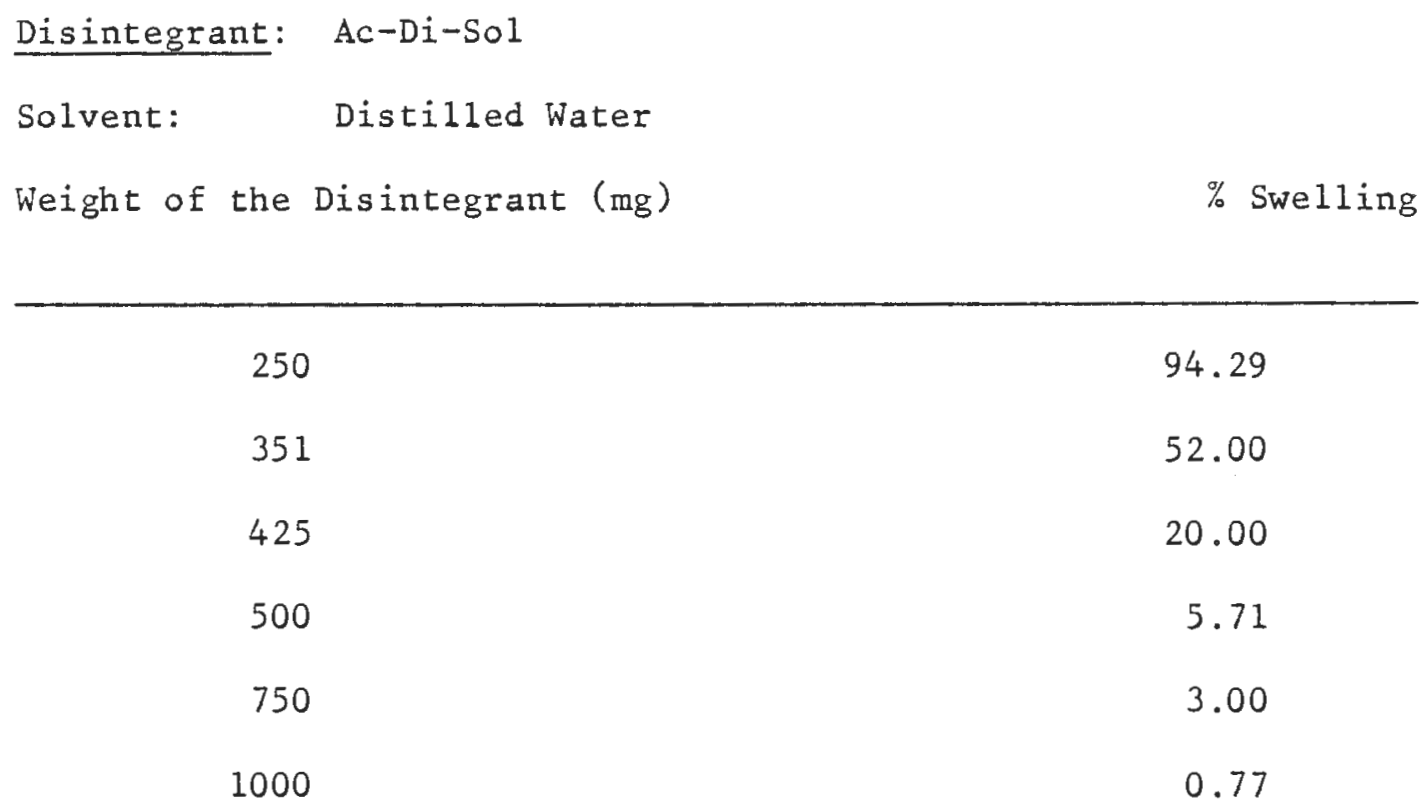


TABLE V

Disintegrant: Emcosoy

Solvent: $\quad$ Alcohol

Solvent

$\%$ Swelling

Average \% Swe11

$0.0 \%$ alcohol

56

52

48

$1.0 \%$ alcohol

43

43

43

$4.0 \%$ alcohol

28

28

28

$6.0 \%$ alcohol

30

29

28

$15.0 \%$ alcohol

33

34.5

36

$40.0 \%$ alcohol

23

23

23

$95.0 \%$ alcohol

0.0

0.0

0.0 
TABLE VI

t-test for Alcohol Reading with Emcosoy as Disintegrant
Alcohol \%
t Computed
t Table Value
Comment

0.0

1.0

2.25

4.3

Not Significant

0.0

4.0

6.00

4.3

Significant

0.0

6.0

5.58

4.3

Significant

0.0

15.0

4.09

4.3

Not Significant

0.0

40.0

7.25

4.3

Significant

0.0

95.0

13.00

4.3

Significant

TABLE VII

Disintegrant: Emcosoy

Solvent: $\quad$ Sodium Lauryl Sulfate (SLS)

Solvent

\% Swell

Average \% Swell

$0.0 \%$ SLS

56

52

48

$0.01 \%$ SLS

43

40.5

$0.10 \%$ SLS

44

51

58

$5.40 \%$ SLS

14

11 
TABLE VIII

$t$ Test for SLS Reading with Emcosoy as a Disintegrant

\begin{tabular}{lccc} 
SLS\% & $t$ Computed & $t$ Table Value & Comment \\
\hline $\begin{array}{l}0.00 \\
0.01\end{array}$ & 2.44 & 4.3 & Not Significant \\
0.00 & 0.12 & 4.3 & Not Significant \\
0.10 & 8.2 & 4.3 & \\
0.00 & & 4 &
\end{tabular}

TABLE IX

Disintegrant: Ac-Di-Sol

Solvent: $\quad$ Citrate-Phosphate-Borate/Hcl Buffer

\begin{tabular}{lcc}
$\mathrm{PH}$ & Average Swelling \\
\hline 2 & 17.14 & \\
& 21.43 & 19.29 \\
& 14.29 & \\
10.00 & 12.15 \\
& 21.21 & \\
& 15.71 & 18.46 \\
& 8.57 & \\
& 17.14 & 12.86
\end{tabular}


TABLE X

$t$ Test for Buffer Reading

\begin{tabular}{cccc} 
Buffer PH & $t$ Computed & $t$ Table Value & Comment \\
\hline $\begin{array}{c}2 \\
4\end{array}$ & 2.35 & 4.3 & Not Significant \\
2 & .23 & & Not Significant \\
6 & & 4.3 & \\
2 & 1.34 & 4.3 & Not Significant
\end{tabular}

TABLE XI

Disintegrant: Ac-Di-Sol

Solvent: $\quad$ Sodium Lauryl Sulfate (SLS)

Solvent $\%$ Swelling of Disintegrant Average Swelling

$\begin{array}{lll}00.00 \% \text { SLS } & 5.71 & 6.48 \\ & 7.24 & \\ 00.01 \% \text { SLS } & 12.86 & 11.43 \\ & 10.00 & \\ 00.10 \% \text { SLS } & 5.71 & 7.14 \\ & 8.57 & \\ 05.40 \% \text { SLS } & 0.00 & 0.00 \\ 10.00 \% \text { SLS } & 0.00 & \\ & 0.00 & 0.00\end{array}$


$65-a$

TABLE XII

$t$ Test for SLS Reading

\begin{tabular}{lccc} 
SLS $\%$ & $t$ Computed & $t$ Table Value & Comment \\
\hline $0.00 \%$ & 3.05 & 4.3 & Not Significant \\
$0.01 \%$ & 0.41 & 4.3 & Not Significant \\
$0.00 \%$ & & & Significant \\
$0.10 \%$ & 8.46 & 4.3 & \\
$05.40 \%$ & & & \\
\hline
\end{tabular}




\section{TABLE XIII}

Disintegrant: Ac-Di-Sol

Solvent

$\%$ Swelling of Disintegrant

Average Swelling

0\% Alcohol

$1 \%$ Alcohol

$4 \%$ Alcohol

$6 \%$ Alcohol

15\% Alcohol

40\% Alcohol

95\% Alcohol

0.00

TABLE XIV
0.00

5.71

7.24

11.43

11.42

7.14

14.28

8.57

11.43

14.29

14.29

14.29

4.28

7.14

0.00

6.48

11.43

10.00

12.86

14.29

5.71
Comment

\begin{tabular}{|c|c|c|c|}
\hline Alcohol \% & $t$ Computed & t Table Value & Comment \\
\hline \multicolumn{4}{|l|}{$0 \%$} \\
\hline $1 \%$ & 6.47 & 4.3 & Significant \\
\hline \multicolumn{4}{|l|}{$0 \%$} \\
\hline $4 \%$ & 1.15 & 4.3 & Not Significant \\
\hline \multicolumn{4}{|l|}{$0 \%$} \\
\hline $6 \%$ & 3.93 & 4.3 & Not Significant \\
\hline \multicolumn{4}{|l|}{$0 \%$} \\
\hline $15 \%$ & 10.21 & 4.3 & Significant \\
\hline \multicolumn{4}{|l|}{$0 \%$} \\
\hline $40 \%$ & 0.47 & 4.3 & Not Significant \\
\hline \multicolumn{4}{|l|}{$0 \%$} \\
\hline $95 \%$ & 8.46 & 4.3 & Significant \\
\hline
\end{tabular}


Swelling of Ac-Di-Sol in water, alcohol, and Sodium Lauryl Sulfate has been shown graphically (Fig. 9 to 11). Emcosoy and Ac-Di-SoI swelling will not be affected significantly by the fluctuation of $\mathrm{PH}$ In the stomach, as well as the intestine. The most interesting observation was their swelling in Sodium Lauryl Sulfate solutions. As it appears in the table, Ac-Di-Sol particles had maximum swelling at $.01 \%$ conc. of the solution, while no swelling was observed in $5.40 \%$ solution, which is recommended as a dissolution medium for drug-like Griseofulvin. The solution of Sodium Laury1 Sulfate at $5.40 \%$ conc. reduced the swelling of Emcosoy significantly.

It was observed that very dilute alcohol solutions and Sodium Lauryl Sulfate solution reduced the surface tension of water, and they also acted as a wetting agent and enhanced the absorption of water by Ac-Di-Sol; but as their concentration increased, they ceased to act as wetting agents and there was relatively small proportions of water available for disintegrant to absorb. Therefore, swelling was reduced or, in some cases, swelling did not occur.

\section{Water Penetration of Disintegrations:}

Water penetration in Explotab, Emcosoy, CLDII, and Ac-Di-Sol was measured. The square of penetrated length of powder bed versus time for various disintegrant was tabulted from Table XV to XViii. Tue same data was plotted on page. 
TABLE XV

Disintegrant: Emcosoy

\begin{tabular}{lc} 
Time (sec.) & Water Penetration in $(\mathrm{cm})^{2}$ at $22^{+}$lc \\
\hline 1500 & 1.02 \\
2400 & 1.86 \\
3600 & 2.82 \\
5160 & 4.15 \\
6000 & 4.41
\end{tabular}

TABLE XVI

Disintegrant: Ac-Di-Sol

Time (sec.)

Water Penetration in $(\mathrm{cm})$ at $22+1 c$

1200

0.18

2400

0.28

3600

0.32

6000

0.40

\section{TABLE XVII}

Disintegrant: CLD II

$\begin{array}{lc}\text { Time (sec.) } & 2 \\ 1200 & 0.18 \\ 2400 & 0.28 \\ 3600 & 0.45 \\ 4800 & 0.71\end{array}$




\section{TABLE XVIII}

Disintegrant: Explotab

\begin{tabular}{lc} 
Time (sec.) & Water Penetration in $(\mathrm{cm})^{2}$ at $22 \pm 1 \mathrm{c}$ \\
\hline 1500 & 3.57 \\
2400 & 6.89 \\
3600 & 9.27 \\
4800 & 11.29 \\
6000 & 14.29 \\
7200 & 16.60
\end{tabular}


THE PENETRATION OF WATER INTO VARIOUS DISINTEGRANTS:

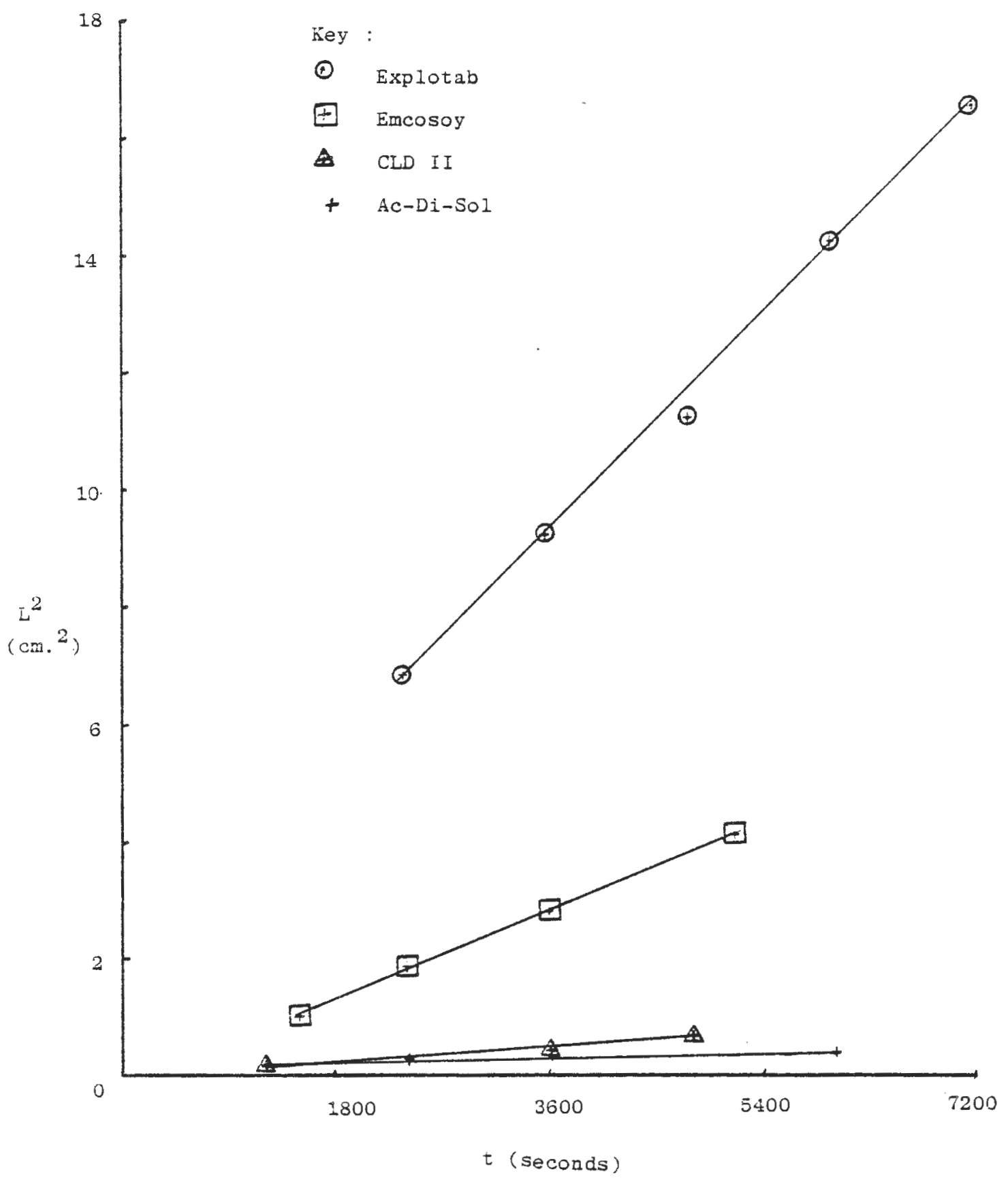

Frig. 12 
is also very important, since in tablet disintegration it is expected that disintegrant swells considerably to rupture the tablet as quickly as possible, so rate and extent of swelling are equally important.

The penetrating rate of liquid into the disintegrant bed is expressed by Peek-McLean's equation ( 55 ):

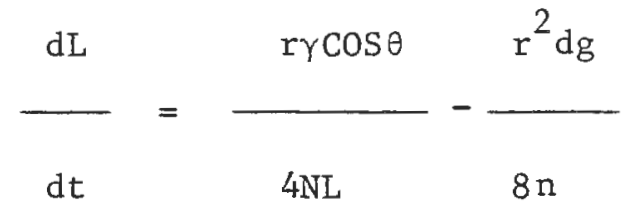

Where $\mathrm{L}$ is the penetrating length at time $t, r$ is the average radius of void space, $\theta$ the contact angle between liquid and powder surface, $g$ the acceleration constant of gravity, and $\gamma, n$, and $d$ are the surface tension, viscosity, and specific gravity of liquids, respectively. The penetration rate also depends on the viscosity of gel formed by the interaction of water and disingegrant. If the gel formed is too viscous, it would impede the further penetration of water in a disintegrant bed. All these factors will be discussed in great detail separately.

In addition to water, water-alcohol mixtures of different strength, sodium lauryl sulfate solution of various concentrations and solutions of $\mathrm{PH}$ range 2 to 8 (Citrate - Phosphate - Borate/Hcl buffer) were used to study the bulk swelling of Encosoy and Ac-Di-Sol. Student $t$ test was performed using Statpack computer program to find out whether the difference in swelling was significant or non-significant. All the readings and results are tabulated from Table IIto XIV. 
From the tables and graph, it appeared that water penetration rate was maximum in Explotab powder bed, followed by Encosoy, CLD II, and Ac-Di-Sol under identical experiment conditions. The reason could be that average void space and contact angle between Explotab particle and water was high, compared to other disintegrants tested.

\section{Energy of Wetting:}

The values of $\mathrm{K}$ for different water temperatures for Emcosoy was tabulated in Table XIX. Log K/T vs. $\frac{1}{T}$ was plotted on page 73. The value of $B$ (the energy of wetting) was calculated for Emcosoy.

The value of energy of wetting obtained by this method according to some critics is an apparent value, since they believe that the approach is too simplified to give any real values.

\section{Wetting and Drying of Disintegrant:}

Emcosoy batches were prepared under different conditions. Bulk swelling was determined for these batches. Results are tabulated in Table XX.

As it can be seen from the Emcosoy table that was dried at room temperature and at $40^{\circ}$ had a bulk swelling less than the untreated (origina1) Emcosoy. One reason could be that these samples were dried at low temperatures, and therefore significant amounts of surface moisture was left in these samples; that could have resulted in low water uptake and less swelling. 
Energy of wetting of Emcosoy particles.

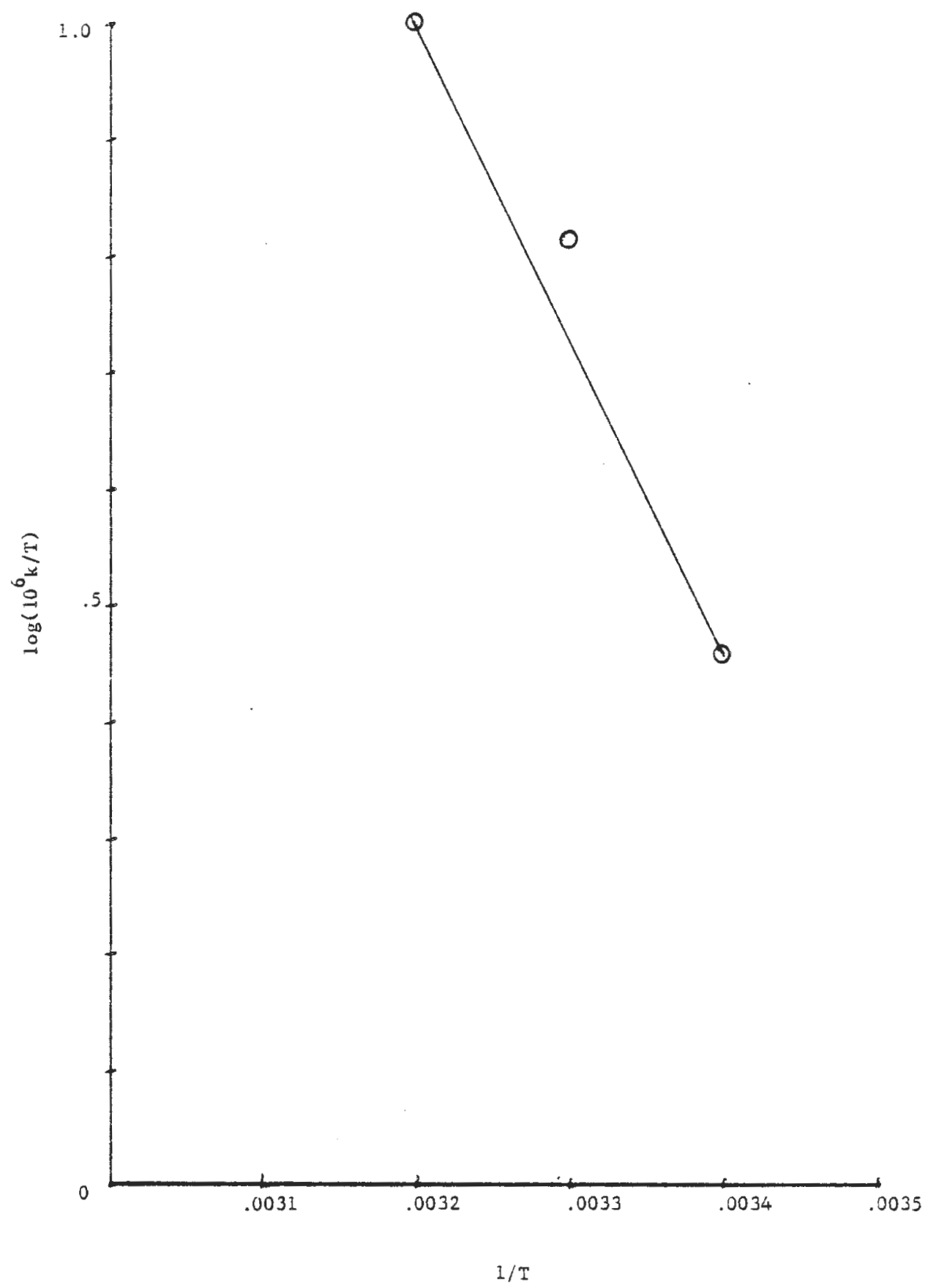

Fig. 13 


\section{TABLE XIX}

Energy of wetting of Emcosoy particles :

$\begin{array}{ll}-\underline{k}-- & -\underline{T}-- \\ 0.848 \times 10^{-3} & 295.0 \\ 1.955 \times 10^{-3} & 302.2 \\ 3.083 \times 10^{-3} & 310.0\end{array}$

$\begin{array}{ll}\log \left(10^{6} \mathrm{k} / \mathrm{T}\right) & -\underline{I / T} \\ 0.4586 & 3.4 \times 10^{-3} \\ 0.8109 & 3.3 \times 10^{-3} \\ 0.9976 & 3.2 \times 10^{-3}\end{array}$

Calculation :

From graph

$$
\begin{aligned}
\text { slope } & =-\beta / R \\
-2.695 \times 10^{3} & =-\beta / 1.987 \mathrm{Cal} . \\
\beta & =5.35 \mathrm{~K} . \mathrm{cal} .
\end{aligned}
$$


Emcosoy dried at $60^{c}$ had bulk swelling more than four times that of an original Emcosoy. The result could be explained by the comparison of baking of a cake with baking (drying) of a disintegrant particle. When the cake is baked, the surface area of the cake increases enormously, and the same thing can happen in the disintegrant particles. The increase in surface area could lead to increased water uptake and increased swelling.

Emcosoy dried at $60^{\circ}$ had an improved flow and high density compared to the original Emcosoy. The color change was from yellowish white to brown. No swelling was observed in the first two minutes in the original Emcosoy, but there was $30 \%$ to $35 \%$ swelling in the first two minutes in Emcosoy dried at $60^{c}$. Wicking effect was very much improved in the Emcosoy dried at $60^{c}$-- the time that was taken by the water to travel through the entire powder bed was 60 minutes, compared to 90 minutes for the original Emcosoy.

There was little offending odor from Emcosoy dried at $40^{c}$ and $60^{c}$, and visible mold growth in Emcosoy which was dried at room temperature. Published literature on the subject indicates that molds require a water activity number of 0.75 , and bacteria requires 0.88 . Below these values, microbial growth cannot be supported. It has been estimated that Emcosoy with a $10 \%$ moisture content = water activity number 0.5 ; and with $20 \%$ moisture content, there exists a water activity of 0.88 . Since original Emcosoy usually contains less than $10 \%$ moisture, it theoretically cannot promote microbial growth. However, in a 
wet granulation process, this argument might not be true all the time. Prolonged storage or improper storage may lead to higher moisture content and consequently makes this disintegrant vulnerable to microbial growth.

As discussed above, that Emcosoy dried at $60^{c}$ had a better physical property than the original Emcosoy; they both were compared in actual tablet formulation. Original Emcosoy was identified as "A", and the processed Emcosoy was identified as "B." In order to get unbiased evaluations of these disintegrants, the tablets were prepared and tested by iny colleague. The results and other details are shown in a tabular form (Table XxI).

As it can be seen from the table and contrary to expectation, processed disintegrant tablets had higher disintegrant time; in other words, the tablets made using it took a long time to disintegrate, compared to tablets made using original Emcosoy. The reason could be poor deformation of processed disintegrant. The three major mechanisms of disintegration are: (1) swelling, (2) porosity and capillary action (wicking), and (3) deformation. As mentioned above, processed disintegrant is better than original Emcosoy in the first two categories. There is no data to compare the third one. When the tablet is compressed, the compression may cause more permanent deformation in original Emcosoy than the processed Emcosoy. When the tablet is put into a disintegrating medium, the energy-rich Emcosoy grains swell rapidly, unlike processed Emcosoy grains, which require more heat in order to swell. The overall effect leads to an early disintegration of the 
TABLE XX

\begin{tabular}{lcc} 
Details & $\%$ Swelling & Average Swelling \\
\hline Emcosoy (original) & 44.3 & 44.6 \\
(Passed through 100 mesh) & 42.9 & 30.0 \\
Emcosoy (dried at room temp.) & 31.4 & 32.15 \\
$\qquad 21^{c}$ & 28.6 & 197.1 \\
Emcosoy (dried at $40^{c}$ ) & 34.3 & \\
& 30.0 & \\
Emcosoy (dried at $60^{c}$ ) & 192.7 & \\
& 201.4 & \\
\hline
\end{tabular}


TABLE XXI

\begin{tabular}{lrrr} 
& $\begin{array}{l}\text { In Each } \\
\text { Tablet }\end{array}$ & Percent & Working Formula \\
\cline { 2 - 3 } & $40.0 \mathrm{mg}$ & 20.0 & $60.0 \mathrm{Gm}$ \\
Hydrochlorothiazide & $2.0 \mathrm{mg}$ & 1.0 & $3.0 \mathrm{Gm}$ \\
Disintegrant A or B P $P$ & $1.0 \mathrm{mg}$ & 0.5 & $1.5 \mathrm{Gm}$ \\
Magnesium Stearate & $157.0 \mathrm{mg}$ & 78.5 & $235.5 \mathrm{Gm}$ \\
Emcompress &
\end{tabular}

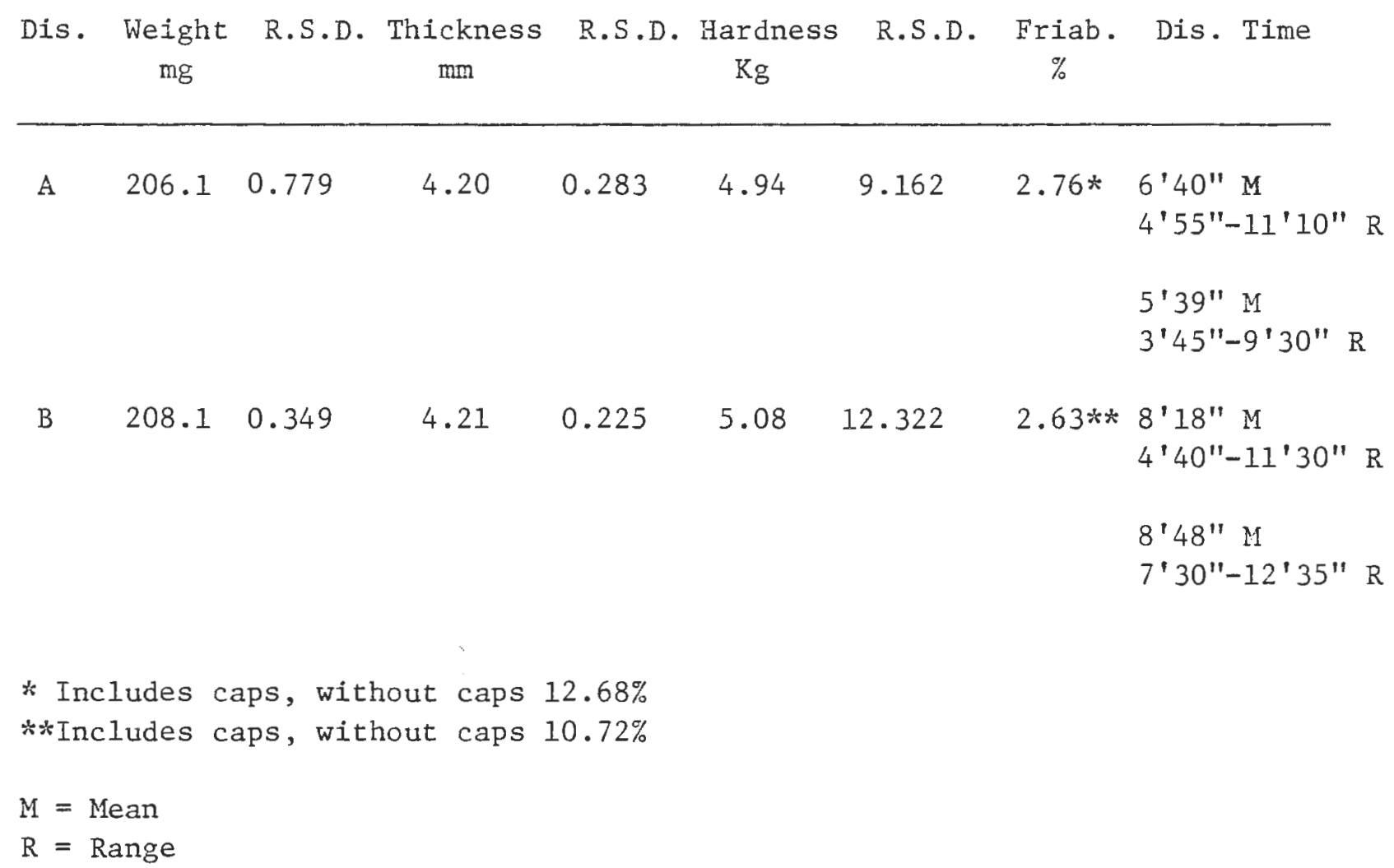


tablet made from original Emcosoy.

\section{Aqueous Dispersion:}

Shangraw, et al, have theorized that substances that swell to very large gelatinous volume might be excellent disintegrants in a tablet that breaks apart rapidly; however, their inclusion in a tablet that disintegrates more slowly could lead to surface gelling that would only further impede liquid penetration of the tablet matrix ( 6 ). They compared two percent aqueous dispersions of various starches, cellulose products, and of cross-linked PVP in water-diluted hydrochloric acid, (1:100) were shaken periodically, and were allowed to stand overnight. They found that all the disintegrants had different swelling; in some of the disintegrants, the swelling was enhanced or supressed in acidic medium.

It is expected of ideal disintegrants that its swelling should remain unchanged or preferably increased in acidic medium, since most of the tablet disintegrates in acidic environments of the stomach. Emcosoy had 187.5 percent swelling in water, and 287.5 percent swelling in acidic medium. The results clearly indicated that vivo $\mathrm{PH}$ changes would have no adverse effect on disintegrating function of Emcosoy (Table XXIV).

7. Comparative Study of the Viscosity of Different Strength Solutions of Various Disintegrants:

Viscosity data of various disintegrant solutions are given from Tables XXII and XXIII. The disintegrants are divided into two groups: one under the heading, "Cetlulose Group," and the other under the heading, "Starch Group." 
TABLE XXII

Viscosity Study of Gel Formed by Various Disintegrants:

$\begin{array}{lllllll}\text { Disintegrants } & \operatorname{rpm} & 2 \% & 4 \% & 6 \% & 8 \% & 10 \%\end{array}$

Cellulose Group:

\begin{tabular}{|c|c|c|c|c|c|c|}
\hline \multirow{3}{*}{$\begin{array}{l}\text { Soy Cellulose } \\
\text { (Encosoy) }\end{array}$} & 20 & 00.00 & 00.10 & 03.30 & 17.00 & 200.00 \\
\hline & 50 & 00.08 & 00.14 & 02.60 & 16.00 & 120.00 \\
\hline & 100 & 00.20 & 00.50 & 01.69 & 14.00 & 88.00 \\
\hline \multirow{3}{*}{$\begin{array}{l}\text { Cotton Cellulose } \\
\text { (Ac-Di-Sol) }\end{array}$} & 20 & 00.13 & 00.13 & 00.30 & 02.73 & 25.60 \\
\hline & 50 & 00.22 & 00.35 & 00.40 & 02.20 & 18.80 \\
\hline & 100 & 00.22 & 00.40 & 00.75 & 02.11 & 13.00 \\
\hline \multirow{3}{*}{$\begin{array}{l}\text { Wood Cellulose } \\
\text { (CLD II) }\end{array}$} & 20 & 05.90 & 224.00 & 1260.00 & --- & $-\cdots$ \\
\hline & 50 & 04.68 & 146.90 & 664.00 & ---- & \\
\hline & 100 & 03.76 & 97.00 & -- - - & ---- & \\
\hline
\end{tabular}

Starch Group:

$\begin{array}{lrrrrrr}\text { Corn Starch } & 20 & 00.00 & 00.00 & 00.00 & 00.00 & 00.00 \\ & 50 & 00.04 & 00.10 & 00.08 & 00.08 & 00.12 \\ & 100 & 00.06 & 00.12 & 00.07 & 00.23 & 00.32 \\ & & & & & & \\ \text { Sta Rx 1500 } & 20 & 00.00 & 00.05 & 00.00 & 00.00 & 00.12 \\ & 50 & 00.00 & 00.16 & 00.12 & 00.14 & 00.14 \\ & 100 & 00.00 & 00.18 & 00.36 & 00.57 & 00.21 \\ & & & & & & \\ \text { Sodium Starch } & 20 & 00.00 & 00.13 & 01.25 & 148.50 & 530.00 \\ \text { Glycolate } & 50 & 00.12 & 00.25 & 01.74 & 63.00 & 252.80 \\ \text { (Explotab) } & 100 & 00.12 & 00.34 & 02.55 & 39.20 & 136.80 \\ & & & & & & \\ \text { Polyplasdone XL } & 20 & 00.00 & 00.00 & 00.00 & 00.05 & 00.45 \\ \text { (Grade c) } & 50 & 00.00 & 00.00 & 00.06 & 00.10 & 00.42 \\ & 100 & 00.26 & 00.35 & 00.45 & 00.65 & 00.54\end{array}$


Viscosity Study of Gel Formed by Various Disintegrants

\begin{tabular}{|c|c|c|c|c|}
\hline Disintegrants & $\mathrm{rpm}$ & $12 \%$ & $14 \%$ & $16 \%$ \\
\hline \multicolumn{5}{|l|}{ Cellulose Group: } \\
\hline \multirow{3}{*}{$\begin{array}{l}\text { Soy Cellulose } \\
\text { (Emcosoy) }\end{array}$} & 20 & 464.00 & $--\infty$ & -- \\
\hline & 50 & 243.20 & $-\cdots$ & $\ldots$ \\
\hline & 100 & 156.00 & --- & --- \\
\hline \multirow{3}{*}{$\begin{array}{l}\text { Cotton Cellulose } \\
\text { (Ac-Di-Sol) }\end{array}$} & 20 & 335.00 & 1310.00 & $-\cdots$ \\
\hline & 50 & 196.00 & 594.40 & --- \\
\hline & 100 & 102.00 & 370.00 & --- \\
\hline \multirow{3}{*}{$\begin{array}{l}\text { Wood Cellulose } \\
\text { (CLD II) }\end{array}$} & 20 & --- & --- & $-\cdots$ \\
\hline & 50 & $-\infty$ & ---- & --- \\
\hline & 100 & --- & --- & --- \\
\hline \multicolumn{2}{|l|}{ Starch Group: } & & & \\
\hline \multirow[t]{3}{*}{ Corn Starch } & 20 & 00.00 & 00.10 & --- \\
\hline & 50 & 00.08 & 00.10 & $-\cdots$ \\
\hline & 100 & 00.44 & 00.70 & $-\cdots$ \\
\hline \multirow[t]{3}{*}{ Sta Rx 1500} & 20 & 00.10 & 00.40 & -- \\
\hline & 50 & 00.30 & 00.50 & --- \\
\hline & 100 & 00.36 & 00.64 & $-\cdots$ \\
\hline \multirow{3}{*}{$\begin{array}{l}\text { Sodium Starch } \\
\text { Glycolate } \\
\text { (Explotab) }\end{array}$} & 20 & 1980.00 & --- & --- \\
\hline & 50 & --- & ---- & --- \\
\hline & 100 & $-\cdots$ & --- & --- \\
\hline \multirow{3}{*}{$\begin{array}{l}\text { Polyplasdone XL } \\
\text { (Grade C) }\end{array}$} & 20 & 02.20 & 07.05 & --- \\
\hline & 50 & 01.66 & 04.36 & $-\cdots$ \\
\hline & 100 & 01.30 & 02.70 & --- \\
\hline
\end{tabular}




\section{Cellulose Group:}

The viscosity of cellulose disintegrant solutions can be arranged in decending order:

1. Viscosity of CLD II solutions,

2. Viscosity of Emcosoy solutions, and

3. Viscosity of Ac-Di-So1 solutions.

CLD II solutions exhibited the maximum viscosity, compared to any disintegrant of either group. The gel formed by Ac-Di-Sol was less viscous compared to that of Emcosoy. If we have to justify the difference in the vitro bioavailability of two vitro formulations containing Emcosoy and Ac-Di-So1, respectively, as disintegrants solely on the basis of viscosity, we can say that Ac-Di-Sol formulations will have a little superiority over Emcosoy formulations since the gel formed by $\mathrm{Ac}-\mathrm{Di}-\mathrm{Sol}$ will be less viscous than the gel formed by Emcosoy. As expected, cellulose derivatives form viscous gel compared to their starch counterparts. Starch Group:

If the viscosity of starch disintegrant solutions has to be arranged in decending order, then:

1. Viscosity of Explotab solutions,

2. Viscosity of Sta-Rx 1500, and

3. Viscosity of Corn Starch.

Explotab gel has the maximum viscosity among starch disintegrants, If we have to predict the performance of Explotab and corn starch as disintegrant solely on the basis of the viscosities 
of their gel, we might expect corn starch as a better disintegrant than Explotab, since the gel formed by the former is less viscous .

In practice, Explotab is much more superior to corn starch; the reason is that in addition to viscosity, there are other important factors, such as rate and extent of swelling, wicking effect, and deformation play crucial roles in disintegration mechanism.

Explotab, Emcosoy, Ac-Di-Sol, and corn starch were compared in actual tablet formulations. The viscosity of the gel of Explotab is greater than that of Emcosoy. The viscosity of Emcosoy is greater than that of Ac-Di-Sol. Vitamin formulations studied clearly indicated that Explotab is inferior to Ac-Di-So1 and Emcosoy. Viscosity study provides the answer. Explotab swells much more compared to Ac-Di-Sol and Encosoy, and we therefore expect it to be better disintegrant compared to Ac-Di-Sol and Encosoy. However, that is not true, because Explotab forms very viscous gel, and it will be shown later that it has poor deformation.

The disintegrant solutions were subjected to different shear rate, and the viscosity were determined. The rheological profiles of the various disintegrants were shown in Fig. 15 to 18 . In theory, there were all three kinds of profiles, as shown in Figure 14. In Newtonian liquids the viscosity remains unchanged with the increase in shear rate. 


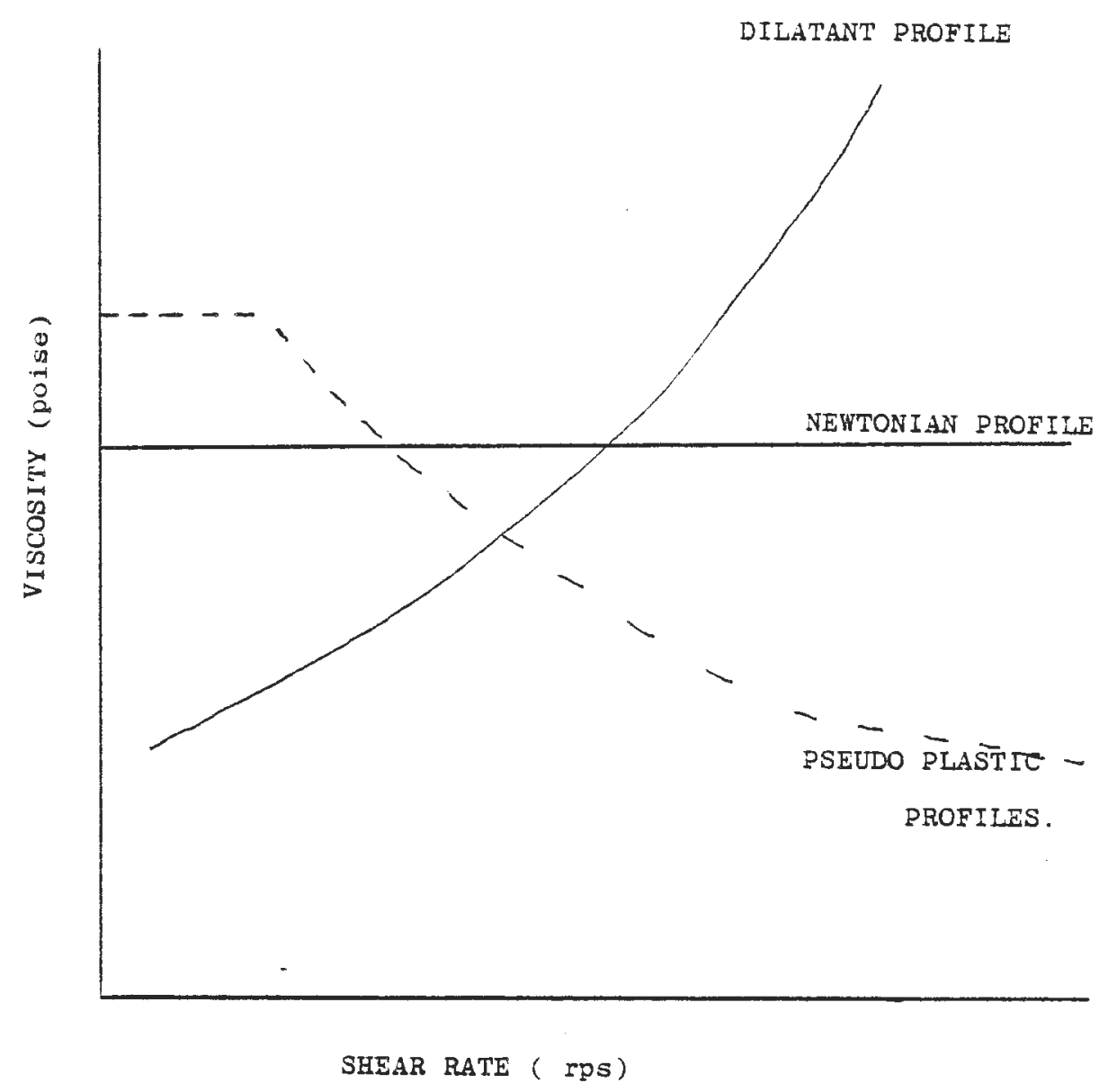

Fig. 14 


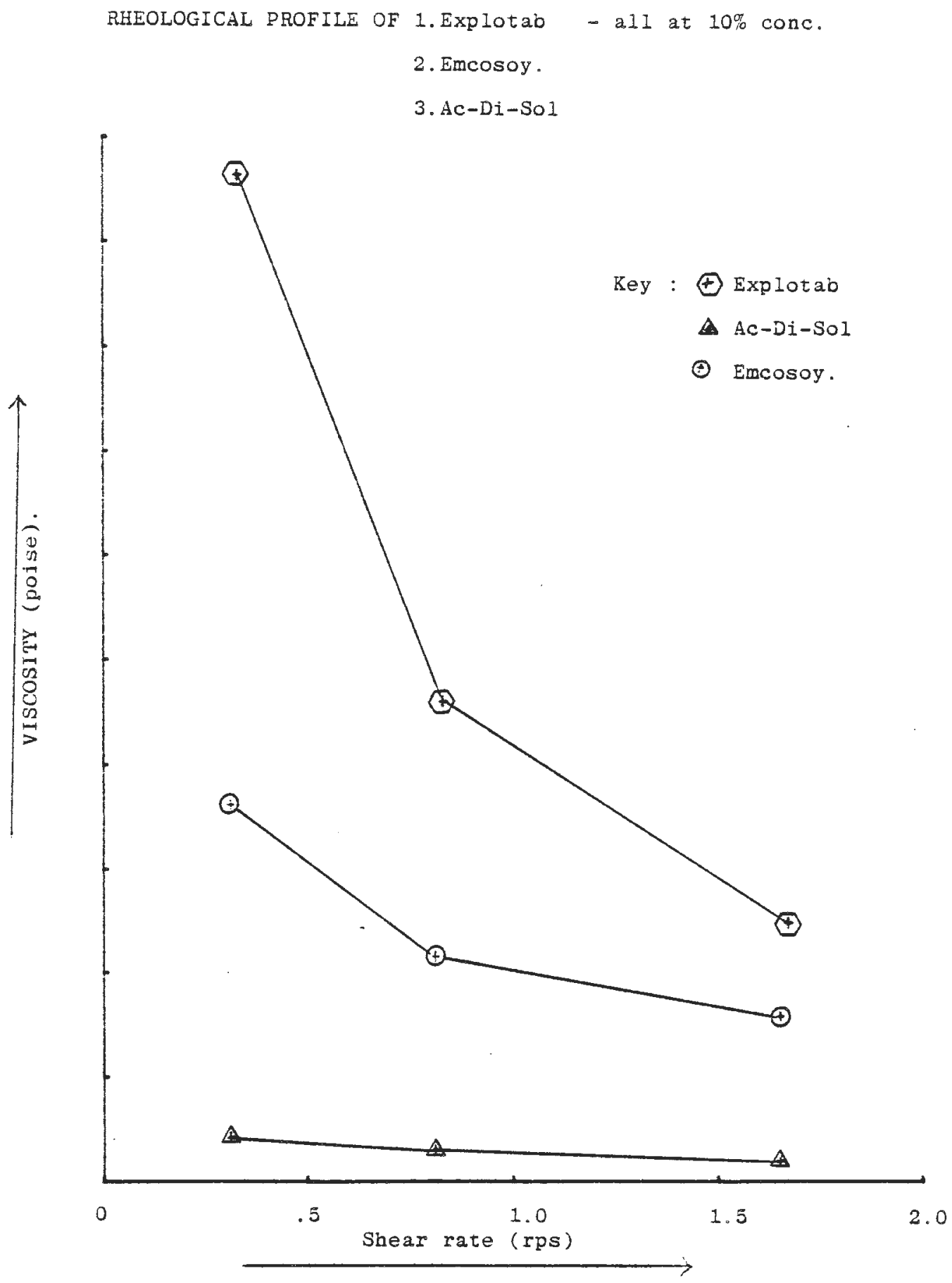

Fig. 15 
RHEOLOGICAL PROFILE OF 1. CORN STARCH GEL -DISINTEGRANT CONC.14\%

2. Sta Rx 1500

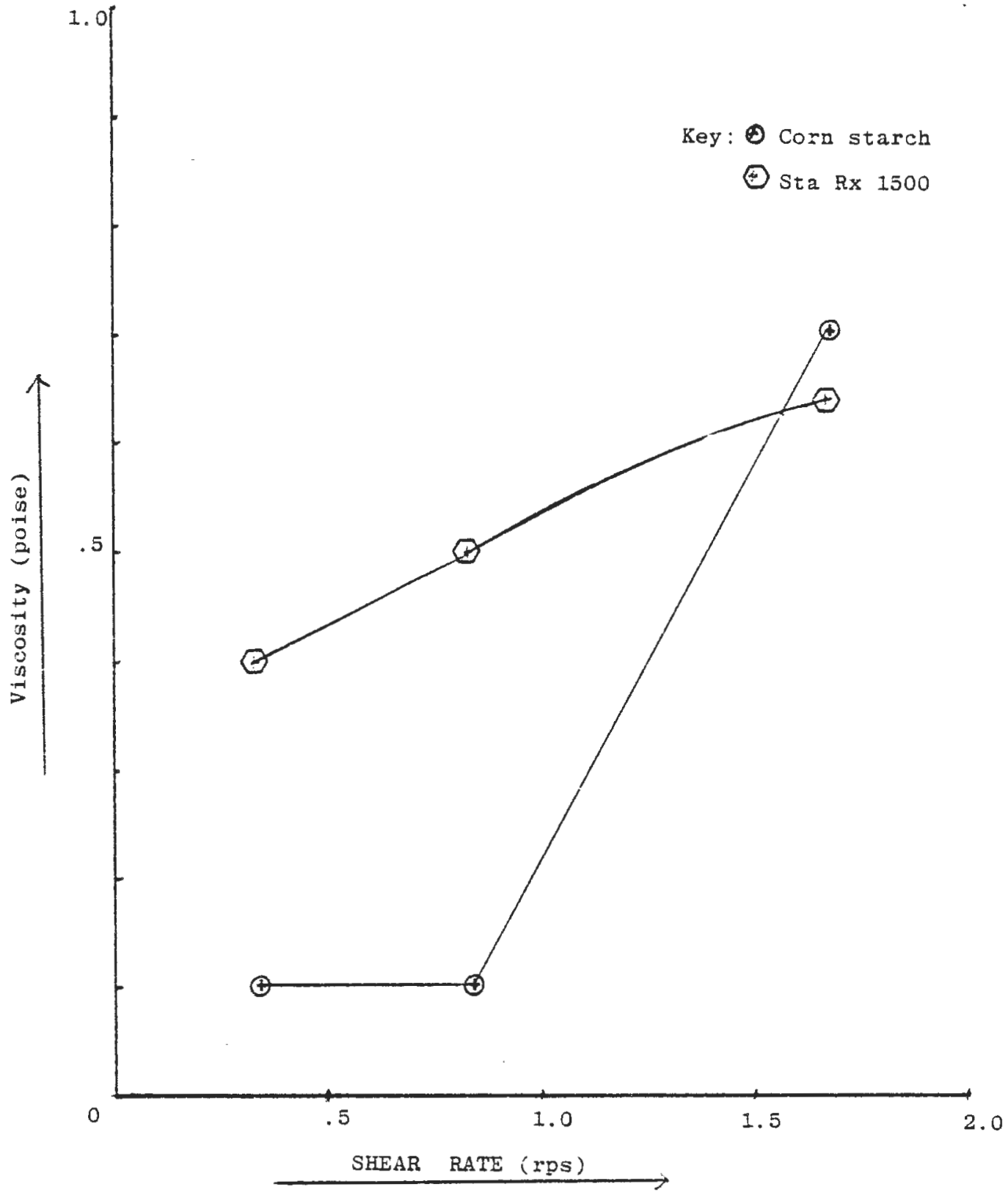

Fig. 16 
RHEOLOGICAL PROFILE OF POLIPLASDONE XI AT $14 \%$ CONC. OF THE DISINTEGRANT.

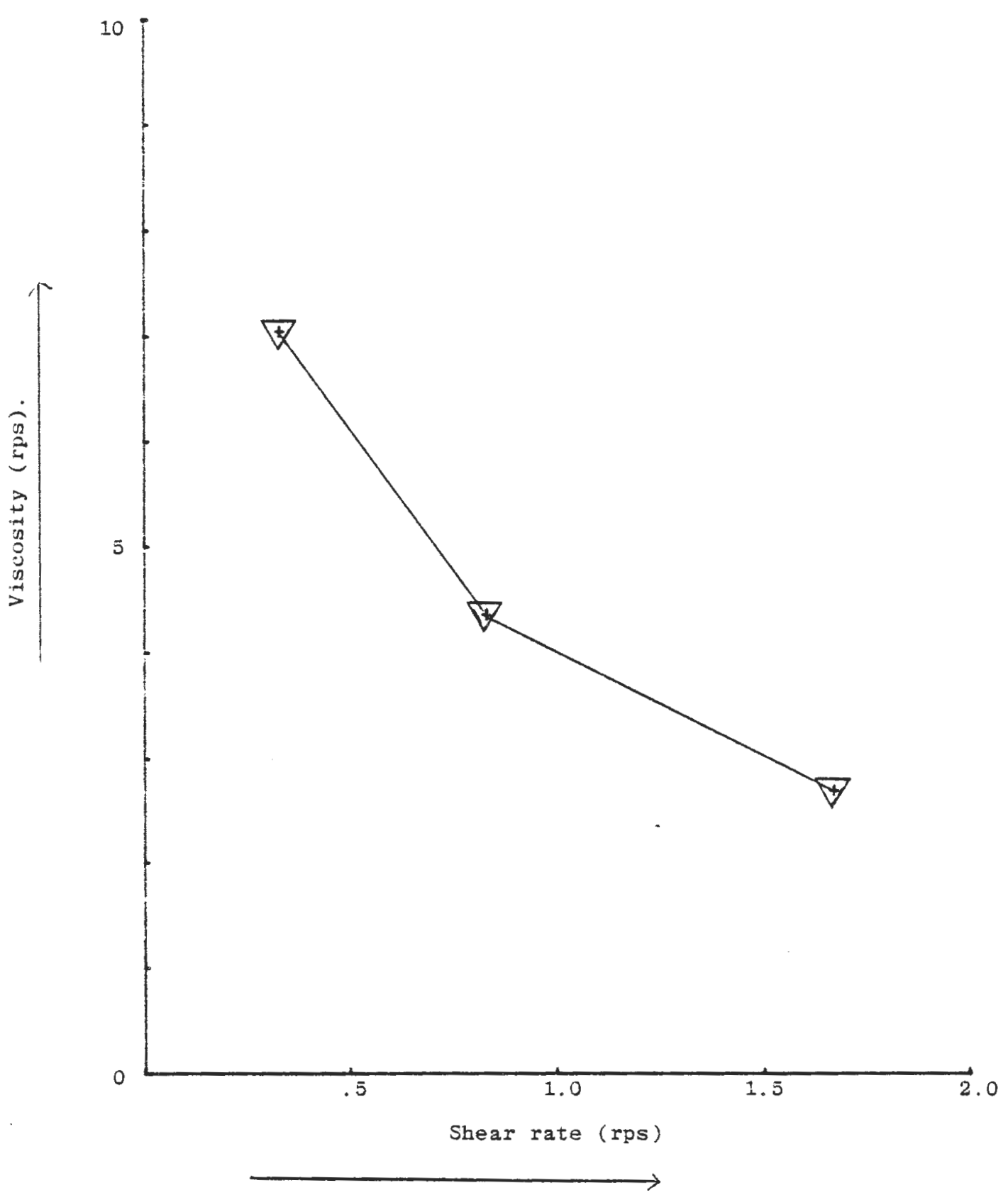

Fiร. 17 
RHEOLOGICAL PROFILE OF CLD II GEL AT $4: \%$ CONC. OF THE DISINTEGRANT.

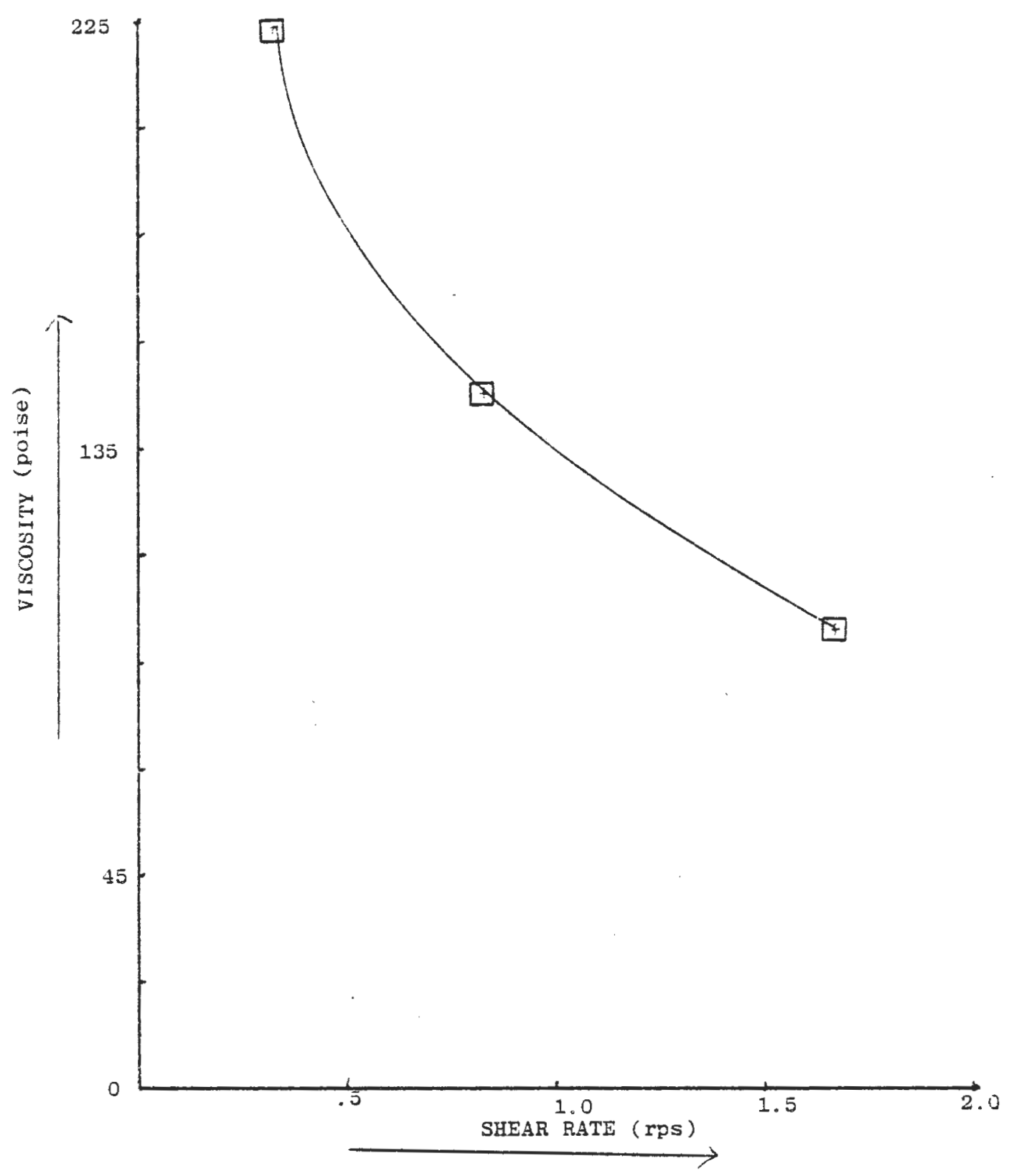

Fig. 18 
In dilatant profiles, the viscosity increases with increases in shear rate. In pseudoplastic profiles, the viscosity decreases with increase in shear rate. Emcosoy, Ac-Di-Sol, CLD II, Explotab, and poliplasdone $\mathrm{X} \amalg$ gave pseudoplastic profiles. Corn starch and Sta Rx 1500 solutions had dilatant profiles. Dilatancy could be one of the reasons for the poor vitro bioavailability of the formulations containing corn starch.

- 8. Maximum Hydration Capacity of Various Disintegrants:

$\begin{array}{lr}\text { Ac-Di-Sol - } & 16 \% \mathrm{~W} / \mathrm{V} \\ \text { Emcosoy - } & 14 \% \mathrm{~W} / \mathrm{V} \\ \text { CLD II - } & 8 \% \mathrm{~W} / \mathrm{V}\end{array}$

High hydration capacity is desirable property of disintegrant. High hydration capacity indicates that the disintegrant requires less amounts of water to wet itself thoroughly. It can be theorized that a disintegrant with high hydration capacity would relatively have smaller water uptake in order to achieve disintegration of the tablet, compared to a disintegrant with low hydration capacity. It can be said from the data that as the viscosity of the gel of disintegrant increases, the maximum hydration capacity decreases.

\section{Sieve Ana1ysis:}

Nogami, et al, found that there should be the critical amount of starch necessary for the disintegration depending upon the particle size or specific area of ingredients. The smaller the particle size of aspirin, the more amount of starch was required for the tablet disinte- 
TABLE XXIV

Emcosoy (2\%) Dispersion in Water and Dilute Acid (Hc1 1 in 100):

Apparatus: $100 \mathrm{ml}$. measuring cylinder.

Dilute Acid ( 1 in 100) Hcl. $\mathrm{pH} .70$

Time Duration: Overnight.

\begin{tabular}{lccc} 
Solvent & Initial Volume & End Volume & $\%$ Swelling \\
\hline Water & $8.0 \mathrm{ml}$ & $23.0 \mathrm{ml}$ & 187.5 \\
Dilute Acid & $8.0 \mathrm{ml}$. & $31.0 \mathrm{ml}$. & 287.5
\end{tabular}

TABLE XXV

Emcosoy - Sieve Analysis:

Sieve Number U.S. Standard

Arithmatic Mean

Wt. Retained

Wt.

(Passed/Retained)

Size of Opening on Smaller Sieve (\%)

Size

$100 / 170$

$170 / 200$

$200 / 230$

$230 / 270$

$270 / 325$

$325 / 400$

400/Bottom
119

81

68

58

49

41

$-$

d

$$
\text { ave }=\frac{5606.6}{90.6}=62 \mathrm{H}
$$

8.5

1011.5

6.8

550.8

11.4

775.2

22.8

1322.4

32.7

1602.3

8.4

344.4

4.5

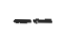


gration. The tablet of the smallest aspirin (11.9 in mean particle size) did not disintegrate by the addition of $20 \%$ of starch. Thus, the particle size of the ingredients play an important part in tablet disintegration (71) .

Rudnic, et al, studied the different particle size grades of crosslinked polyvinylpolypyrrolidone (Polyplasdone, G.A.F. Corporation) in direct compression tablet formulations showed that jucreases in mean particle size enhanced powder flow, disintegration and dissolution, although hardness and friability were slightly better for tablets made from the finer grades ( 72$)$. Therefore, particle size of the ingredients, as well as disintegrants, are equally important. There is nothing like optimum particle size of disintegrant or matrix. Particle size varies for various disintegrants and tablet matrices. However, the particle size should be such that disintegrant can be mixed and distributed uniformly with the rest of the ingredients. The particle size of Emcosoy was determined using sieving. Table xxV shows the size-weight distribution of Emcosoy as measured by U.S. Standard sieves.

10. Plastic Deformation and Elasticity of Various Disintegrants: Modulus of elasticity at various attempted deformations and compressive force needed to achieve that deformation were tabulated in Table XXVI.The percentage of plastic deformation and the percentage re- 
TABLE XXVI

\begin{tabular}{lccc} 
Disintegrant & $\begin{array}{c}\text { Deformation } \\
\text { Attempted }\end{array}$ & $\begin{array}{c}\text { Modules of } \\
\text { Elasticity } \\
\text { Ib/in }\end{array}$ & $\begin{array}{c}\text { Compressive } \\
\text { Force (Ibs) }\end{array}$ \\
\hline Emcosoy & $10 \%$ & 328.35 & 100 \\
& $20 \%$ & 391.47 & 175 \\
& $40 \%$ & 1063.95 & 1240 \\
CLD II & $10 \%$ & 429.56 & 340 \\
& $20 \%$ & 570.45 & 2000 \\
& $40 \%$ & 1677.85 & 3000 \\
Ac-Di-Sol & $50 \%$ & 2013.42 & 3750 \\
Explotab & $20 \%$ & 6291.95 & 2850 \\
& $10 \%$ & 9357.93 & 8050 \\
Sta-Rx 1500 & $20 \%$ & 12931.26 & 3250 \\
Polyplasdone-XI & $20 \%$ & 5706.98 & 120 \\
& $10 \%$ & 377.41 & 1400
\end{tabular}


TABLE XXVII

\begin{tabular}{lccc} 
Disintegrant & $\begin{array}{c}\text { Deformation } \\
\text { Attempted }\end{array}$ & $\begin{array}{c}\% \text { Plastic } \\
\text { Deformation }\end{array}$ & $\%$ Recovery \\
\hline Emcosoy & $10 \%$ & 4.89 & 5.11 \\
& $20 \%$ & 13.33 & 6.67 \\
CLD II & $10 \%$ & 7.56 & 2.44 \\
& $20 \%$ & 13.33 & 6.67 \\
AC-Di-So1 & $10 \%$ & 9.30 & 0.70 \\
& $20 \%$ & 12.44 & 7.56 \\
Explotab & $10 \%$ & 3.89 & 6.11 \\
Sta-Rx 1500 & $10 \%$ & 8.0 & 2.0 \\
& $20 \%$ & 14.78 & 5.22 \\
Polyplasdone-X工 & $10 \%$ & 6.22 & 3.78 \\
& $20 \%$ & 12.22 & 7.78
\end{tabular}


covery of various disintegrants were tabulated in Table XXVII.

From the elasticity data, the disintegrants were arranged in the decending order of their elasticity on page 96 . The order remained unchanged for CLD II, polyplasdone-XL, and Emcosoy at $10 \%, 20 \%$, and $40 \%$ attempted deformation.

Force required to achieve various percentage of deformations for various disintegrants was tabulated on page 98 . The force needed to attain $20 \%$ deformation in CLD II was little more than double of the force needed to attain $10 \%$ deformation in the same disintegrant. Similar observation was made in polyplasdone-XI, and to some extent in Emcosoy. However, when the deformation was doubled from $20 \%$ to $40 \%$, the force needed to achieve that deformation was almost five to six times than the force needed to achieve $20 \%$ of deformation. From these results, it was concluded that it was easy to deform particles initially; but as the percentages of deformation increased, the task became very difficult and greater force was needed to achieve those deformations. It was also observed that unusually high force was needed to achieve even 10\% deformation in Explotab. It might be due to high degree of cross-linking among starch glycolate molecules. Cross-linked polymers of starch are more elastic, compared to their cellulose counterparts. At $20 \%$, attempted deformation starch polymers required much more compressive force compared to cellulose polymers. 
The percentages of plastic deformation and the percentages of recovery at various attempted deformations for different disintegrants were tabulated on page 93. As it could be seen from the table, at $10 \%$ attempted deformation Ac-Di-Sol had more plastic deformation than Sta-Rx 1500 and CLD II, but at 20\% attempted deformation order was reversed. It was clear from the data that the initial deformation might be more in AC-Di-Sol compared to Sta-Rx 1500 and CLD II, but the additional deformation -- the deformation after some initial range -- was less compared to Sta-Rx 1500 and CLD II, which indicated that Ac-Di-Sol particles deformed initially easily but later they resisted more deformations. The recovery was least at $10 \%$ in $\mathrm{Ac}-\mathrm{Di}-\mathrm{So} 1$, but at $20 \%$ the recovery was more than those of Emcosoy, CLD II, and Sta-Rx 1500. The disintegrants were arranged in decending order according to the plastic deformation (at $10 \%$ attempted deformation) on page 97 . The deformed particles are energy rich, and that energy is released when the grains are exposed to water. The energy-rich particles swell more rapidly in water, unlike undeformed grains, which require more heat in order to swell. These data provide an answer that why Ac-Di-Sol containing formulations had better disintegration and dissolution compared to formulations containing Emcosoy and Explotab. 
ELASTICITY (decending order):

At $10 \%$ attempted deformation:

1. Explotab

2. CLD II

3. Polyplasdone-XI

4. Emcosoy

At $20 \%$ attempted deformation:

1. Explotab

2. Ac-Di-Sol

3. Sta-Rx 1500

4. CLD II

5. Polyplasdone-XI

6. Emcosoy

At $40 \%$ attempted deformation:

1. CLD II

2. Polyplasdone-XL

3. Emcosoy 
\% PLASTIC DEFORMATION (decending order):

$\begin{array}{ll}\text { at } 10 \% & \frac{\text { at } 20 \%}{} \\ \text { 1. Ac-Di-Sol } & \text { 1. Sta-Rx } 1500 \\ \text { 2. Sta-Rx } 1500 & \text { 2. CLD II, Emcosoy } \\ \text { 3. CLD II } & \text { 3. Ac-Di-Sol } \\ \text { 4. Polyplasdone-XL } & \text { 4. Polyplasdone-XL } \\ \text { 5. Emcosoy } & \\ \text { 6. Explotab } & \end{array}$

RECOVERY (decending order):

$\begin{array}{ll}\text { at } 10 \% & \frac{\text { at } 20 \%}{} \\ \text { 1. Explotab } & \text { 1. Polyplasdone-XI } \\ \text { 2. Emcosoy } & \text { 2. Ac-Di-So1 } \\ \text { 3. Polyplasdone-XL } & \text { 3. Emcosoy, CLD II. } \\ \text { 4. CLD II } & \text { 4. Sta-Rx 1500 } \\ \text { 5. Sta-Rx 1500 } & \\ \text { 6. Ac-Di-So1 } & \end{array}$


FORCE REQUIRED FOR 10\% DEFORMATION OF VARIOUS DISINTEGRANTS:

\begin{tabular}{lc} 
DISINTEGRANT & COMPRESSIVE FORCE (1bs) \\
\hline Explotab & 2850 \\
CLD II & 150 \\
Polyplas done-XI & 120 \\
Emcosoy & 100
\end{tabular}

FORCE REQUIRED FOR 20\% DEFORMATION OF VARIOUS DISINTEGRANTS:

\begin{tabular}{ll} 
DISINTEGRANT & COMPRESSIVE FORCE (lbs) \\
\hline Explotab & 8050 \\
Ac-Di-Sol & 3750 \\
Sta-Rx 1500 & 3250 \\
CLD II & 340 \\
Polyplasdone-XI & 300 \\
Emcosoy & 175
\end{tabular}

FORCE REQUIRED FOR 40\% DEFORMATION OF VARIOUS DISINTEGRANTS:

$\begin{array}{ll}\text { DISINTEGRANT } & \text { COMPRESSIVE FORCE (1bs) } \\ \text { CLD II } & 2000 \\ \text { Polyplasdone-XL } & 1400 \\ \text { Emcosoy } & 1240\end{array}$


11. TARLET PRODUCTION:

Tables XXVIII through XXXII show physical properties of the tablet formulae I, II, and III.

High weight variation, thickness and high hardness variation were observed in multivitamin formulation (Formula I). Capping was observed in a formulation having Emcompress as a matrix. Emdex matrix formulation gave friability less than .90\%. Disintegration time was less than 20 minutes in most of the formulation except formulation containing corn starch at $3 \%$ level in Emcompress matrix. It is obvious from the disintegration time in Tables XXVIII and XXIX that the effect of various disintegrant is much pronounced in water-insoluble matrix, such as Emcompress, compared to water-soluble matrix, such as Emdex. Dissograph was used for the dissolution study. Total optical absorbance was measured. From each formulation three dissolution profiles were studied. The results were quite reproducible (Tables XXXIII and XXXIV). Emdex matrix gave $t_{50}, t_{75}$, and $t_{90}$ within a range of two to nine minutes for various disintegrants at various concentration; while in the case of Emcompress matrix, those values differed considerably. Corn starch at $3 \%$ level gave $t_{75}$ and $t_{90}$ more than 30 minutes. Corn starch and Emcosoy was compared at $3 \%$ level in Emcompress as a matrix. Obviously, Emcosoy was a better disintegrant than corn starch $(\mathrm{Fig} \cdot 27)$. 
A narrow weight variation, hardness variation, and thickness variation were observed in pyridoxine HCl formulation (Formula II). Hardness was optimum. Tablets with Emdex as a matrix were thicker than Emcompress matrix tablet. Capping was a problem in some of the formulation containing Emcompress as a matrix. The friability was less than $.50 \%$ in Emdex matrix formulations. As observed in multivitamin formulation, the effect of various disintegrants at different concentration was more pronounced in Emcompress matrix compared to Emdex matrix formulation. At .5\% disintegrant level the tablet containing Explotabs disintegrant and Emcompress as matrix failed to disintegrate within one hour, although at $1 \%$ and $2 \%$ the same disintegrant was found satisfactory. At $2 \%$ disintegrant level, all the disintegrants except corn starch were found satisfactory. Tablet containing corn starch as disintegrant at $2 \%$ level failed to disintegrant within one hour. All formulations containing Emdex as a matrix gave disintegration time less than at eight minutes at various disintegrant levels. Two dissolution profiles were studied from each formulation. At $0.5 \%$ disintegration level in Emcompress matrix Emdosoy, Ac-Di-Sol and Explotab had $t_{90}$ more than 30 minutes; at 1\% and $2 \%$ disintegrant level $t_{50}, t_{75}$, and $t_{90}$ was found satisfactory for these three disintegrants. However, at $2 \%$ level corn starch gave ${ }^{t} 90$ more than 30 minutes compared to ${ }^{9} 90$ 's of Emcosoy 1.5 minutes, Ac-Di-Sol three minutes, and Explotab 9.5 minutes (Fig.49). In Emdex 
matrix all disintegrants gave satisfactory $t_{50}, t_{75}$, and $t_{90}$. However, it was obvious from Tables XXXV and XXXVI that Emcosoy was superior to corn starch in both matrixes, and it competed successfully with Explotab and Ac-Di-Sol.

High weight, thickness and hardness variation were found in Ascorbic acid formulations (Formula III, Table XXXII). Ascorbic acid formulations contained only Emcompress matrix. Hardness was 1ittle less than optimum when applied pressure. Hardness increased first, and then decreased. Capping was found at low concentration level of disintegrant. Ascorbic acid is highly water soluble compared to other active ingredients used, so the disintegration time was much less except when corn starch was used as disintegrant. Al1 formulations at $2 \%$ disintegrant level contained granulated Ascorbic acid (90\%) (Roche); the rest of the formulation contained Ascorbic acid U.S.P. Granulated Ascorbic acid was less soluble compared to Ascorbic acid U.S.P.; hence, little high disintegration time was observed at $2 \%$ compared to $1 \%$ and $.5 \%$ disintegrant level. Two dissolution profiles were studied from each formulation. The results were generally reproducible (Table XXXVII) $t_{50}, t_{75}$, and $t_{90}$ were satisfactory except for corn starch formulations. Corn starch at $2 \%$ and $3 \%$ gave $t_{75}$ and $t_{90}$ more than 30 minutes. It was very interesting to compare corn starch and Emcosoy at 3\% level (Fig. 80), since both were all natural disintegrants: $t_{90}$ for Emcosoy was two minutes, while for corn starch it was more than 30 minutes. 
TABLE XXVIII

MULTIVITAMIN FORMULATIONS WITH EMCOMPRESS AS A MATRIX

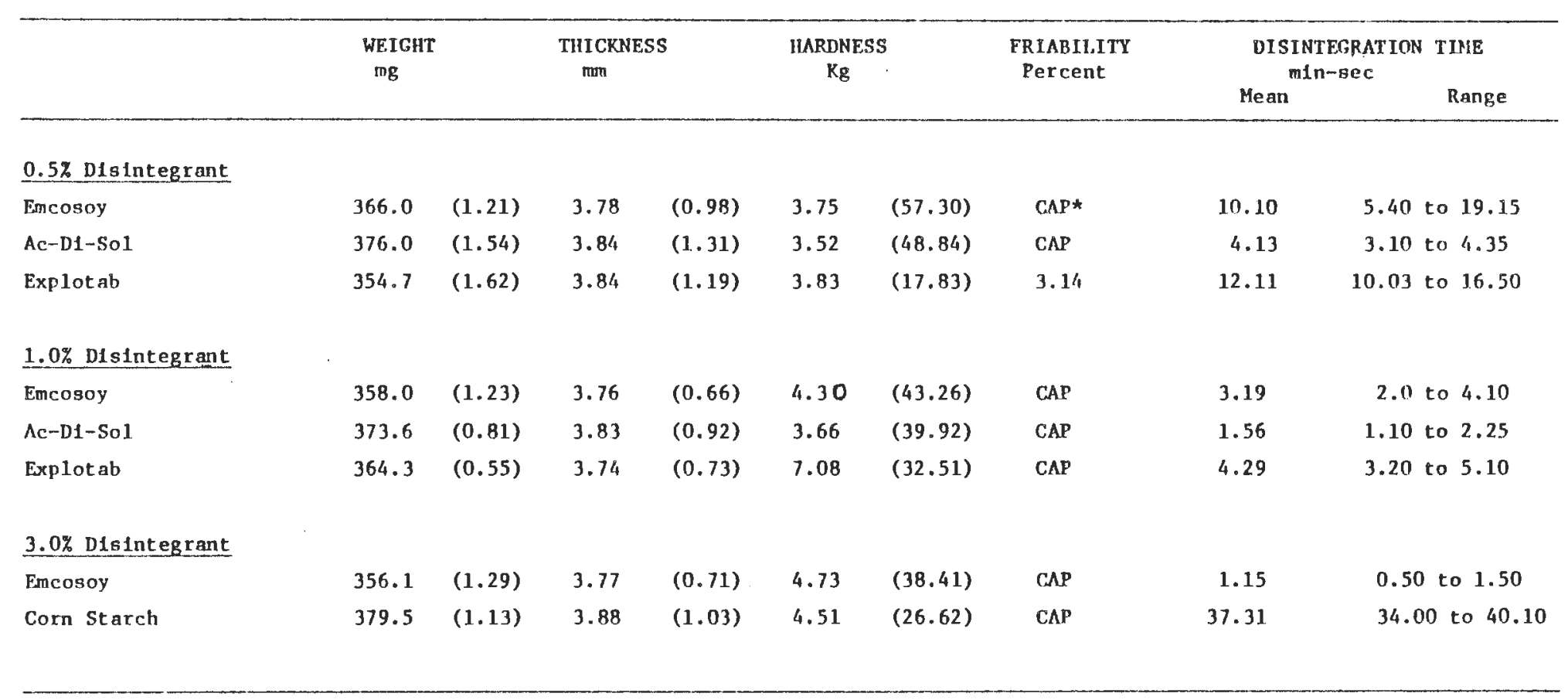

*Capping

NOTE: In this and all subsequent tables, values in parentheses are Relat 1ve Standard Devlation. 
MULTIVITAMIN FORMULATIONS WITH EMDEX AS A MATRIX

\begin{tabular}{|c|c|c|c|c|c|c|c|}
\hline & $\begin{array}{l}\text { WEIGHT } \\
\cdot \mathrm{mg}\end{array}$ & & $\begin{array}{c}\text { THICKNESS } \\
\mathrm{mm}\end{array}$ & $\begin{array}{l}\text { HARDNESS } \\
\mathrm{Kg}\end{array}$ & $\begin{array}{l}\text { FRIABILITY } \\
\text { Percent }\end{array}$ & $\begin{array}{l}\text { DISINTEGRATION } \\
\text { min } \mathrm{Bec} \\
\text { Mean }\end{array}$ & $\begin{array}{l}\text { ME } \\
\text { Range }\end{array}$ \\
\hline \multicolumn{8}{|c|}{$0.5 \%$ Dlsintegrant } \\
\hline Emcosoy & 346.2 & $(0.73)$ & $4.42(0.70)$ & $11.53(7.78)$ & 0.51 & 3.50 & 3.30 to 4.05 \\
\hline $\mathrm{Ac}-\mathrm{D1}-\mathrm{So} 1$ & 357.5 & $(1.29)$ & $4.46(0.89)$ & $11.37(9.58)$ & 0.62 & 3.13 & 2.50 to 3.20 \\
\hline Explotab & 355.8 & $(1.60)$ & $4.47(1.08)$ & $10.37(7.51)$ & 0.55 & 3.19 & 3.15 to 3.20 \\
\hline \multicolumn{8}{|c|}{$1.0 \%$ D1sintegrant } \\
\hline Emcosoy & 353.1 & $(1.33)$ & $4.36(0.98)$ & $9.60(16.60)$ & 0.73 & 3.25 & 3.20 to 3.40 \\
\hline$A C-D 1-S o 1$ & 362.1 & $(1.18)$ & $4.40(0.94)$ & $11.26(13.17)$ & 0.80 & 4.08 & 3.50 to 4.20 \\
\hline Explotab & 372.5 & $(1.68)$ & $4.58(1.39)$ & $10.65(10.64)$ & 0.73 & 4.06 & 3.40 to 4.20 \\
\hline \multicolumn{8}{|c|}{$3.0 \%$ Disintegrant } \\
\hline Emcosoy & 342.7 & $(1.13)$ & $4.48(0.90)$ & $9.33(14.03)$ & 0.59 & 4.18 & 4.00 to 4.40 \\
\hline Corn starch & 412.4 & $(2.05)$ & $5.13(5.74)$ & $11.51(14.58)$ & 0.64 & 5.05 & 4.40 to 5.10 \\
\hline
\end{tabular}


TABIE XXX

PYRIDOXINE HCL FORMULATIONS WITH FMCOHPRFSS AS A MATRIX

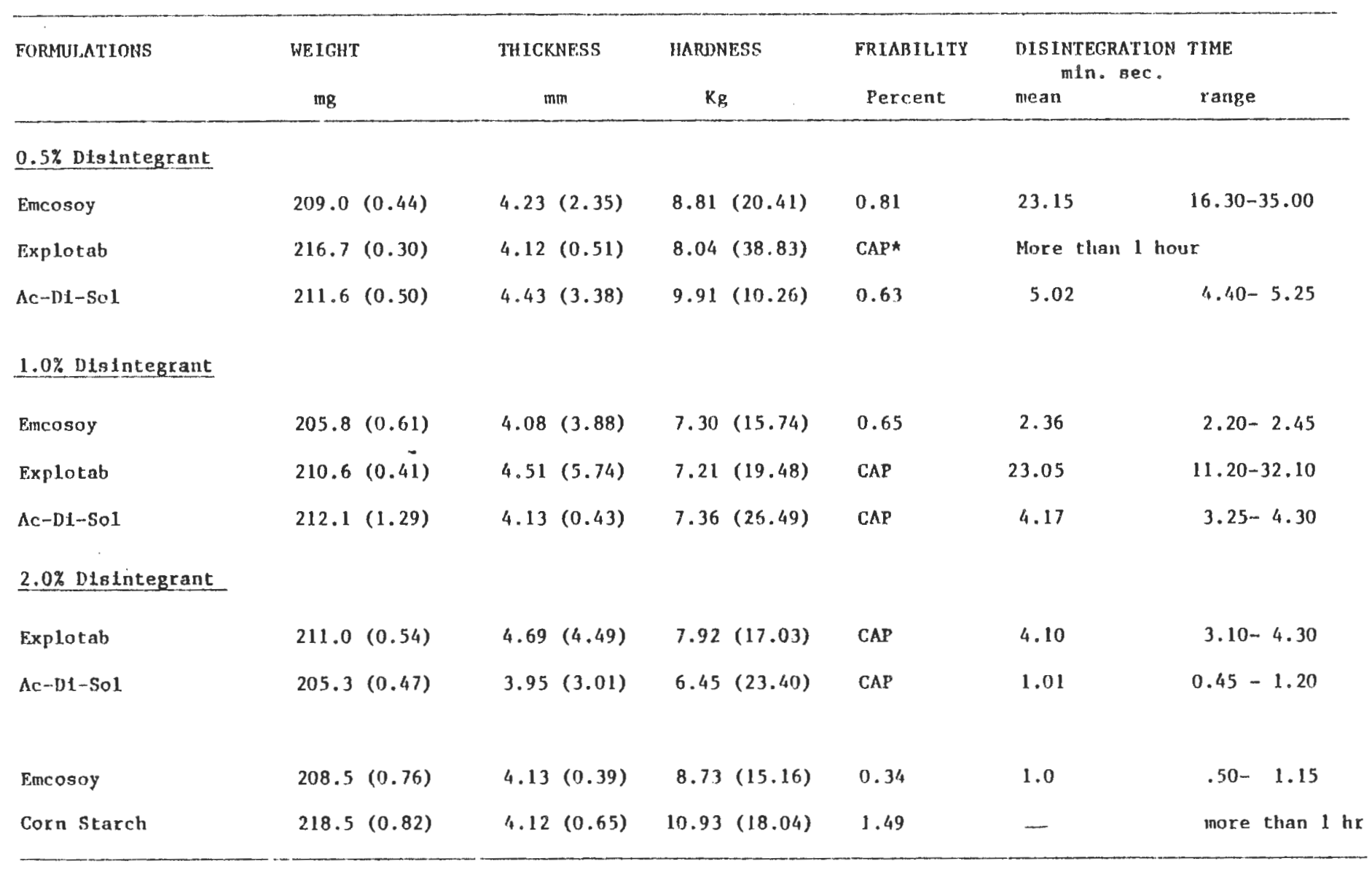

*CAP - CAPPING 
TABLE. XXXI

PYRIDOXINE HCL FORMULATION WITH EMDEX AS A MATRIX

\begin{tabular}{|c|c|c|c|c|c|c|}
\hline & $\begin{array}{l}\text { WE IGHT } \\
\text { mg }\end{array}$ & $\begin{array}{c}\text { THICKNESS } \\
\mathrm{mm}\end{array}$ & $\begin{array}{l}\text { HARDNESS } \\
\qquad \mathrm{K}_{\mathrm{B}}\end{array}$ & $\begin{array}{l}\text { FRIABILITY } \\
\text { Percent }\end{array}$ & 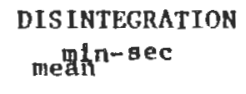 & $\begin{array}{l}\text { TIME } \\
\text { range }\end{array}$ \\
\hline \multicolumn{7}{|c|}{$0.5 \%$ Disintegrant } \\
\hline Emcosoy & $202.3(0.60)$ & $5.36(0.31)$ & $12.47(11.73)$ & 0.29 & 5.10 & 4.50 to 5.30 \\
\hline Ac-DL-Sol & $207.8(0.50)$ & $5.37(0.37)$ & $13.38(11.61)$ & 0.39 & 3.51 & 3.40 to 4.00 \\
\hline Erplotab & $205.9(0.44)$ & $5.34(0.31)$ & $12.44(14.33)$ & 0.35 & 5.09 & 4.40 to 6.00 \\
\hline \multicolumn{7}{|c|}{$1.0 \%$ Disintegrant } \\
\hline Encosoy & $209.3(0.47)$ & $5.37(0.40)$ & $13.05(11.47)$ & 0.29 & 4.02 & 3.50 to 4.10 \\
\hline$A C-D 1-S o 1$ & $213.3(0.80)$ & $5.39(0.53)$ & $12.58(12.66)$ & 0.45 & 4.05 & 3.50 to 4.30 \\
\hline Explotab & $212.9(0.52)$ & $5.65(2.82)$ & $12.41(10.02)$ & 0.38 & 4.11 & 3.20 to 4.30 \\
\hline \multicolumn{7}{|c|}{3.02 Dis Integrant } \\
\hline Emcosoy & $214.5(0.47)$ & $5.61(0.75)$ & $10.88(12.91)$ & 0.44 & 3.00 & 2.80 to 3.20 \\
\hline Corn starch & $226.1(0.79)$ & $5.73(0.40)$ & $13.37(12.19)$ & 0.33 & 6.00 & 5.10 to 7.25 \\
\hline
\end{tabular}


TABLE XXYII

ASCORBIC ACID FORMULATION WITH EMCOMPRESS AS A MATRIX

\begin{tabular}{|c|c|c|c|c|c|c|}
\hline & $\begin{array}{l}\text { WEIGUT } \\
\mathrm{mg}\end{array}$ & $\begin{array}{l}\text { THI LCKNESS } \\
\text { mom }\end{array}$ & $\begin{array}{l}\text { HARDNESS } \\
\qquad \mathrm{Kg}\end{array}$ & $\begin{array}{c}\text { FRIABILITY } \\
\text { Percent }\end{array}$ & $\begin{array}{l}\text { DISINTEGRATIO } \\
\text { mlns,--sec } \\
\text { meañ }\end{array}$ & $\begin{array}{l}\text { N TIME } \\
\text { range }\end{array}$ \\
\hline \multicolumn{7}{|c|}{$0.5 \%$ Disintegrant. } \\
\hline Emcosoy & $397.9(0.88)$ & $4.05(0.80)$ & $3.50(60.29)$ & CAP* & 1.15 & 0.58 to 1.30 \\
\hline Ac-D1-Sol & $402.2(1.36)$ & $4.07(1.26)$ & $3.35(67.07)$ & CAP & 0.56 & 0.40 to 1.20 \\
\hline \multicolumn{7}{|c|}{$1.0 \%$ DLsintegrant } \\
\hline Emcosoy & $399.9(5.47)$ & $40.60(2.16)$ & $4.81(34.74)$ & CAP & 0.51 & 0.25 to 1.25 \\
\hline$A C-D 1-S o 1$ & $466.1(4.67)$ & $4.39(3.24)$ & $3.00(53.32)$ & CAP & 0.31 & 0.20 to 0.40 \\
\hline Explotab & $377.4(1.97)$ & $3.90(1.44)$ & $4.61(15.17)$ & 2.05 & 2.21 & 1.20 to 3.25 \\
\hline \multicolumn{7}{|c|}{$2.0 \%$ Dis Integrant } \\
\hline Emcosoy & $378.0(1.92)$ & $4.08(1.06)$ & $4.25(19.92)$ & 1.74 & 0.46 & 0.40 to 0.55 \\
\hline Ac-DI-Sol & $388 \cdot 0(0.96)$ & $4.13(0.85)$ & $4.9(13.48)$ & 1.67 & 0.46 & 0.40 to 0.55 \\
\hline Explotab & $395.3(0.79)$ & $4.18(0.83)$ & $5.32(15,46)$ & 1.44 & 2.57 & 2.20 to 3.20 \\
\hline Corn Starch & $408.3(0.94)$ & $4.20(0.63)$ & $5.9(18.66)$ & 1.67 & 22.18 & 18.10 to 24.30 \\
\hline \multicolumn{7}{|c|}{$3.0 \%$ D1s Integrant } \\
\hline Encosoy & $393 \quad(3.30)$ & $4.07(2.24)$ & $5.37(33.30)$ & 1.39 & 0.30 & 0.25 to 0.40 \\
\hline Corn Starch & $440.2(1.58)$ & $4.34(1.13)$ & $2.11(84.24)$ & CAP & 14.10 & 12.30 to 15.00 \\
\hline
\end{tabular}

*CAPPING 


\section{TABLE XXXIII}

$\begin{aligned} \text { Formulation: } & \text { Riboflavin } 0.57 \% \\ & \text { Eyridoxine Hci } 0.86 \% \\ & \text { Niacin } 5.70 \% \\ & \text { Ascorbic acid } 17.10 \% \\ & \text { Disintegrant } 0.5 \% \text { or } 1.0 \% \text { or } 3.0 \% \\ & \text { Stearic acid } 2.5 \% \\ & \text { Emcompress ad } 100 \%\end{aligned}$

Dissolution data:

\begin{tabular}{|c|c|c|c|}
\hline Formulation & $t_{50}(\min )$ & $t_{75}(\min )$ & $t_{90}(\min )$ \\
\hline \multicolumn{4}{|l|}{$0.5 \%$ D1sintegegrant } \\
\hline \multirow[t]{2}{*}{ Encosoy } & 8.45 & 11.75 & 14.00 \\
\hline & $\begin{array}{l}8.75 \\
10.10\end{array}$ & $\begin{array}{l}12.40 \\
12.80\end{array}$ & $\begin{array}{l}14.60 \\
14.75\end{array}$ \\
\hline$A C-D 1-S o I$ & $\begin{array}{l}3.70 \\
3.80 \\
4.20\end{array}$ & $\begin{array}{l}4.80 \\
5.00 \\
5.30\end{array}$ & $\begin{array}{l}6.75 \\
7.65 \\
8.40\end{array}$ \\
\hline Explotab & $\begin{array}{l}10.10 \\
10.25 \\
11.50\end{array}$ & $\begin{array}{l}15.10 \\
16.30 \\
17.30\end{array}$ & $\begin{array}{l}17.40 \\
18.30 \\
20.20\end{array}$ \\
\hline \multicolumn{4}{|l|}{$1.0 \%$ Disintegrant } \\
\hline Encosoy & $\begin{array}{l}2.60 \\
6.20 \\
9.30\end{array}$ & $\begin{array}{l}4.10 \\
8.30 \\
13.95\end{array}$ & $\begin{array}{l}6.80 \\
10.55 \\
16.90\end{array}$ \\
\hline$A C-D i-S o l$ & $\begin{array}{l}1.50 \\
1.90 \\
1.90\end{array}$ & $\begin{array}{l}2.60 \\
2.75 \\
3.10\end{array}$ & $\begin{array}{l}3.60 \\
3.60 \\
5.20\end{array}$ \\
\hline Explotab & $\begin{array}{l}5.10 \\
5.20 \\
6.75\end{array}$ & $\begin{array}{l}6.25 \\
7.20 \\
8.00\end{array}$ & $\begin{array}{l}7.15 \\
8.90 \\
10.80\end{array}$ \\
\hline \multicolumn{4}{|l|}{-3. $0 \%$ Disintegrant } \\
\hline Encosoy & $\begin{array}{l}1.55 \\
2.00\end{array}$ & $\begin{array}{l}2.95 \\
2.95\end{array}$ & $\begin{array}{l}3.60 \\
3.60\end{array}$ \\
\hline Corn starch & $\begin{array}{l}18.25 \\
20.55\end{array}$ & $\begin{array}{l}>30.00 \\
>30.00\end{array}$ & $\begin{array}{l}>30.00 \\
>30.00\end{array}$ \\
\hline
\end{tabular}


Dissolution profiles.

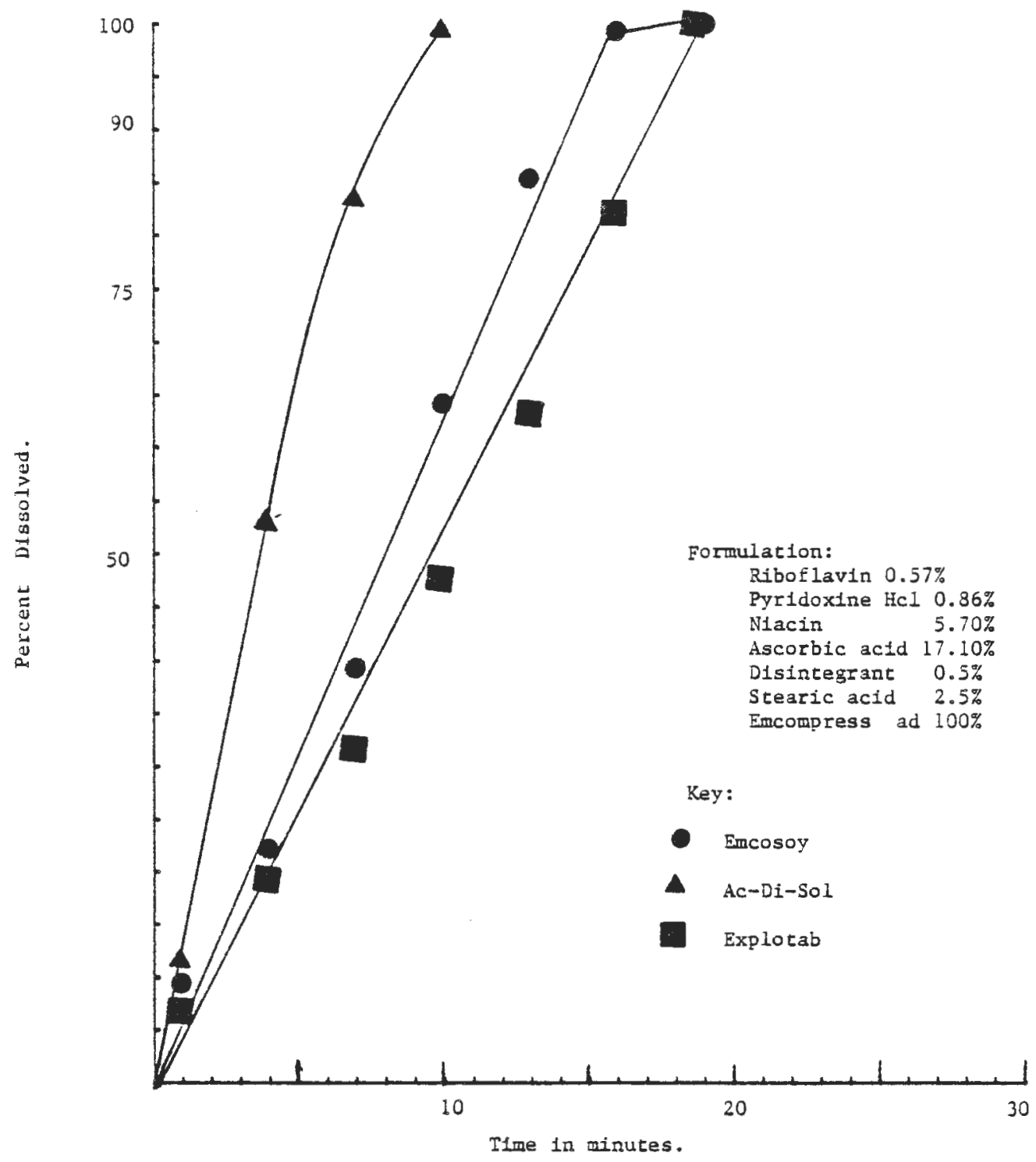

Fig. 19 


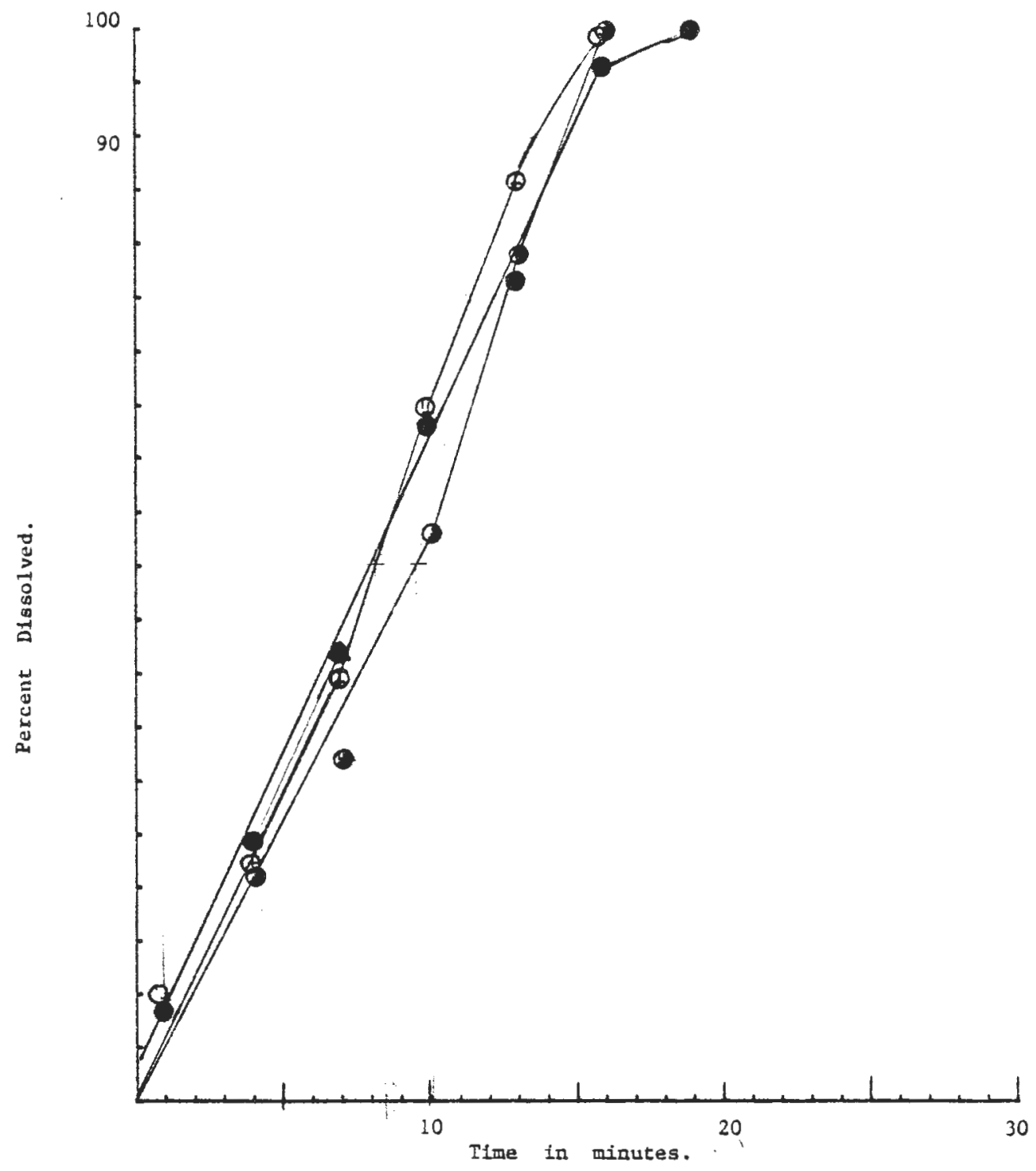

Dissolution proftle of multi vitamin formulation contalning $0.5 \%$ of Tmcosoy Replicate $1-$, Replicate 20 , Replicate 30 , Emcompress as a matrix. 


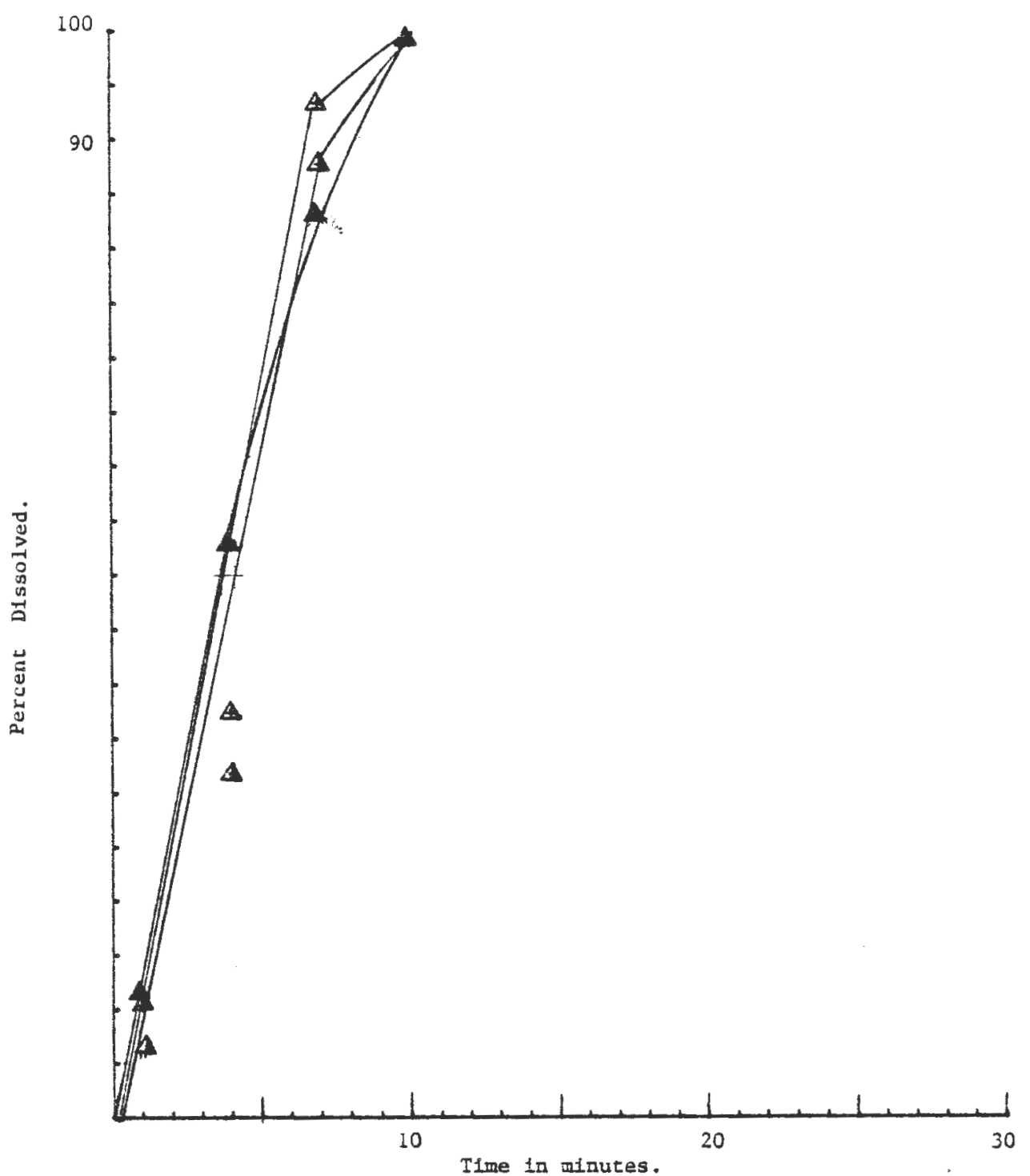

Dissolution profile of mult vitamin formulation containing $0.5 \%$ of Ac-D1-SOI Replicate $1 \Delta$, Replicate $2 \Delta$, Replicate $3 \Delta$ Emcompress as a matrix.

Fig. 21 


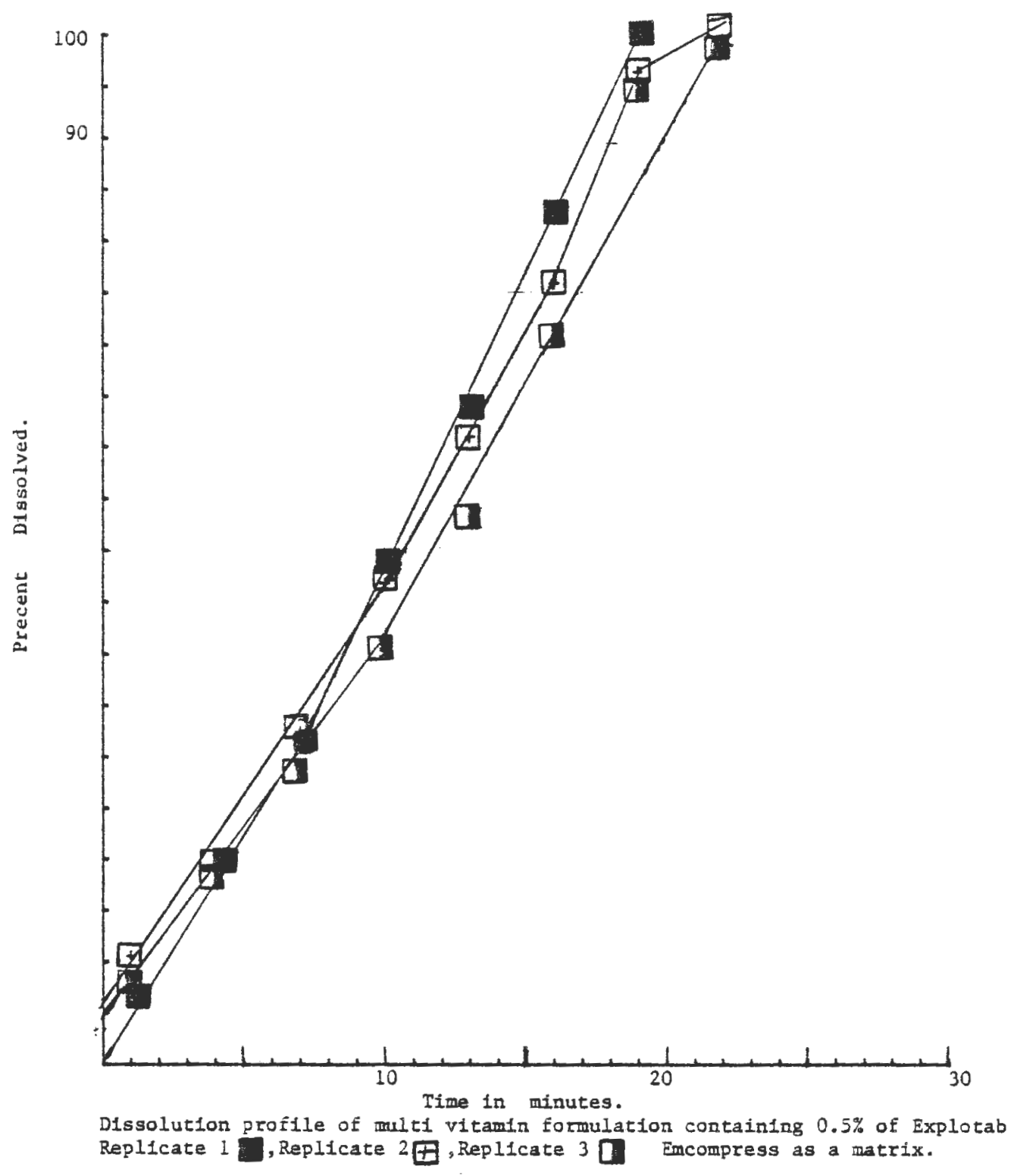

Fig. 22 
Dissolution profiles.

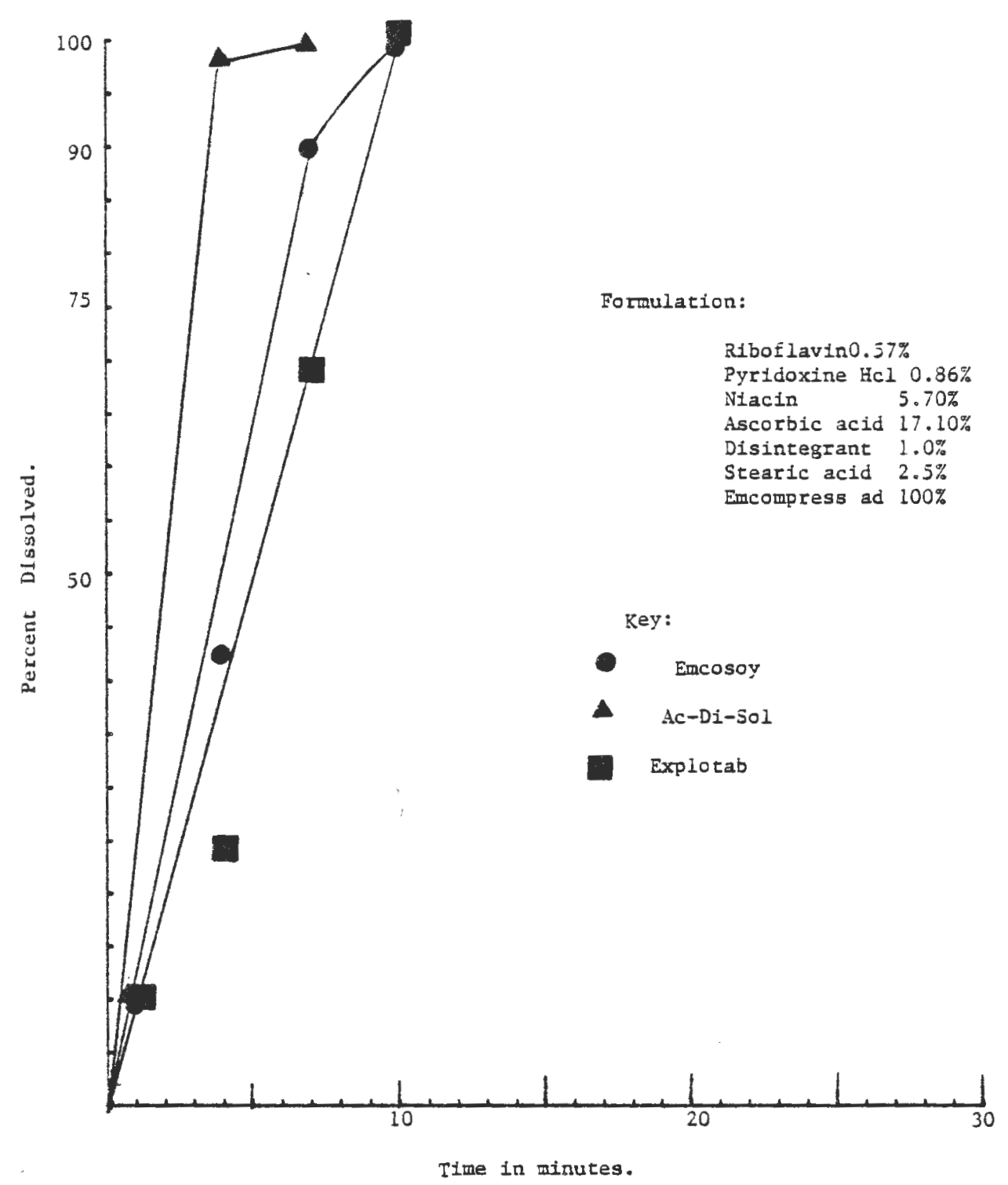

Fig. 23 


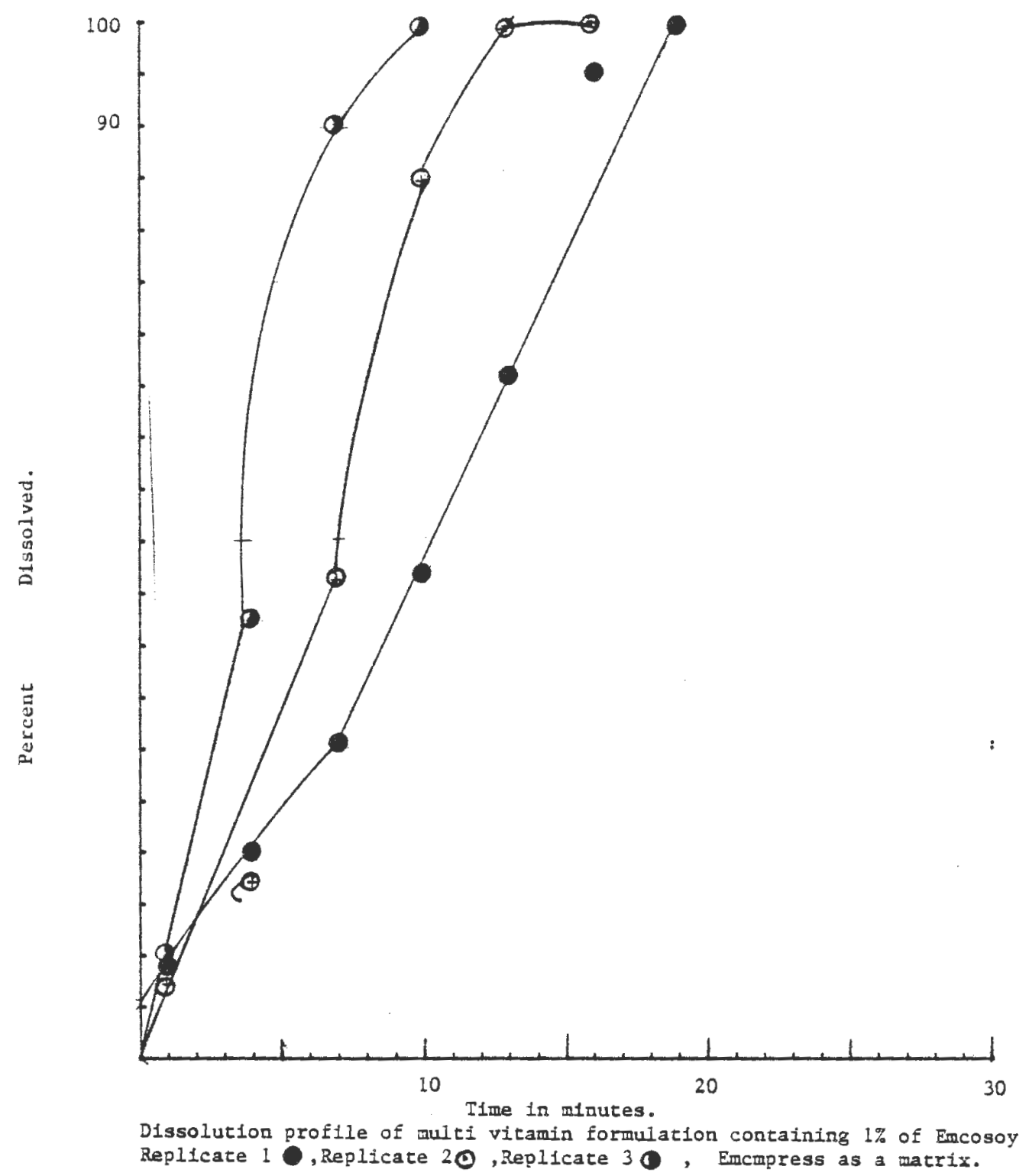

Fig. 24 


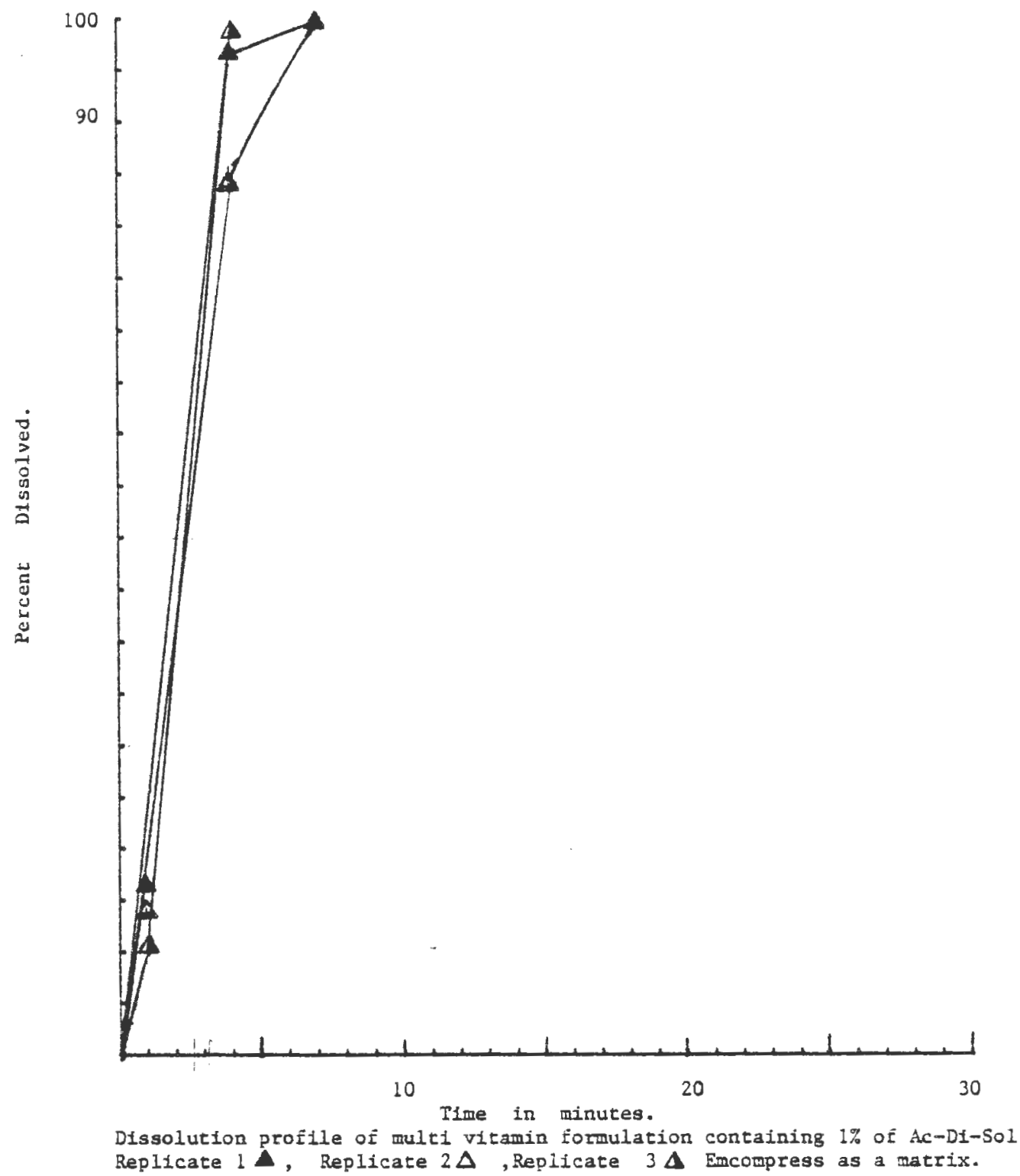

공. 25 


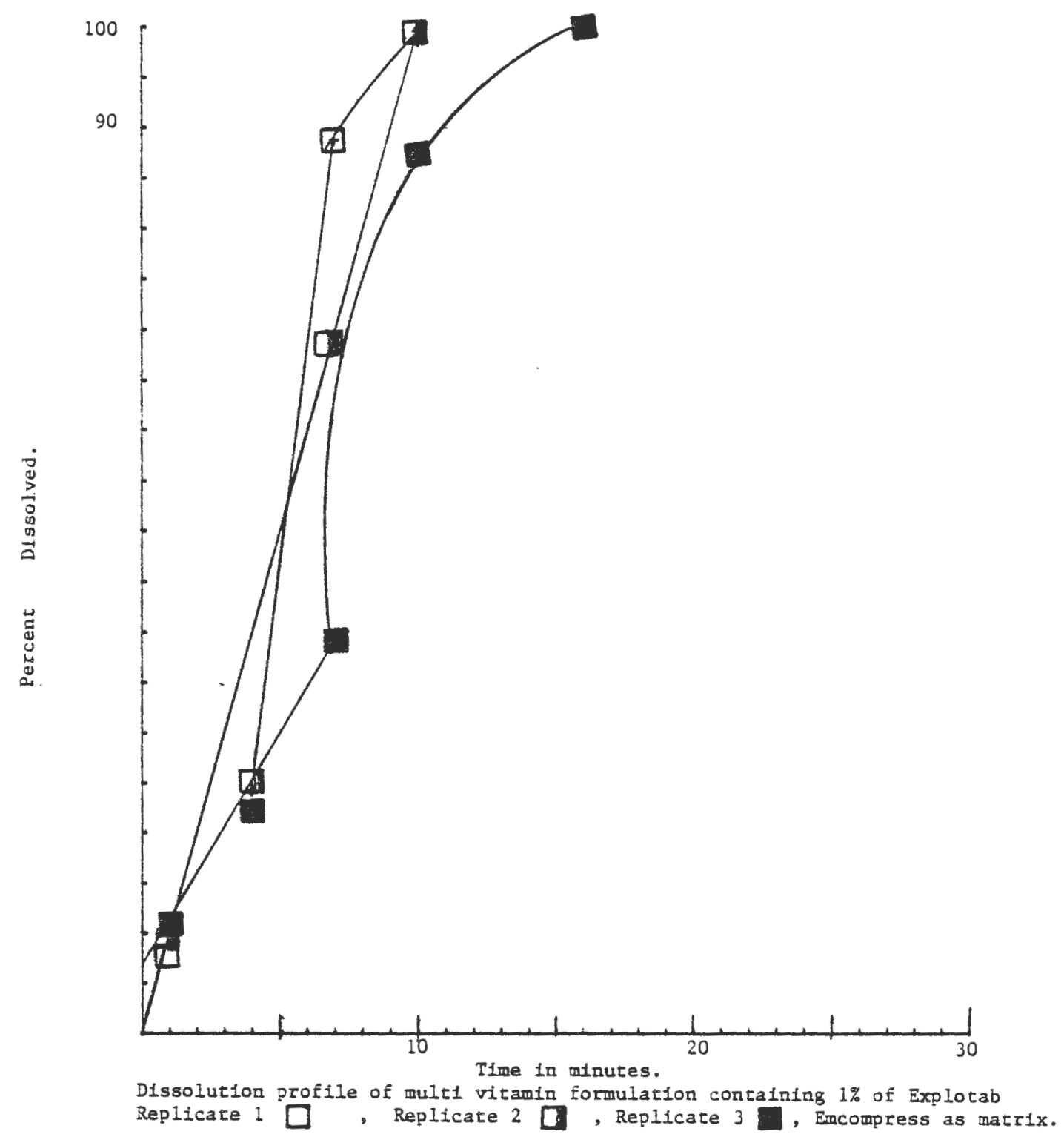

Fig. 26 
Dissolution profiles.

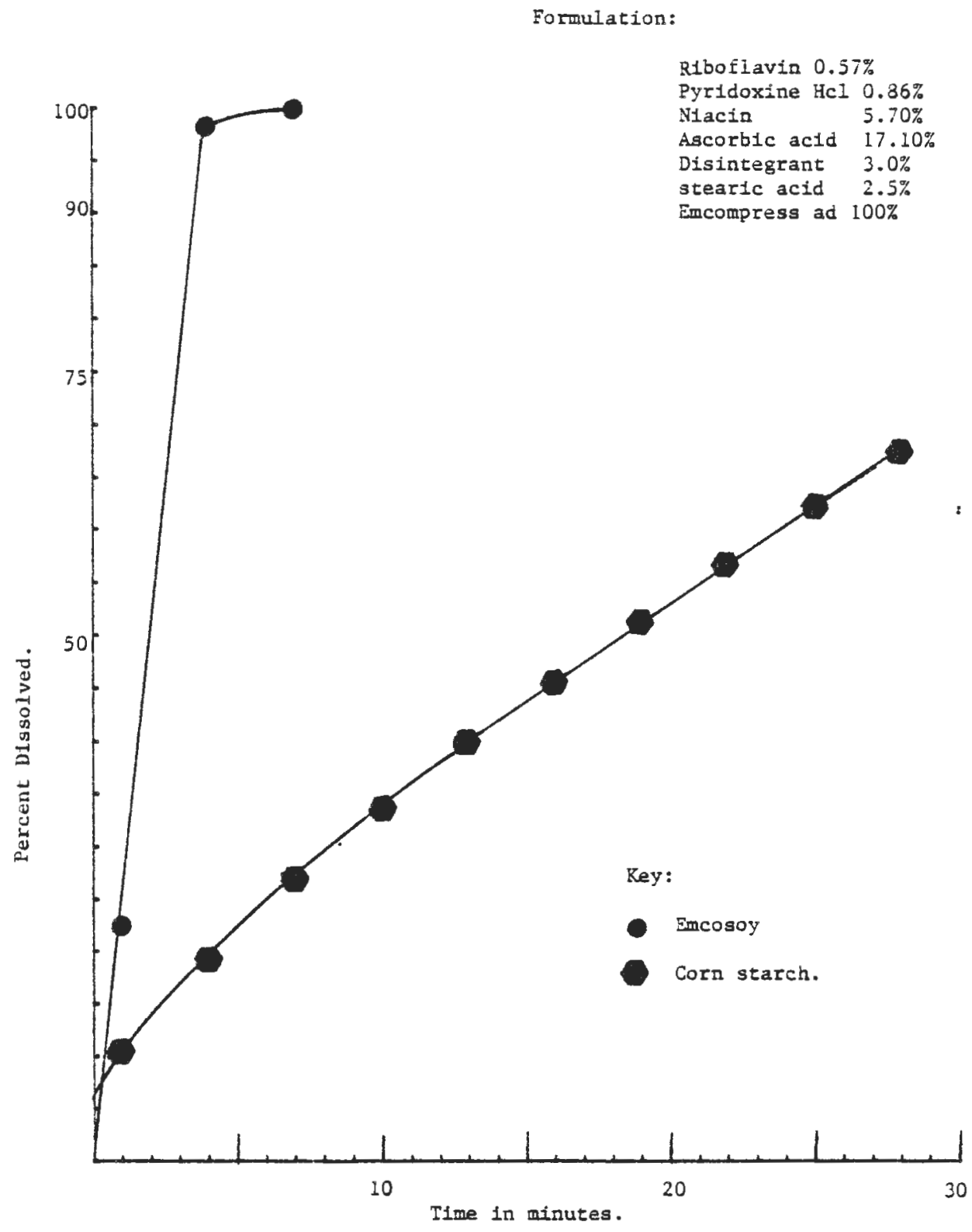

Fig. 27 


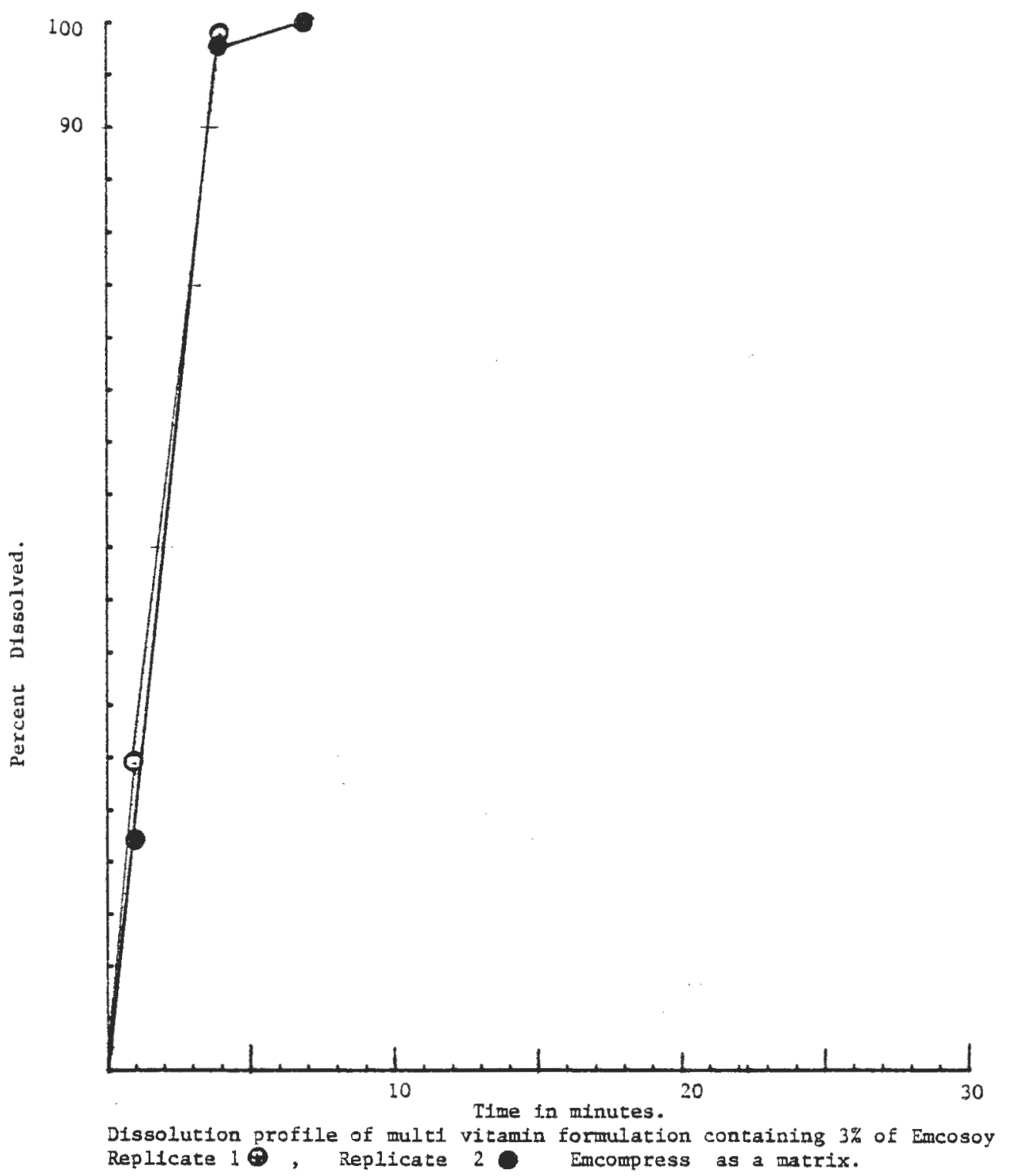

Fig. 28 


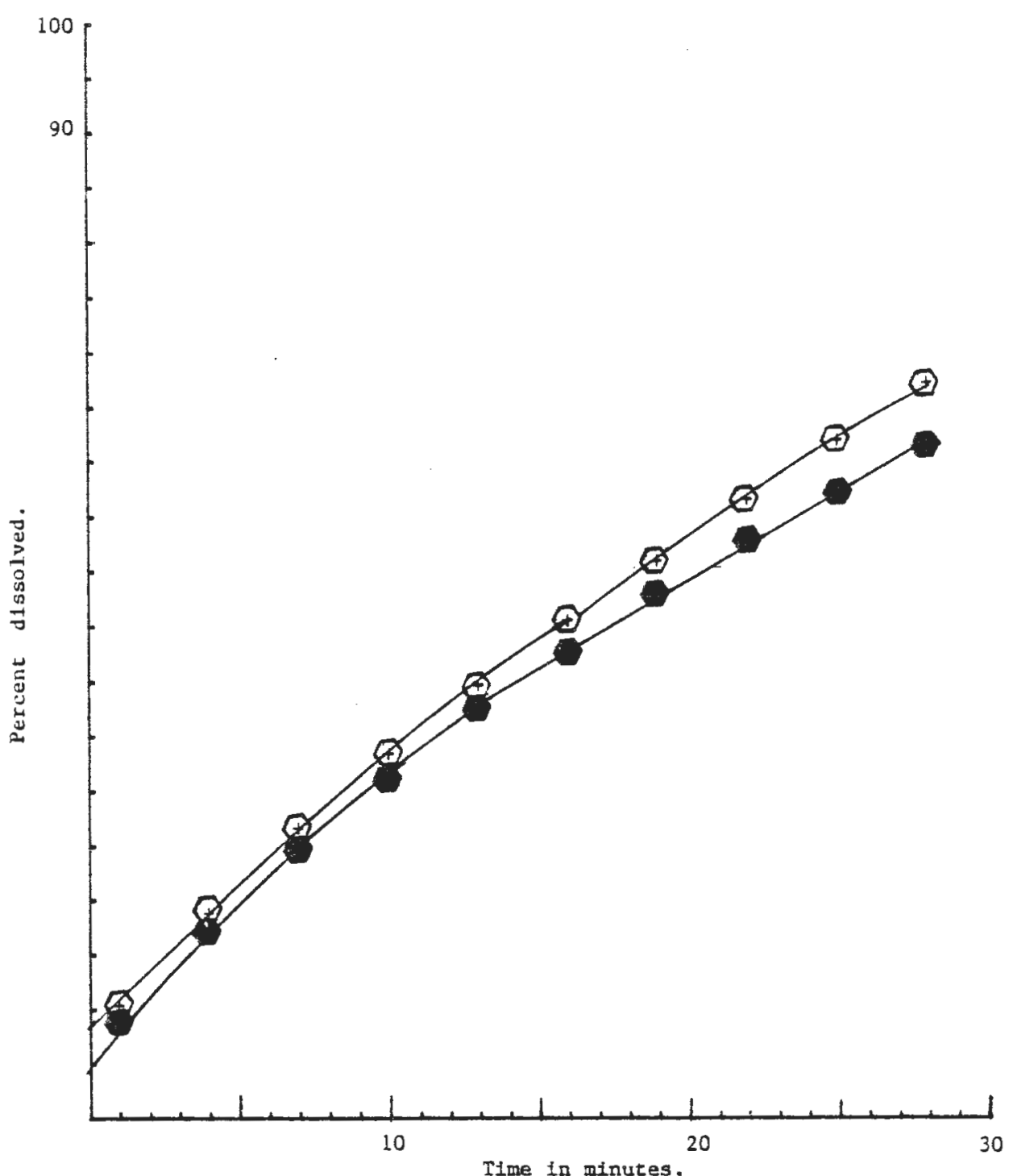

Dissolution profile of aulti vitamin formulation containing $3 \%$ of Corn starch Replicate $1 \oplus$, Replicate 20 Emcompress as a matrix.

Fig. 29 


\section{TABLE XXXIV}

Formulation: Riboflavin $0.57 \%$

Pyridoxine icl $0.86 \%$

Viacin $5.70 \%$

Ascorbic acid $17.10 \%$

Disincegrant $0.5 \%$ or $1.0 \%$ or $3.0 \%$

Stentic acid $2.5 \%$

Endex ad 100\%

Dissolution data:

\begin{tabular}{|c|c|c|c|}
\hline Formulation & $t_{50}(\min )$ & $\mathrm{t} 75(\min )$ & $c_{20}(m i n)$ \\
\hline \multicolumn{4}{|l|}{ ㅇ.5\% Disincegrant } \\
\hline Emcosoy & $\begin{array}{l}2.95 \\
2.95 \\
3.20\end{array}$ & $\begin{array}{l}3.55 \\
3.55 \\
3.75\end{array}$ & $\begin{array}{l}4.75 \\
4.75 \\
4.75\end{array}$ \\
\hline$A C-D i-S o 1$ & $\begin{array}{l}3.00 \\
2.60 \\
2.40\end{array}$ & $\begin{array}{l}4.80 \\
4.20 \\
3.90\end{array}$ & $\begin{array}{l}5.65 \\
6.00 \\
5.30\end{array}$ \\
\hline Explotab & $\begin{array}{l}2.40 \\
2.65 \\
2.85\end{array}$ & $\begin{array}{l}3.60 \\
4.00 \\
4.20\end{array}$ & $\begin{array}{l}6.00 \\
5.70 \\
5.30\end{array}$ \\
\hline \multicolumn{4}{|l|}{ 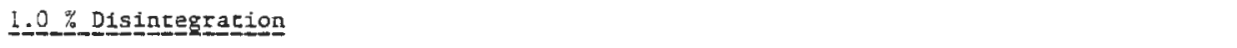 } \\
\hline Encosoy & $\begin{array}{l}2.80 \\
3.15 \\
3.25\end{array}$ & $\begin{array}{l}5.20 \\
5.40 \\
5.40\end{array}$ & $\begin{array}{l}6.75 \\
5.20 \\
6.75\end{array}$ \\
\hline$A c-D i-S o l$ & $\begin{array}{l}2.45 \\
2.55 \\
2.75\end{array}$ & $\begin{array}{l}3.75 \\
3.75 \\
4.25\end{array}$ & $\begin{array}{l}5.20 \\
5.20 \\
6.10\end{array}$ \\
\hline Explotab & $\begin{array}{l}3.55 \\
3.60 \\
3.60\end{array}$ & $\begin{array}{l}4.20 \\
4.60 \\
4.60\end{array}$ & $\begin{array}{l}6.45 \\
6.65 \\
6.65\end{array}$ \\
\hline \multicolumn{4}{|l|}{ 3.0\% Disintegrant } \\
\hline Encosoy & $\begin{array}{l}2.75 \\
2.75\end{array}$ & $\begin{array}{l}3.85 \\
4.05\end{array}$ & $\begin{array}{l}5.20 \\
5.40\end{array}$ \\
\hline Corn starch & $\begin{array}{l}3.20 \\
3.75\end{array}$ & $\begin{array}{l}5.60 \\
6.50\end{array}$ & $\begin{array}{l}8.00 \\
8.90\end{array}$ \\
\hline
\end{tabular}


Dissolution profiles.

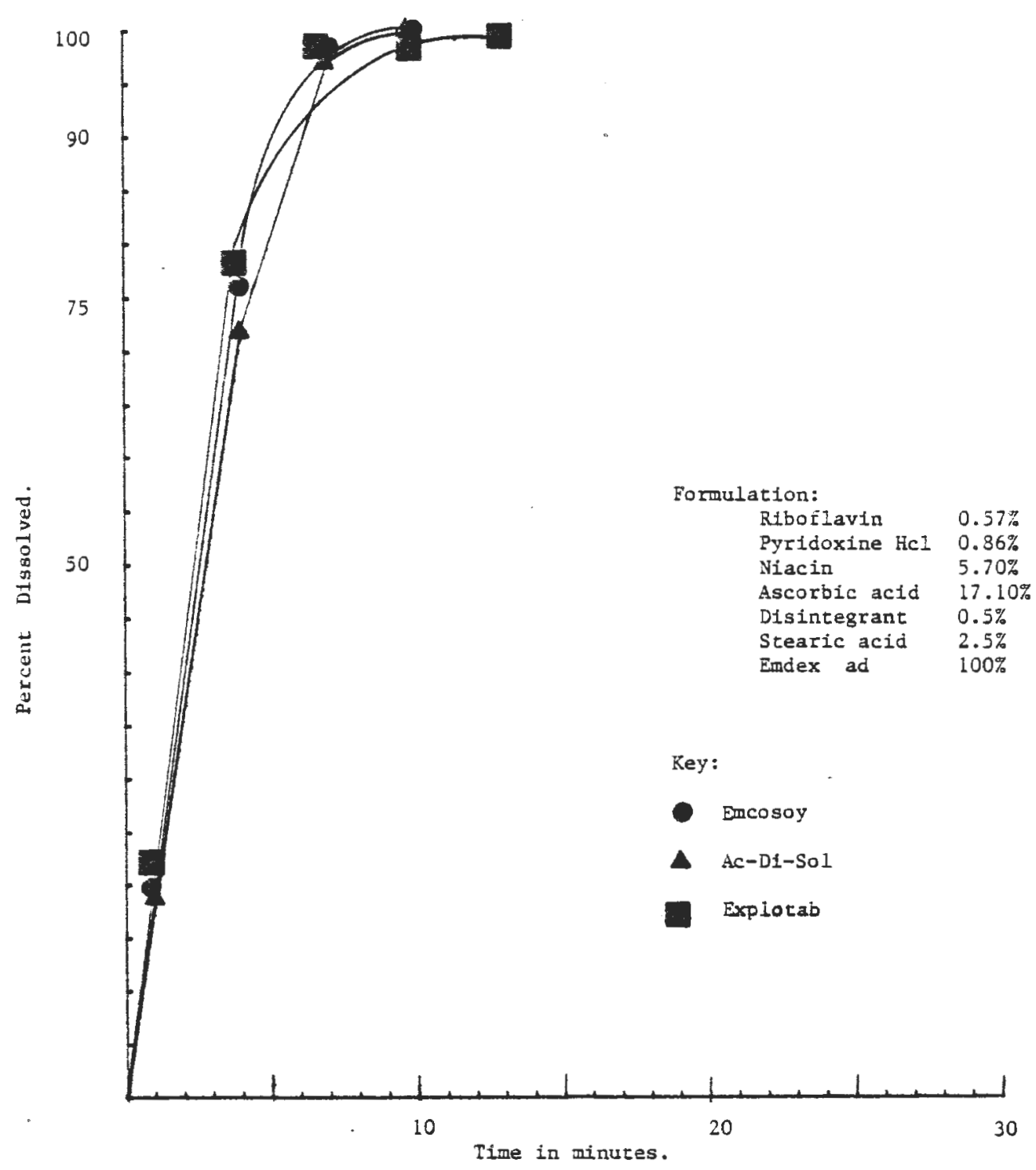

Fig. 30 


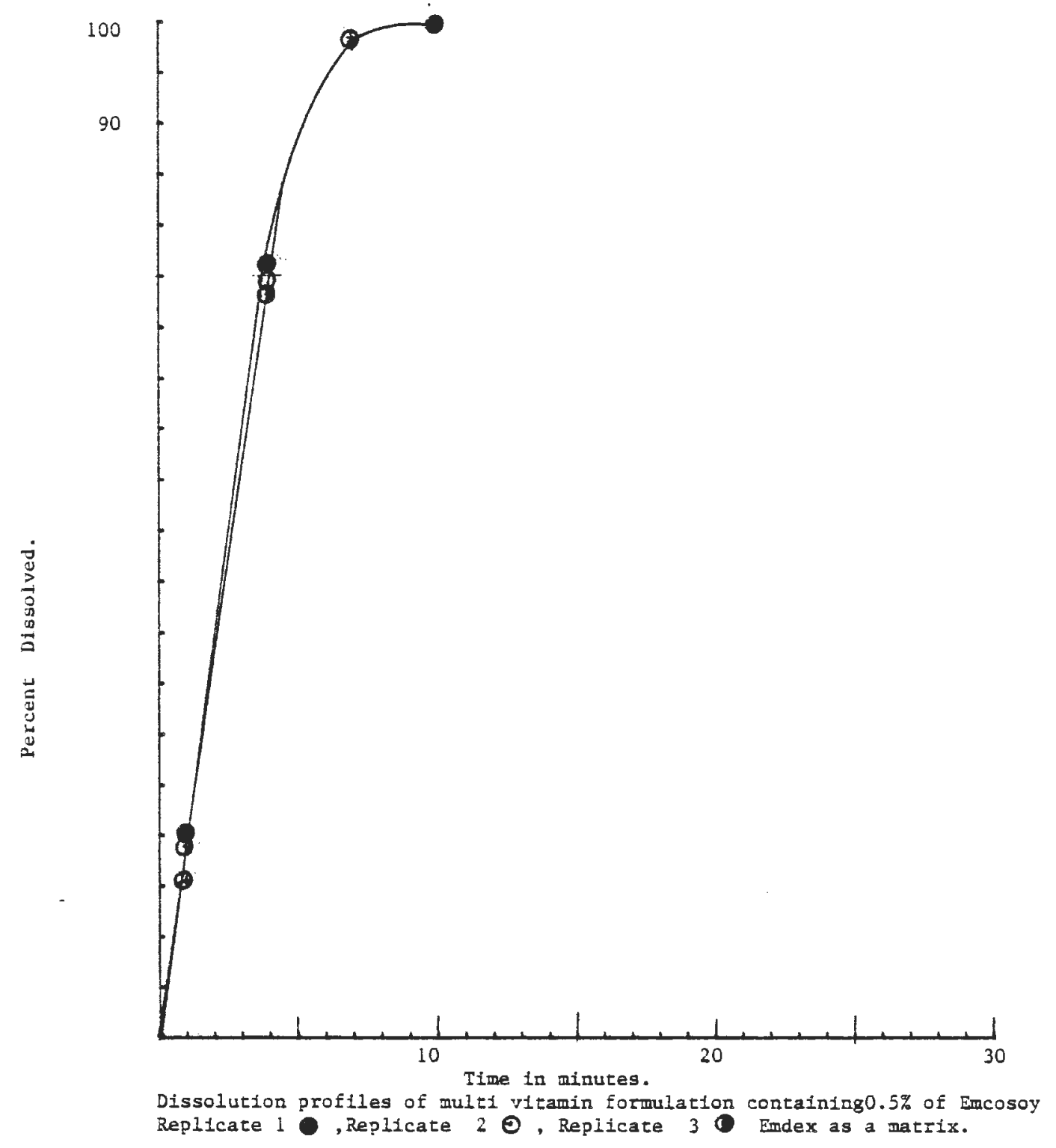

Fig. 31 


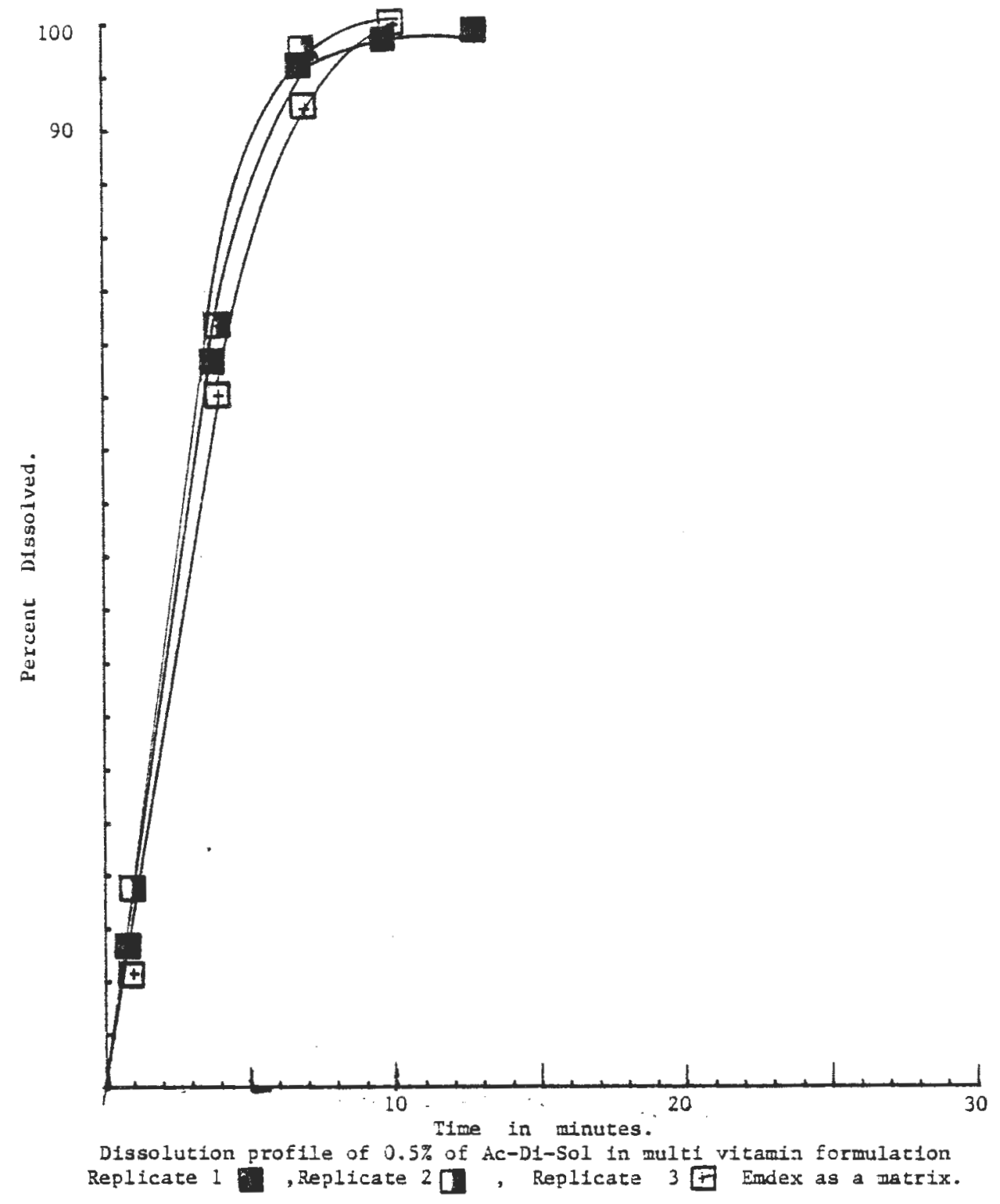

Fig. 32 


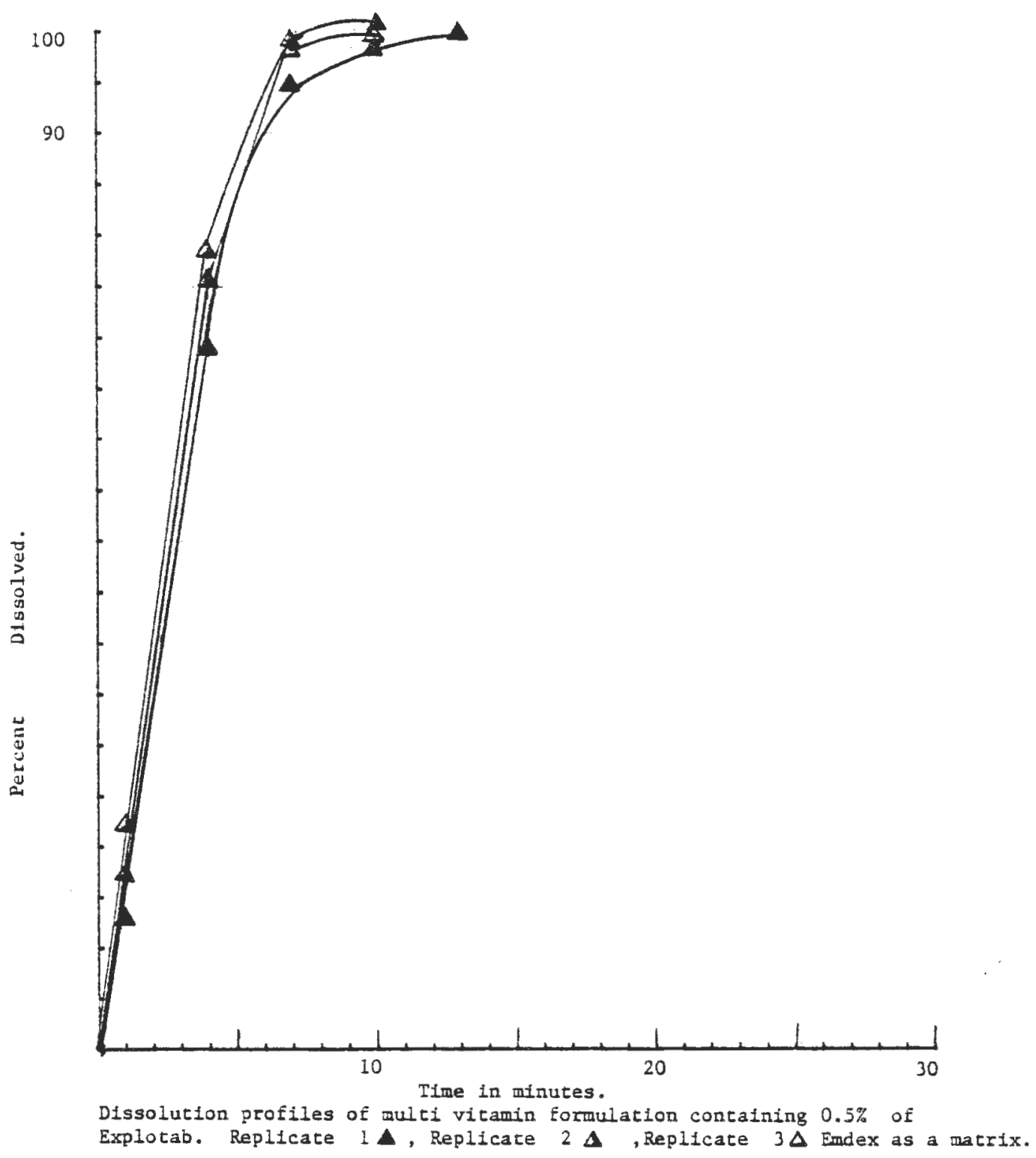

Fig. 33 


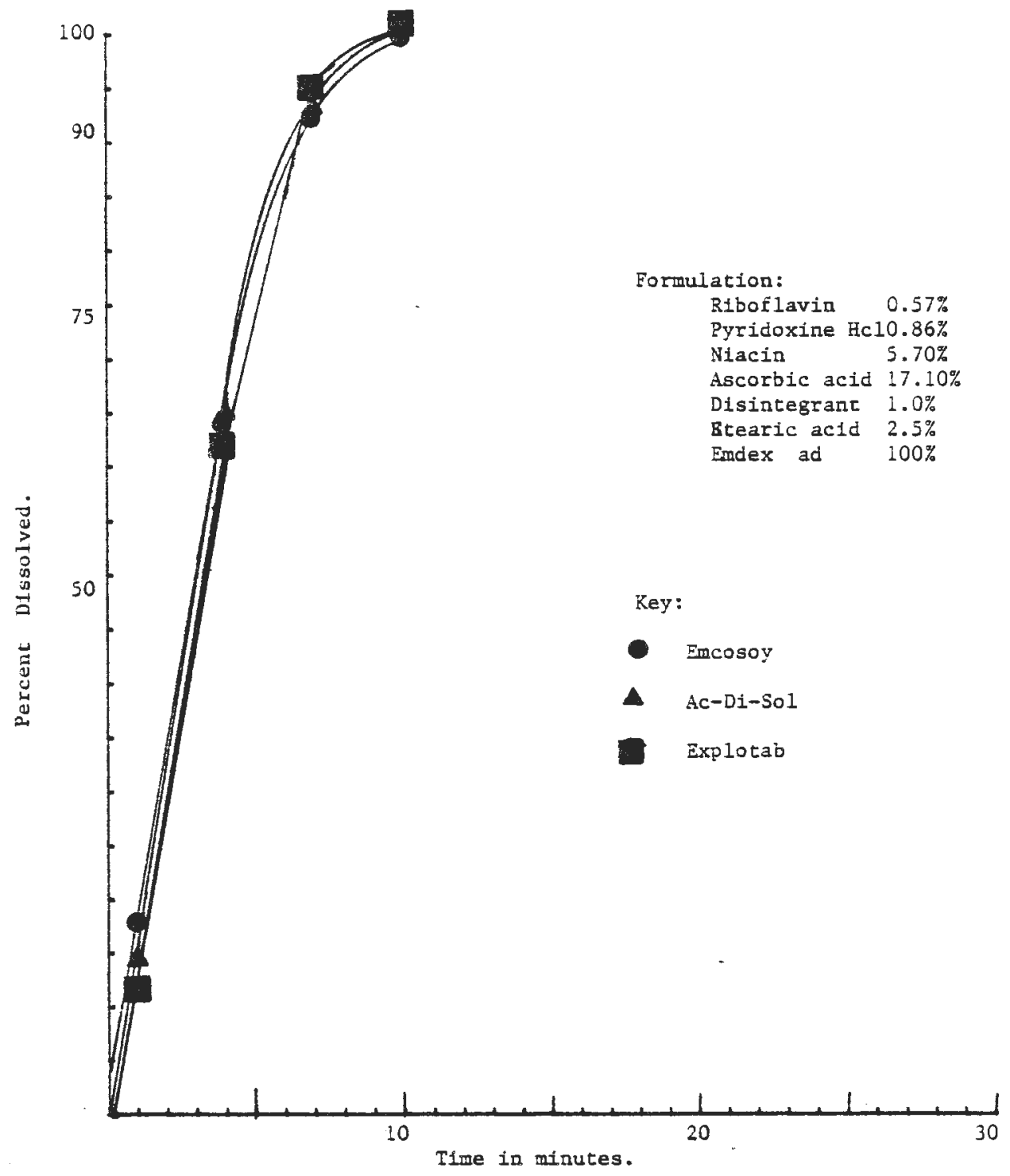

Fig. 34 


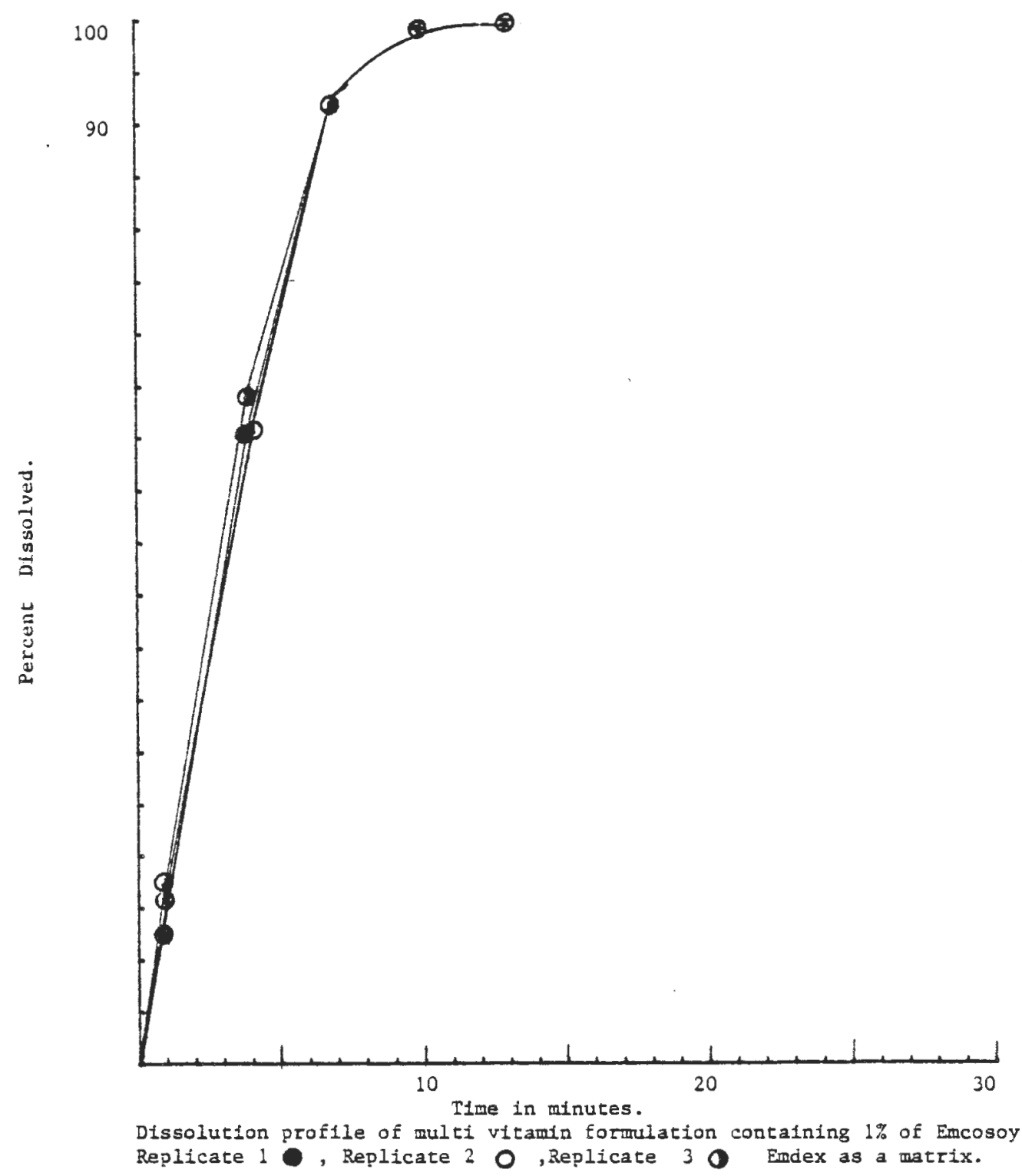

Fig. 35 


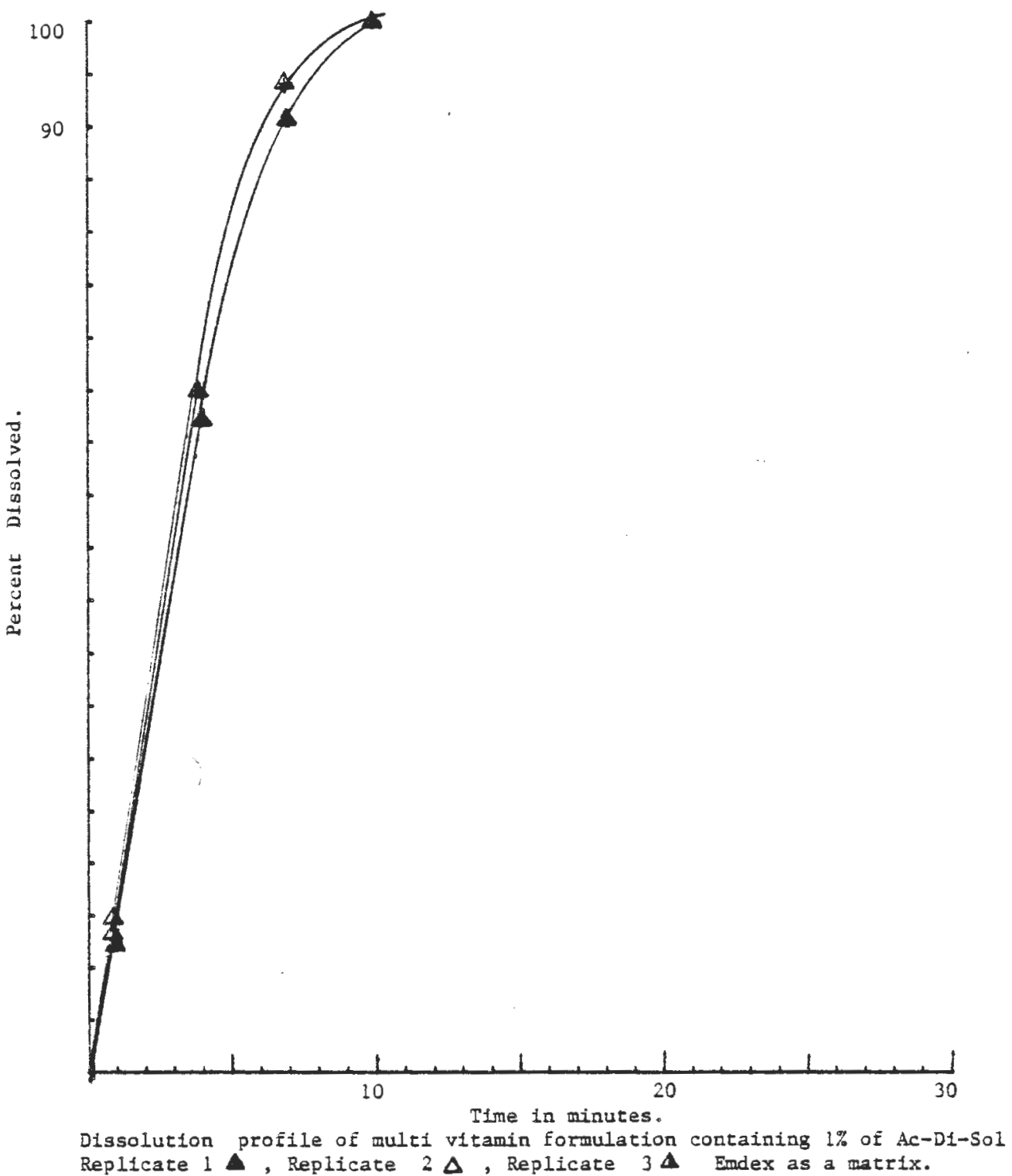

Fig. 36 


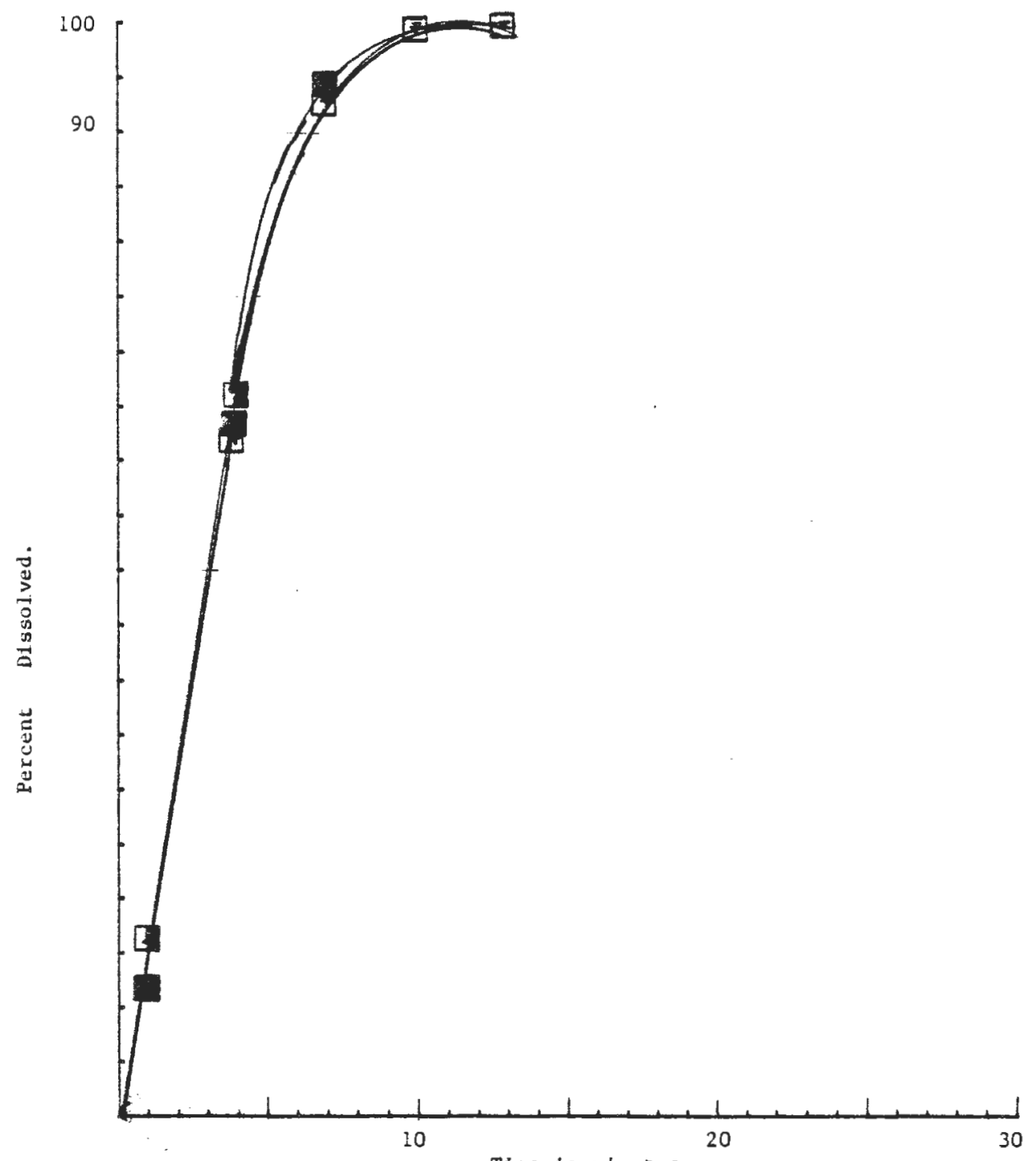

Time in minutes.

Dissolution profiles of mult1 vitamin formulation containing $1 \%$ of Explotab Replicate $1 \square$, Replicate 2 , Replicate 30 Endex as a matrix. 


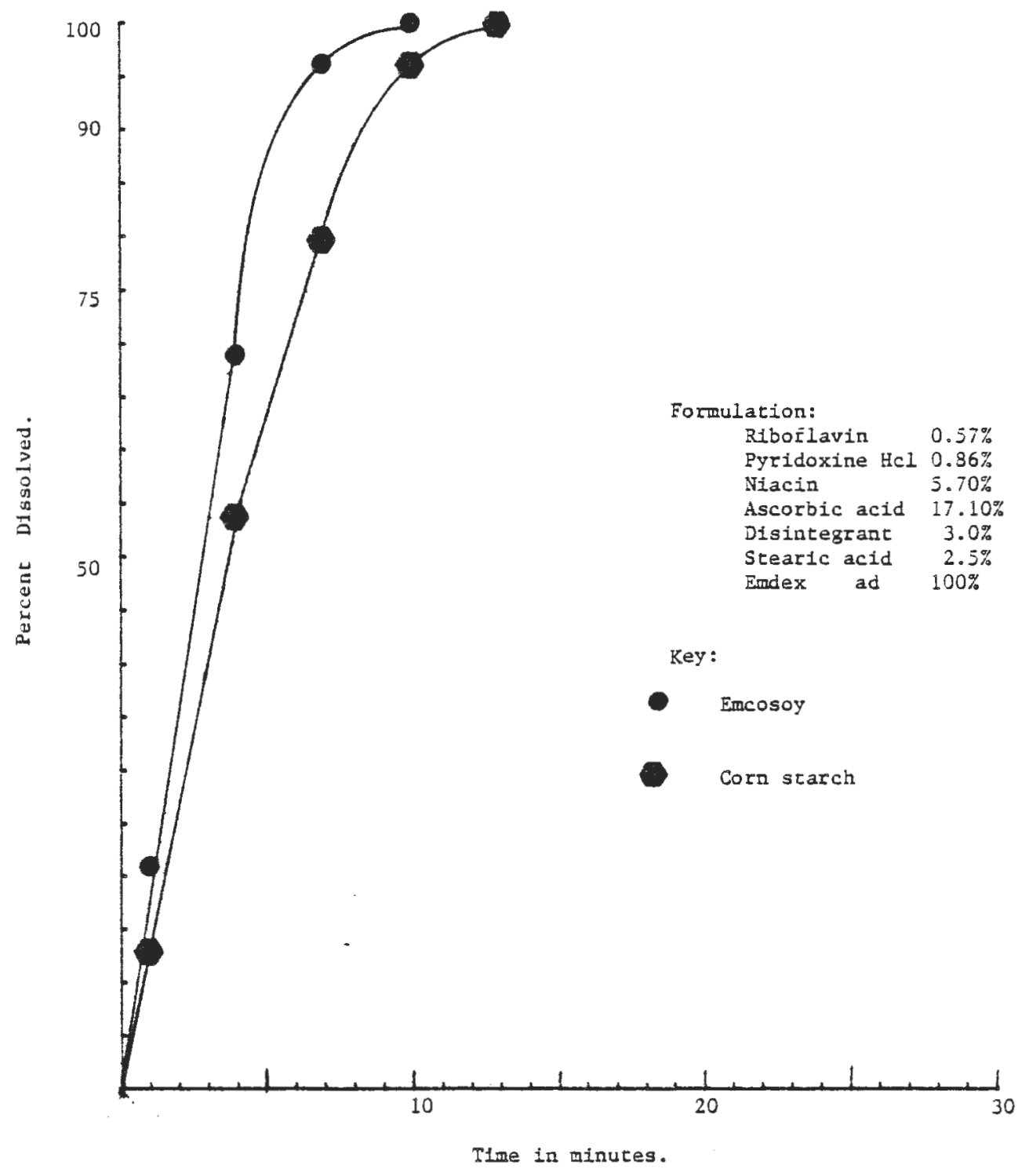

Fig. 38 


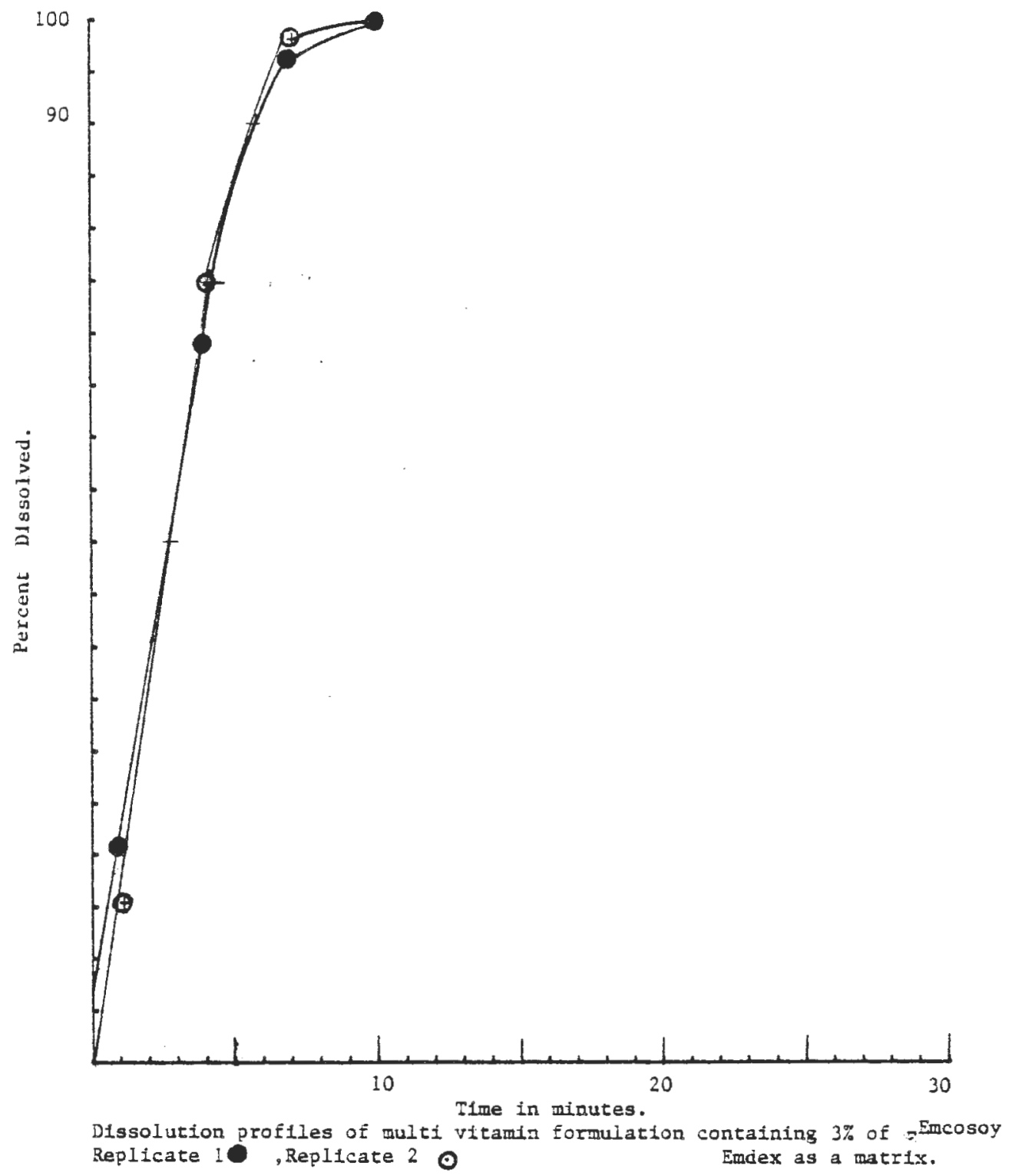

Fig. 39 


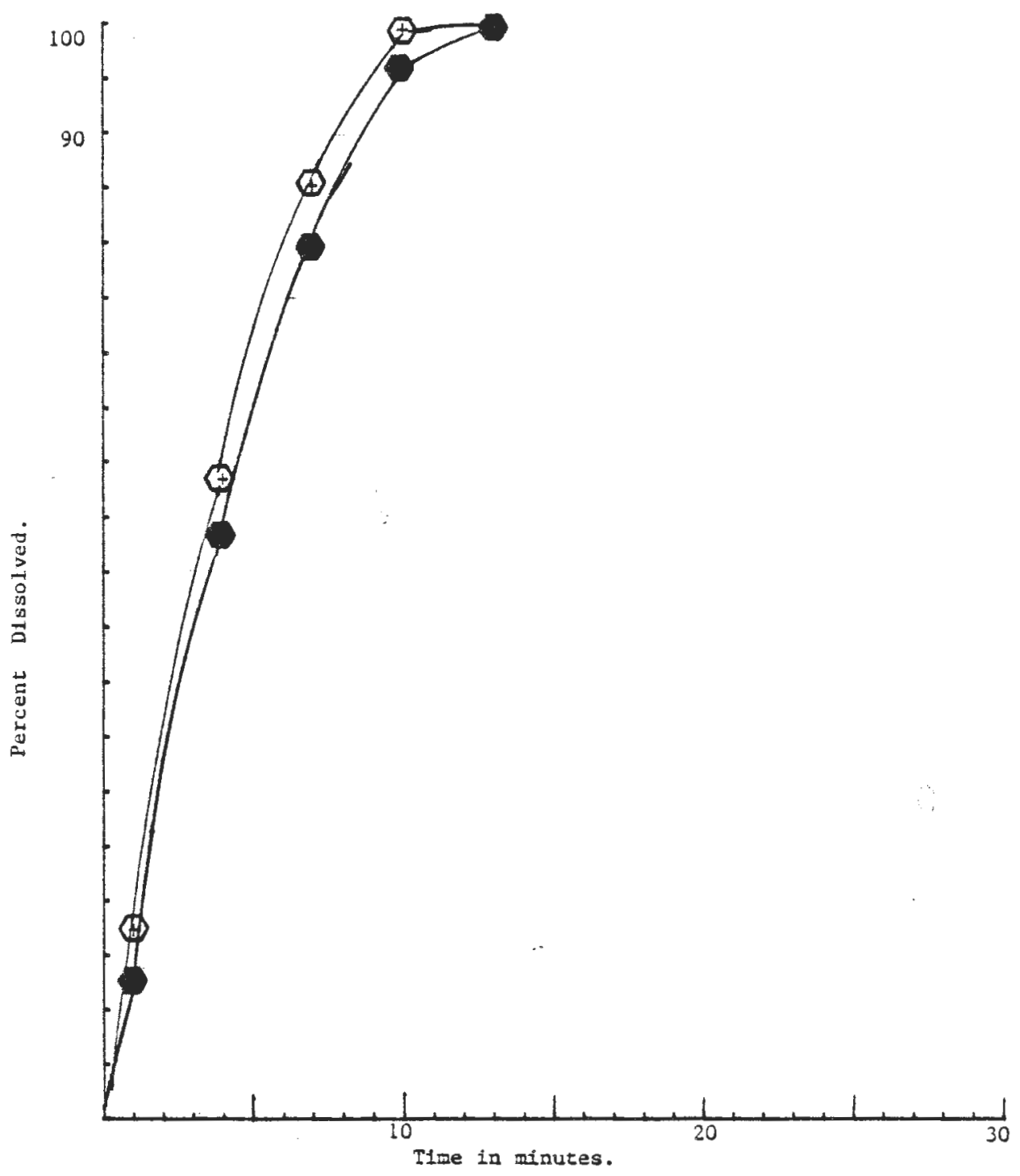

Dissolution profiles of multi vitamin formulation containing $3 \%$ of corn starch Replicate I 9 , Replicate 2 Emdex as a matrix.

Fig. 40 


\section{TABLE XXXV}

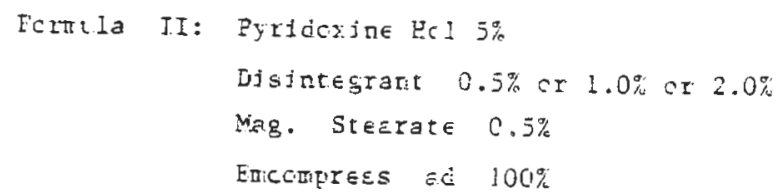

\begin{tabular}{|c|c|c|c|}
\hline Formulacion & $t_{50}(\min )$ & $t_{75}(\min )$ & $t_{90}(m 1 n)$ \\
\hline \multirow[t]{2}{*}{ Disiztegrant } & & & . \\
\hline & $\begin{array}{l}12.2 \\
16.0\end{array}$ & $\begin{array}{r}22.2 \\
>30.0\end{array}$ & $\begin{array}{r}29.1 \\
>30.0\end{array}$ \\
\hline Explocab & $\begin{array}{l}14.1 \\
19.9\end{array}$ & $\begin{array}{l}>30.0 \\
>30.0\end{array}$ & $\begin{array}{l}>30.0 \\
>30.0\end{array}$ \\
\hline$A C=D 1-S 01$ & $\begin{array}{l}2.7 \\
3.8\end{array}$ & $\begin{array}{r}9.5 \\
15.8\end{array}$ & $\begin{array}{r}18.4 \\
>30.0\end{array}$ \\
\hline \multicolumn{4}{|l|}{$1.0 \%$ Disintegrant } \\
\hline Encosoy & $\begin{array}{l}1.8 \\
4.8\end{array}$ & $\begin{array}{r}3.8 \\
10.5\end{array}$ & $\begin{array}{r}6.5 \\
18.2\end{array}$ \\
\hline Explotab & $\begin{array}{l}3.7 \\
6.2\end{array}$ & $\begin{array}{l}14.0 \\
15.0\end{array}$ & $\begin{array}{l}\text { approx } 30.0 \\
\text { approx } 30.0\end{array}$ \\
\hline$A c-D 1-S a 1$ & $\begin{array}{l}2.0 \\
2.9\end{array}$ & $\begin{array}{l}5.1 \\
6.8\end{array}$ & $\begin{array}{l}13.1 \\
15.2\end{array}$ \\
\hline \multicolumn{4}{|l|}{$2.0 \%$ Disintegrant } \\
\hline Explotab & $\begin{array}{l}0.9 \\
1.6\end{array}$ & $\begin{array}{l}3.3 \\
4.3\end{array}$ & $\begin{array}{l}9.5 \\
9.5\end{array}$ \\
\hline$A C-D 1-S o l$ & $\begin{array}{l}0.8 \\
0.8\end{array}$ & $\begin{array}{l}1.2 \\
1.2\end{array}$ & $\begin{array}{r}2.0 \\
-3.0\end{array}$ \\
\hline Emcosoy & $\begin{array}{l}0.5 \\
0.5\end{array}$ & $\begin{array}{l}0.8 \\
1.0\end{array}$ & $\begin{array}{l}1.0 \\
1.5\end{array}$ \\
\hline Corn starch & $\begin{array}{l}16.0 \\
25.0\end{array}$ & $\begin{array}{r}27.0 \\
>30.0\end{array}$ & $\begin{array}{l}>30.0 \\
>30.0\end{array}$ \\
\hline
\end{tabular}



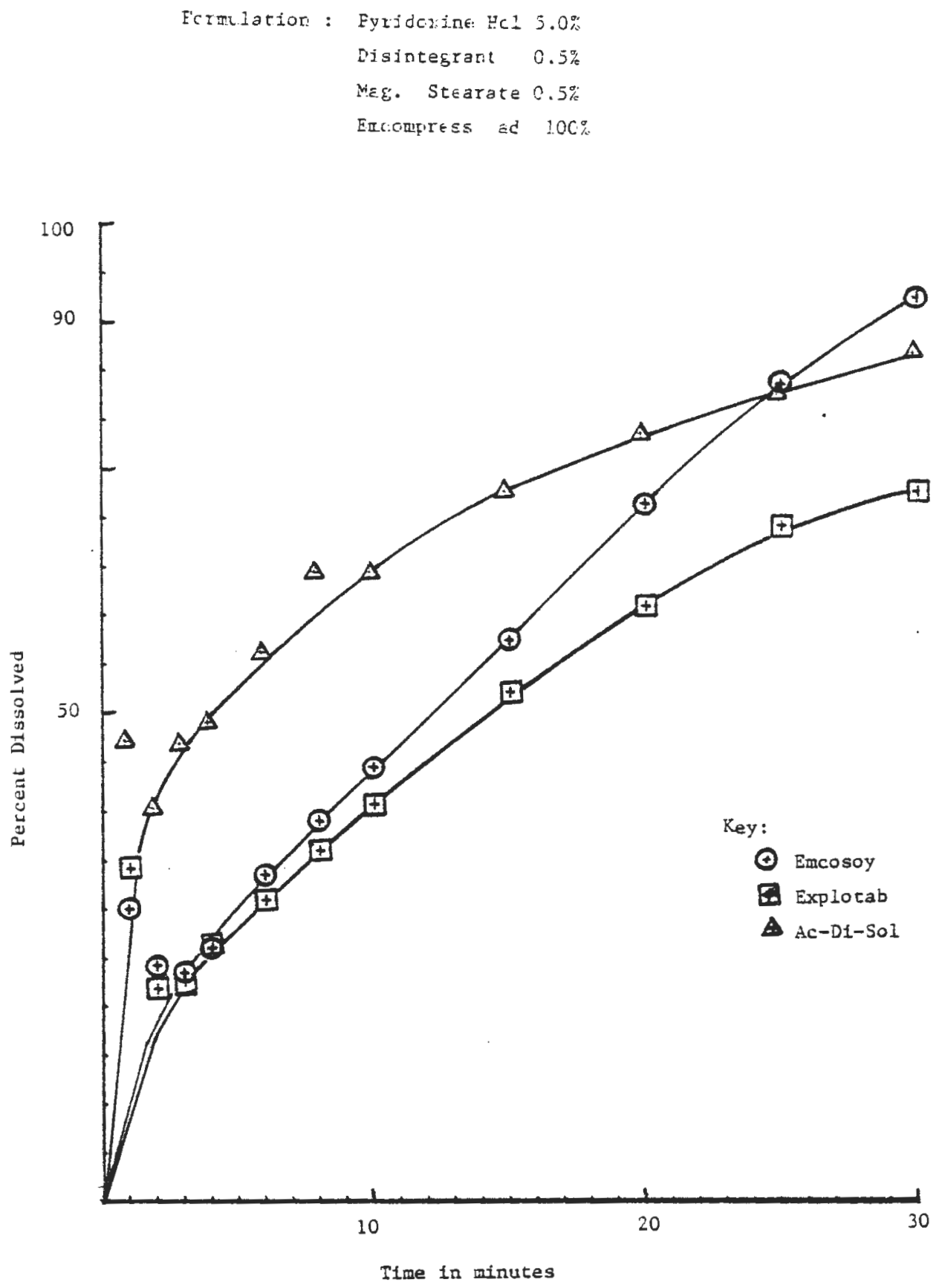

Dissolurfon profiles for pyridoxine ECl tablet formulations containing $0.5 \%$ of different disintegrants 


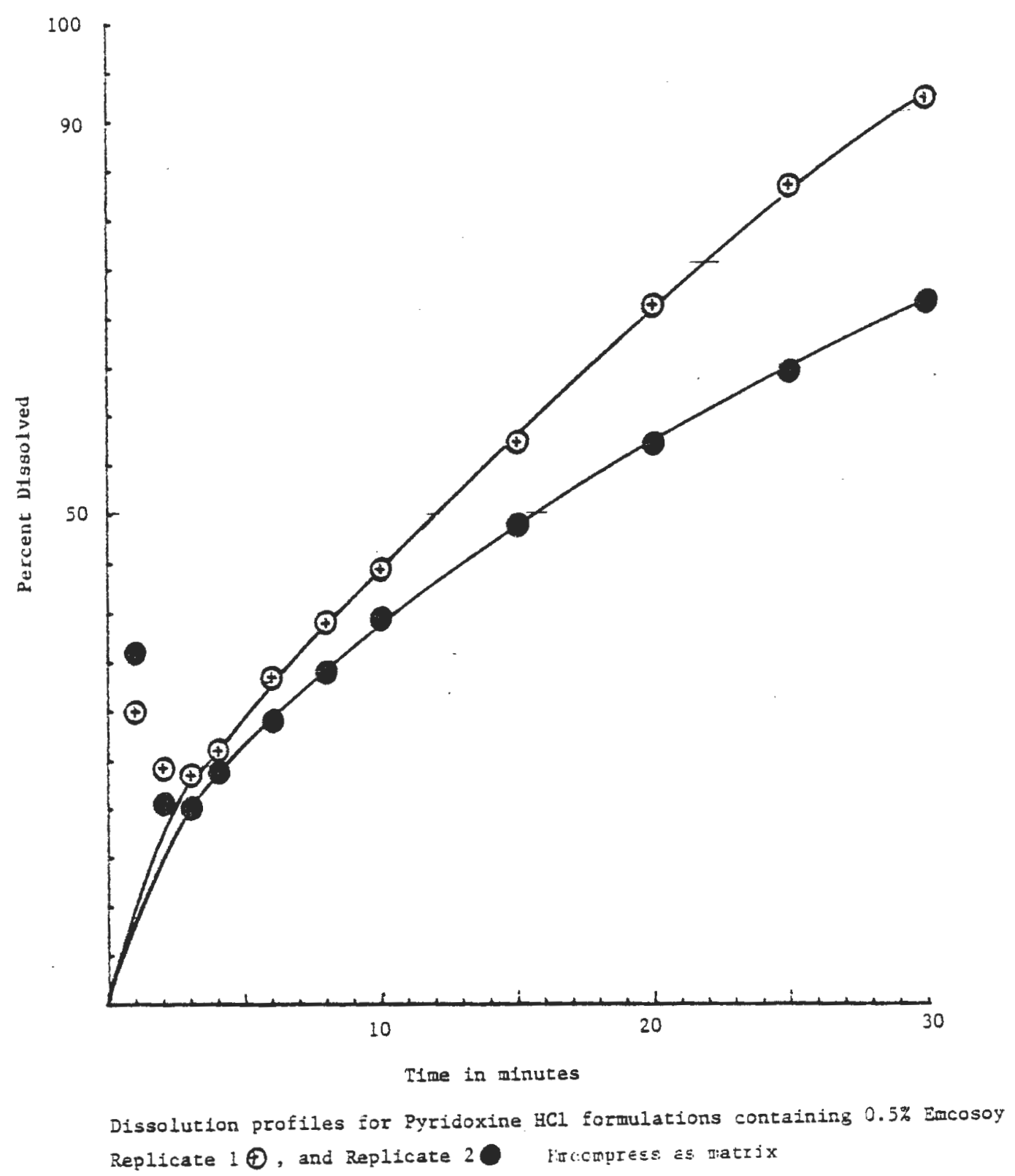

Fig. 42 


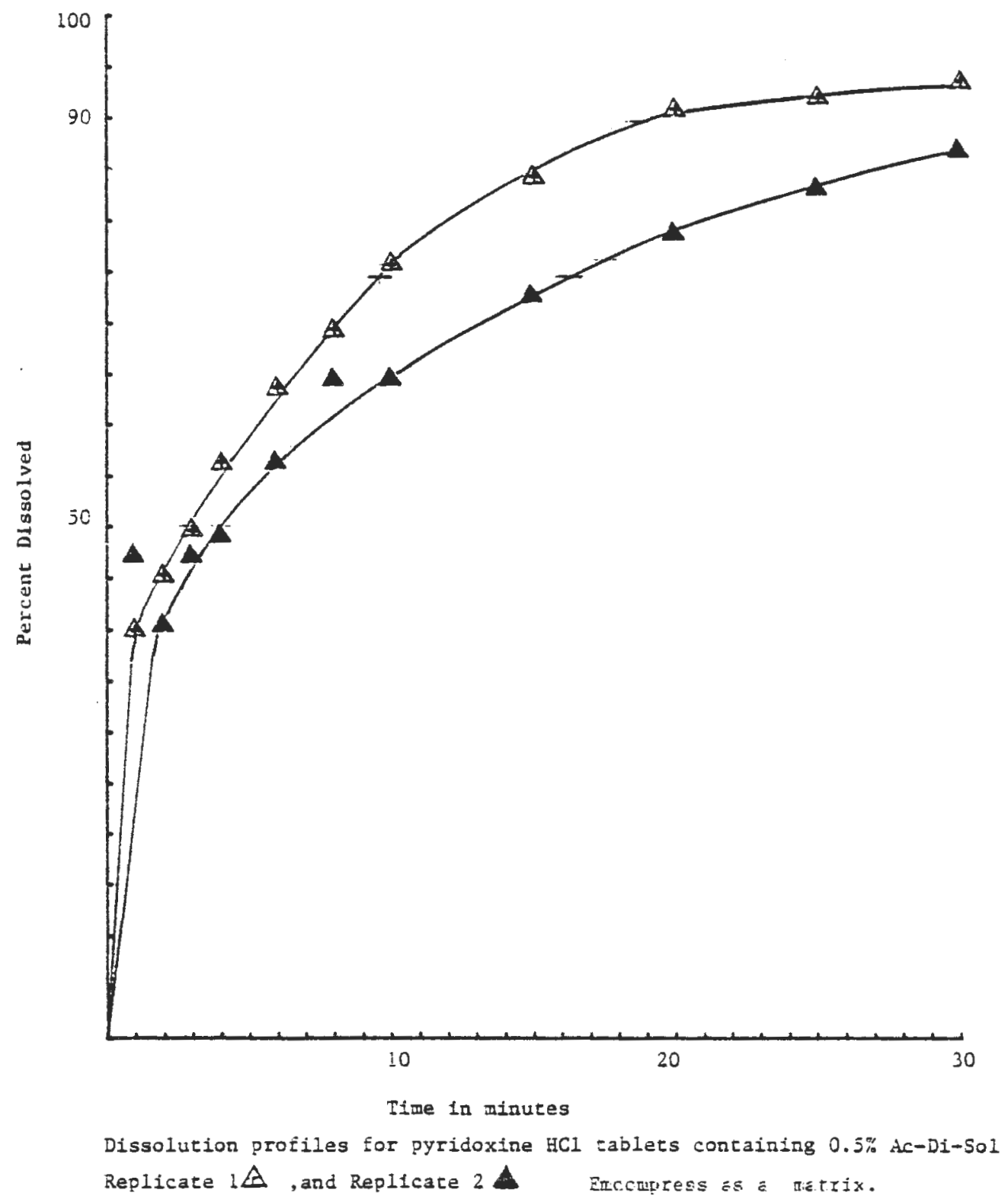

Fig. 43 


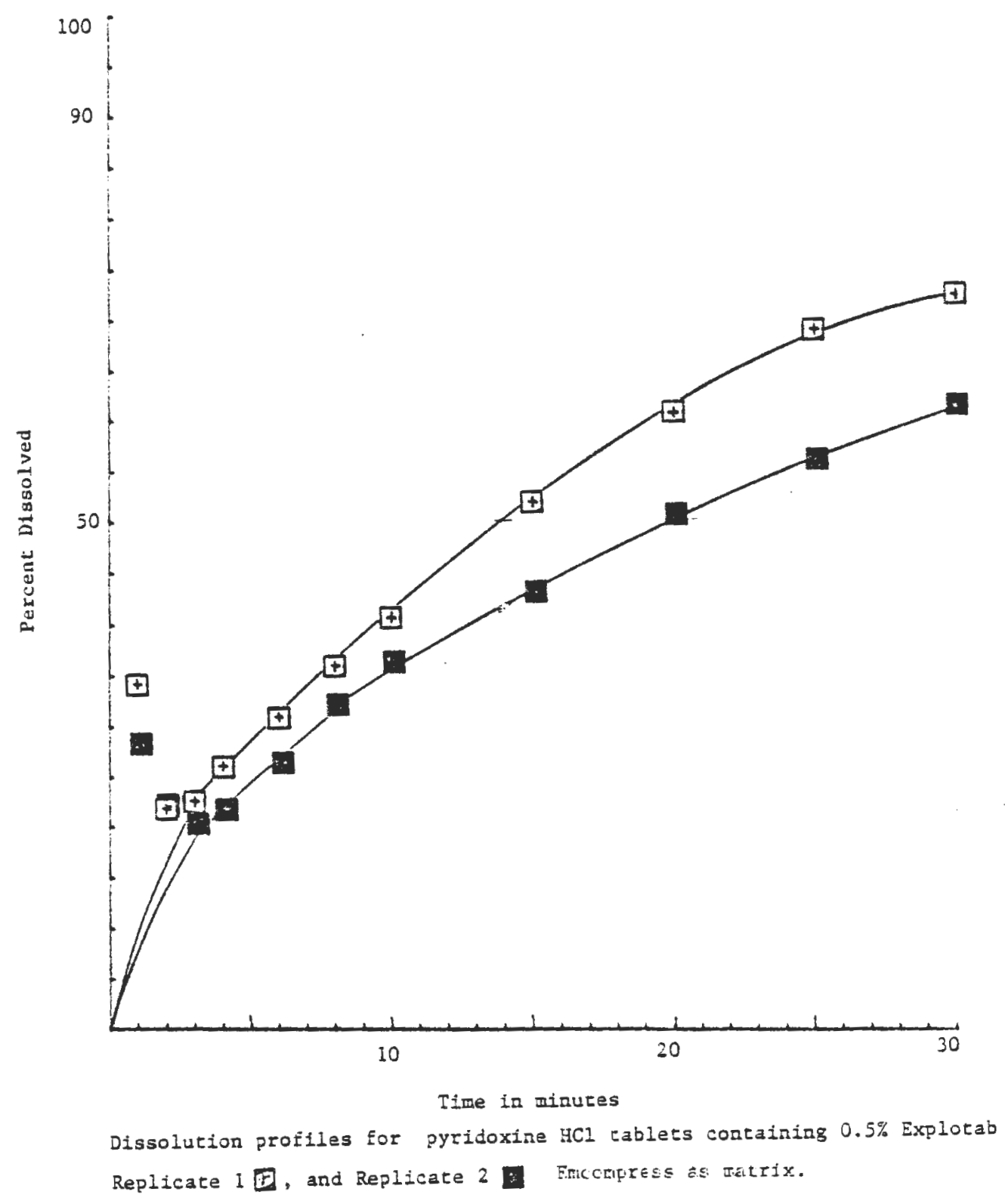

Fig. 44 


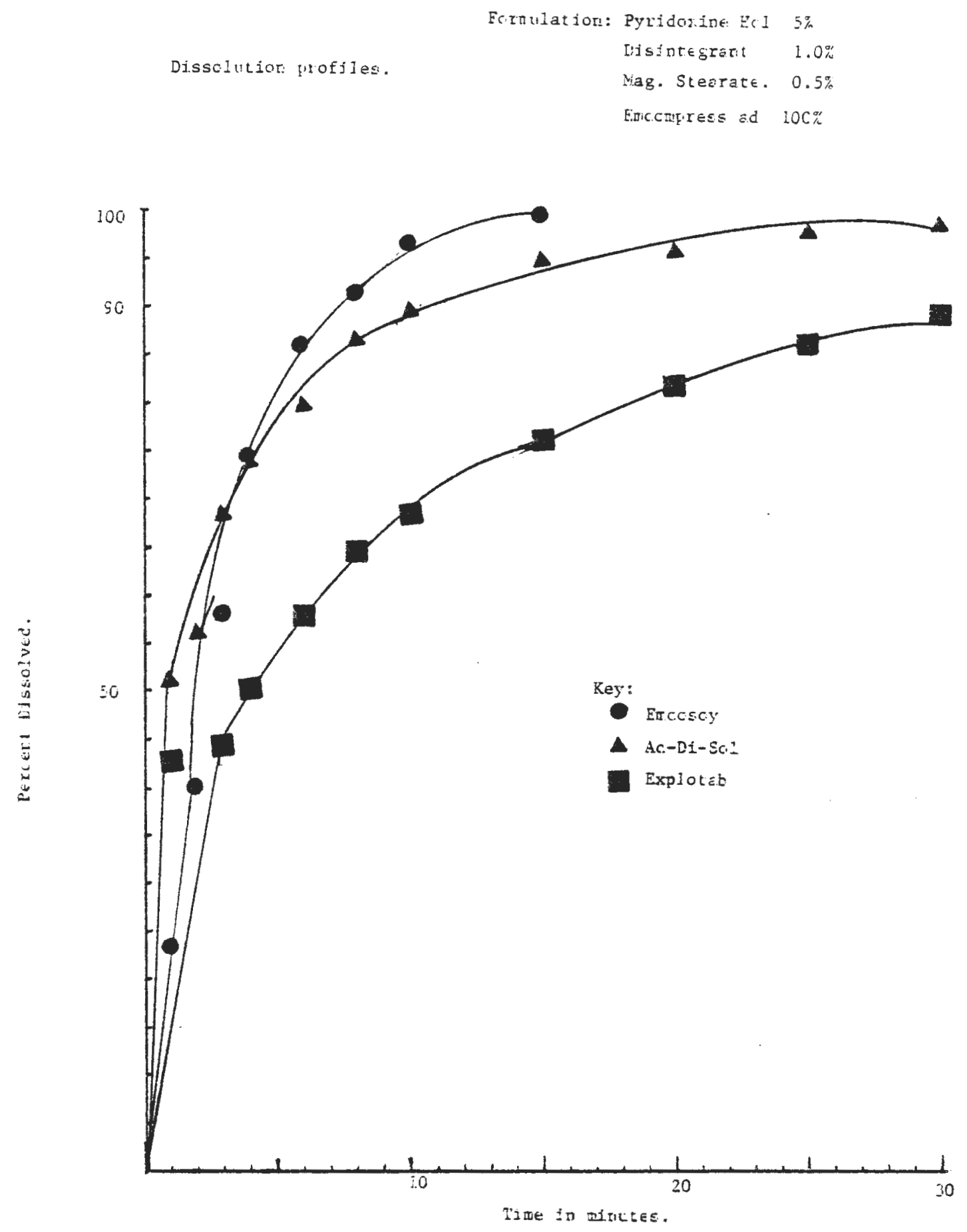

Fig. 45 


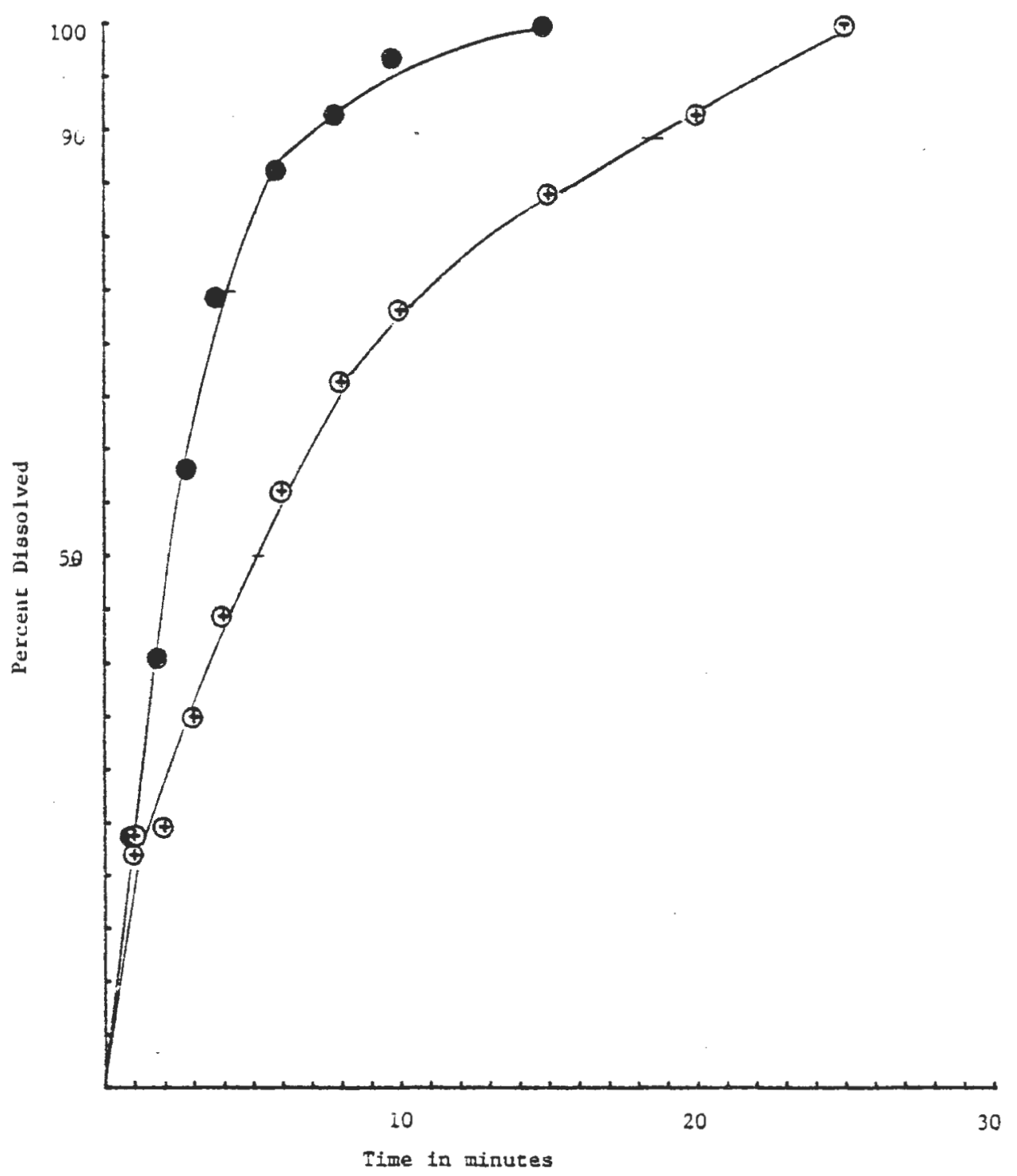

Dissolution profiles for pyridoxine $\mathrm{HCl}$ tablets concaining $1 \%$ Emcosoy Replicate $1 \oplus$, and Repilcate 29 Emconpress es a metrix.

Fig. 46 


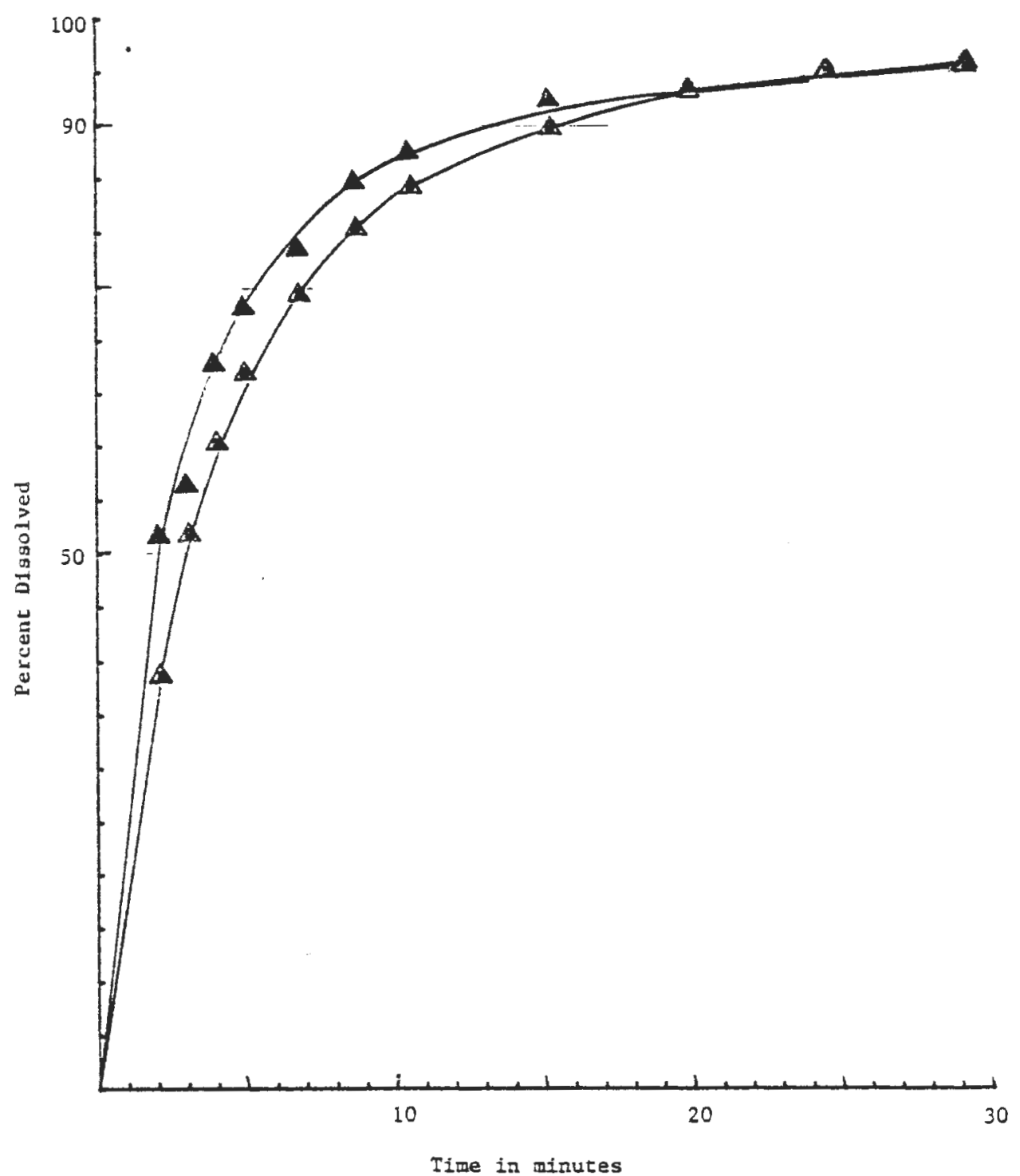

Dissolution proflles for pyridoxine aCl tablets containing If AC-D1-30I Replicate $1 \Delta$, and Replicate $2 \Delta$ Enic colfress as a Ratrix. 


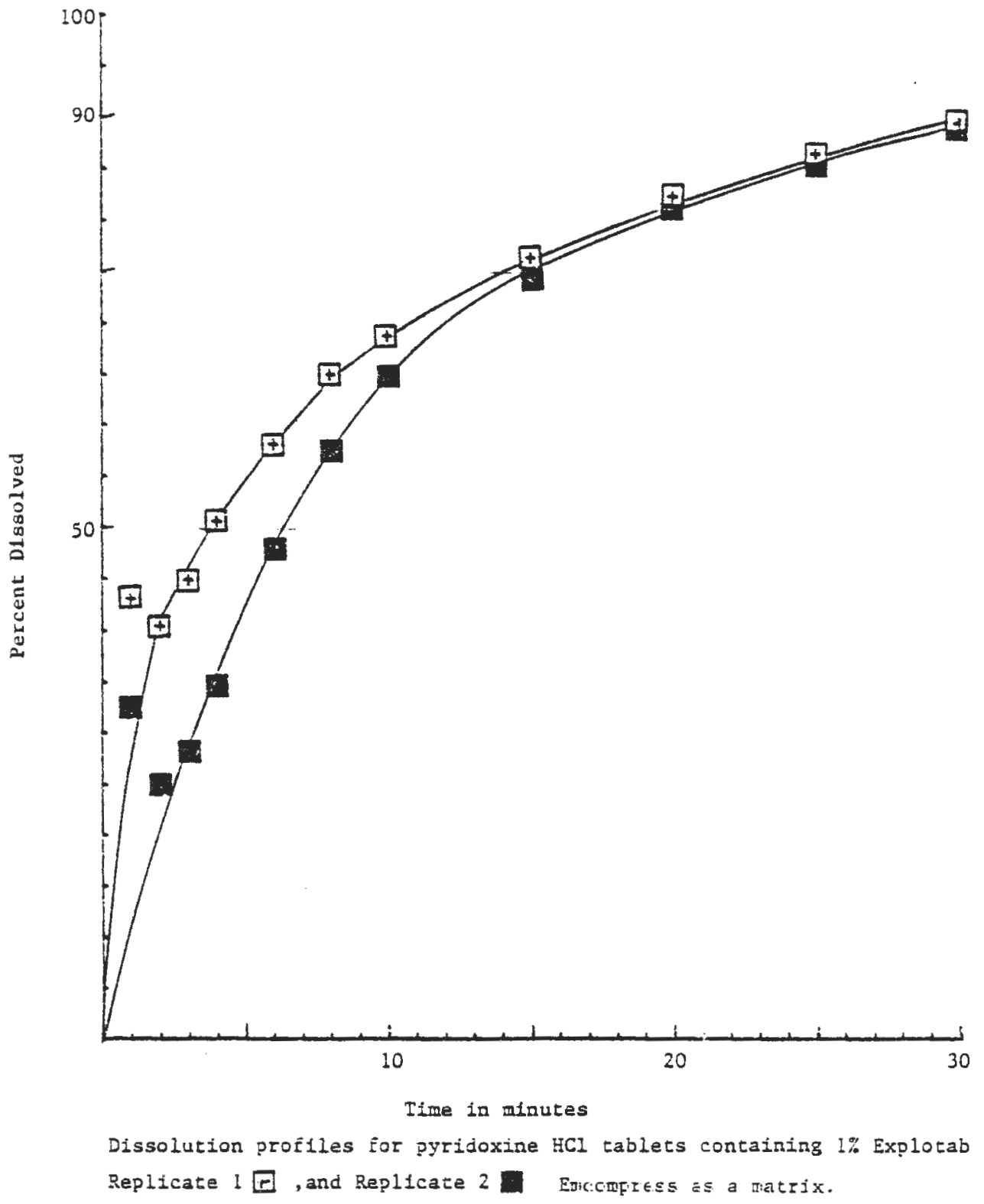

Fig. 48 
Dissciution frofiles.

Ferulatior: Fyridozine: Lel $5 \%$

Dj.sintegrart $2.0 \%$

Miig.Stezrete. $0.5 \%$

Emconteres al $100 \%$

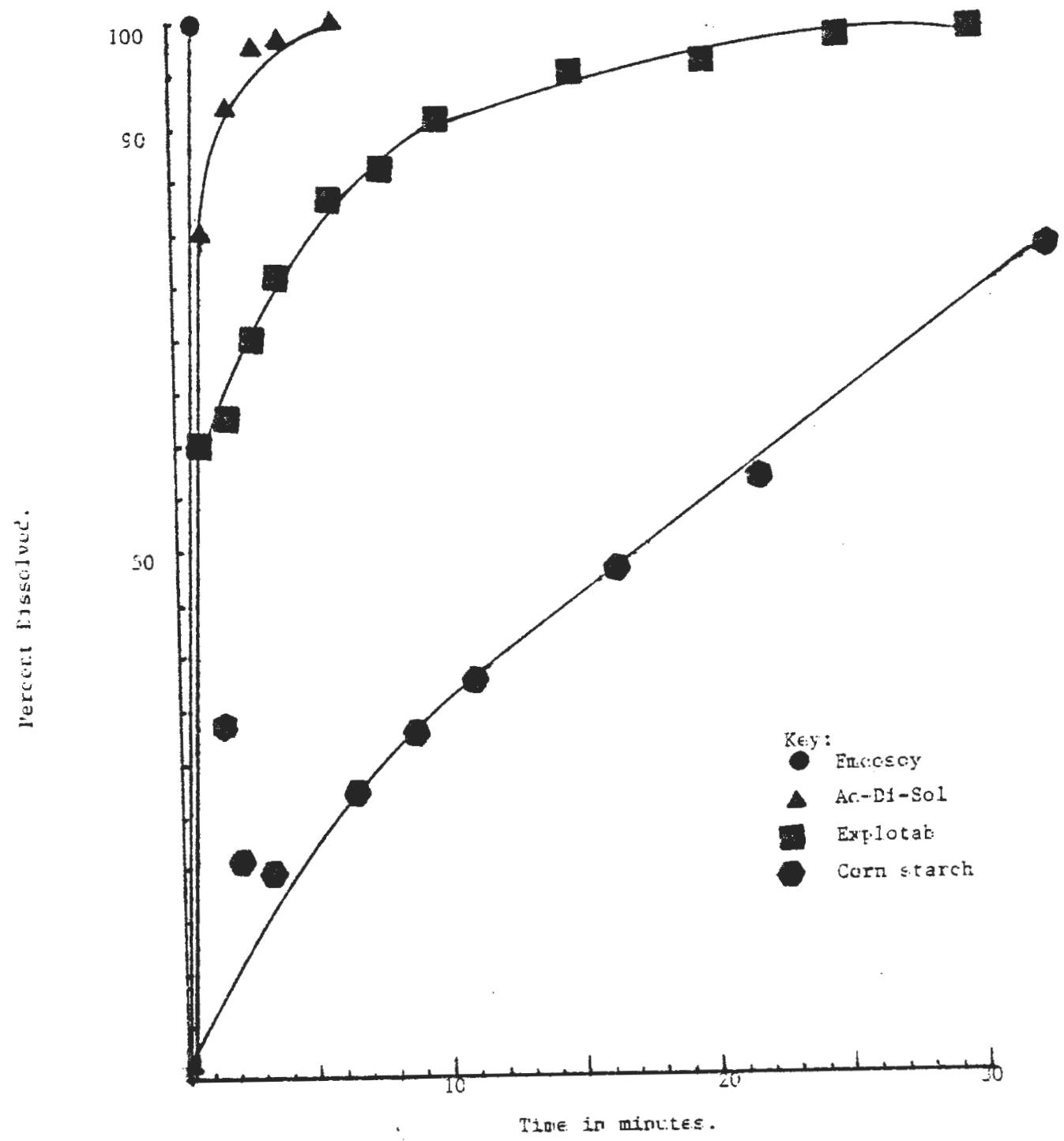

Fig, 49 


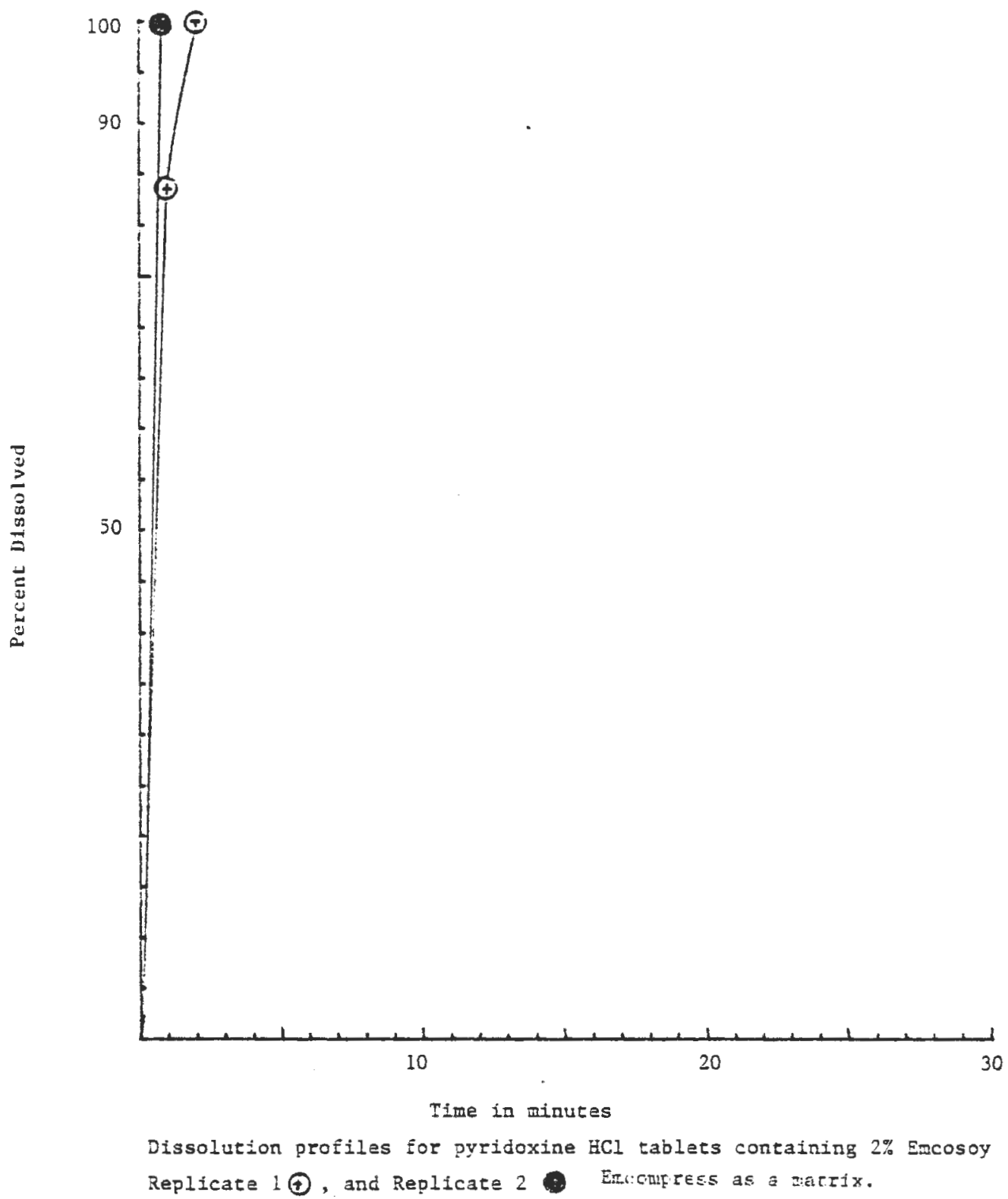

Fig. 50 


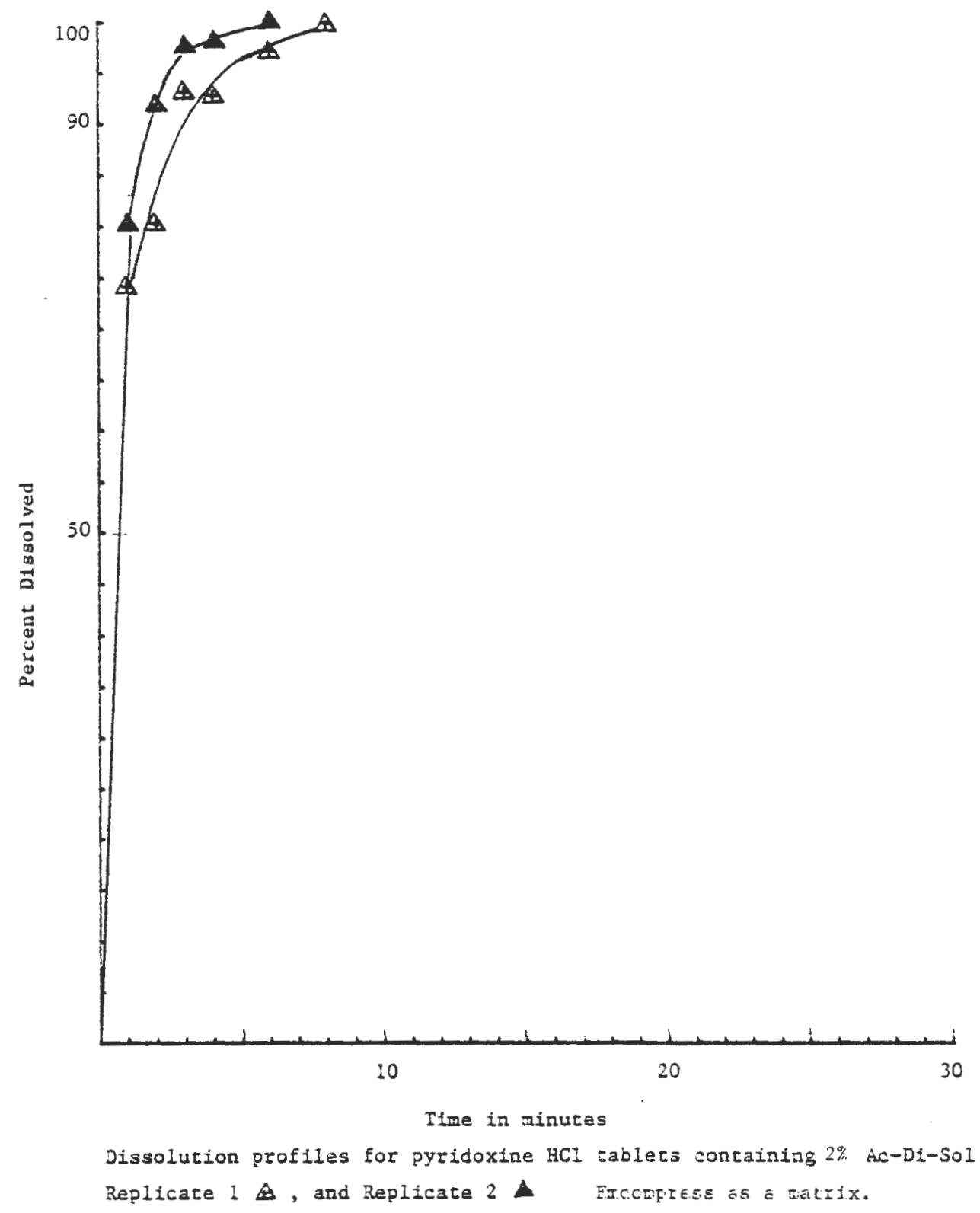

Fig. 51 


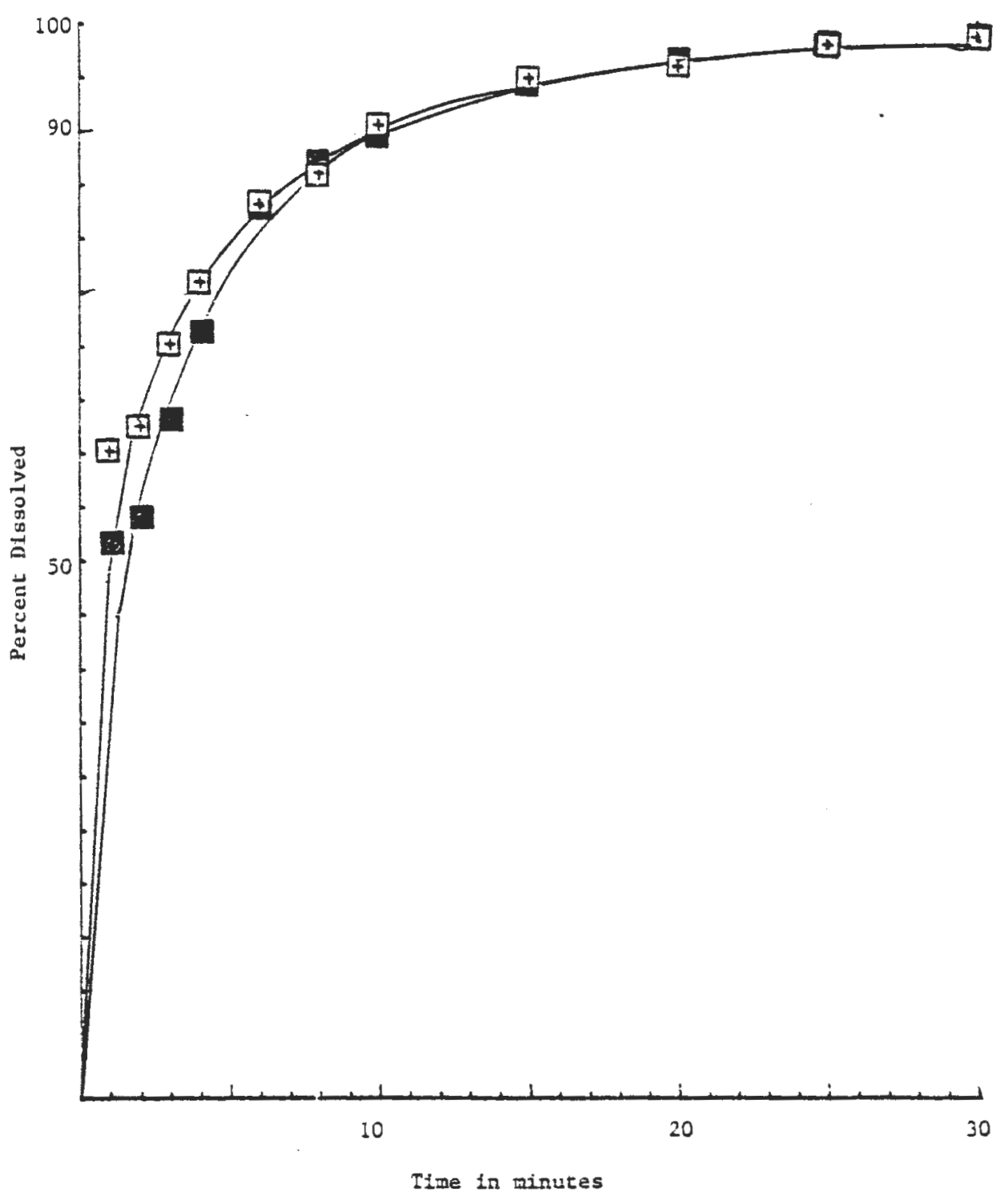

Dissolution profiles for pyridoxine HCI tablets containing 2\% Explotab Replicate $1 巴$, and Replicate 29 Emcodferess es átrix.

Fig. 52 
TABLE XXXVI

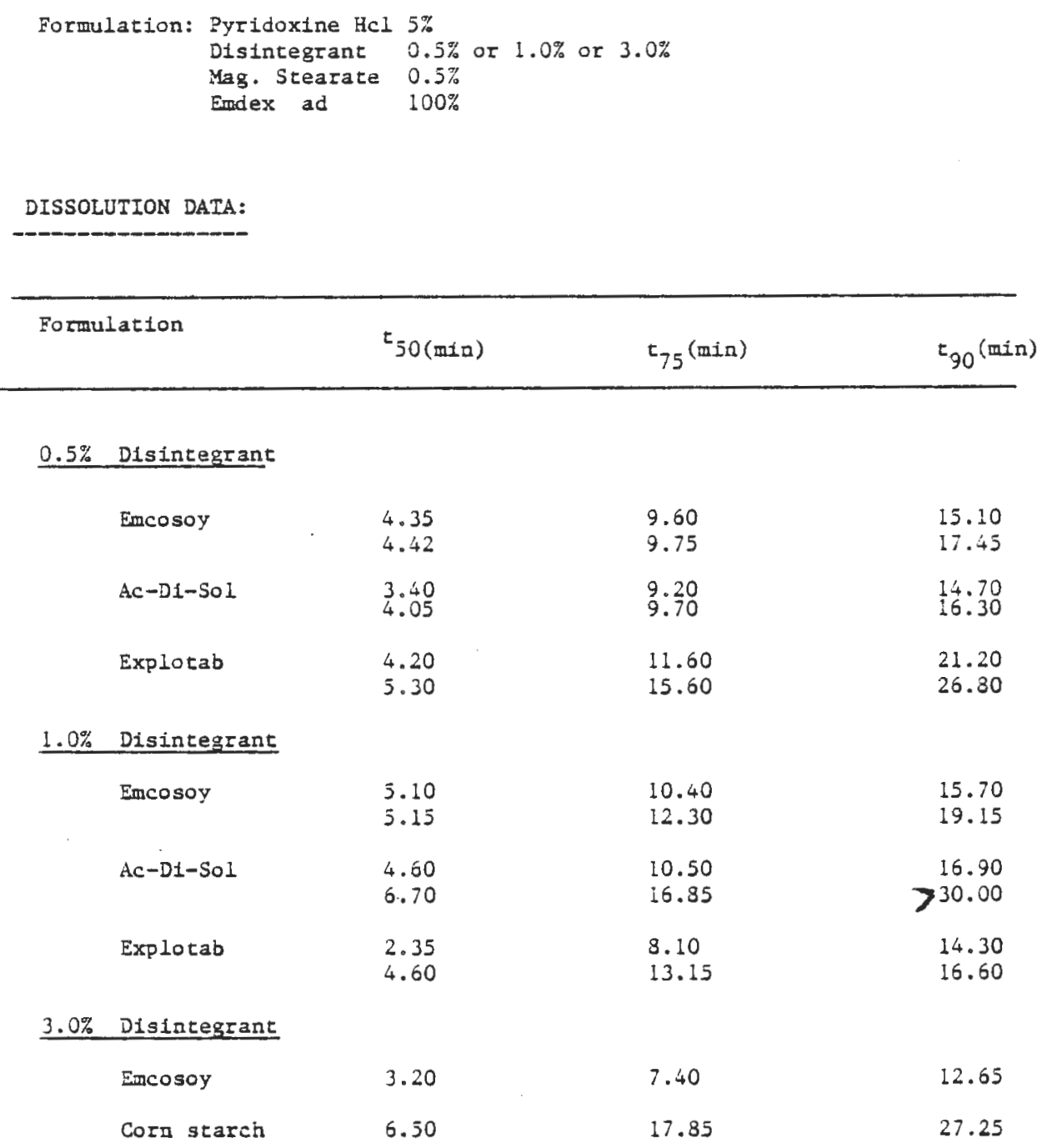


Dissolution profiles.

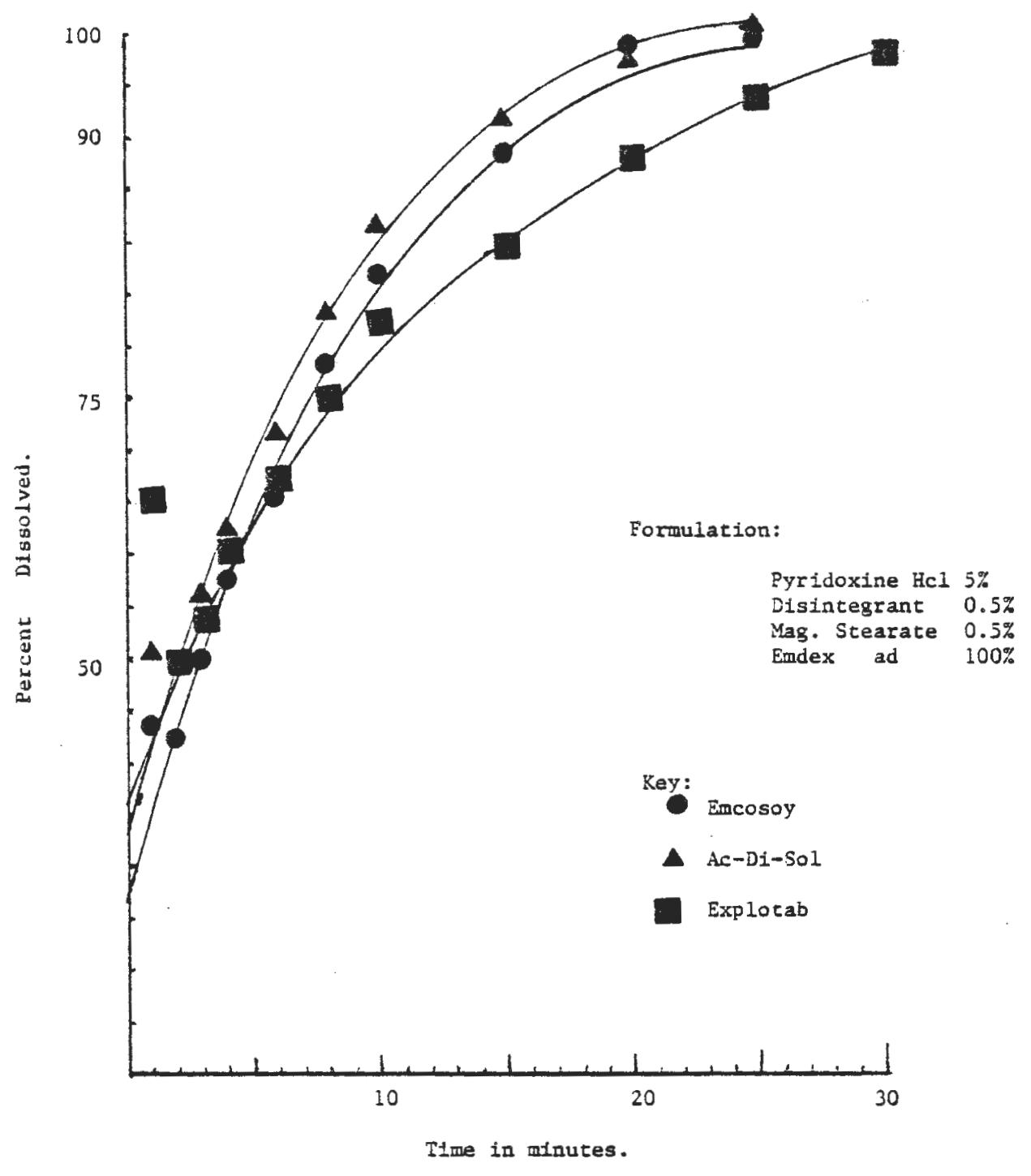

Fig. 53 


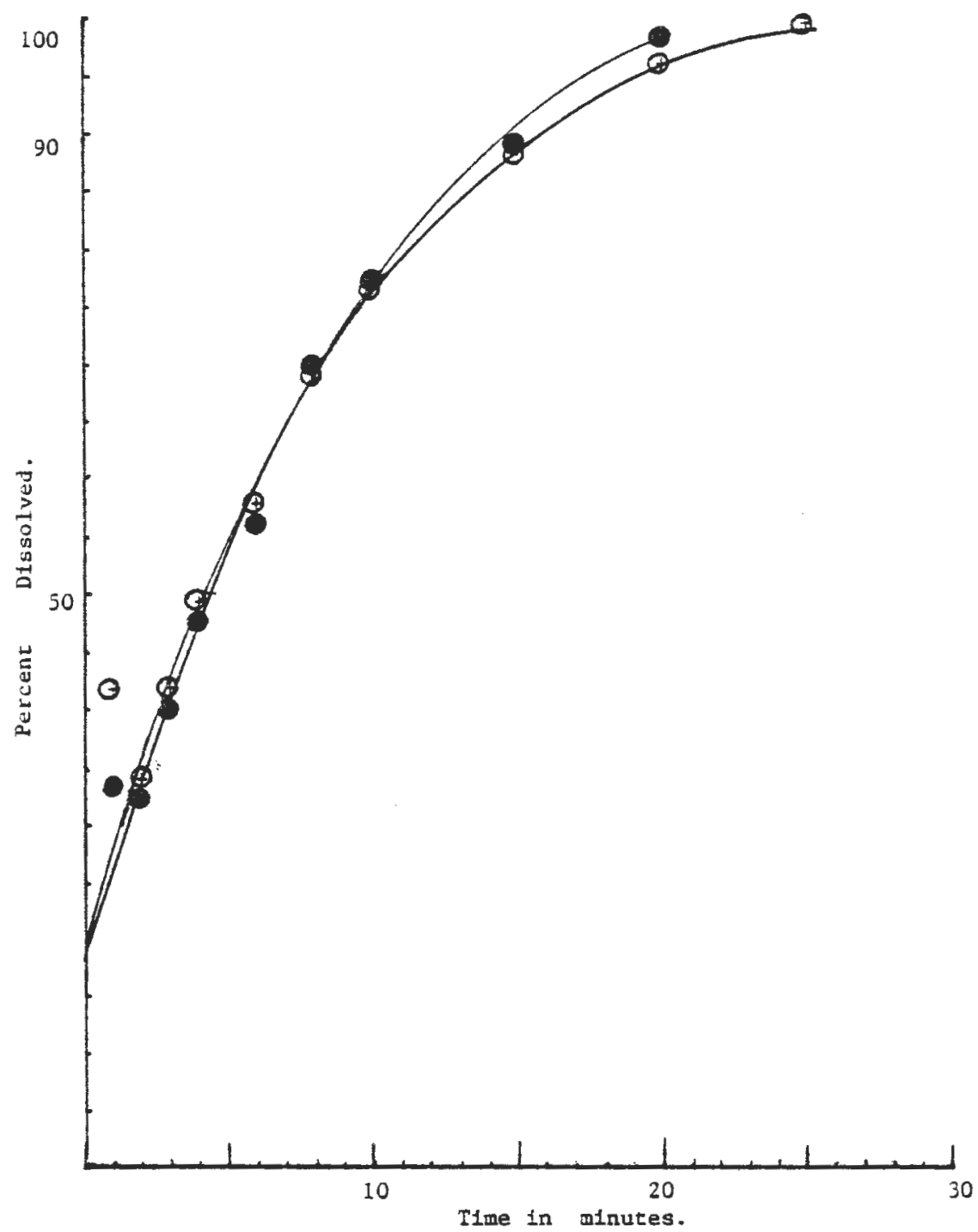

Dissolution profile of pyridoxine formulation concaining $0.5 \%$ of Emcosoy Replicate 10 , Replicate. 20 Emdex as a Jatrix. 


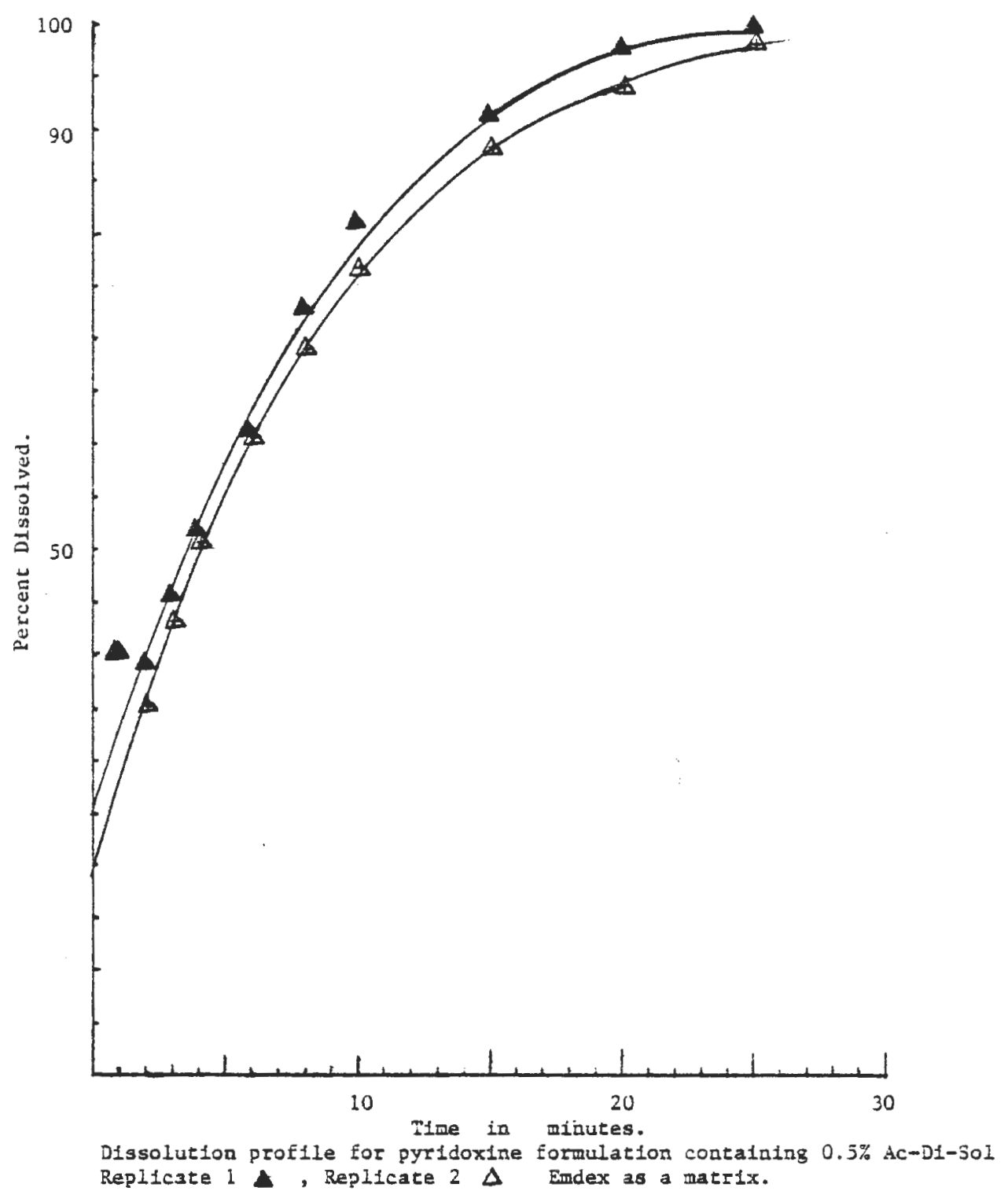

Fig. 55 


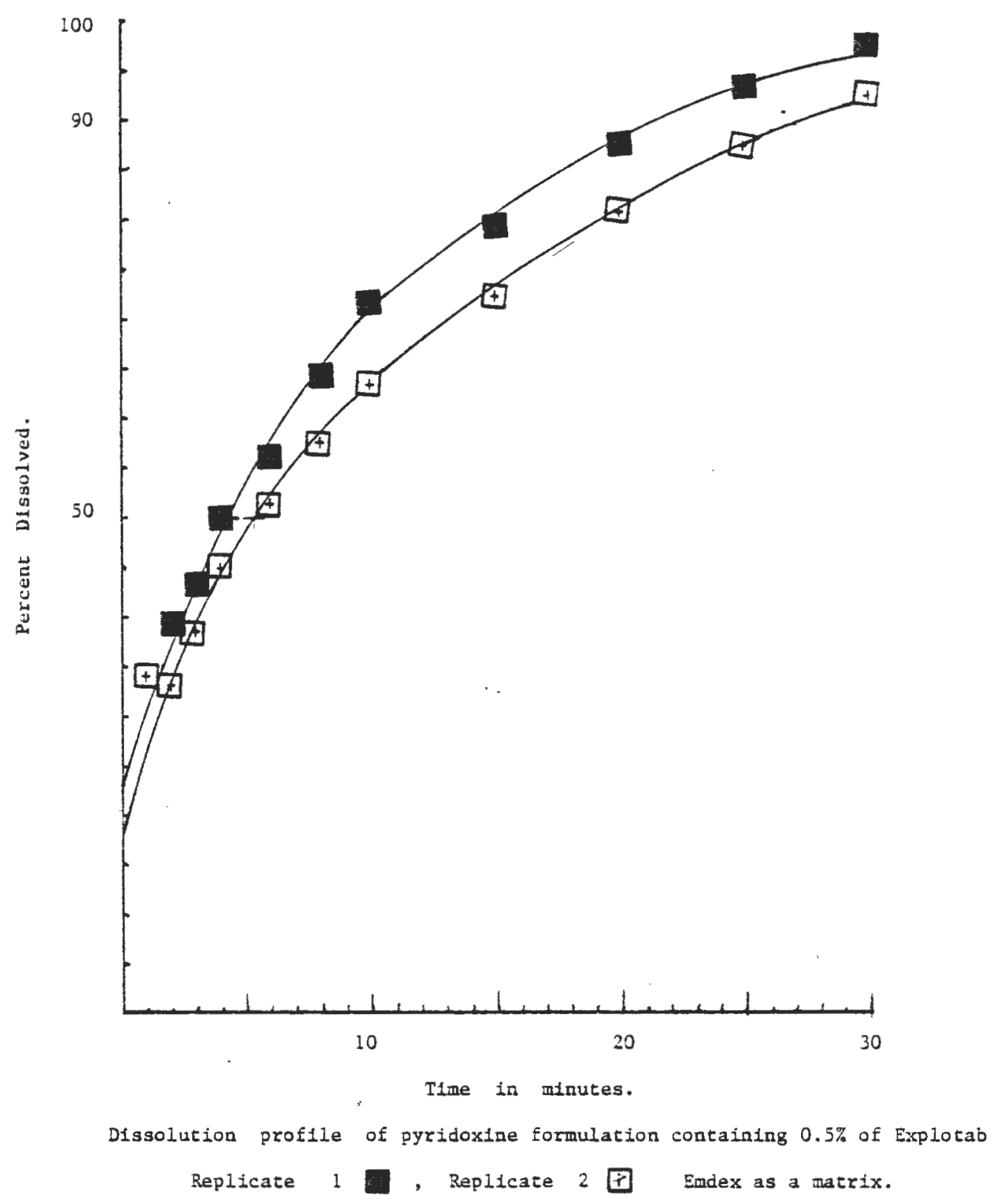

Fig. 56 
Dissolution Proftles.

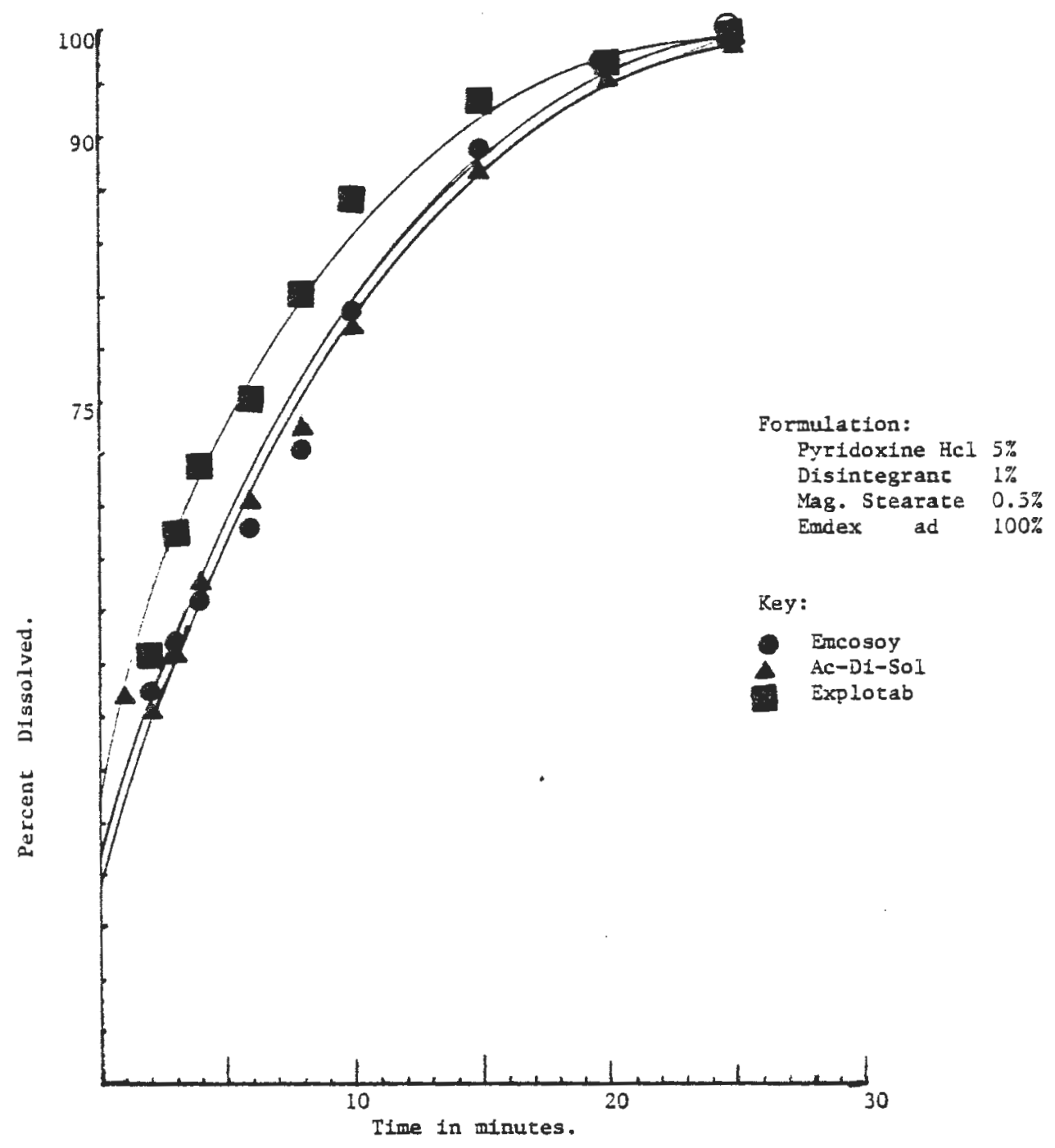

Fig. 57 


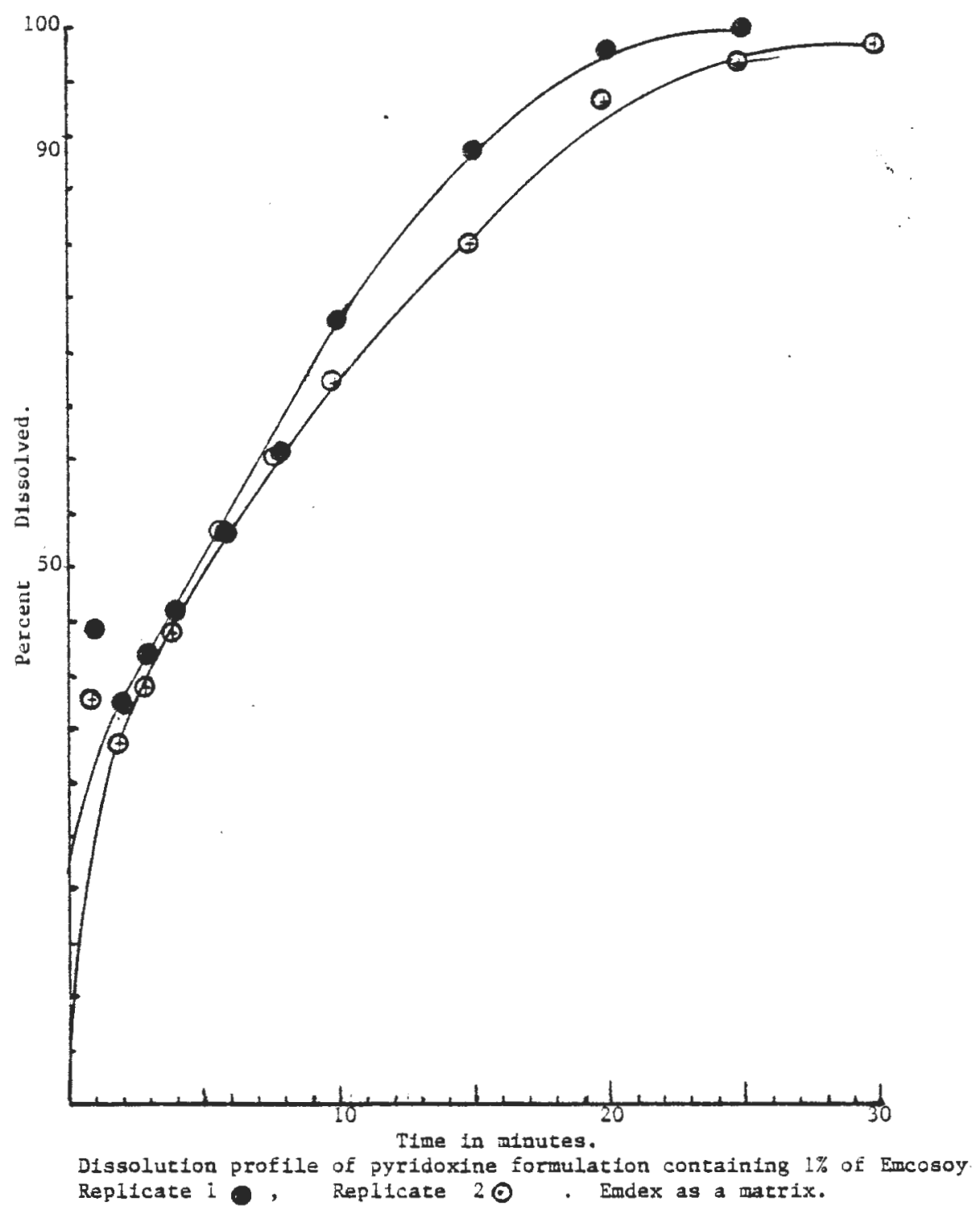

Fig. 58 


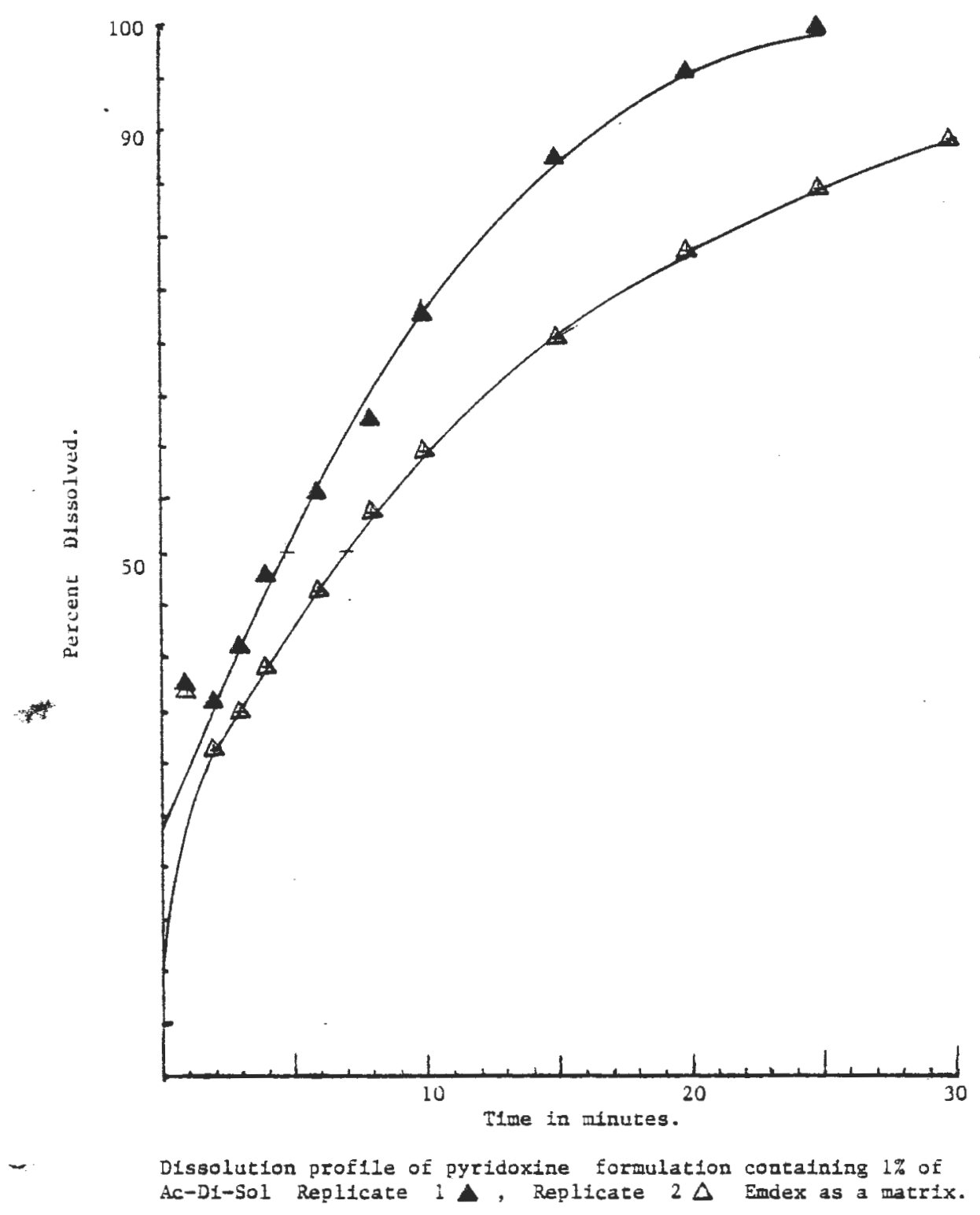

Fig. 59 


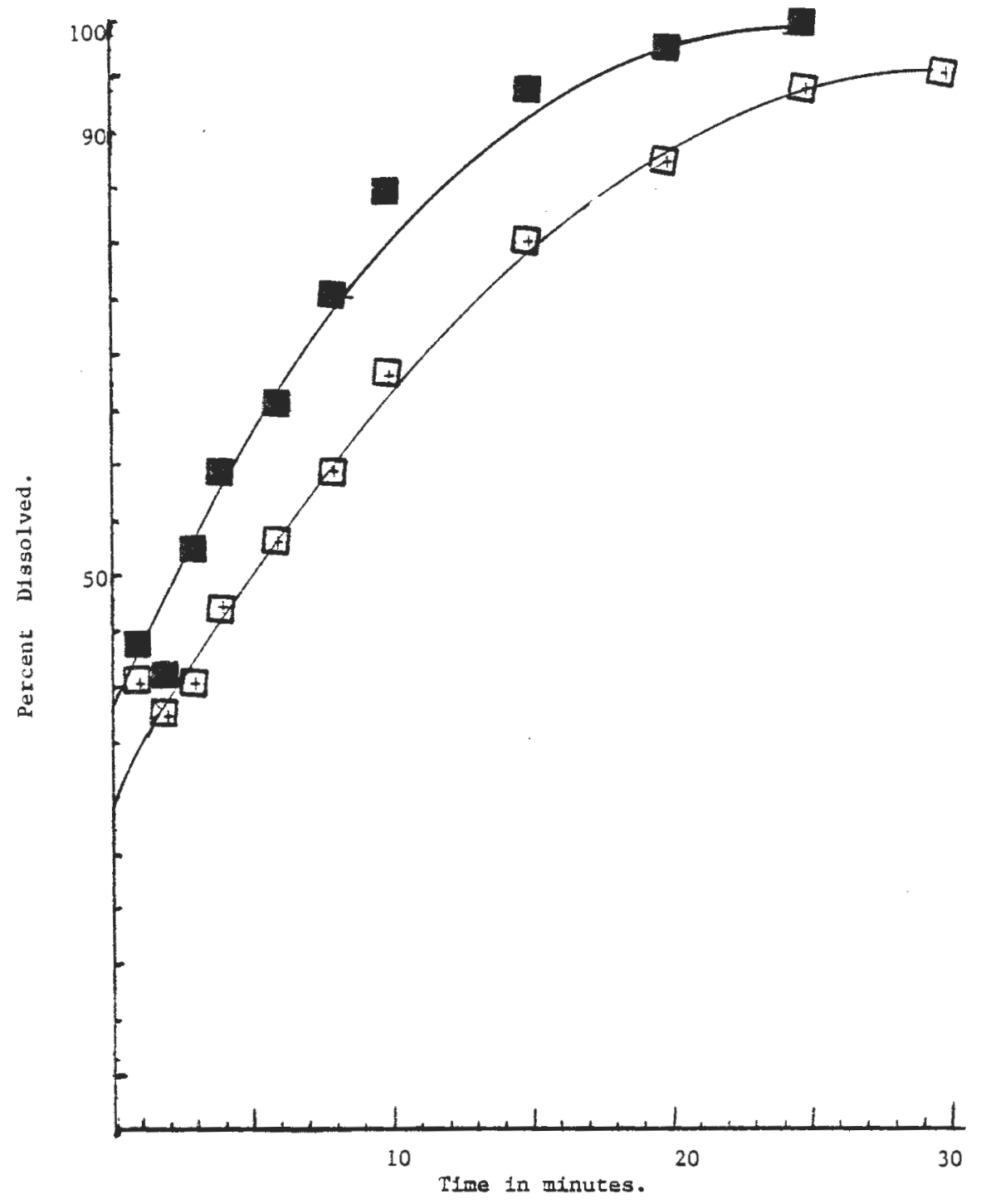

Dissolution profile for pyridoxine formulation containfing $1 \%$ of Explotab Replicate 1 , Replicate 2 Emdex as a matrix.

Fig. 60 
Dissolution profiles.

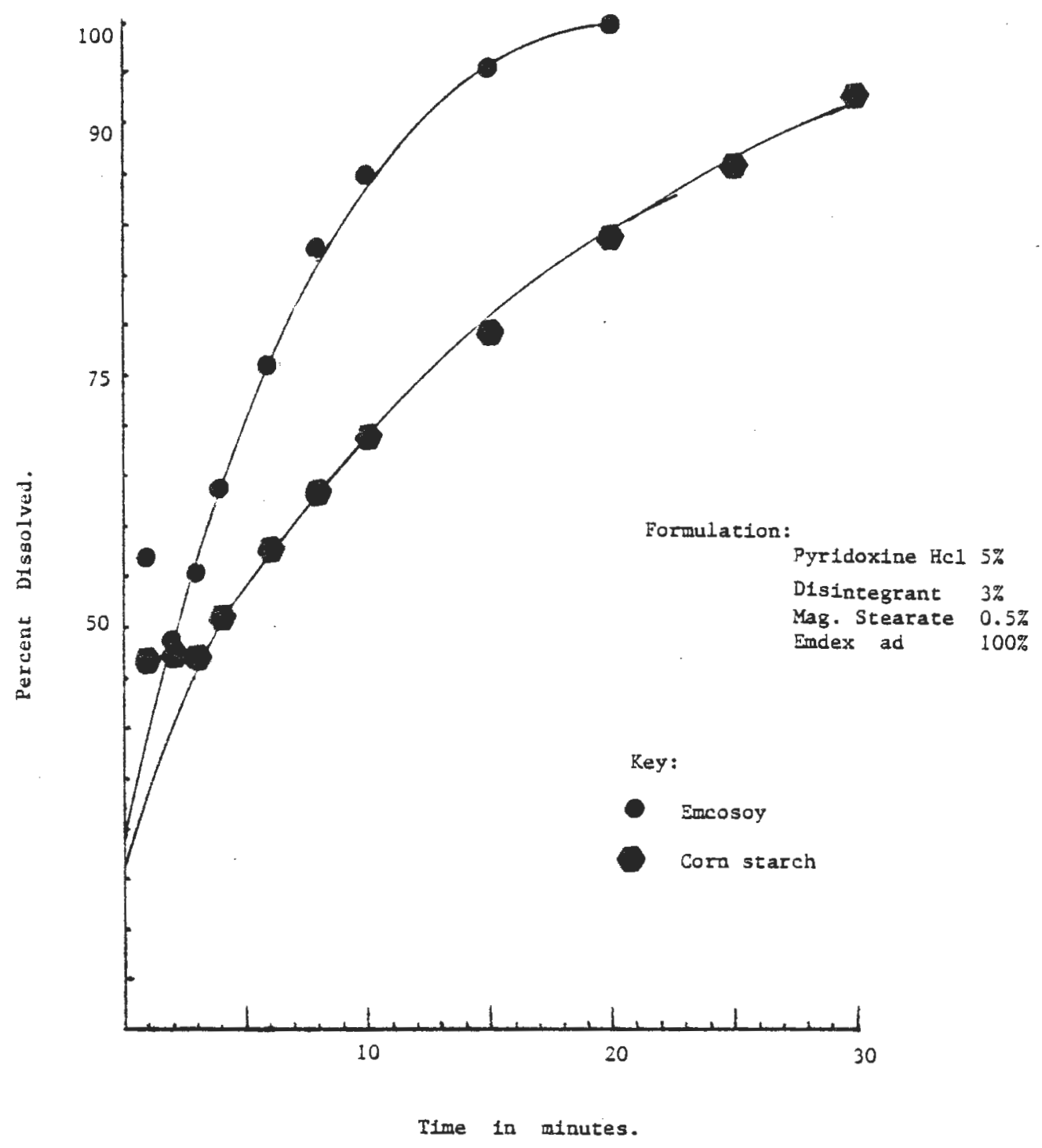

Fig. 61 


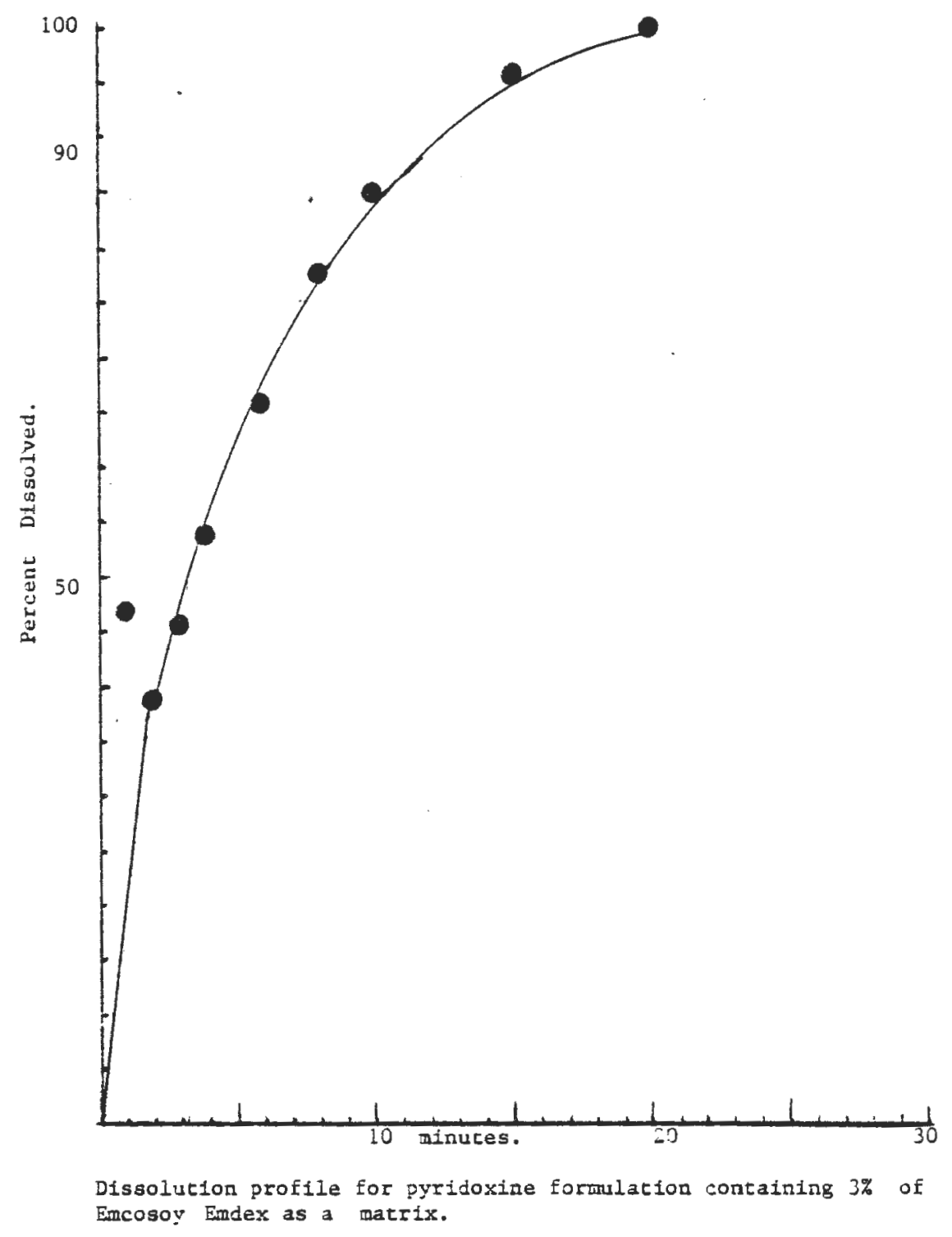

Fig. 62 


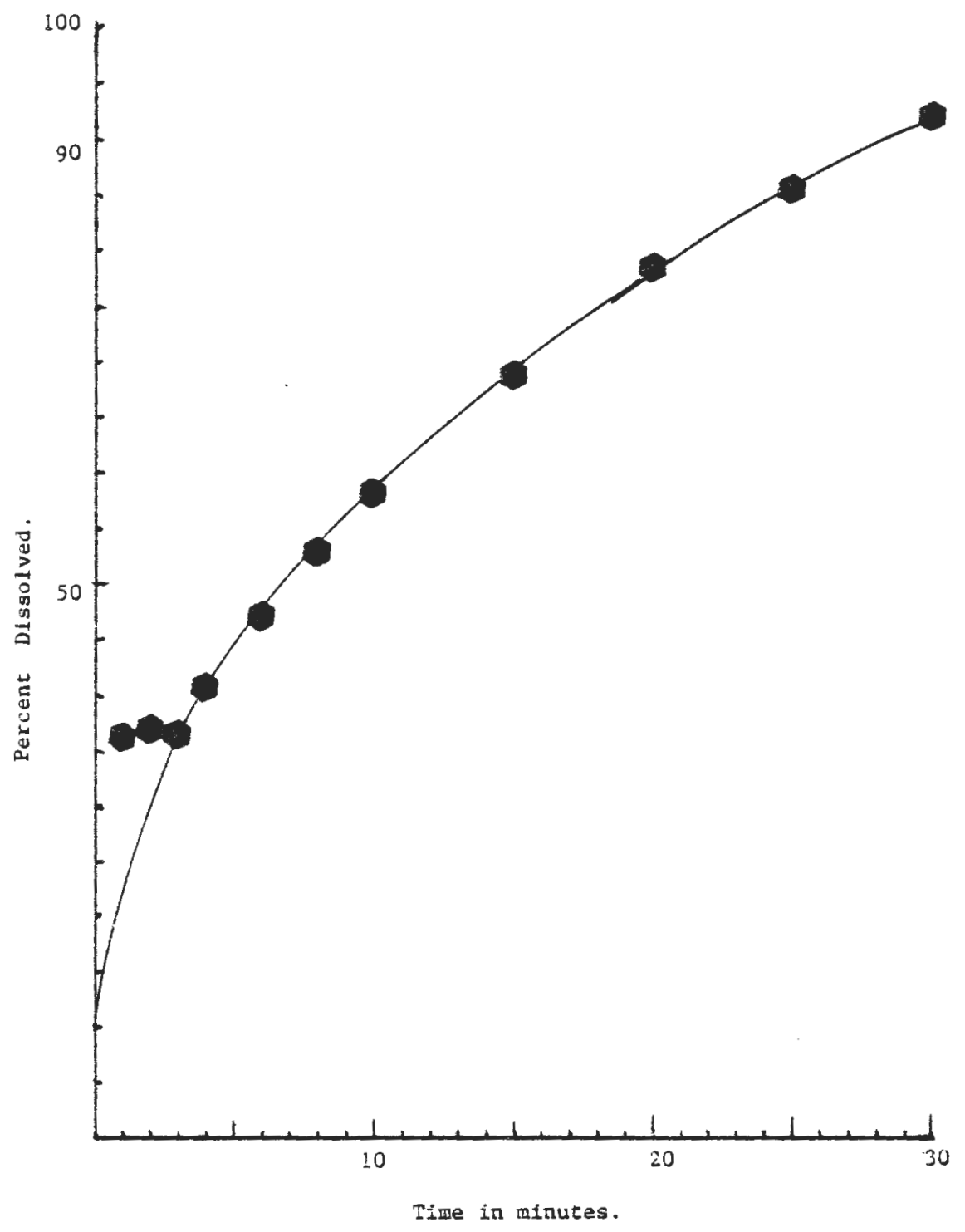

Dissolution proíle for Pyridoxine formulation containing $3 \%$ of Corn starch. Endex as a matrix.

Fig. 63 
TABLE XYVII

Fortulation: Ascorbic acid $25 \%$

Disfutegrant $0.5 \%, 1 \%, 2 \%$ or $3 \%$

steartc acid $2.5 \%$

Emcompress ad 100\%

DISSOLITION DETA :

\begin{tabular}{|c|c|c|c|}
\hline Formulation & t50 (min) & 57 (min) & $t_{90(m i n)}$ \\
\hline \multicolumn{4}{|l|}{$0.5 \%$ Disintegrant } \\
\hline Emcosoy & $\begin{array}{l}2.20 \\
2.50\end{array}$ & $\begin{array}{l}3.20 \\
3.70\end{array}$ & $\begin{array}{l}4.05 \\
5.60\end{array}$ \\
\hline Ac-Di-Sol & $\begin{array}{l}1.20 \\
1.35\end{array}$ & $\begin{array}{l}1.60 \\
1.95\end{array}$ & $\begin{array}{l}2.40 \\
2.35\end{array}$ \\
\hline \multicolumn{4}{|l|}{$1.0 \%$ Disintegrant } \\
\hline Emcosoy & $\begin{array}{l}0.60 \\
1.05\end{array}$ & $\begin{array}{l}0.84 \\
1.50\end{array}$ & $\begin{array}{l}1.80 \\
1.80\end{array}$ \\
\hline$A c-D i-S o 1$ & $\begin{array}{l}0.85 \\
0.85\end{array}$ & $\begin{array}{l}1.30 \\
1.30\end{array}$ & $\begin{array}{l}2.20 \\
2.20\end{array}$ \\
\hline Explotab & $\begin{array}{l}2.25 \\
2.45\end{array}$ & $\begin{array}{l}4.80 \\
5.10\end{array}$ & $\begin{array}{l}5.75 \\
6.15\end{array}$ \\
\hline \multicolumn{4}{|c|}{$2.0 \%$ Disintegrant } \\
\hline Emcosoy & $\begin{array}{l}1.30 \\
1.20\end{array}$ & $\begin{array}{l}-.00 \\
1.40\end{array}$ & $\begin{array}{l}3.20 \\
2.00\end{array}$ \\
\hline AC-Di-So1 & $\begin{array}{l}1.50 \\
1.80\end{array}$ & $\begin{array}{l}2.55 \\
2.40\end{array}$ & $\begin{array}{l}4.00 \\
2.80\end{array}$ \\
\hline Explotab & $\begin{array}{l}4.35 \\
6.00\end{array}$ & $\begin{array}{l}6.60 \\
8.30\end{array}$ & $\begin{array}{l}7.85 \\
9.60\end{array}$ \\
\hline Corn Starch & $\begin{array}{l}23.10 \\
30.00\end{array}$ & $\begin{array}{l}>30.00 \\
>30.00\end{array}$ & $\begin{array}{l}>30.00 \\
>30.00\end{array}$ \\
\hline \multicolumn{4}{|l|}{$3.0 \%$ Disintegrant } \\
\hline \multirow[t]{2}{*}{ Emcosoy } & 0.45 & 0.90 & 1.05 \\
\hline & 0.80 & 1.40 & 2.00 \\
\hline Corn starch & $\begin{array}{l}17.60 \\
18.40\end{array}$ & $\begin{array}{l}>30.00 \\
>30.00\end{array}$ & $\begin{array}{l}>30.00 \\
>30.00\end{array}$ \\
\hline
\end{tabular}

* Granulated Ascorbic acid(90\%) (Roche) used at $2.0 \%$ disintegrant level, rest fermulations contained Ascortic acid U.S.P. 


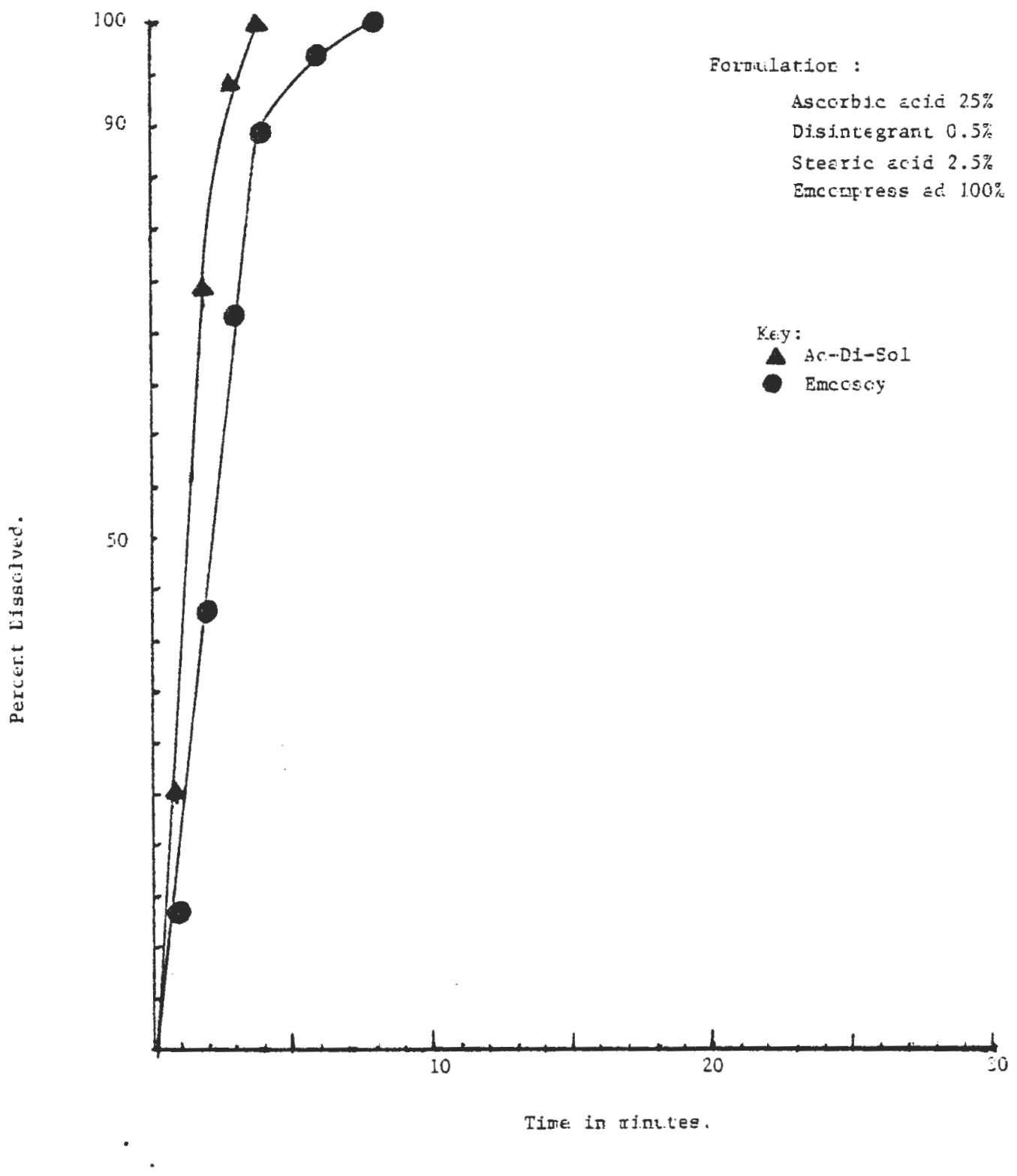

Fig. 64 


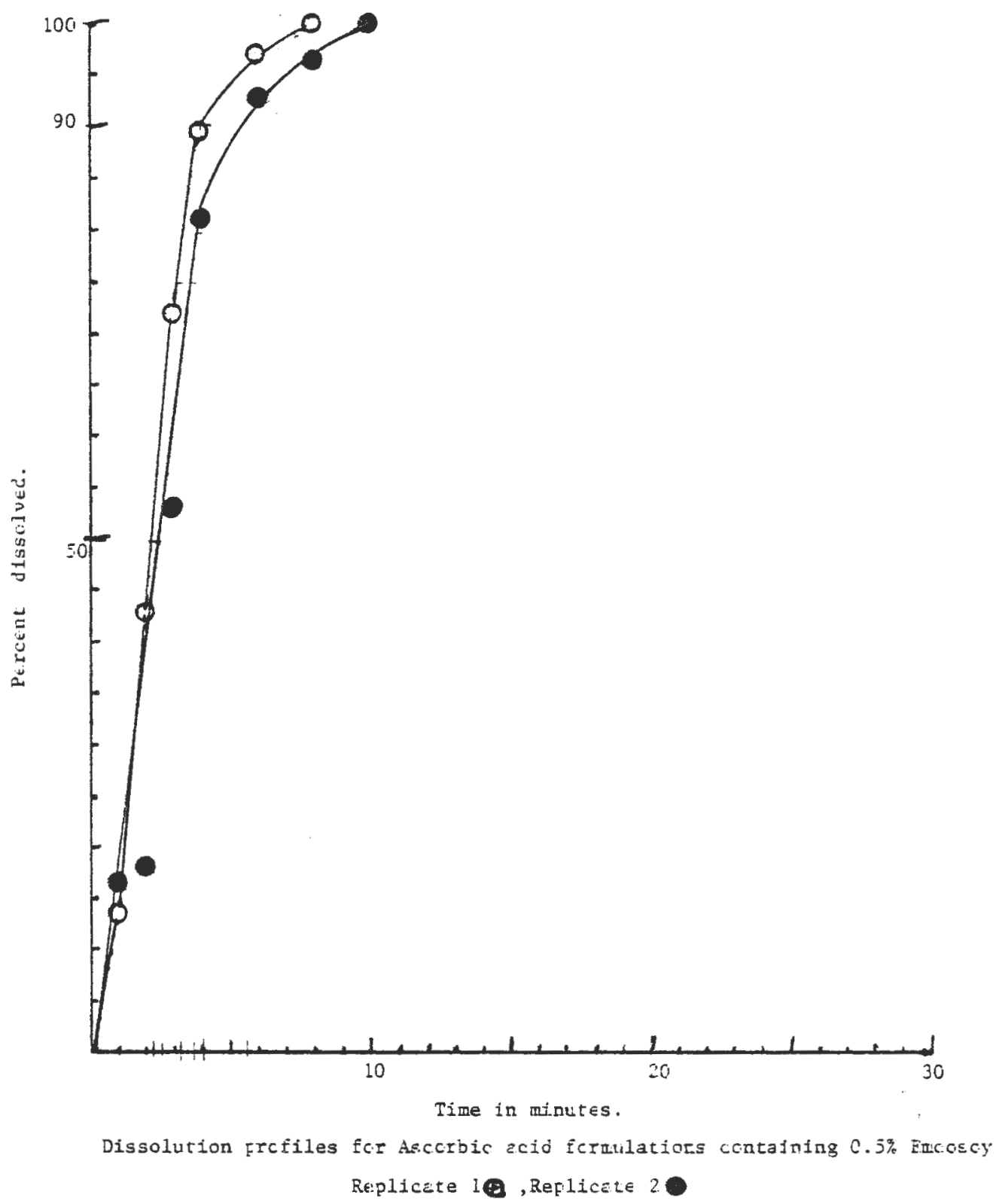

Fig. 65 


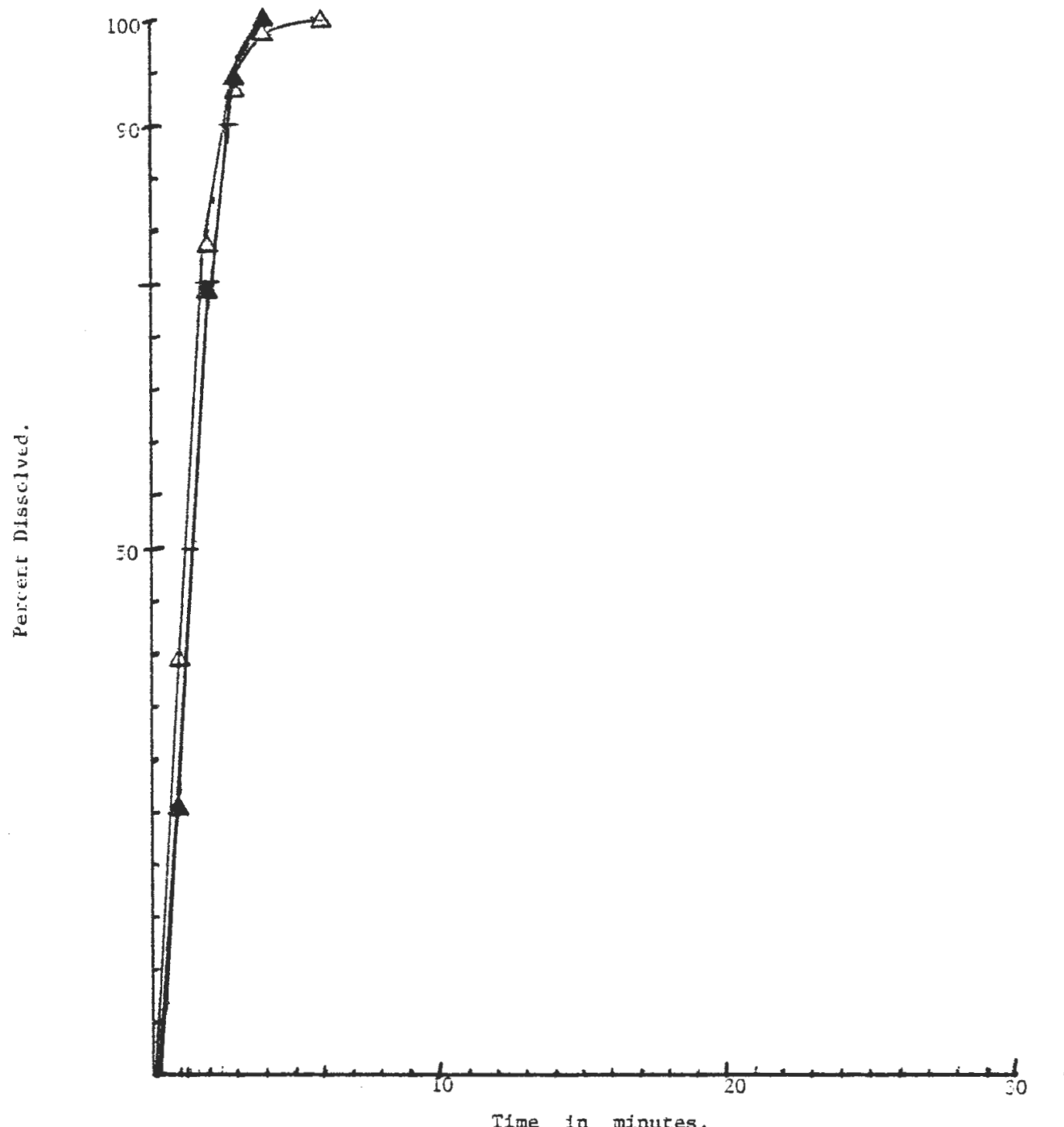

Dissolutfor profiles for Ascorbic actd formulatiors containing $0.5 \%$ Ar-DI-Eci Reflicate $1 \Delta$, Reflicete. 
Dissolution profiles.

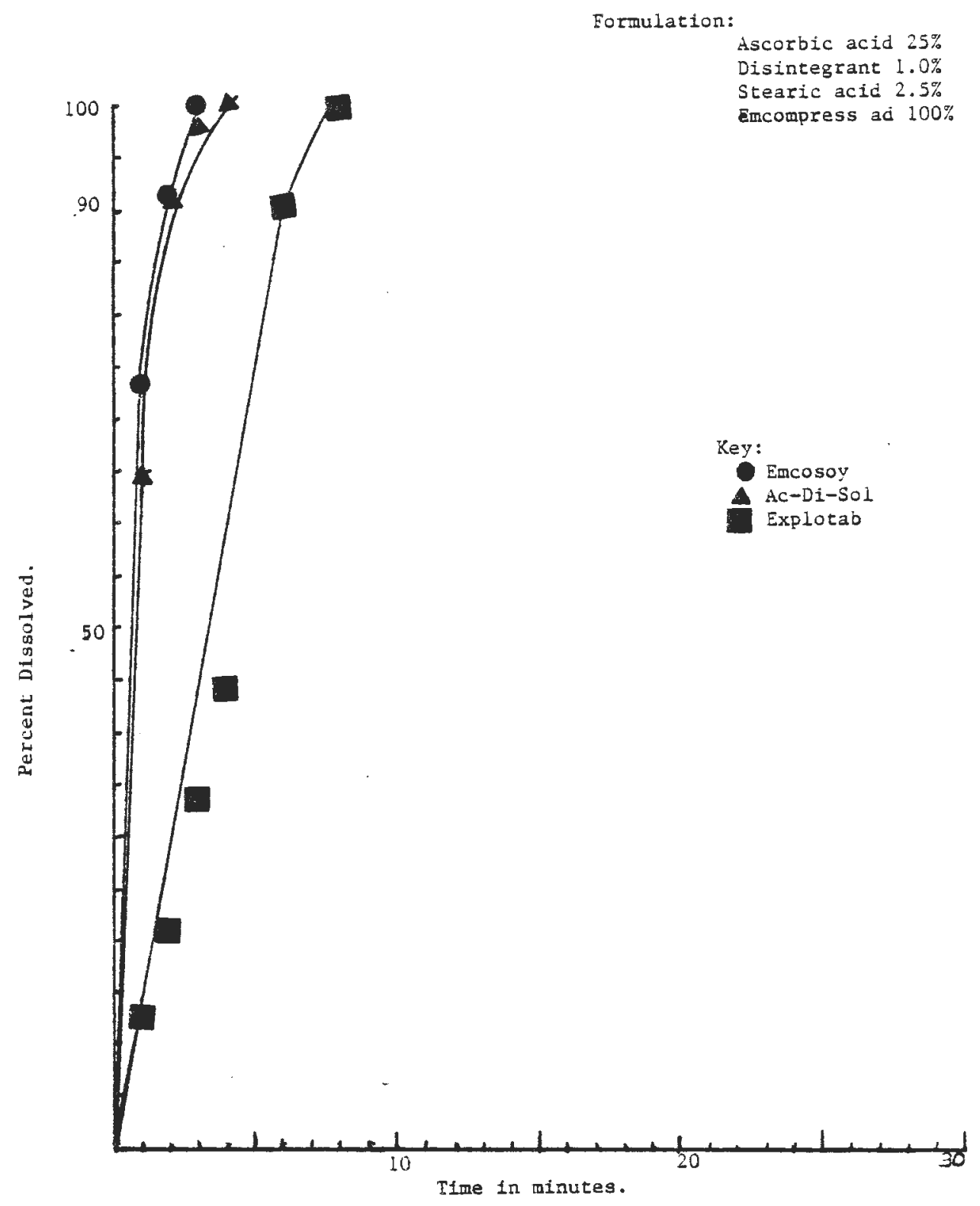

Fig. 67 


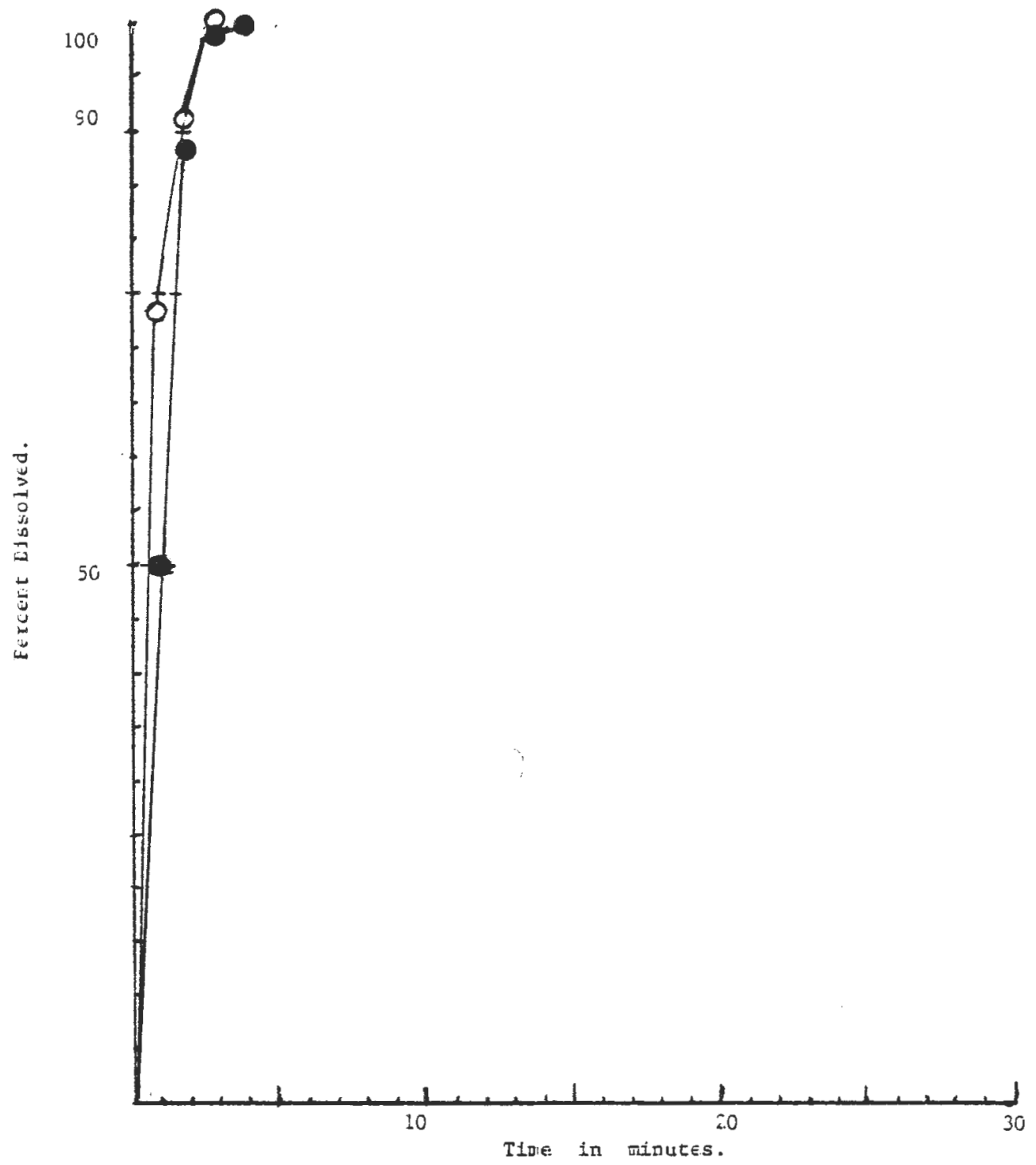

Dissolution proflles for Ascorbsc acid formulations ccrtaining 1\% Enc:csoy Repiicate 10 , Replicate 2

Fig. 68 


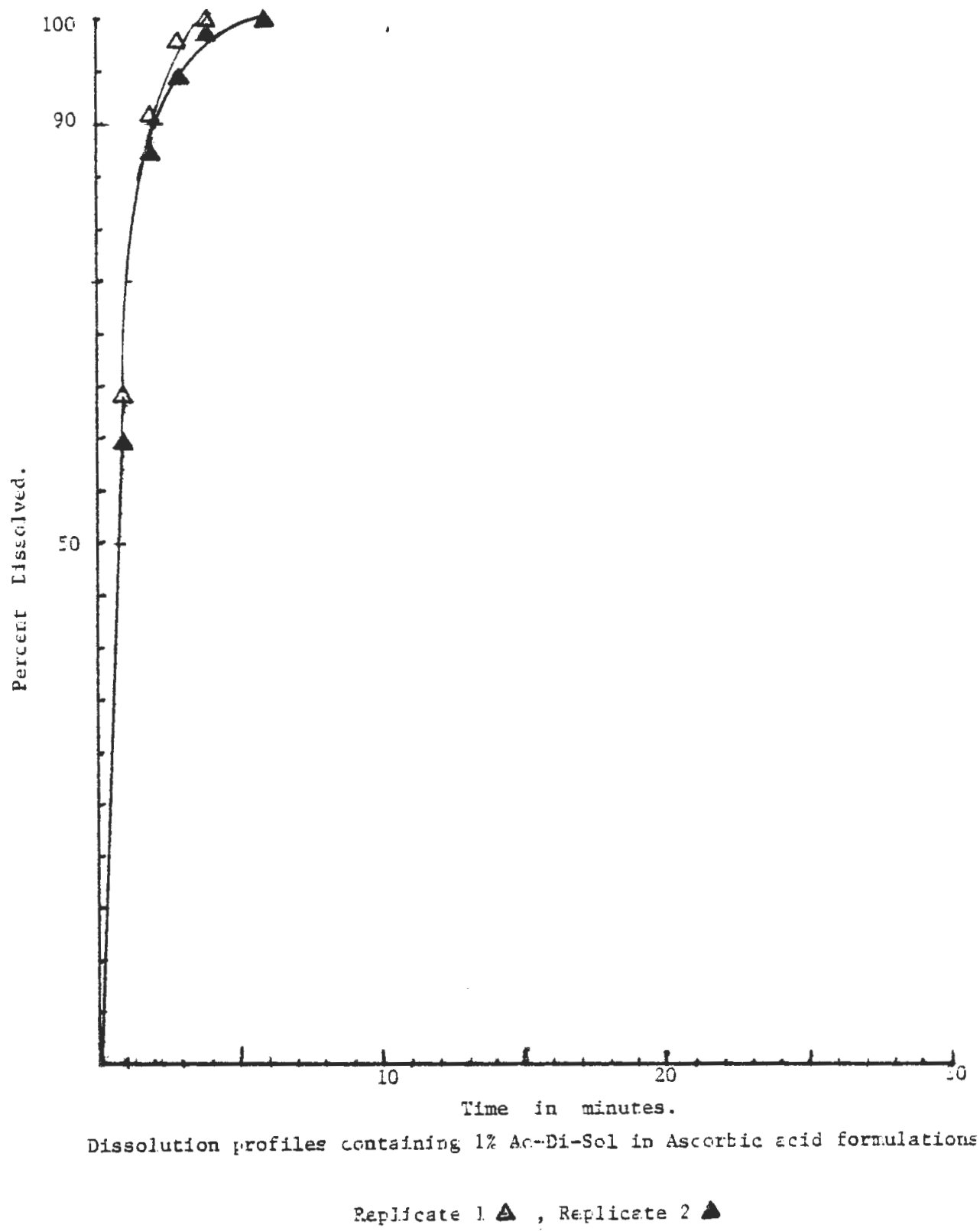

Fig. 69 


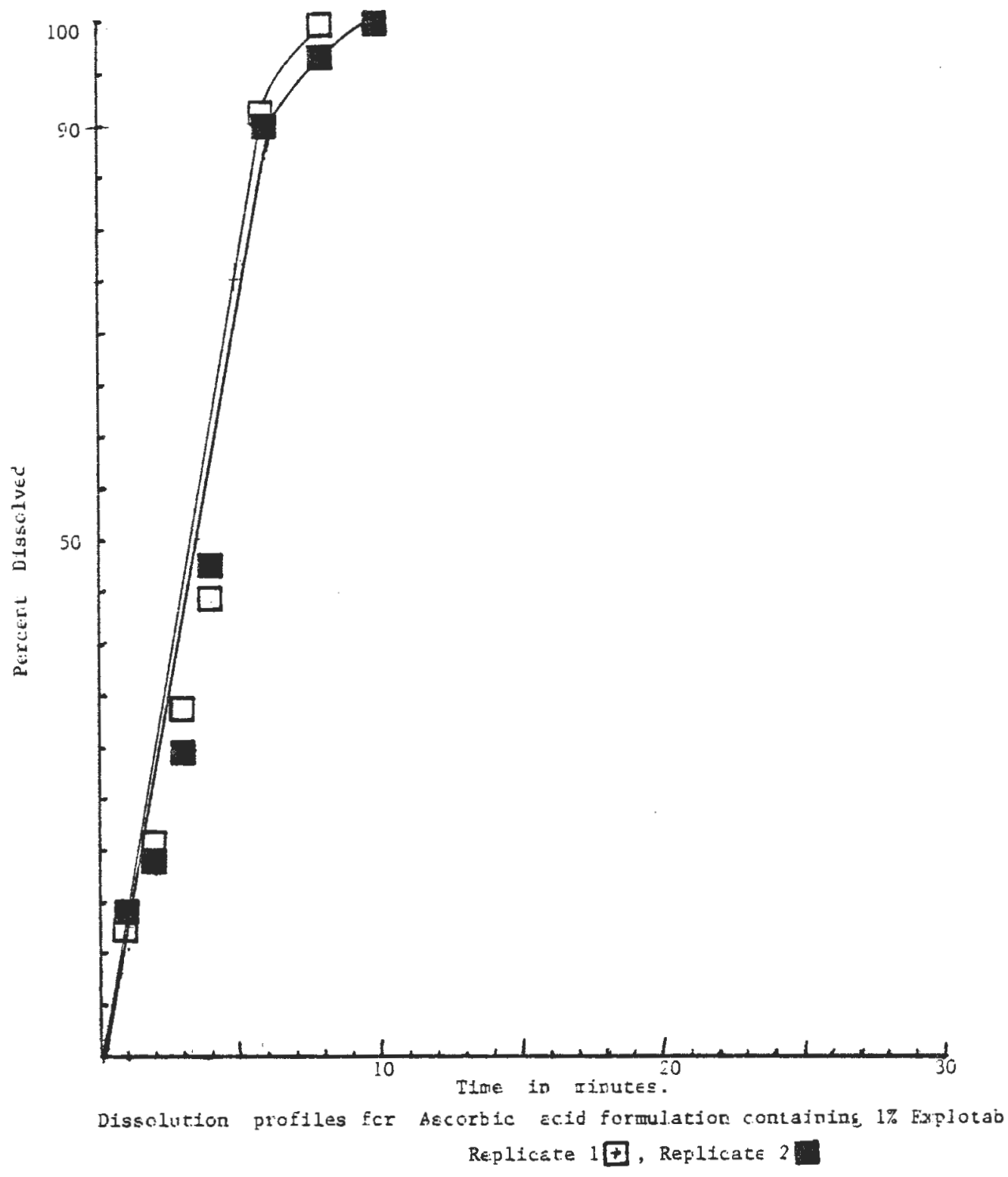

Fig. 70 
Dissclution profiles.

Asccrbic acid $25 \%$

[isjutegrant $2 \%$

steeric acid 2.5\%

Emcompress ac $1.00 \%$

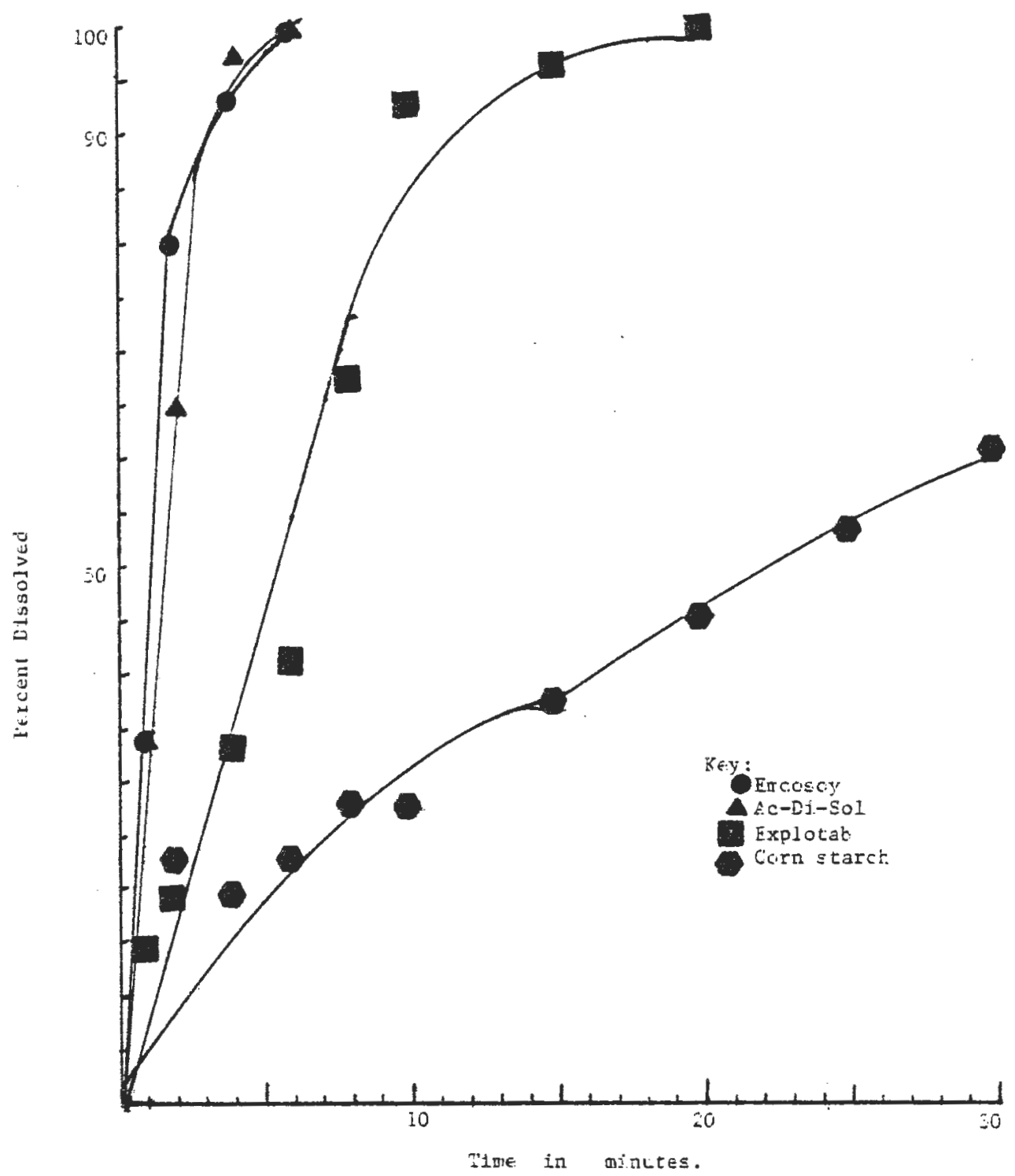

Fig. 71 
Replicate?

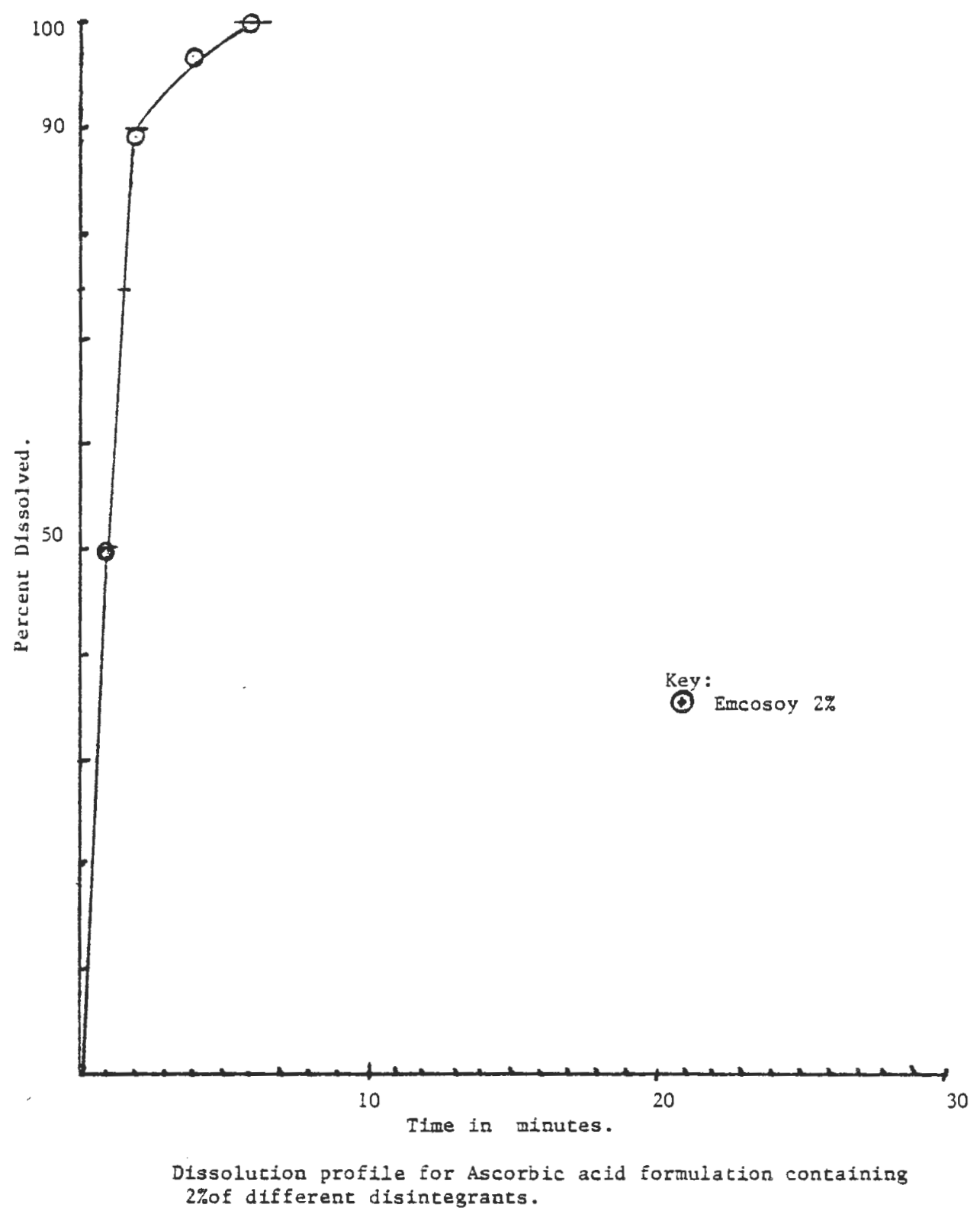

Fig. 72 


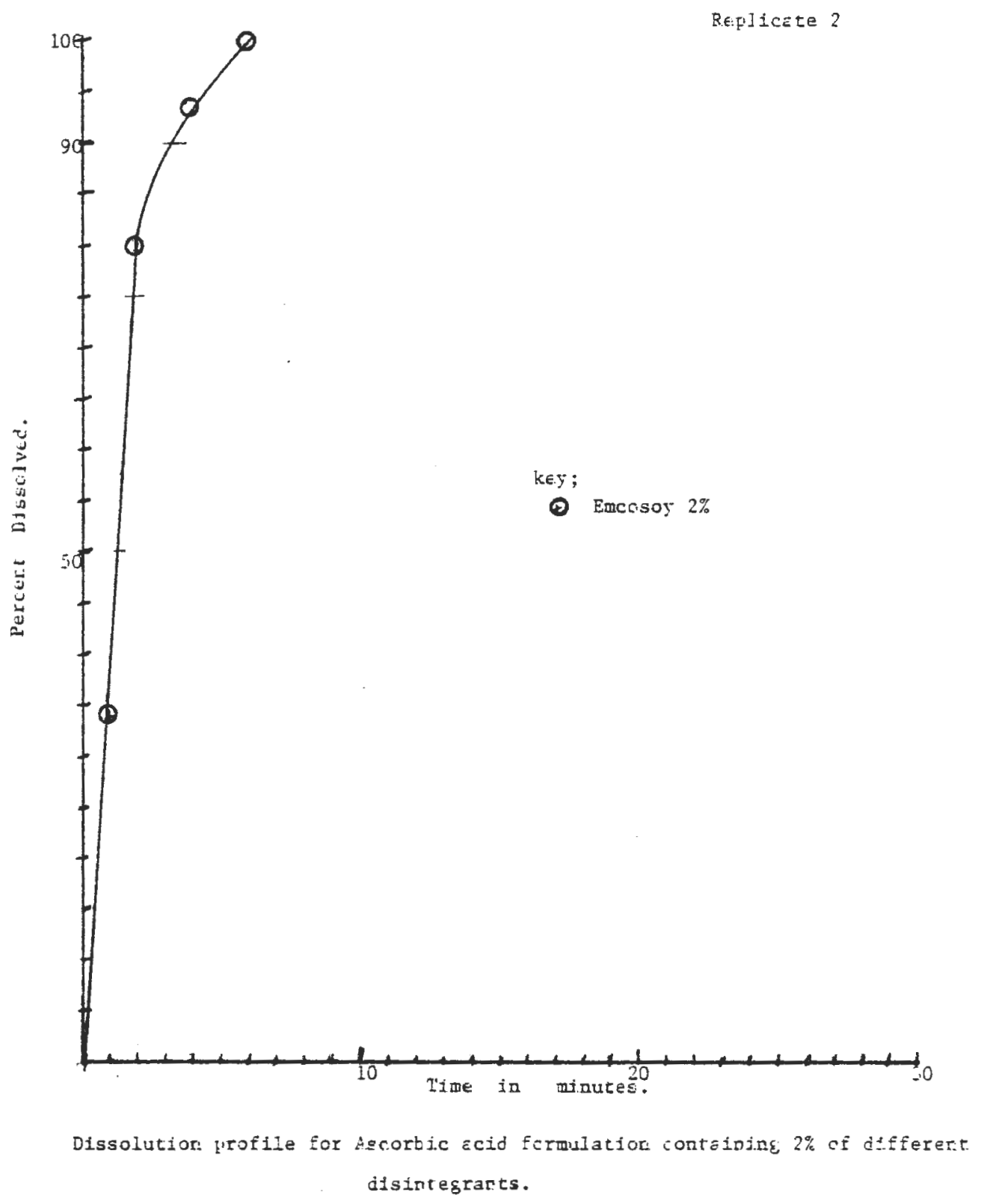

Fis. 73 
Reflic: $t \in$ I

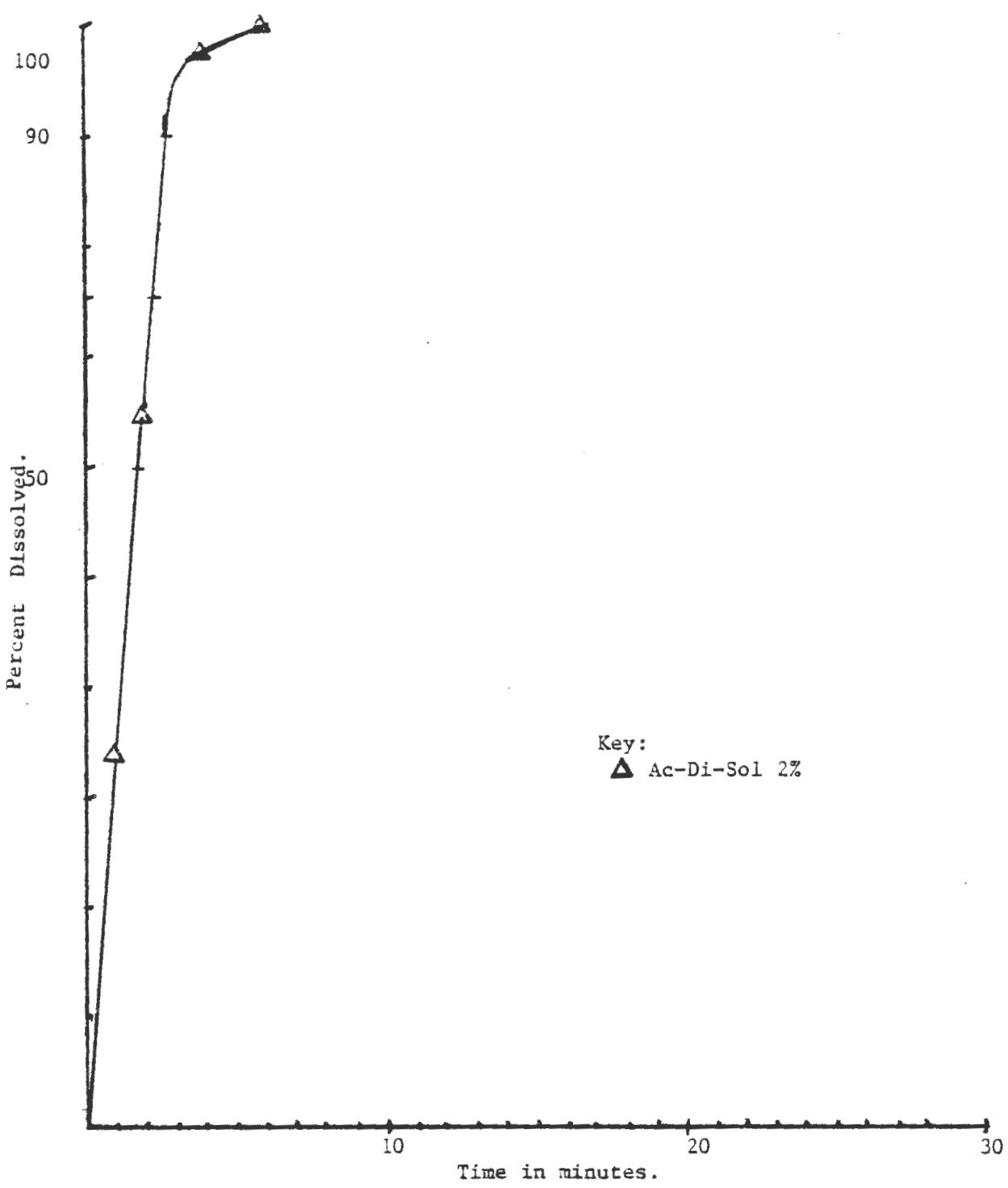

DISSOLUTION PFOFILE FOR ASCORBIC ACID FORMULATION CCNTAINING 2\% OF DIFFEFENT DISINTEGRANTS. 


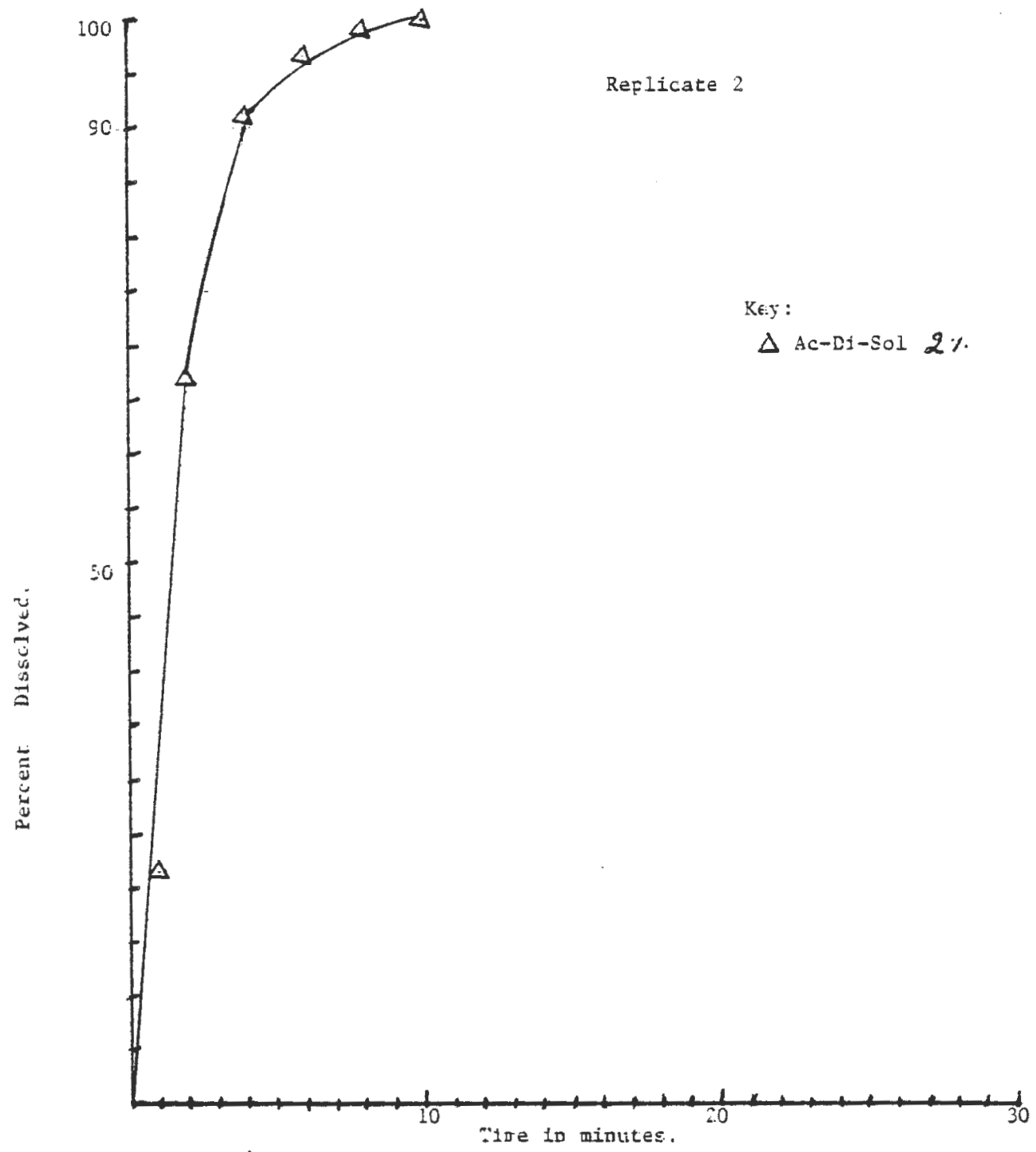

Dissolution frefile for Ascorbic acid for tilation containing different disintegrartit at $2 \%$ level.

Fig. 75 
Replicate I.

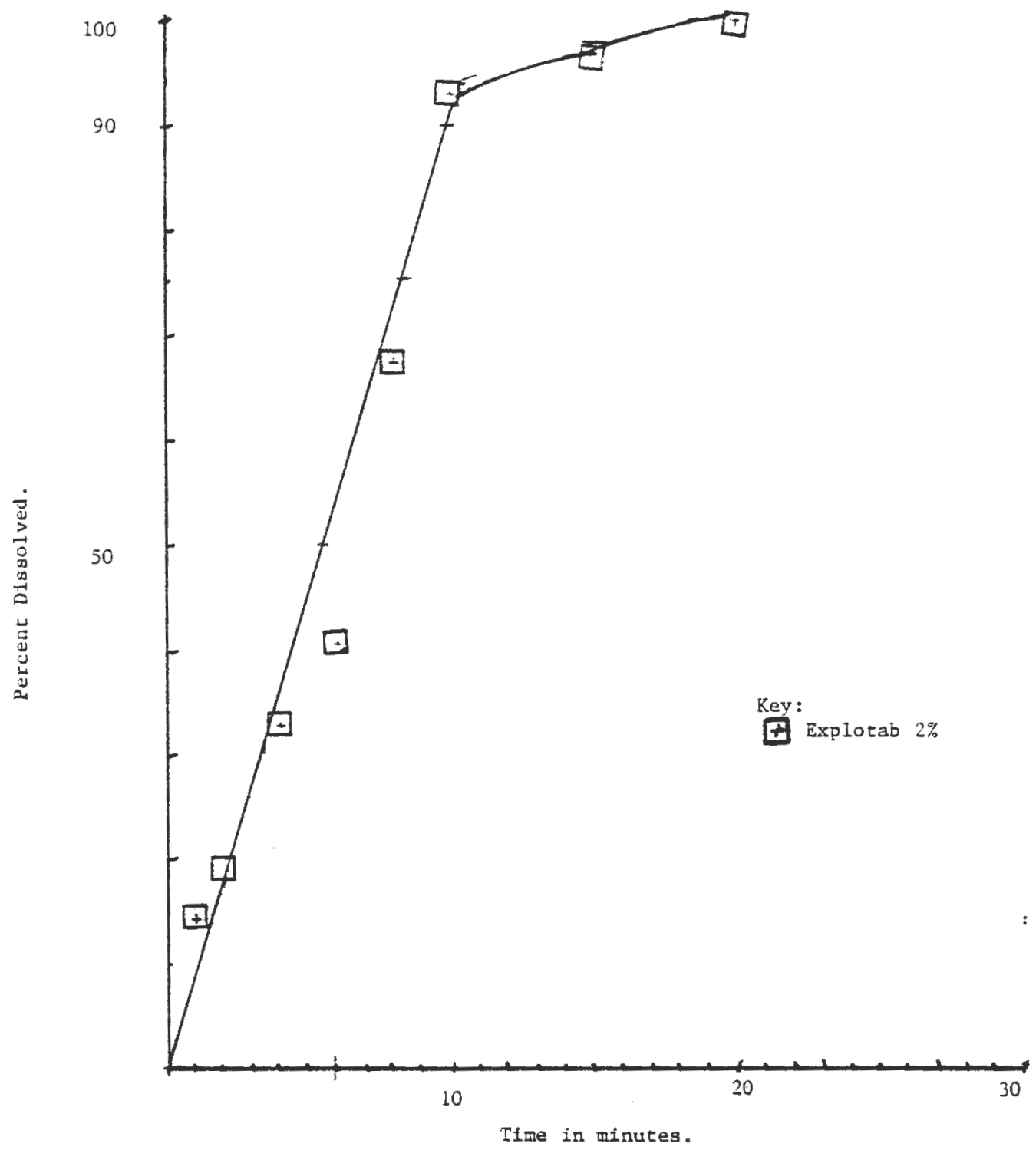

DISSOLUTION PROFILE FOR ASCORBIC ACID FORMULATION CONTAINING $2 \%$ OF DIFFERENT DISINTEGRANTS. 


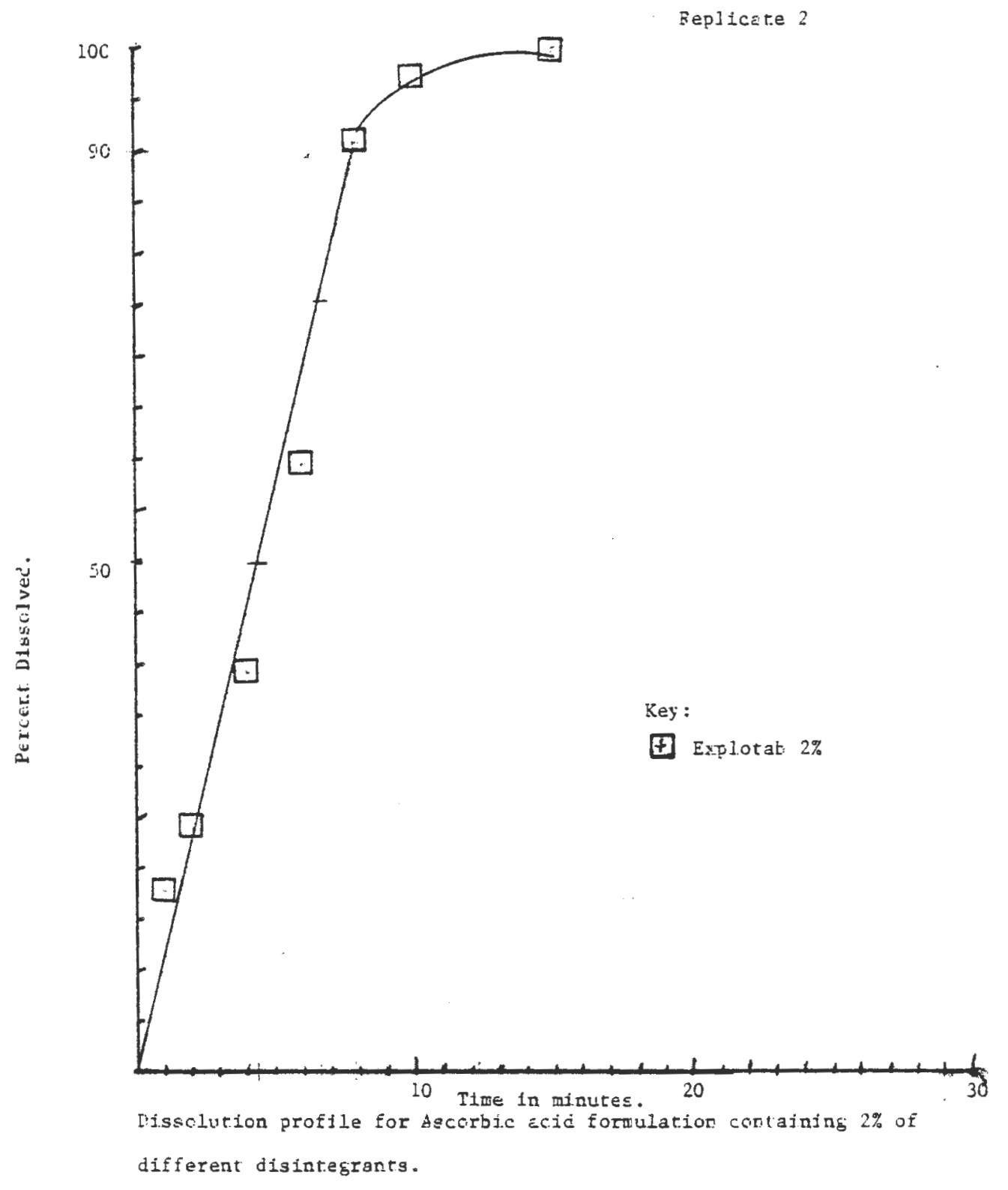

Fig. 77 
ReFIicate 1

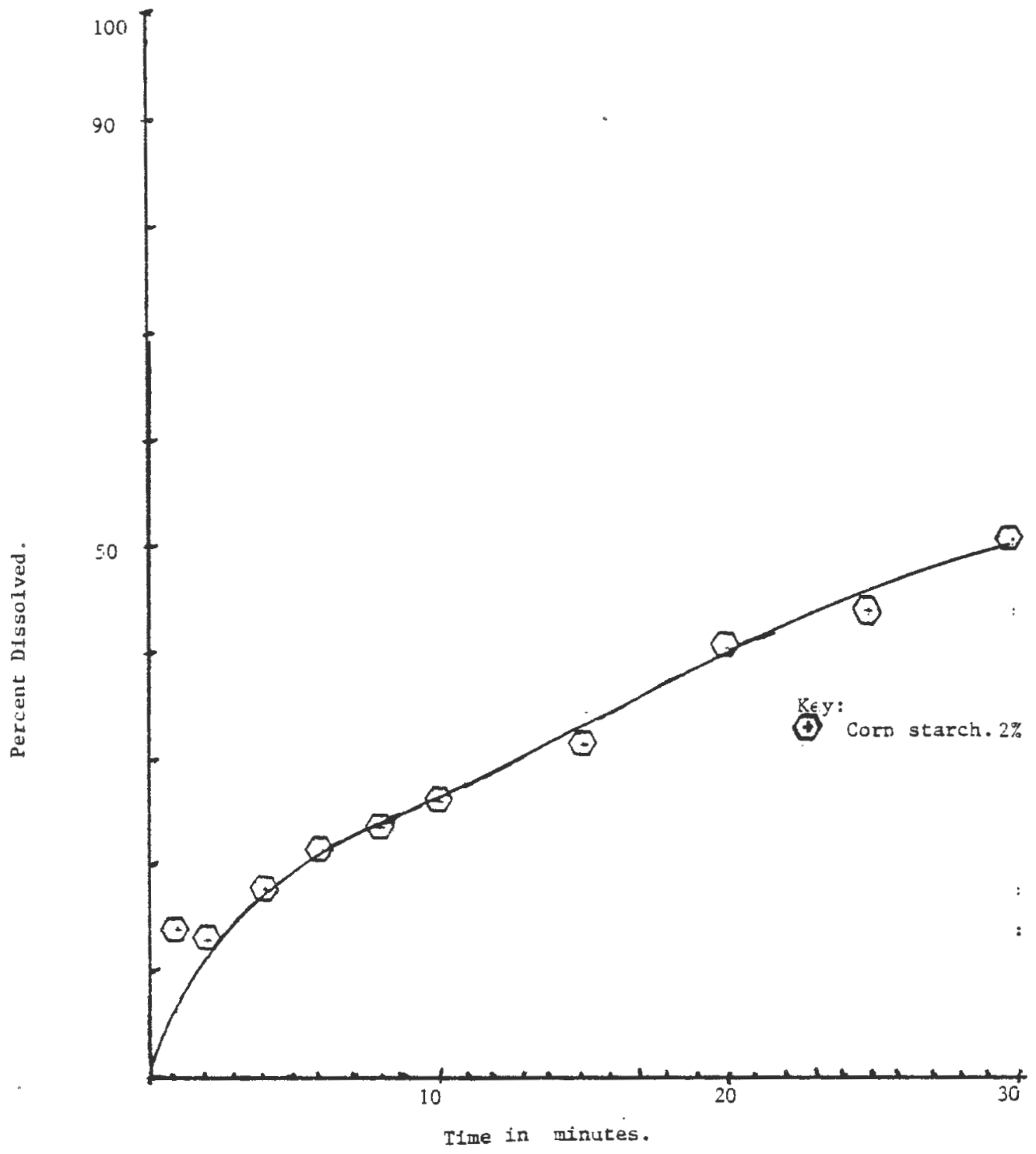

DISSOLUTZON PROFILE FOR ASCORBIC ACID FORMULATION CONTAINIYG $2 \%$ OF DIFFERENT DISINTEGRANTS.

Fig. 78 


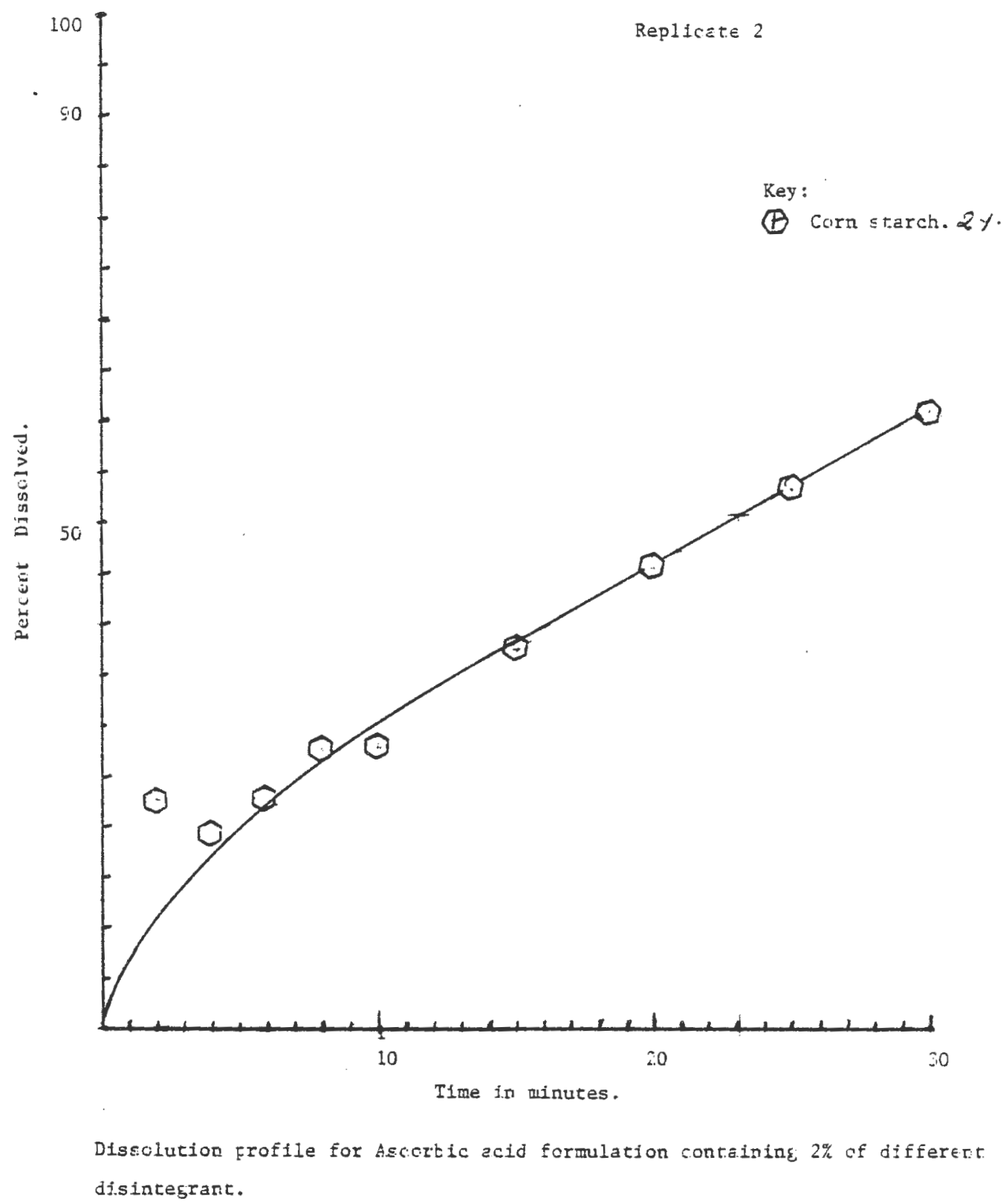

Fig. 79 
Dissclution Erofiles.

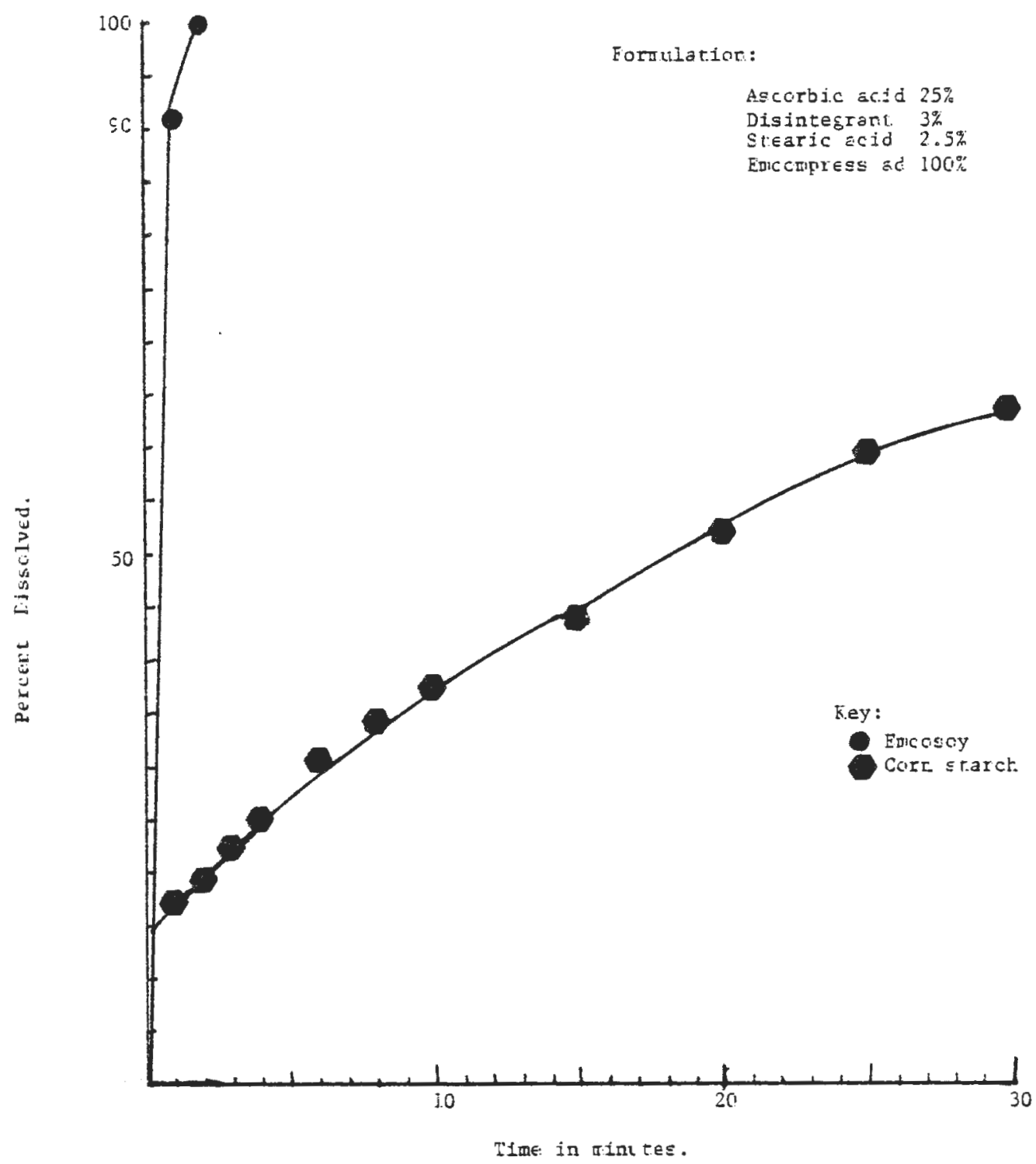

Fig. 80 


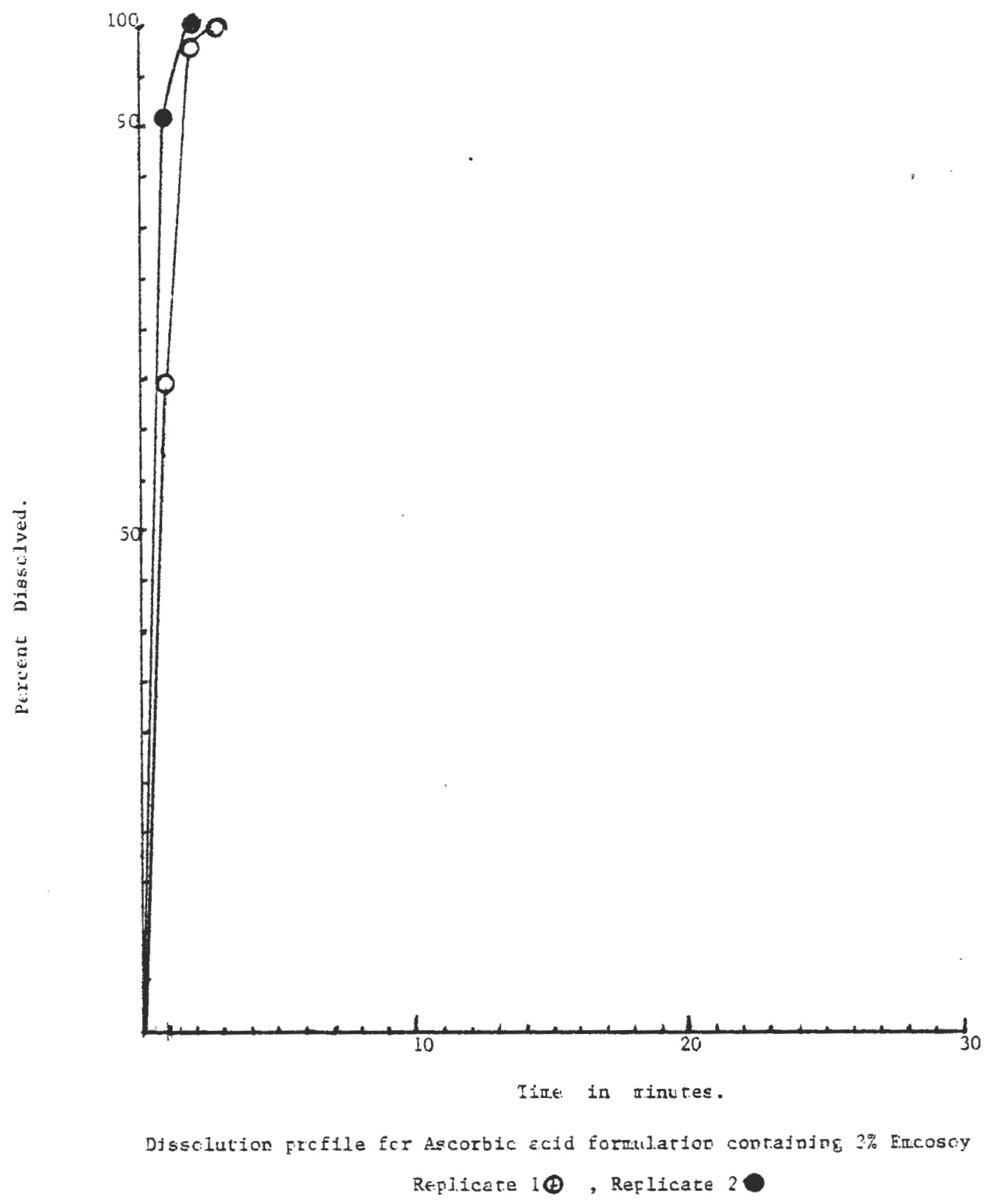

Fis. 81 


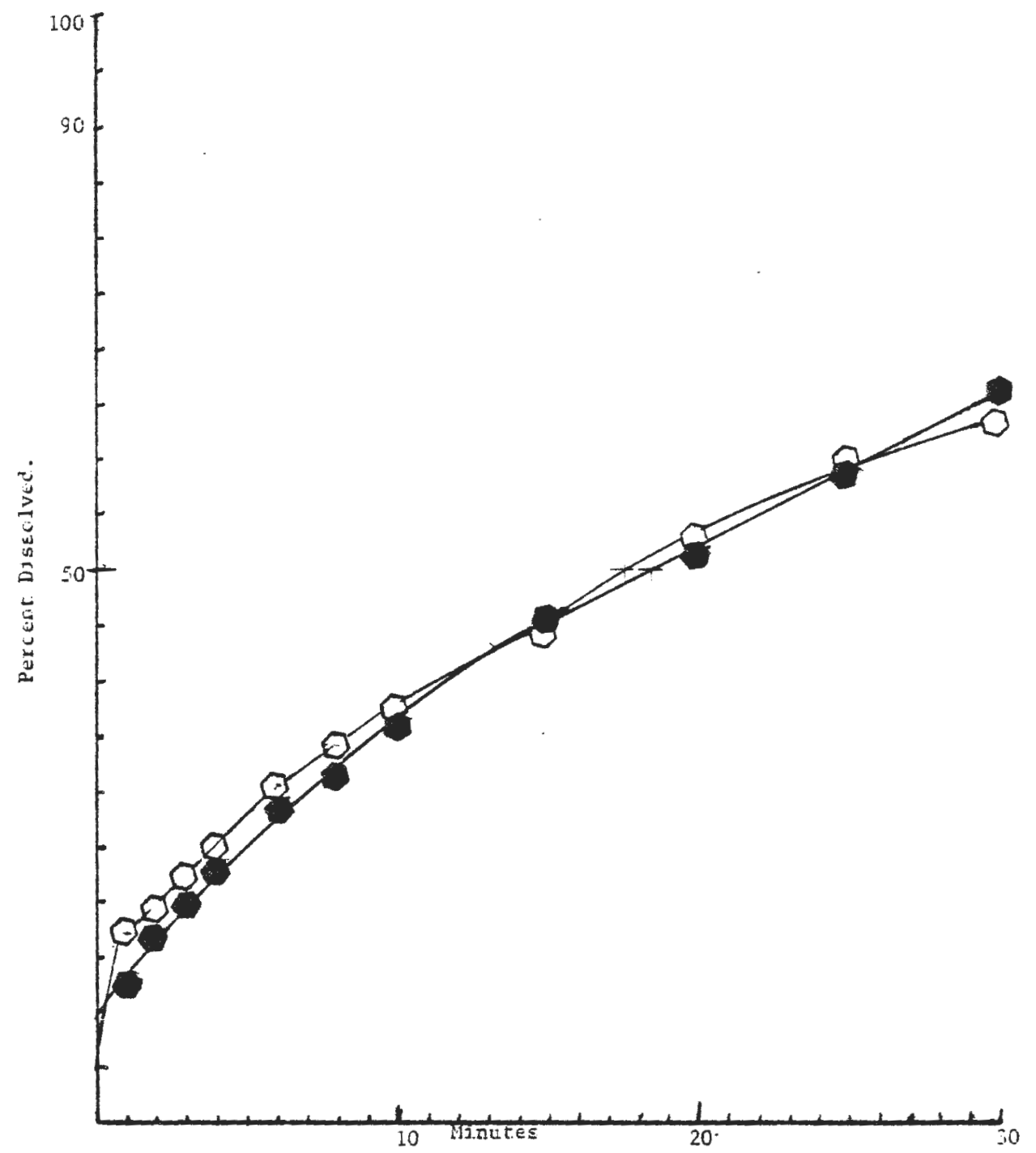

Lissolution profiles for fscortte acid formulation cortaining $3 \%$ corn starch Replicate $\mathbb{\theta}$, Replicate 


\section{CONCLUSION}

Emcosoy was tested for three major mechanisms of disintegration: (i) swelling, (ii) porosity and capillary action (wicking), and (iii) deformation. Swelling and wicking were adequate in the comparison of other satisfactory disintegrants, but Emcosoy had a poor plastic deformation. The viscosity of the gel produced by Emcosoy on wetting is less than the gel produced by CLD II, but higher than that by ACDi-Sol. All these factors were considered separately; but in actual disintegration of a tablet, inter-relationships always take place. Proper storage precautions are advised for this disintegrant because it has a tendency to promote microbial growth in the presence of high moisture at room temperature as observed during the wetting and drying test.

In this project, a total of 45 tablet formulations were studied, and about 100 dissolution profiles were obtained on various vitamin formulations using either Emcompress or Emdex as the tablet matrix. The results obtained clearly indicate that:

1. Emcosoy is superior to corn starch as a tablet disintegrant at two or three percent levels;

2. Encosoy competes favorably with other disintegrants, such as Explotab and Ac-Di-Sol, at half, one, and two percent levels;

3. Encosoy demonstrates superior dissolution profiles when evaluated against other disintegrants in vitamin formulations; and 
4. Water-insoluble matrix is more helpful in the evaluation of different disintegrants.

Emcosoy is demonstrably a powerful tablet disintegrant of natural source which deserves careful consideration by all formulators. 
V. SUGGESTIONS FOR FUTURE WORK

Life is the sum of unfulfilled dreams. So is research -- there is always the nagging doubt that one could have done better.

The author would have liked to change the particle size of Emcosoy to determine its effect on disintegration and other properties of the tablet.

Emcosoy has one great advantage over other popular disintegrants in that it is of natural origin. If we want to retain this advantage, there is very little we can do to change its property. It would be of great advantage to reduce the proteinaceous fraction of Emcosoy composition (at present, about $17.5 \%$ ) by some changes in processing procedure. The author anticipates that such changes would improve the plastic deformation of the Emcosoy particles; and consequently, the disintegration property. Low protein fraction would also help in protecting disintegrant at higher moisture level from lumping, as well as from microbial degradation. 


\section{REFERENCES}

1. Bioavailability Considerations. Committee on Biologic Performance of Drug Products: Guidelines for Biopharmaceutical Studies in Man, Washington, D.C.: Am. Pharm. Assoc., Acad. Pharm. Sci., 1972. P 2.

2. D.S. Greene and C.T. Rhodes: An Introduction to Biopharmaceutics and Pharmacokinetics. A book for PHC 338 students at the University of Rhode Island. Fourth Edition, 1980. p XVII/1.

3. A.J. Glazko, A.W. Kinkel, W.C. Alegnani, and E.L. Holmes: An Evaluation of the Absorption Characteristics of Different Chloramphenicol Preparations in Normal tuman Subjects. Clin. Pharmacol. Ther. ㅇ, 472-483 (1968).

4. G. Levy, K. Arnold, and N. Gerber: Absorption and Dissolution Studies on Sodium Diphenylhydantoin in Capsules. Can. J. Pharm. Sci. 5, 89-92 (1970).

5. J.G. Wagner: Biopharmaceutics and Relevant Pharmacokinetics. Drug Intelligence Publication, First Edition (1971). p 66.

6. R. Shangraw, A. Mitrevej, and M. Shah: Pharm. Tech., Vol. 4, No. 10, 1980, p 49 .

7. D.S. Greene and C.T. Rhodes: Introduction to Biopharmaceutics and Pharmacokinetics, Vol. 1, p v/l.

8. J.G. Wagner: Biopharmaceutics and Relevant Pharmacokinetics. Drug Intelligence Publication, First Edition (1971). p 66.

9. E. Nelson: J. Pharm. Sci., 46:607 (1957).

10. G.S. Banker, G.E. Peck, and G. Baley: Tablet Formulation and Design. In: Pharmaceutical Dosage Forms: Tablet. Vol. I (H.A. Lieberman and L. Lachman, Eds.) Marcel Dekker, Inc. 1980, p 70.

11. G. Levy, J.M. Antkowiak, J.A. Procknar, and D.D. White: J. Pharm. Sci., $52: 1047$ (1963).

12. L. Lachman. I. Pharm. Sci. S4:1519 (1965).

13. P. Rieckmann. Pharm. Z. 34:1207 (1971).

14. F.A. Campagna, G. Crulton, R.A. Mirigian, and E. Nelson: J. Pharm. Sci. $52: 605$ (1963).

15. The National Formulary, 13th Edition, Mack Publishing Co., Easton, PA. p 878 . 
16. J.K. Richards: U.S. Pat. 216, 107 (1879).

17. Sheth, Bandelin, and Shangraw: In: Pharmaceutical Dosage Forms:

Vol. 1, p 135.

13. G.S. Banker, G.E. Peck, and G. Baley: Ibid, p 86.

19. W. Lowenthal: J. Pharm. Sci. Vol. 61, No. 11, 1695-1711.

20. R.F. Shangraw, J.W. Wallace, and F.M. Bowers: Pharm. Tech., Vol. 5, No. 10, pp 44-60.

21. J. Bennett: Pharm. Acta Helv. 12, 1337 (1937).

22. L. Chwialkowska and L. Krowcyznski: Acta. Pol. Pharm. 25, 583 (1958).

23. I. Krowczynski, K. Kolarski, and K. Swoboda: Ibid, 25, p 443 (1968).

24. H. Berry and C. Ridout: J. Pharm. Pharmacol: 2, 619 (1950).

25. F. Jaminet: J. Pharm. Belg. 19, 144 (1964).

26. H.V. Czetsch-Lindenwald, F. Elkhawas, and R. Tawaski: J. Soc. Cosmet. Chem. 16, 251 (1965).

27. E.E. Borzunov and T.Y. Nesmiyan: Khim-Form. Zh., 2, 44 (1968); through Int. Pharm. Abstr., 8, 1283 (1971).

28. E.E. Borzunov and S.M. Shevchenko: Formatsiya (Moscow) 19, 20 (1969); through Chem. Abstr. 71, (1969).

29. K.S. Hanudhane, A.M. Contractor, H.Y. Kim, and K.F. Shangrav: J. Pharm. Sci. 58:616 (1969).

30. N.R. Patel and R.E. Hopponen: J. Pharm. Sci. Vol. 55, 1966, pp 1065-1068.

31. V.E. Nurenberg: Pharm. Ind., Vol. 34, 1972, pp 193-206.

32. F. Modezejewski and L. Wochna: Acta. Pol. Pharm. Vol. 28, 1965, pp 396-402.

33. C.D. Fox, M.D. Richman, G.E. Reier, and R.F. Shangraw: Drug Cosmet. Ind. 92, 161 (1963).

34. T. Higuchi, A.N. Rao, L.Ŵ. Burre, and J.V. Swintosky: J. Amer. Pharm. Ass. Sci. Ed. 42, 194 (1953). 
35. D. Ganderton and A.B. Selkiek: J. Pharm. Pharmacol. 22, 345 (1970).

36. A.B. Selkirk and D. Ganderton: Ibid. 22, 795 (1970).

37. Ibid. 22, 865 (1970).

38. B. Reich and F. Gstiener: Arch. Pharm. 301, 830 (1968).

39. P. Fuchs, Ibid, 303, 471 (1970).

40. K. Nogami, H. Fukuzawa, and Y. Nakai: Chem. Pharm. Bu11., 11, 1389 (1963).

41. H. Nogami, J. Hasegawa, and M. Miyamoto: Ibid, 15, 279 (1967).

42. T. Bano, T. Szarvas, and L. Aradi: Pharm. Zentrath, 100, 221 (1961).

43. U. Bogs and H. Moldenhauer: Pharmazie, 19, 708 (1964).

44. R. Yamamoto and T. Tahahashi: Ann. Rep. Shiongi Res. Lab. 3, 310 (1953).

45. H. Matsumaru: Yakugaku Zasshi, 78, 1201 (1958).

46. K. Minzel and W. Kagi: Sci. Pharm. 24, 237 (1956).

47. T.A. Fakouki and L. Krowczynski: Acta. Pol. Pharm. 27, 593 (1970).

48. R.A. Burrus and W. Lowentha1: J. Pharm. Sci. 60, 1325 (1971).

49. K.C. Commons, A. Bregen and G.C. Walker: I. Pharm. Sci. 58, 1253 (1968).

50. H. Nogami, T. Nagai, E. Fukuoka, and T. Sonobe: Chem. Pharm. Bull. 17,1450 (1969).

51. P. Singh, S.J. Desai, A.P. Simonelli, and W.I. Higuchi: J. Pharm. Sci., 57, 217 (1968).

52. H. Burlinson and C. Pickering: J. Pharm. Pharmacol. 2, 630 (1950).

53. L.C. Curlin: J. Pharm. Assoc. Sci. Ed. Vol. 40, 1955, p 16.

54. A.M. Schwartz: Ind. Eng. Chem. 61, 10 (1969).

55. H. Nogami, T. Nagai, and H. Uchida: Chem. Pharm. Bull. 14, 132 (1966). 
56. J.H. Wood: Pharm. Acta. Helv. 42, 129 (1967).

57. H. Hess: Pharm. Tech. Vol. 2, No. 9, 1978, pp 36-37.

58. C. Fuhrer: Informationscienst APV, Vo1. 10, 1964, p 58, From: Pharm. Acta. Helv., Vol. 48, 1973, pp 589-609.

59. C.T. Rhodes: In: Proceedings of 1981 Pharm. Tech. Conf., in New York.

60. "Emcosoy," Edward Mendell Technical Bulletin, Edward Mendell, Carme1, NY.

61. E.M. Rudnic, S. Weich, P. Bernardo, and C.T. Rhodes: Drug Development and Industrial Pharmacy, 8 (1), 87, 1981.

62. P. Fuchs: Arch. Pharm., 1970, p 303. From: Pharm. Acta. Helv. Vo1. 48, 1973, pp 589-609.

63. H. Hess: In: Pharm. Tech., Vol. 2, No. 9, 1978, pp 36-37.

64. C. Funrer: Informationsdienst APV, Vo1. 10, 1964, p 58. From: Pharm. Acta. Helv., Vo1. 48, 1979, pp 589-609.

65. C.M. Lee and R.T. Toledo: Journal of Food Science, Vol. 41, 1976, pp 391-397.

66. K.N. Wai, H.G. Dekay, and G.S. Banker: J. Pharm. Sci., Vo1. 11, 1076-1080, 1962 .

67. R.B. Wortz: J. Pharm. Sci., Vol. 9, 1169-1173, 1967.

68. "The National Formulary," XIV Ed. Mack Publishing Co., Easton, PA, 1975.

70. W. Lowenthal: Pharm. Acta. Helv., 48, 1973, pp 589-609.

71. H. Nogami, J. Hasegawa, and M. Miyamoto: Chem. Pharm. Bull., 15(3), 279-289 (1967).

72. E.M. Rudnic, J.M. Lausier, R.N. Chilamkurti, and C.T. Rhodes: In: Drug Development and Industrial Pharmacy, 6, 291 (1980). 


\section{BIBLIOGRAPHY}

Banker G.S., Peck G.E., and Baley G: Tablet Formulation and Design. In: Fharmaceutical Dosage Forms: Tablet. Vol. 1. (H.A. Lieberman and L. Lachman, Eds.), Marcel Dekker, Inc., 1980, p. 70.

Banker G.S., Peck G.E., and Baley G: Pharmaceutical Dosage Forms: Vol. 1. F. 86 .

Bano T, Szarvas F, and Aradi L: Pharm. Zentrath, 100, 221.

Bennet J: Pharm. Acta. Helv. 12, 1337 (1937).

Berry H, and C. Ridout: I. Pharm. Pharmacol. 2, 619 (1950).

Bogs V, and Moldenhauer $\mathrm{E}$ : Pharmazie, 19, 708 (1964).

Burlinson H, and Pickering C: J. Pharm. Pharmacol. 2, 630 (1950).

Burrus R.A. and Lowenthal W: J. Pharm. Sci. 60, 1325 (1971).

Borzunov E.E., and Shevchenko S.M.: Formatsiya (Moscow) 18, 20 (1969);

through Chem. Abstr. 71 (1969).

Borzunov E.E., and Nesmiyan T.Y.: Khim-Form. Zh. 2, 44 (1968) : through Int. Pharm. Abstr. 8, 1283 (1971).

Campagna F.A., Crulton G, Nirigian R.A., and Nelson E: J. Pharm. Sci. $52: 605$ (1963).

Chwialkowska L, and Krowcyznski L: Acta. Pol. Pharm. 25, 583 (1958).

Commons K.C., Bregen A, and walker G.C.: J. Pharm. Sci. 58, 1253 (1968).

Curlin L.C.: I. Pharm. Assoc. Sci. Ed., Vol. 40, 1955, p 16.

Czetsch-Lindenwald H.V., Elkhawas F, and Tawaski R: J. Soc. Cosmet. Chem. 16,251 (1965).

Fakouki I.A., and Krowczynski L: Acta. Pol. Pharm. 27, 593 (1970).

Fox C.D., Richman M.D., Reier G.E., and Shangraw R.F.: Drug Cosmet. Ind. 92, 161 (1963).

Fuchs P: Arch. Pharm. 1970, p. 303. From: Pharm. Acta. Helv. Vol. 48, 1973, pp 589-609. 
Fuchs P: Arch. Pharm. 303, 471 (1970).

Fuhrer C: Informationsdiense APV, Vol. 10, 1964, p. 58. From: Pharm. Acta. Helv., Vo1. 48, 1979, pp 589-609.

Fuhrer C: Informationsdiense APV, Vol. 10, 1964, p 58. From: Pharm. Acta. Helv., Vol. 48,1979 , pp 589-609.

Ganderton C, and Selkeik A.B.: I. Pharm. Pharmacol. 22, 345 (1970).

Glazko A.J., Kinkel A.W., Alegnani W.C., and Holmes E.L.: Clin. Pharmacol. Ther. 9, 472-483 (1968).

Greene D.S., and Rhodes C.T.: An Introduction to Biopharmaceutics and Pharmacokinetics. A book for PHC 338 students at the University of Rhode Island. Fourth Edition, 1980, p v/i.

Greene D.S., and Rhodes C.T.: Ibid. p XVII/1.

Hess H: Pharm. Tech., Vol. 2, No. 9, 1978, pp 36-37.

Higuchi T, Rao A.N., Burre L.W., and Swintosky J.V.: J. Amer. Pharm. Ass. Sci. Ed. 42, 194 (1953).

Jaminet F: J. Pharm. Belg. 19, 144 (1966).

Krowczynski I., Kolarski K., and Swoboda K.: Acta. Pol. Pharm., p 443 (1968).

Lachman L.: J. Pharm. Sci. $54: 1519$ (1965).

Lee C.M., and Toledo R.T.: Journal of Food Science, Vol. 41, 1976, pp 391397.

Levy G., Arnold K., and Grebel N.: Can. J. Pharm. Sci., 5, 89-92 (1970).

Levy G., White D.D., Procknal J.A., and Antkowiak J.M.: I. Pharm. Sci. $52: 1047$ (1963).

Lowenthal W.: Pharm. Acta. Helv., 48, 1973, pp 589-609.

Lowenthal W.: J. Pharm. Sci, Vo1. 61, No. 11, 1695-1711.

Manudhane K.S., Contractor A.M., Kim H.Y., and Shangraw R.F.: J. Pharm. Sci., $58: 616$ (1969). 
Mastumaru H.: Yakugaku Zasshi, 78, 1201 (1958).

Minzel K., and Kagi W.: Sci. Pharm. 24, 237 (1956).

Modezejewski F., and Wochna L.: Acta. Po1. Pharm., Vol. 23, 1965, pp 396-402.

Ne1son E.: J. Pharm. Sci., 46:607 (1957).

Mrogami Ki., Hasagawa J., and Miyamoto M.: Chem. Pharm. Bu11., 15, 279 (1967) .

Nogami H., Fukuzawa H., and Nakai Y.: Ibid 11, 1389 (1963).

Nogami H., Nagai T., and Uchida H.: Ibid, 14, 132 (1966).

Nogami H., Hiasegawa J., and Miyamoto M.: Ibid, 279-289 (1967).

Nogami H., Nagai T., Fukuoka E., and Sonobe T.: Ibid, 17, 1450 (1969).

Nurenberg V.E.: Pharm. Ind., Vol. 34, 1972, pp 193-206.

Patel N.R., and Hopponsen R.E.: J. Pharm. Sci., Vol. 55, 1966, pp 10651068.

Reich B., and Gstiener F.: Arch. Pharm. 301, 830 (1968).

Reickmann P.: Pharm. Z., 34:1207 (1971).

Rhodes C.T.: at Proceedings of 1981 Pharm. Tech. Conf. in New York, 1981.

Richards J.M.: U.S. Pat., 216, 107 (1979).

Rudnic E.M., Weich S., Bernardo P., and Phodes C.T.: Drug Development and Industria1 Pharmacy, 8CD, 87, 1981.

Ruanic E.M., Lausier J.M., Chilamkurti R.N., and Rhodes C.T.: In: Drug Development and Industrial Pharmacy, 6, 291 (1980).

Schwartz A.M.: Ind. Eng. Chem. 61, 10 (1969).

Selkiek A.B., and Ganderton D.: J. Pharm. Pharmacol. 22, 795 (1970). 
Sheth, Bandelin and Shangraw: In: Pharmaceutical Dosage Forms, Vol. 1, p 135.

Singh P., Desai S.J., Simonelli A.P., and Higuchi W.I.: J. Pharm. Sci., 57,217 (1968).

Wagner J.G.: Biopharmaceutics and Relevant Pharmacokinetics. Drug Intelligence Publication, First Edition (1971), p 66.

Wai K.N., Dekay H.G., and Banker G.S.: J. Pharm. Sci., Vol. 11, 1076$1080,1962$.

Wood J.H.: Pharm. Acta. Helv., 42, 129 (1967).

Wortz R.B.: J. Pharm. Sci., Vol. 9, 1169-1173, 1967.

Yamamoto R., and Tahahashi T.: Ann. Rep. Shiongi Res. Lab., 3, 310 (1953). 
VIII APPENDIX

1. Computer Program For The Calculation of Mean, Standard Deviation And Relative Standard Deviation

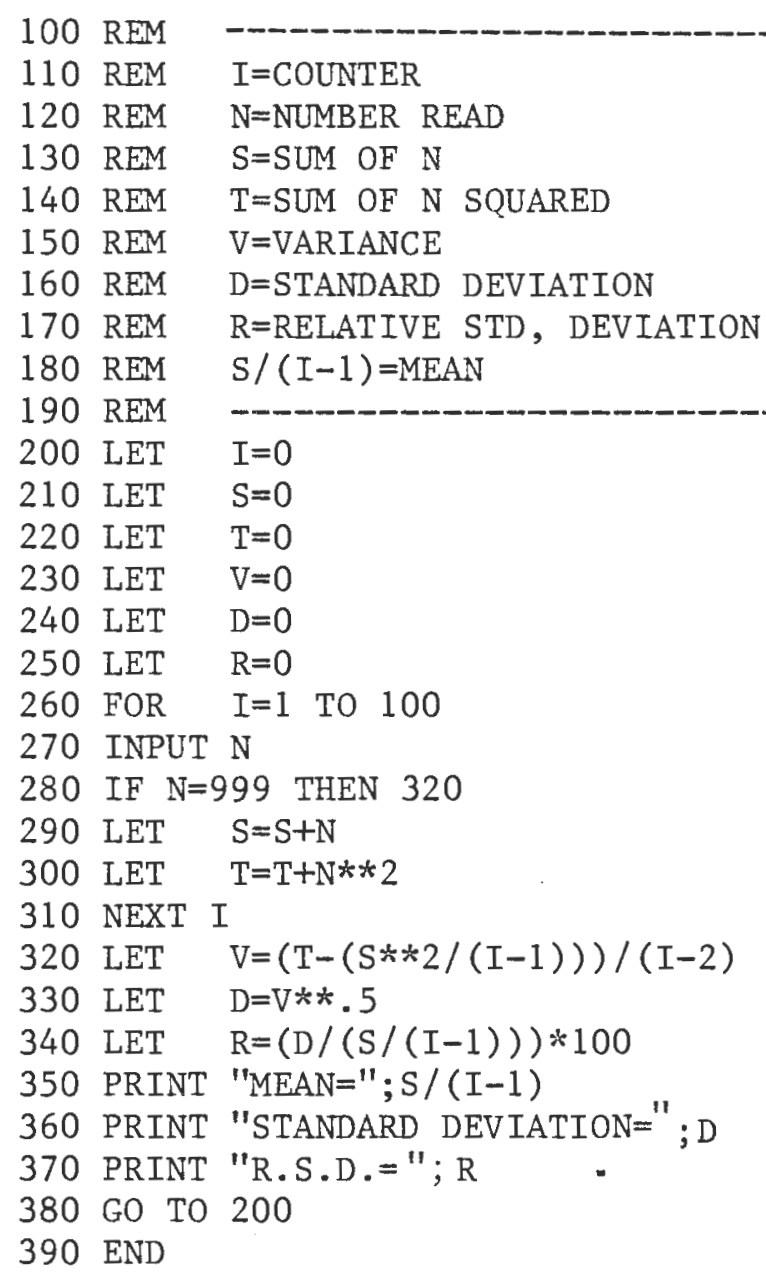

2. Computer Program For The Calculation of Percentage Of Drug Dissolved 100 DIMENSION TIME (30), ABS(30), CONC (30), AMT (30), TITLE (6) 110 WRITE $(6,155)$

120155 FORMAT (//1X, 'ENTER THE NAME OF FORMULATION')

$130 \operatorname{READ}(5,160)$ (TITLE (I), I=1,6)

140160 FORMAT (6A4)

142 WRITE $(6,112)$

144112 FORMAT(//1X, 'ENTER TOTAL VOLUME OF DISSOLUTION MEDIUM')

$146 \operatorname{READ}(5, *) \mathrm{TV}$

150 WRITE $(6,105)$

160105 FORMAT (//1X, 'ENTER SLOPE OF BEERS PLOT (ABS/MCG PER ML)')

$170 \operatorname{READ}(5, *)$ SLOPE

180100 FORMAT $(/ / 1 \mathrm{X}$, 'SLOPE='F10.5)

182 WRITE $(6,117)$

184117 FORMAT (//1X, 'ENTER DILUTION FACTOR')

$186 \operatorname{READ}(5, *) \mathrm{D}$

190 WRITE $(6,115)$

200115 FORMAT (//1X, 'ENTER NUMBER OF DATA POINTS')

$210 \operatorname{READ}(5, *) \mathrm{N}$ 
220 WRITE $(6,135)$

230135 FORMAT (//1X, 'ENTER TOTAL THEREOTICAL AMOUNT OF DRUG IN MG')

$240 \operatorname{READ}(5, *) \mathrm{TD}$

250 WRITE $(6,125)$

260125 FORMAT (//1X, 'ENTER TIME, ABSORBANCE')

$270 \operatorname{READ}(5, *)(\operatorname{TIME}(I), \operatorname{ABS}(I), I=1, \mathrm{~N})$

280 WRITE $(6,100)$ SLOPE

290 DO $20 \mathrm{~J}=1, \mathrm{~N}$

$300 \operatorname{CONC}(J)=0.0$

31020 CONTINUE

320 TLCONC $=0.0$

$330 \mathrm{CORRX}=0.0$

340 DO $25 \quad I=1, N$

350 CONCX $=0.0$

$360 \mathrm{CONCX}=(\operatorname{ABS}(I) / S L O P E) * \mathrm{D}$

370 TLCONC $=$ TLCONC+CORRX

$380 \mathrm{CORRX}=(\mathrm{CONCX} * 5.0) / \mathrm{TV}$

$390 \operatorname{CONC}(I)=$ CONCX + TLCONC

$400 \operatorname{AMT}(I)=(\operatorname{CONC}(I) * T V) / 1000.00$

41025 CONTINUE

$420 \operatorname{WRITE}(6,165)(\operatorname{TITLE}(I), I=1,6)$

430165 FORMAT $(/ / 1 \mathrm{X}, 6 \mathrm{~A} 4)$

$440 \operatorname{WRITE}(6,190)$

450190 FORMAT (//10X, 'TIME (MIN)', 4X, 'AMT (MG)', 5X, 'PERCENT', 5X, 'PERCENT')

$460 \operatorname{WRITE}(6,300)$

470300 FORMAT $(/ / 33 \mathrm{X}$, ' (ACTUAL AMT) ', 2X, '(CLAIMED AMT) ')

480 DO $30 \quad I=1, N$

$490 \operatorname{PERCNT}=(\operatorname{AMT}(\mathrm{I}) / \operatorname{AMT}(\mathrm{N})) * 100$

$500 \mathrm{CPRCNT}=(\mathrm{ANT}(\mathrm{I}) / \mathrm{TD}) * 100.00$

$510 \operatorname{WRITE}(6,250)$ (TIME (I), AMT (I), PERCNT, CPRCNT)

520250 FORMAT $(/ / 1 \mathrm{X}, 4(3 \mathrm{X}, \mathrm{F} 10.2))$

53030 CONTINUE

$540 \mathrm{PD}=(\mathrm{AMT}(\mathrm{N}) / \mathrm{TD}) * 100.00$

550 WRITE $(6,145)$ PD

560145 FORMAT(//1X, 'PERCENT OF DRUG IN TABLET=',F10.2)

570 STOP

580 END 
Spectrophotometer Reading For Pyridoxine Hydrochloride (USP)
Concentration $(\mu \mathrm{g} / \mathrm{m} 1)$
14.50
0.623
7.25
3.63
0.304
1.81
0.205
0.153

Absorbance

\begin{tabular}{cc}
\multicolumn{2}{c}{$\begin{array}{c}\text { Spectrophotometer Reading For } \\
\text { Ascorbic Acid (USP) }\end{array}$} \\
Concentration $(\mathrm{kg} / \mathrm{ml})$ & Absorbance \\
& \\
14.10 & 0.833 \\
9.04 & 0.567 \\
7.05 & 0.386 \\
5.64 & 0.303 \\
& \\
Spectrophotometer Reading For \\
Granulated Ascorbic Acid (Roche) \\
\multicolumn{2}{c}{} \\
Concentration( $\mathrm{kg} / \mathrm{ml})$ & Absorbance \\
17.7 & 0.880 \\
13.3 & 0.735 \\
8.8 & 0.493 \\
6.6 & 0.374
\end{tabular}




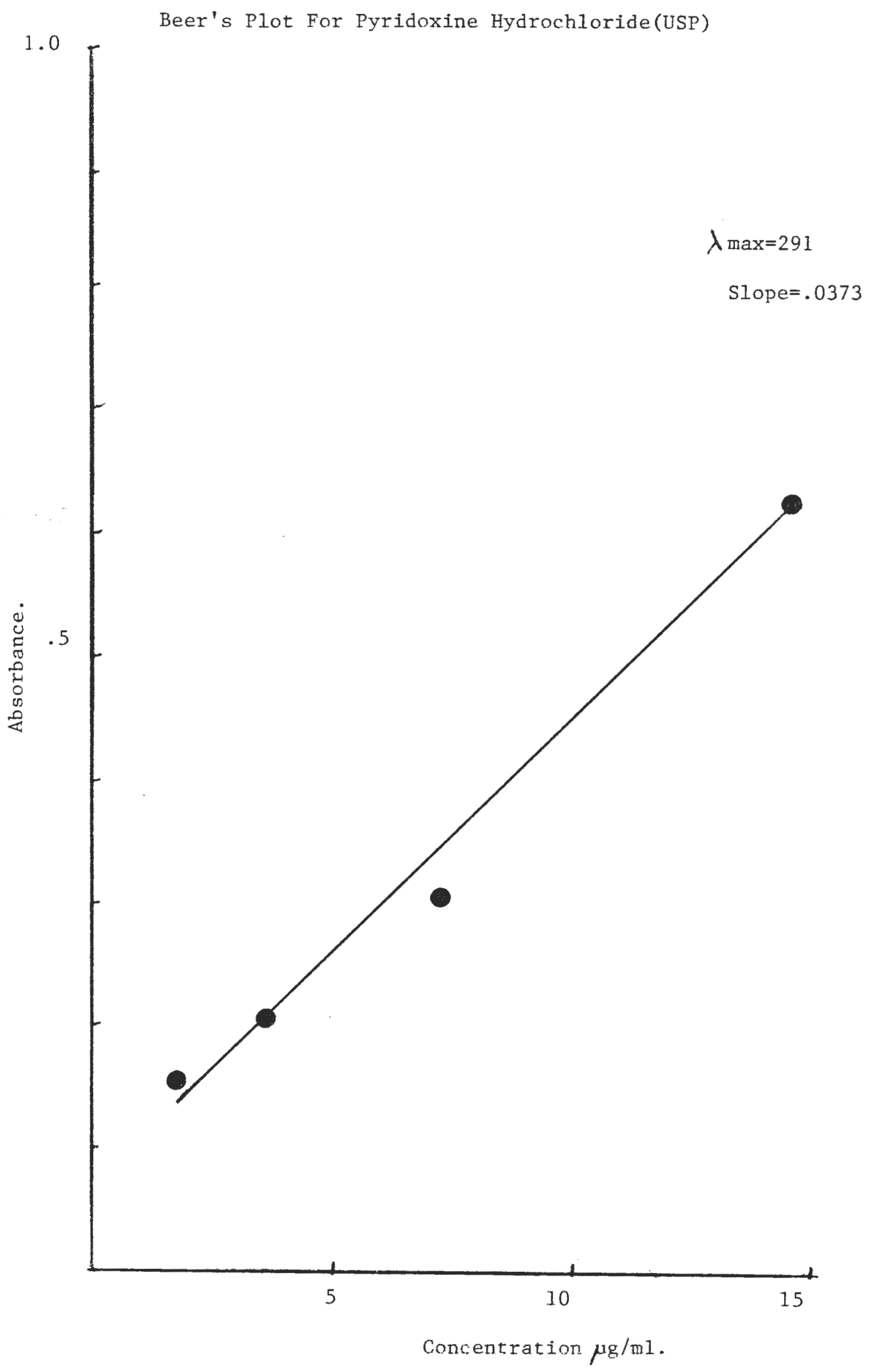




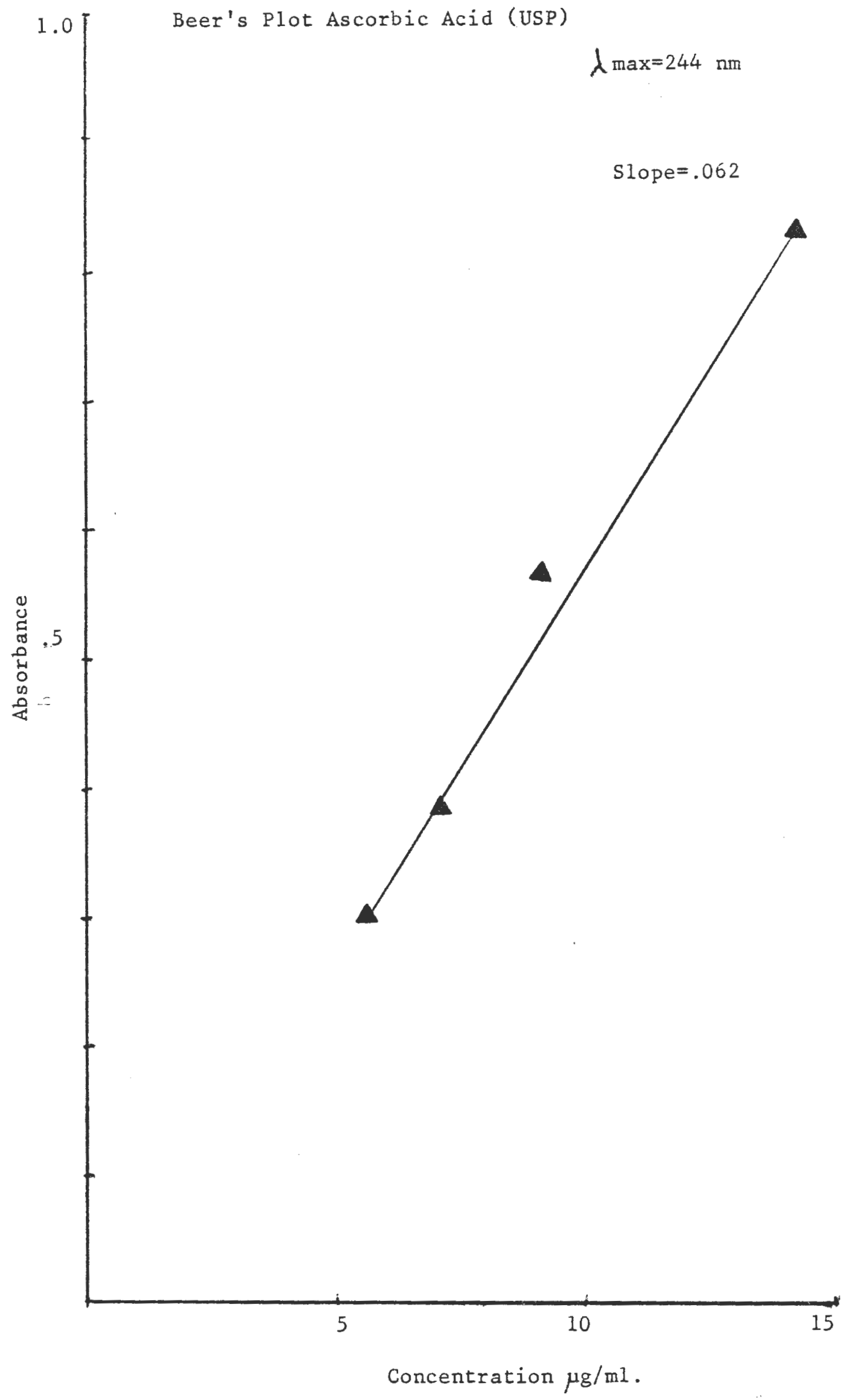




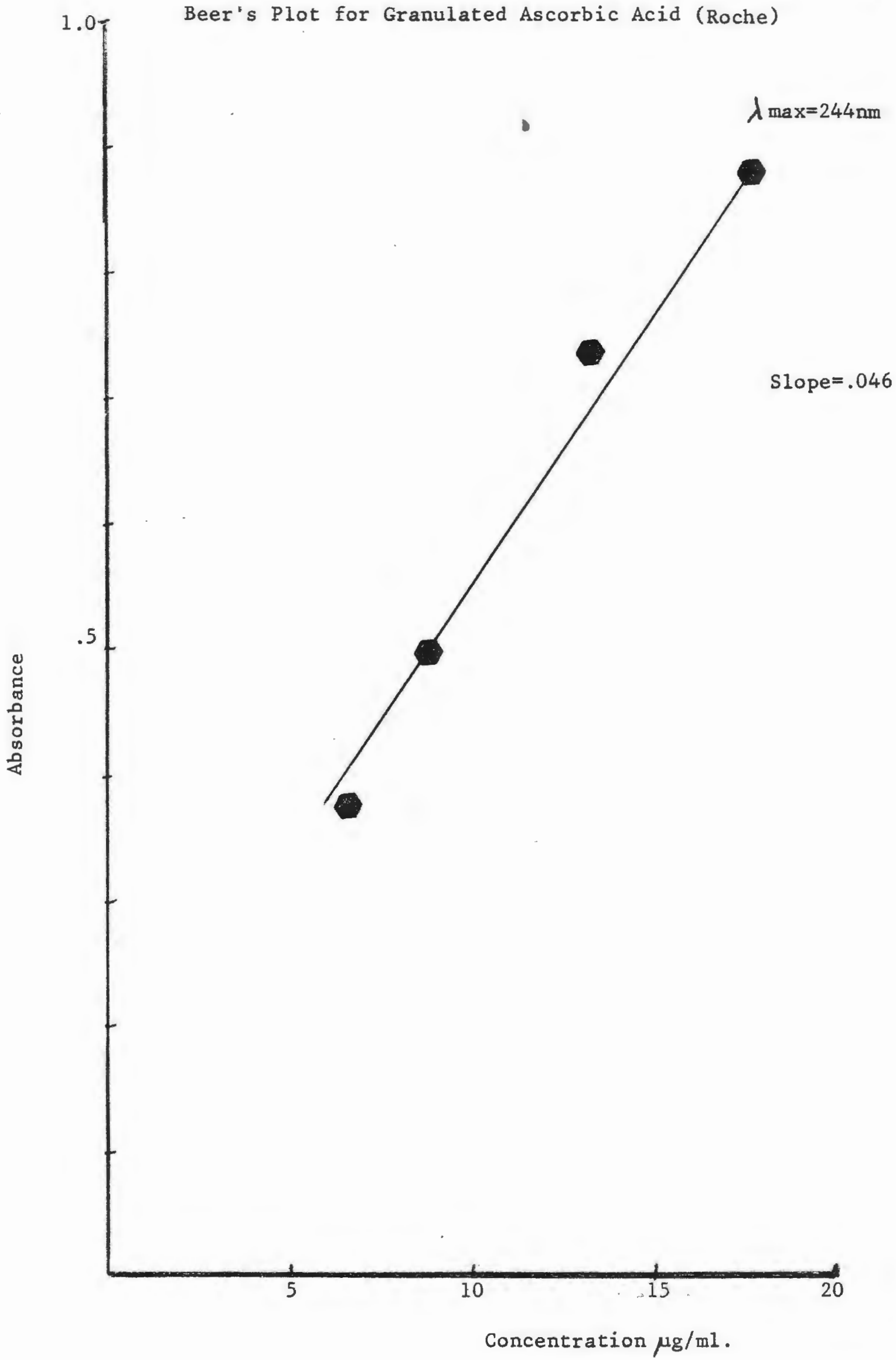

